\section{HE. ARPFIDD}

RADIOISOTOPE FUELED AUXILIARY POWER UNIT

MND-P-3007

THIS DOCUMENT CONSISTS OF 172 PAGES No. 40 of 100 copies, series A A<smiles>[As]=[Pd]</smiles>

\title{
QUARTERLY PROCRESS REPORT
}

NUMBER 10

APRIL JUNE 1959

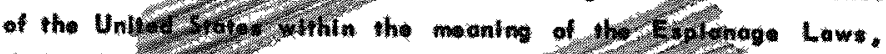

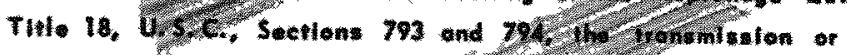

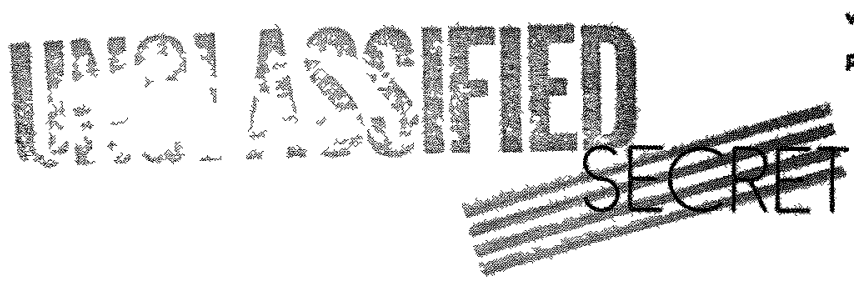

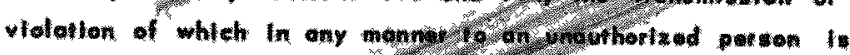
prokiblled by law. 


\section{DISCLAIMER}

This report was prepared as an account of work sponsored by an agency of the United States Government. Neither the United States Government nor any agency Thereof, nor any of their employees, makes any warranty, express or implied, or assumes any legal liability or responsibility for the accuracy, completeness, or usefulness of any information, apparatus, product, or process disclosed, or represents that its use would not infringe privately owned rights. Reference herein to any specific commercial product, process, or service by trade name, trademark, manufacturer, or otherwise does not necessarily constitute or imply its endorsement, recommendation, or favoring by the United States Government or any agency thereof. The views and opinions of authors expressed herein do not necessarily state or reflect those of the United States Government or any agency thereof. 


\section{DISCLAIMER}

Portions of this document may be illegible in electronic image products. Images are produced from the best available original document. 


\section{RADIOISOTOPE FUELED AUXILIARY POWER UNIT}

\section{QUARTERLY PROGRESS REPORT NUMBER 10}

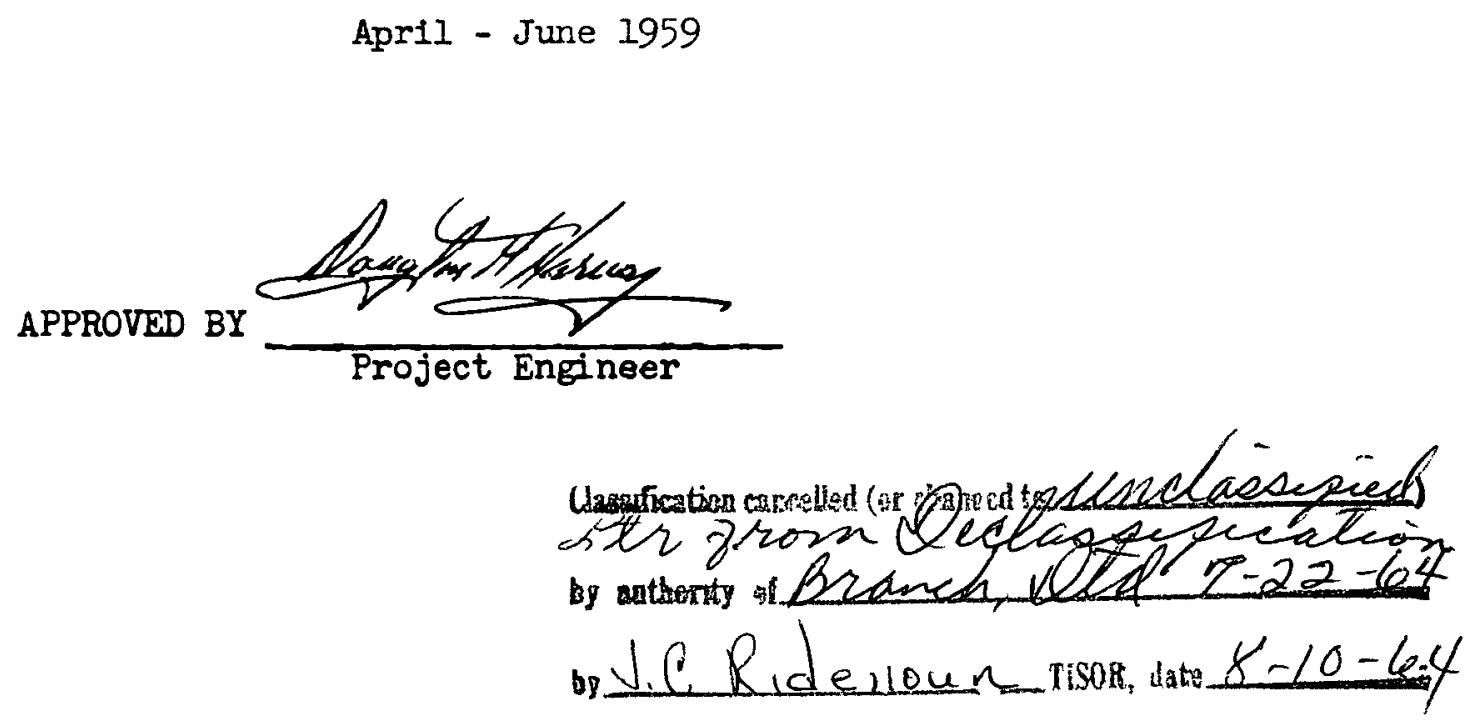

Research \& Development

C-83

MND-P-3007

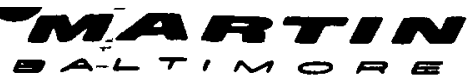

DEEETISE INFORMATION 
page blank

ii

MND-P-3007 
LEGAL NOTICE

This report was prepared as an account of Government sponsored work. Nelther the United States, nor the Commission, nor any person acting on beholf of the Commission:

A. Makes any warranty or representation, express or implied, with respect to the accuracy, completeness, or usefulness of the information contained in this report, or that the use of any information, apparatus, method, or process disclosed in this report may not infringe privately owned rights; or

B. Assumes any liabilities with respect to the use of, or for damages resulting from the use of any information, apparatus, method, or process disclosed in this report.

As used in the above, "person acting on behalf of the Commission" Includes any employee or contractor of the Commission to the extent that such employee or contractor prepares, handles or distributes, or provides access to, any information pursuant to his employment or contract with the Commission. 
Copy No.

1. Air Force Ballistic Missile Division

For: Major George Austin

2. Air Research and Development Command

2 Attn: RDTAPS, Capt.W. G. Alexander

3. Army Bollistic Missile Agency 3,4 Attn: ORDAB-c

4. Atamic Bnergy Commission, Washington

U. S. Atomic Energy Commission

Attn: Mrs. J. M. O'Ieary

For: Lt. Col. G. M. Anderson, DRD

Capt. John P. Wittry, DRD

Lt. Col. Robert D. Cross, DRD

R. G. OehI, DRD

Edward F. Miller, PROD

Technical Reports Library

5. Atomics International

Attn: Dr. Chauncey Starr

For: J. Wetch

6. Bureau of Aeronautics

12

Attn: C. L. Gerhardt, NP

7. Bureau of Ordnance

Attn: Mrs. Maryle R. Schmidt or Laura G. Meyers (To be opened by addressee only)

For: $\operatorname{Ren}$

$\mathrm{SP}$

8. Bureau of Ships, Code 1500

Attn: Melvin L. BaII

9. U. S. Atomic Energy Commission

Canoga Park Area Office

Attn: A. P. Pollman, Area Manager
13

14

15

16 


\section{DISTRIBUTION LIST (Cont'd)}

10. Chicago Operations Office

U. S. Atomic Energy Comission

Attn: A. I. Mylyck

For: T. A. Nemzek

Mr. Klein

11. Chief of Naval Operations

Copy No.

12. Department of the Army, Atomic Division

13. Diamond Ordnance Fuse Laboratories

20 Attn: ORDTL 06.33, Mrs. M. A. Hawkins

$21,22,23$

14. Hanford Operations Office

17,18

Attn: Technical Information Iibrary

24

15. Lockheed Aircraft Corporation

25,26

Asst. AF Plant Representative

For: John H. Carter

16. Mound Laboratory

27

Attn: Library and Records Center

For: Mrs. Roberson

17. National Advisory Committee for Aeronautics, Ames

28

Attn: Smith J. De France, Director

18. National Advisory Committee for Aeronautics, Langley

29 Attn: Henry J. E. Reid, Director

19. National Advisory Committee for Aeronautics

Lewis Flight Propulsion Laboratory

Attn: George Mandel

20. Naval Ordnance Laboratory

$31,32,33$

Attn: Eva Iieberman, Iibrarian

21. Naval Research Laboratory, Code 1572

Attn: Mrs. Katherine H. Cass 
22. New York Operations Office

U. S. Atomic Energy Commission

Copy No.

Attn: Document Custodian

23. Oak Ridge National Laboratory

X-10, Laboratory Records Department

35,84

Attn: Eugene Lamb

24. Office of Naval Research, Code 735

Attn: E. E. Sullivan

For: Code 429

25. Project Rand

Director, USAF Project Rand

Attn: F. R. Collbohm

For: Dr. John Huth

26. Rome Air Development Center

Attn: RCSG, J. L. Briggs

27. Technical Information Service Extension

40 through 64

U. S. Atomic Inergy Comnission

Oak Ridge, Tennessee

28. Thompson Ramo Wooldridge

Staff Research and Development

Attn: C. G. Martin

29. University of Calffornia Radiation Laboratory

Technical Information Division

Attn: Clovis G. Craig

For: Dr. Hayden Gordon

30. Wright Air Development Center

Attn: WCACT

For: Capt. Clarence N. Munson, WCIPS

G. W. Sherman, WCLEE

WCOSI

31. Jet Propulsion Laboratory

Attn: W. H. Pickering, I. E. Newlan 


\section{DISTRIBUTION LIST (Cont' ')}
32. University of California Radiation Iaboratory Technical Information Division
Attn: Clovis G. Craig For: Dr. Robert H. Fox

33. Ios Alamos Scientific Iaboratory

Attn: Report Iibrarian For: Dr. George M. Crover

Copy No.

34. Alr Force Special Weapons Center Attn: Kathleen P. Nolan

35. School of Aviation Medicine Randolph Air Force Base, Texas

Attn: Col. J. E. Pickering

36. Air Technical Intelligence Center Wright-Patterson Air Force Base, Ohio Attn: H. Holzbauer, AFCIN-4 Bla

37. National Aeronauctics and Space Administration Attn: Dr. Addison N. Rothrock

Addresses based on the latest edition of $M-3679$ as issued by the USAEC. 
viii

SECRET

MND-P-3007 


\section{FOREWORD}

This is the tenth Quarterly Progress Report prepared under Contract $\operatorname{Ar}(30-3) 217$. It covers the work of The Martin Company and their subcontractors for the period of ApriI I through June 30, 1959.

\section{SECReT}

MND $-\mathrm{P}-3007$ 


\section{CONTENTS}

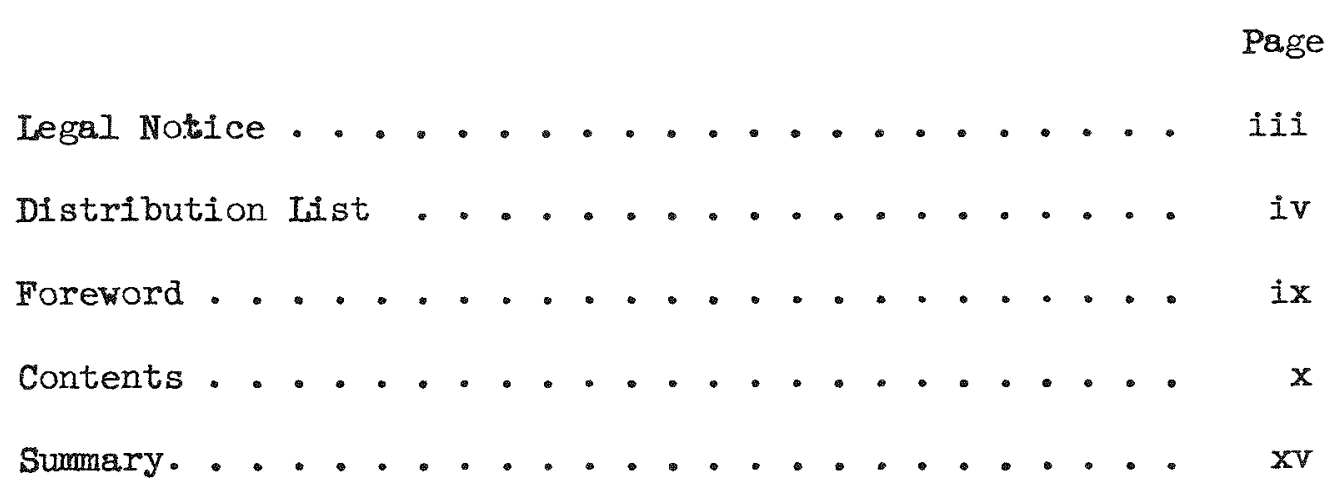

I. Task 1--Overall System Design............. I

A. System Design................ 1

B. Shielding Analysis ........... 5

c. Operational Hazards ............ 5

1. Aerodynamic Heating Analysis . . . . . . . 5

2. Missile Abort on Various Points of the WS II7L
Launch Trajectory. . . . . . . . . . II

D. Results. ............... 12

1. Analysis of Hazards Resulting from Missile FailFaliures . . . . . . . . . . . . .

2. A Statistical Analysis of Earth Impact Probabilities for a North-South Polar Orbit. ..... 15

II. Task 2--Boiler Development . . . . . . . . . 19

A. Electric Mercury Boilers ............ 19

B. Isotope Boiler No. I............ 19

C. SNAP I-A Thermoelectric Generator ....... 20

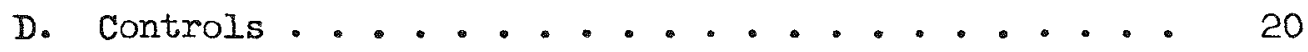

E. Heat Transfer ............ 27

1. Experimental ............ 27

III. Task 3--Fuel Development . . . . . . . . . 33 
CONTENTS (continued)

Page

A. Cerium Fuel Studies............. 33

1. Ceric Oxide Re-Bntry Type Fuel........ 33

2. Cerium Burnup Type Fuel........... 34

B. Molybdenum Test Specimens. . . . . . . . 46

C. Re-Entry Type Fuel Assembly .......... 47

D. Oxidation Resistant Coatings ......... 47

IV. Task 4--Materials Corrosion Program. ......... 49

A. Lead Corrosion Tests........... 49

B. Woods Metal Tests.............. 51

C. Mercury Corrosion........... 51

1. Type 347 stainless Stee1........ 52

2. Niobium Clad with Type 347 Stainless Steel. . . 55

V. Task 5--Power Conversion System.......... 61

A. Prototype Design ............... 62

B. Breadboard Test Rig. ........... 62

C. Systems Test Enclosure ........... 62

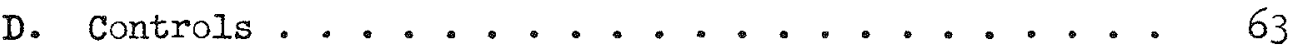

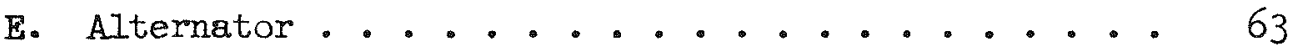

F. Condenser. ................. 64

G. Materials Evaluation ........... 64

1. Loop Testing................ 64

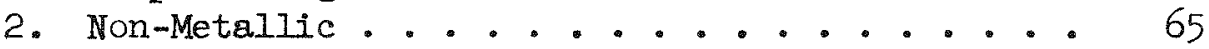

H. Turbine............. 65

I. Pump ............... 66 
CONTENTS (continued)

Page

VI. Task 6--Ground Test. .............. 67

A. Ground Test Fixture............ 67

B. Environmental Testing. ........... 67

1. Cumulative Effects .......... 67

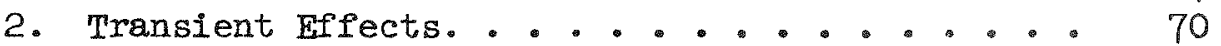

VII. Task 7--Thermoelectric Power System. ......... TI

A. STIP III-A . . . . . . . ..... $7 I$

B. SNAP III-B ............ 71

VIII. Task 8--Ground Handling and Transportation ...... 83

IX. Task 9--Thermionic Conversion System ......... 91

A. SNAP III-C ................ 91

B. $\operatorname{SNAP} I I I-D \cdot . \cdot . \cdot . \cdot . \cdot . \cdot 92$

X. Task 11--Iower Powered Operational SNAP III-F. . . . 93

A. Vehicle Integration............ 93

1. Generator Requirements .......... 93

2. Ground Handling. . . . . . . . . . . 96

3. Hazards and Shielding. ......... 96

B. Fuel Element Design, Fabrication and Test. .... 106

c. Generator Design, Fabrication, and Test. ..... 116

1. Generator Design .......... 116

2. Environmental Testing. . . . ....... 123

3. Power Flattening............ 126

4. Material Tests........... 133

XI. Task 12--Thermoelectric Conversion ......... 135

A. Thermoelectric Design............. 135

B. Thermoelectric Test Equipment......... 136

l. Guarded Hot Plate........... 136 
CONTENTS (continued)

Page

2. Materials Test Devices......... 139

C. New Thermoelectric Materials ......... 139

XII. Task 13--System Design and Integration--SNAP VII . . . 141

A. Program Management and Integration ........ 141

B. Generator Design ............ 141

C. Hazards Analysis ............ 142

1. Chemical Properties of Curium. ....... 149

D. Fuel Development............ 150 
SUMMARY

TASK I - OVERAIL SYSTEM DESIGN

The early operational date of the latest AFBMD requirement resulted in a phase-out of the SNAP I program.

Conceptual design studies were performed on several Auxiliary Power Units utilizing a thermoelectric conversion system. The current design, designated SNAP I-A, employs Ce-144 as the fuel and generates a constant $250 \mathrm{w}$ of $28 \mathrm{v}$ electricity for 374 days. Two identical units of $125 \mathrm{w}$ each will be used to meet the present AFBMD requirement.

All conceptual design parameters were conservative and available materials were used in the design. Lead telluride elements operating at hot junction temperatures between 900 and $1000^{\circ} \mathrm{F}$ are used. Calculated efficiencies for individual couples are as high as $6.7 \%$ while the overall conversion efficiency for the generator is $5 \%$.

An aerodynamic heating analysis for a SNAP I-A unit was performed. Results indicated that a redesign of the assumed core configuration was necessary for re-entry with core intact.

\section{TASK 2 - BOILER DEVELOPMENT}

The first isotope fueled boiler of the SNAP I program was cancelled at the $50 \%$ complete stage; two electrically heated boilers were cancelled at various stages of fabrication, and a third unit (PBP5A) was allowed to continue as a spare boiler for the dual boiler test program. Dual boiler testing was carried out until the middle of April, when the complete loop with partial instrumentation was transferred to Thompson Ramo Wooldridge for use in the system test enclosure. Electric boiler PBP 5A was assembled, tested under superheated mercury vapor conditions, and delivered to Thompson Ramo Wooldridge by May 1959.

Conceptual and manufacturing drawings were prepared for the initial SNAP I-A electrically heated thermoelectric generator. Fabrication will begin in July.

A heat transfer mockup test unit was designed, fabricated, and tested under a vacuum environment to check the qualities of MinK-I301 insulation. Heat loss values for the mockup were measured at $432 \mathrm{w}$, which proved to be equal to theoretical losses based on vendor supplied data. 


\section{TASK 3 - FUEL DEVELOPMEINT}

Since the advent of the SNAP I-A thermoelectric generator, the cerium fuel investigation was divided into two distinct programs. The objective of one was the continued development of a stable fuel form of ceric oxide that could withstand atmospheric re-entry, while the second objective was to develop a fuel that would burn up under reentry conditions. Both objectives were pursued during this quarter but the major emphasis was placed on the study of burnup type fuels.

\section{TASK 4 - MATERIAIS CORROSION PROGRAM}

Inhibited liquid lead corrosion tests were made at $1500^{\circ} F$ on cerium fuel pellets. Results will be compared with identical tests using pure lead.

Static tests on molybaenum samples in woods metal at $500^{\circ} \mathrm{F}$ showed no discernible effects.

Dynamic mercury corrosion loop tests were made over a temperature range of 350 to $1350^{\circ} \mathrm{F}$ on $347 \mathrm{SS}, 446 \mathrm{SS}$, niobium and tantalum materials. While evidence of mercury corrosion was present, premature failures in the test coils were due to defects in the tubing.

\section{TASK 5 - POWER CONVERSION SYSTEM}

Major effort was devoted to the fabrication, checkout and calibration of the ground test system (GTS) hardware and subsequent installation in the systems test enclosure (STE). A system test run of nearly one hour with turbine speeds up to $40,000 \mathrm{rpm}$ was completed.

A phase-out of the SNAP I program resulted in termination of the condenser study program. The turbine development program was reduced to extended systems testing in which no component development would be performed and no new test hardware fabricated.

\section{TASK 6 - GROUND TEST}

Plans were made for the testing of lead telluride thermoelectric elements under simulated environmental conditions. The scope of work will cover the effect on operating efficiency of an accelerated accumulated dose as well as the effect of simulated radiation levels of 
2 mev gamma rays. Qualitative or semiquantitative indications of radiation damage will be obtalned. Two mev electrons from an electron accelerator will be focused onto elements which have been sliced sufficiently thin so that fairly unfform penetration will be realized and fairly accurate simulation of the Ce-144 source obtalned.

\section{TASK 7 - THERMOELECTRIC POWER SYSTEM}

The Westinghouse SNAP III-A program is in the construction phase and will require increased effort to meet the delfvery date of 1 December 1959. Parameteric tests are scheduled thereafter at The Martin Company.

SNAP III-B has undergone a serles of electrical life tests at The Martin Company. Varlous schemes were used to develop data on operating conditions, load requirements and overall performance. The results Indicated favorable electrical reliability under programmed environments.

\section{TASK 8 - GROUND HANDITING AND TRANSPORTAMION}

A new conceptual design report covering the various phases of transporting, installing and servicing of the SNAP I-A fuel container was completed. The fuel block will be loaded Into a transport cask and shipped to Martin for the ground tests. Special purpose equipment to facilitate transportation and handling is belng designed.

\section{TASK 9 - THERMIONIC CONVERSION SYSTEM}

Fabrication is continuing on the sIx single stage SNAP III-C prototypes. One completed unit is undergoing test in a bell jar. The test results will provide applicable modifications to the operational prototypes currently in the fabrication phase. The development of a two-stage prototype using the cerium isotope, is progressing. Fuel loading is expected sometime in November 1959.

Experimental work in SNAP III-D is continuing. Bmitter and collector improvement is under investigation. 
TASK 11 - LOWER POWERED OPERATIONAL- SNAP III-F

Preliminary generator requirements were established through discussions with personnel at LMSD and Jet Propulsion Laboratory. A hazards study was initiated based on conceptual generator designs using $\mathrm{Cm}-242, \mathrm{Sr}-90$, $\mathrm{Po}-210$ and $\mathrm{Pm}-147$ as radioisotope fuels. Initial reports are in the final phases and will be released next month.

Studies of fuel forms and containment materials have been started. Sample isotope capsules were fabricated and welding tests have been made.

Reliability tests of electrically heated SNAP III-B type generators are well under way. Environmental test specifications have been published based on LMSD and JPL requirements. To date, generator operation has been satisfactory for all environments.

Power flattening investigations and analysis indicate that adequate control of a SNAP III-B generator output is feasible. The simplest and most reliable method devised was to reduce the insulation conductivity with time by allowing an initial gas charge in the generator case to leak out.

\section{TASK 12 - THERMOELECTRIC CONVERSION}

Conceptual design studies were made to evaluate the operational parameters of the thermoelectric power conversion system. As a back-up to these studies, and to improve on the present design, apparatus is being designed to evaluate various types of insulation, thermoelectric materials, heat transfer materials, protective coatings, and assembly configurations.

\section{TASK 13 - SYSTTEM DESIGN AND IITEGGRATION, SNAP VII}

Contacts with Jet Propulsion Laboratory to establish operational and ground handling requirements met with negative results for a unit in this power range.

Preliminary generator design studies were started and the first of three configurations is in the final stages of analysis.

Report No. MND-1963, "Preliminary Hazards of a Curium-242 Auxiliary Power Supply," has been published. A report on the hazards of the ericium and curium fuel fabrication process is in the final stages. 


\section{TASK 1--OVERALL SYSTEM DESTGN}

\section{A. SYSTEM DFSIGN}

During this quarter a new (AFBMD) requirement for the DiscovererSentry program was announced. The early operational date precluded the possibility of using the Rankine power conversion cycle of SNAP I. This system is in the early stages of development and the power conversion system could not be developed to the degree of reliability required. As an alternate to the SNAP I device, a thermoelectric direct conversion device designated SNAP I-A was proposed.

While work on the SNAP I program was being terminated and development of the SNAP I-A unit started, the operational parameters for the new unit were not firmly established. Several conceptual design studies were performed upon Auxiliary Power Units (APU) to be able to compare different concepts. Three of these concepts are as follows:

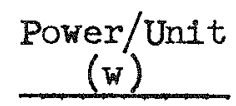

125

175

125
APU Iife

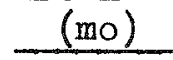

6

4

12

The current design for the SNAP I-A APU system also employs Ce-144 as the fuel. As in the SNAP I concept, two identical units are used to aid vehicle stablifization. A summary of the important design parameters of a SNAP I-A unit are:

$\begin{array}{ll}\text { Fuel loading } & 0.88 \text { megacuries Ce-I44 } \\ \text { Output power } & 125 \mathrm{w} \text { for } 374 \text { days, flat output } \\ \text { Voltage } & 28 \mathrm{v} \\ \text { Current } & 4.46 \mathrm{amp} \\ \begin{array}{l}\text { Overall generator } \\ \text { efficiency }\end{array} & 5.0 \%\end{array}$

After the nominal one-year of satellite life, there will be a power decline similar to the decay rate of the Ce-144 fuel.

All conceptual design parameters were maintained well within present day state-of-the-art limitations such that few developmental problems should arise in future experiments. Figure 1 illustrates the current 


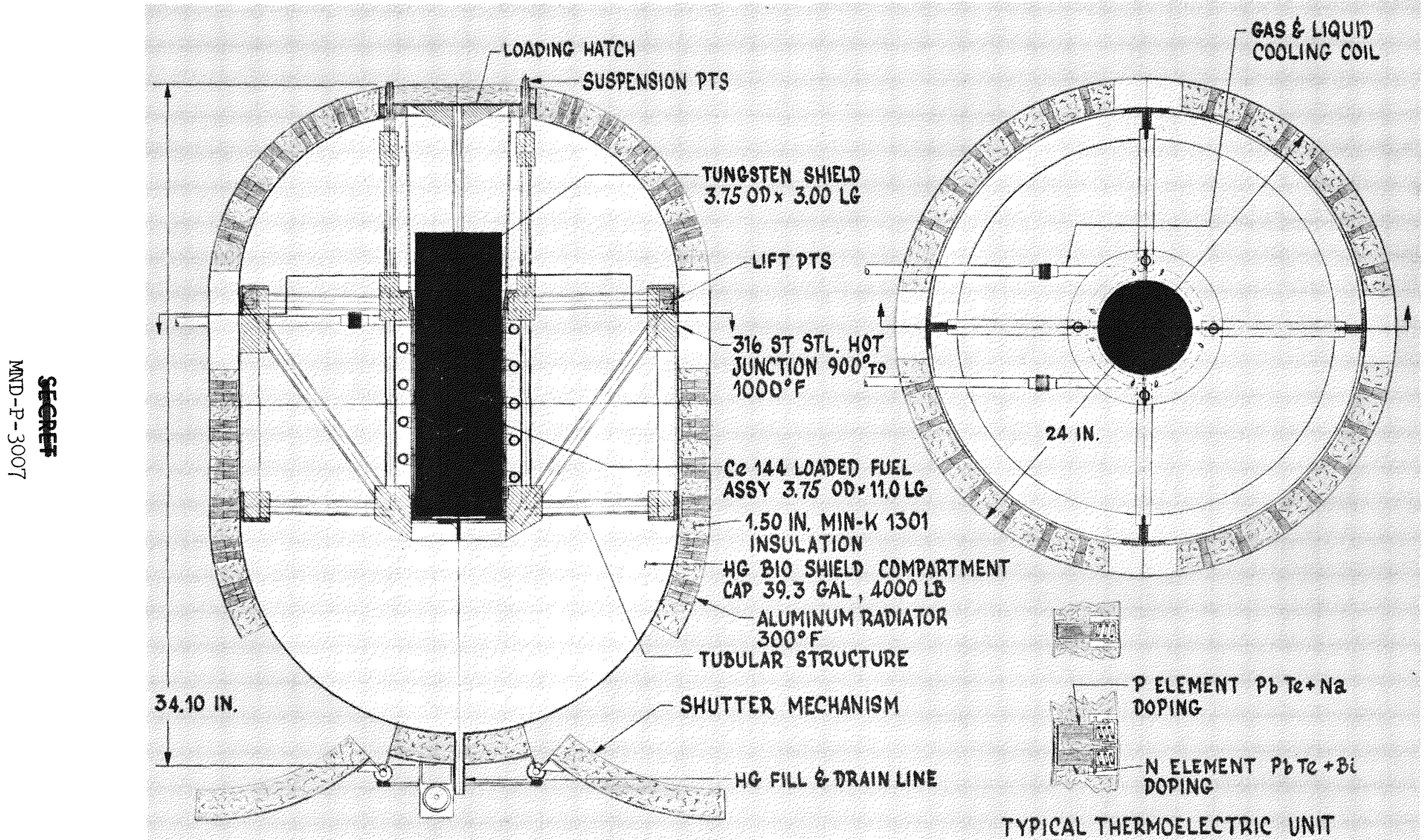

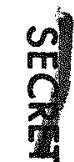


design of the SNAP I-A generator. Cerium-144 pellets are used to load the internal fuel assembly. This unit will operate in the temperature range of $1600^{\circ} \mathrm{F}$ to maintain a hot junction temperature between 900 to $1000^{\circ} \mathrm{F}$. Lead telluride thermoelectric elements with both sodium and lodine doping are used to convert the decay heat into $28-\mathrm{v}$ electricity. The overall efflclency for the complete generator is $5 \%$, however, the individual couples are as high as $6.7 \%$.

The SNAP I-A generator is made of a structurally supported fuel block and an outer shell. The shell of the unit, which contains the thermoelectric elements, is made up of two 1ntegral skins. An inner skin of stainless steel serves as the thermo-element hot junction, and an outer skin of aluminum provides the cold junction. A thermo insulating material is packed around the elements between the two skins.

Since the generator is designed to operate for $12 \mathrm{mo}$, it is best from an operational standpoint that the generator output remain flat for as long a period as possible. This feat is accomplished by means of synthetic power flattening of the generator by radiating excessive heat to the surroundings. As the isotope fuel decays, the amount of radiated heat is decreased to effectively maintain a constant output of heat through the thermoelectric elements. This is accomplished in the SNAP I-A generator by exposing the inner skin (hot junction) for direct radiation to space and then varying the effective radiator area to power flatten the output of the generator. At the bottom of the unit the insulation is hinged and is opened by a mechanism which responds to a sensed signal, thus permitting the inner skin to radiate directly to outer space.

The fuel block is supported from the shell by tubular truss members, which, in turn, are suspended by tension members passing through the top of the unit. These members are attached to the flight vehicle structure at the top.

A tungsten block is located over the fuel block assembly to provide in-flight shielding. Ground shielding is provided by completely filling the interlor of the unit with mercury. Just prior to launch, the biological mercury shield is drained remotely. A coll surrounding the 1sotope block serves to carry coolant for the shield mercury.

The energy-time characteristics of the SNAP I-A unit over the nominal operational life of one year are shown in the plot of Fig. 2 . The total thermal energy available from the encapsulated isotope at any time is shown by the curve labeled "Isotope Output." This thermal energy is used in three different ways: some is converted to electrical energy, some rejected and some lost through leakage. The energy which passes through the thermoelectric elements is labeled "Conversion Requirement." Approximately $61 / 2 \%$ of this energy is converted into 
THERMOELECTRIC GENERATOR

ELECTRICAL OUTPUT (W FOR 374 D)

125

VOLTAGE (V)

CURRENT (AMP)

EXTERNAL LOAD (OHMS)

4.46

FUEL (MEGACURIES Ce-144)

6.28

0.88

THERMOELECTRIC ELEMENTS

NUMBER

DIAMETER (IN.)

LENGTH (IN.)

RESISTIVITY $\left(1000-335^{\circ} \mathrm{F}, \mu \Omega \mathbb{I N}\right.$.)

SEBECK EFFECT $\left(1000-335^{\circ} \mathrm{F}, \mathrm{V} / \mathrm{CM}^{\circ} \mathrm{C}\right)$

THERMAL CONDUCTIVITY $\left(1000-335^{\circ} \mathrm{F}, \mathrm{W} / \mathrm{CM}^{\circ} \mathrm{C}\right)$

FIGURE OF MERIT $\left({ }^{\circ} F^{-1}\right)$

COUPLE EFFICIENCY $(\%)$

GENERATOR EFFICIENCY $(\%)$
N-ELEMENT

277

0.375

0.78

1251

135.5

$0.019307 \quad 0.016191$

$0.541204 \times 10^{-3}$

6.75

5.0 
electricity. The heat rejected is that energy which is passed through the movable insulation (termed thermal shutter) to regulate the electrical output. The heat leakage is the energy which passes through the insulation. It should be noted that the sum of the rejected energy, the leakage, and the conversion requirement equal the isotope output at any time.

\section{B. SHIELDING ANALYSIS}

Dose rates were calculated at a distance of one meter from the center of the core to determine the adequacy of the shielding. Since the available IBM program was not made to automatically handle cylindrical shields with rounded corners dose rates were calculated at three points $90^{\circ}$ apart, i.e., directly above, below and to one side of the unit. Maximum dose rates occur at these points for cylindrical shields. The results are tabulated in Table 1. At an inner shell design radius of $10.5 \mathrm{in}$. it can be seen from Table 1 that the maximum dose rate at one meter is $125 \mathrm{mr} / \mathrm{hr}$. The IBM program is currently being rewritten to handle the chosen shield configuration. Results should be available in the next quarter.

\section{OPERATIONAL HAZARDS}

During the quarter hazards effort was curtailed somewhat pending the design changes from SNAP I to SNAP I-A. Effort applicable to SNAP I-A consisted of the following:

(1) An aerodynamic heating analysis of an intact re-entry and impact design of SNAP I-A.

(2) An analysis of the launch trajectory of the WS $117 \mathrm{~L}$ vehicle with respect to aborts along this trajectory.

(3) An analysis of the subsequent hazards resulting from missile failures.

(4) A statistical analysis of earth impact probabilities for a north-south polar orbit.

These are discussed separately in the following paragraphs.

1. Aerodynamic Heating Analysis

An aerodynamic heating analysis was performed for a SNAP I-A untt in which the molybdenum fuel core was coated with $3 / 8$ in. of graphite. The orbital decay calculated was assumed to start at (time $=0$ ) an al- 


\section{TABLE I}

Dose Rates for SNAP I-A

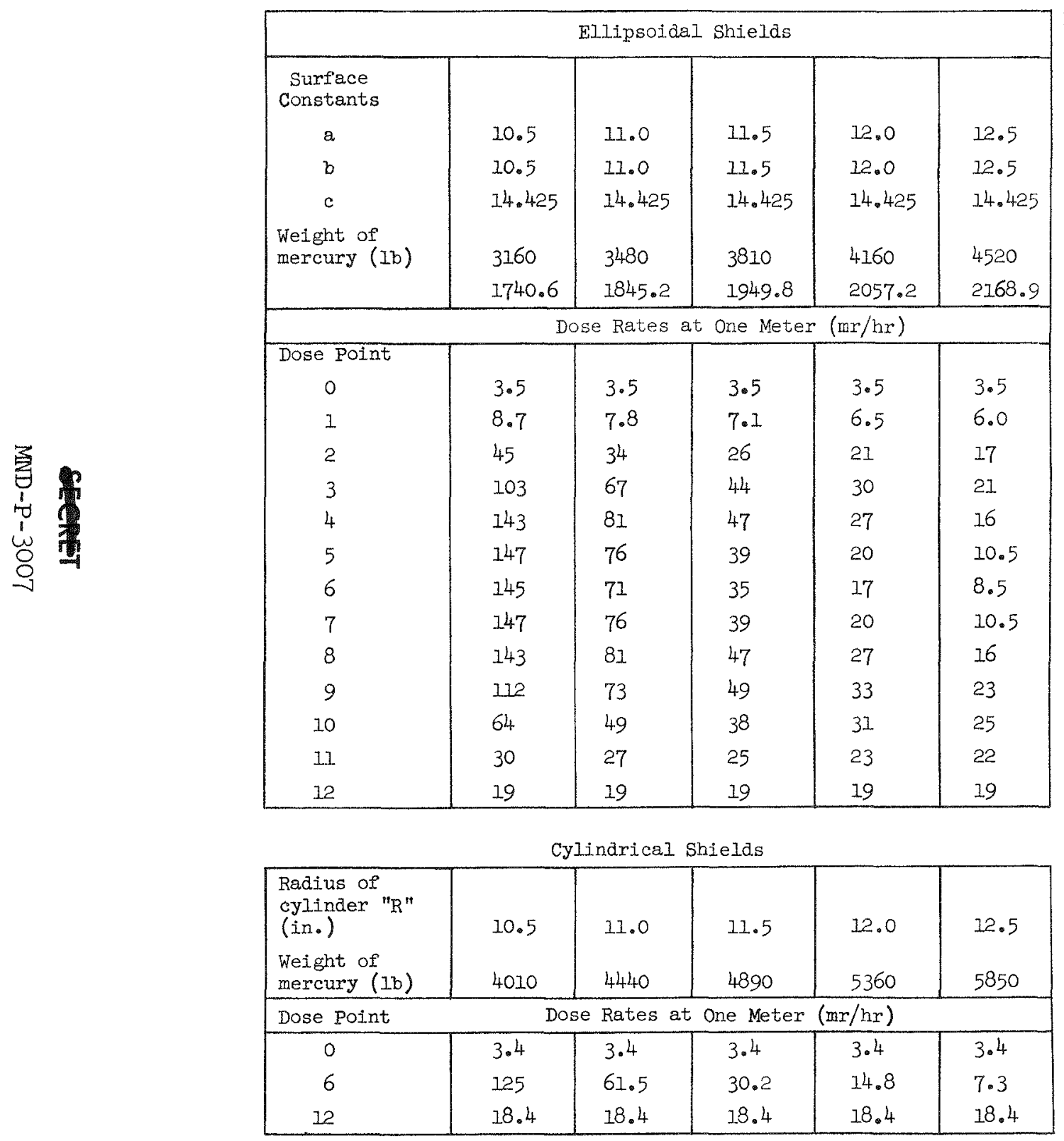

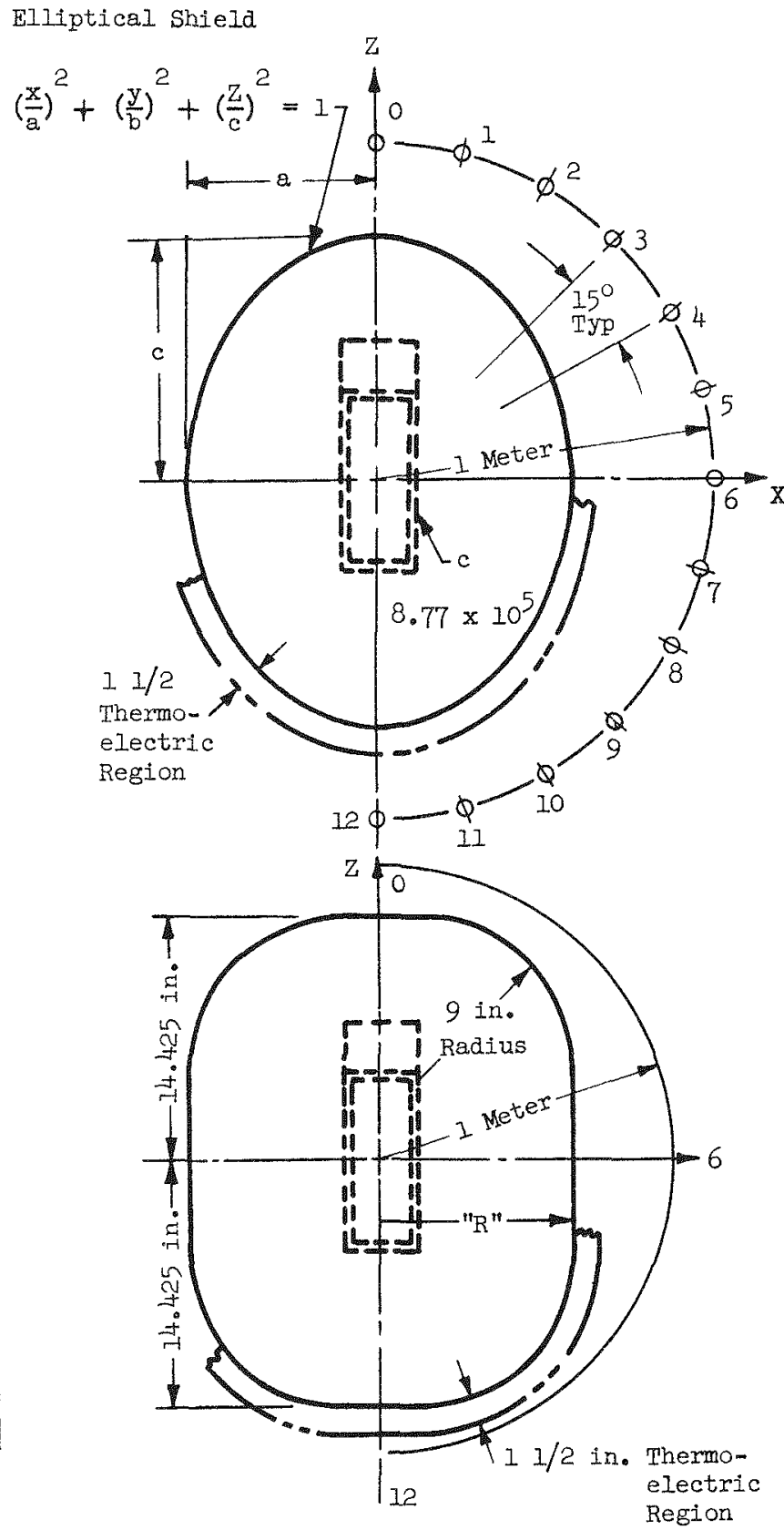


titude of $500,000 \mathrm{ft}$ at an incident angle of $-0.01^{\circ}$. The APU remains above 400,000 ft for approximately $20,000 \mathrm{sec}$. The total time to impact is approximately $28,000 \mathrm{sec}$.

Figure 3 shows the failure of steel components of the APU at $27,400 \mathrm{sec}$ and the re-entry history up to the point of failure. Figure 4 shows the re-entry history from $27,400 \mathrm{sec}$ to impact.

It is assumed that the aluminum outer skin failed at a temperature of $1265^{\circ} \mathrm{R}$, and that the Min-K insulation failed at the same point at $21,000 \mathrm{sec}$.

Failure of the inner stainless steel skin, baffle, and supporting structure is assumed to occur simultaneously when a skin stagnation temperature of approximately $2565^{\circ} \mathrm{F}$ is attained at $27,350 \mathrm{sec}$. Since significant acceleration and dynamic pressure starts shortly after this time, the inner container was assumed to separate from its surrounding structure at $27,400 \mathrm{sec}$. At this point the stagnation temperature at the skin is $2720^{\circ} \mathrm{R}$, the altitude is $303,000 \mathrm{ft}$, and the velocity is 25,600 fps.

History of inner container.- The inner container carries the fuel pellets and consists of a cylindrical molybdenum block which has been coated with $3 / 8$ in. of graphite. Because of a rather drastic change in the drag parameter, $\left(\mathrm{W} / \mathrm{C}_{\mathrm{D}} \mathrm{A}\right)$ caused by separation of the inner container from the other structure, a new trajectory was computed.

Figure 5 shows the equilibrium skin stagnation temperature for the trajectory of the inner container. The maximum surface temperature shown here is $6000^{\circ} \mathrm{R}$ which is below the melting point of graphite but above the melting point of molybdenum. It is realistic to assume that just prior to separation of the outer structure the inner container is at $2000^{\circ} \mathrm{R}$. Figure 5 shows that upon separation, the carbon skin stagnation temperature is $3500^{\circ} \mathrm{R}$ and increases to $6000^{\circ} \mathrm{R}$ in about 380 sec.

Next an isotropic, homogeneous carbon cylinder, the same size as the inner container was assumed and the time required to bring a point $3 / 8$ in. below the surface to $3800^{\circ} \mathrm{R}$ was calculated to be $78 \mathrm{sec}$. Actually, since the carbon is only a coating over the molybdenum and the diffusivity of molybdenum is four times that of carbon, the time required to produce $3800^{\circ} \mathrm{R}$ at the molybdenum outer surface will be on the order of $100 \mathrm{sec}$. Thus, the molybdenum temperature will lag the carbon surface temperature by about $100 \mathrm{sec}$. If the maximum skin temperature of $6000^{\circ} \mathrm{R}$ is considered, it can be seen from Fig. 5 that a $100-\mathrm{sec}$ lag time will place the molybdenum skin temperature at $5300^{\circ} \mathrm{R}$, which is in excess of its melting point of $4900^{\circ} \mathrm{R}$. 


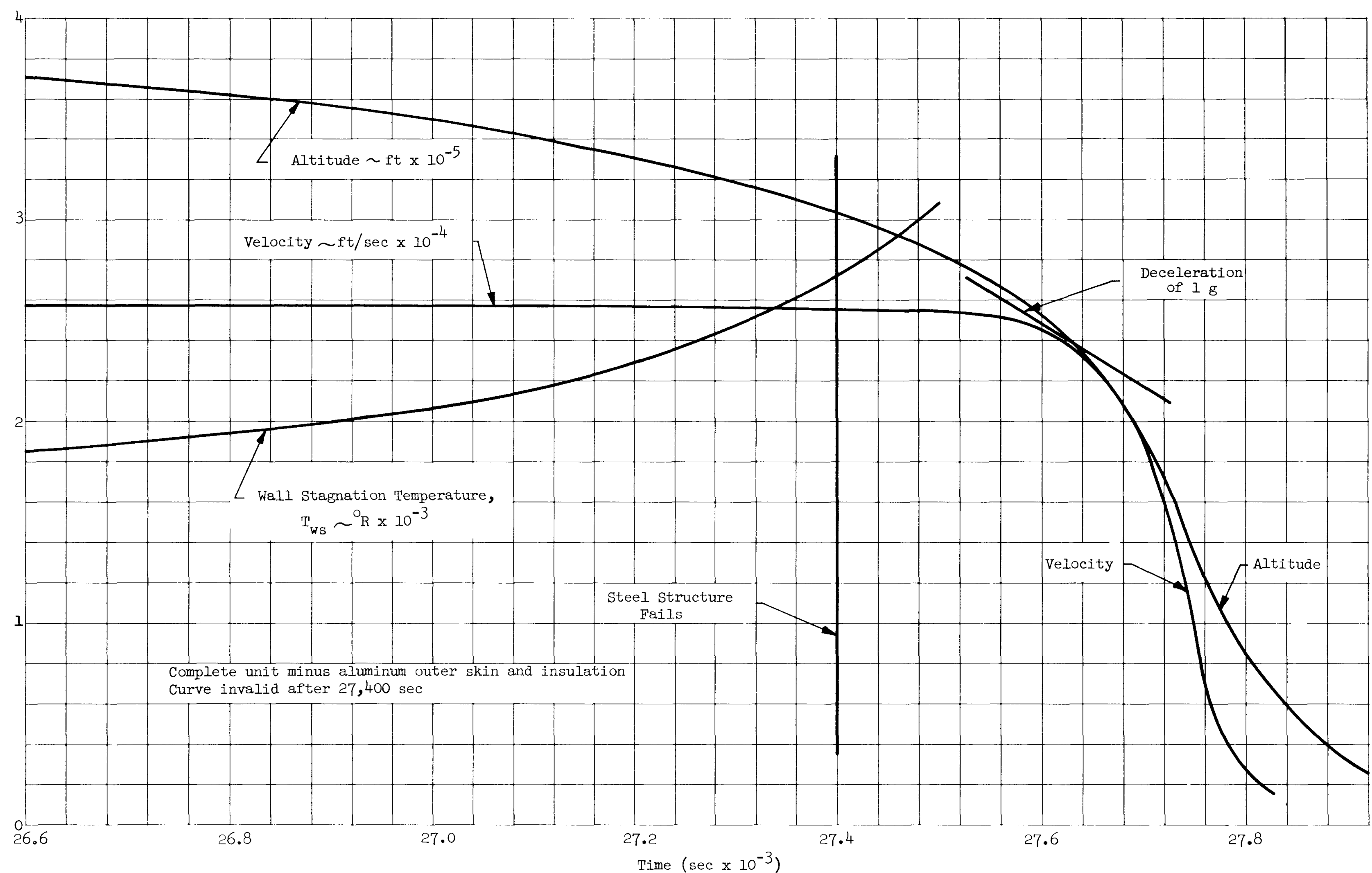

Fig. 3. Re-Entry Parameters for SNAP I-A APU 


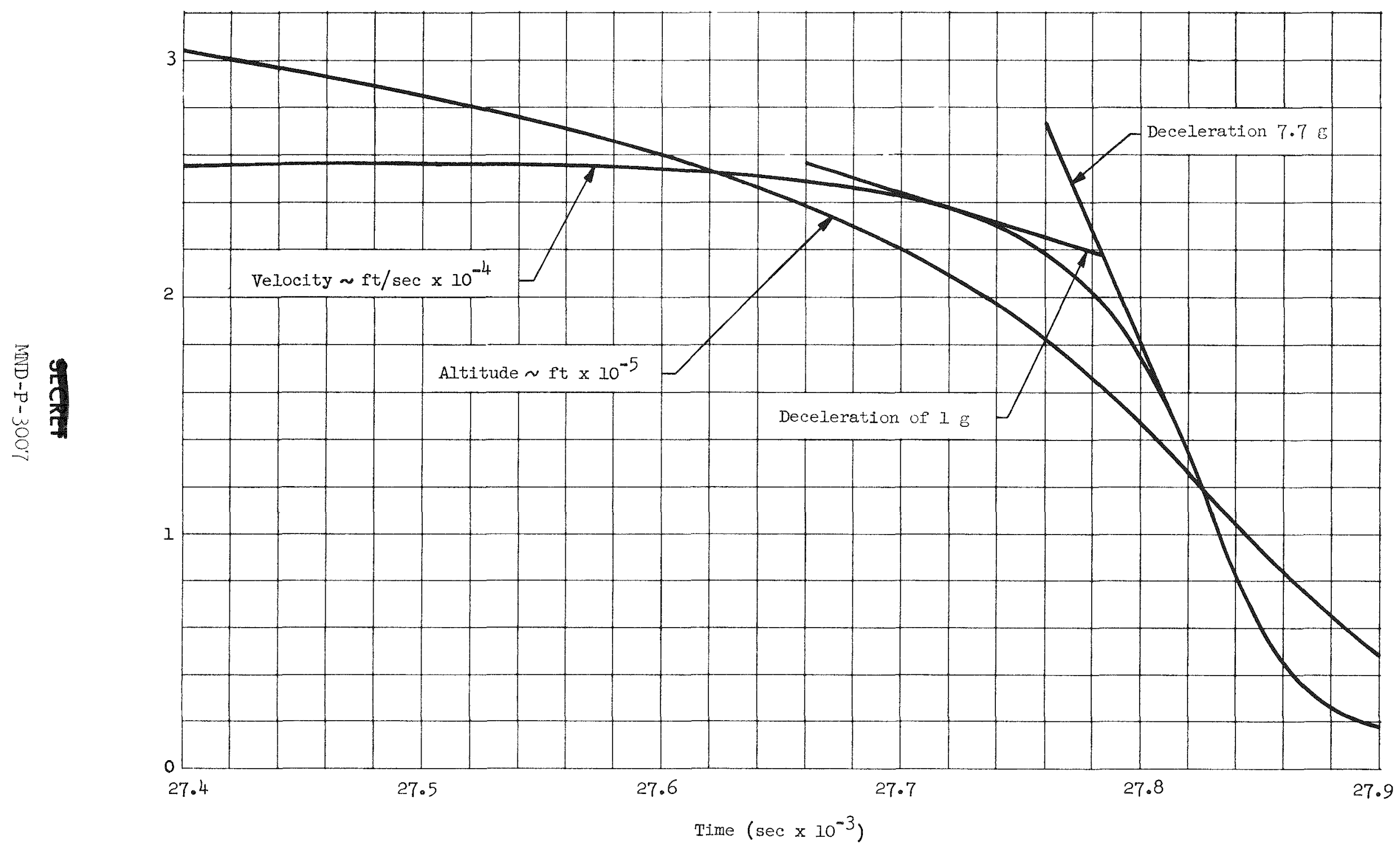




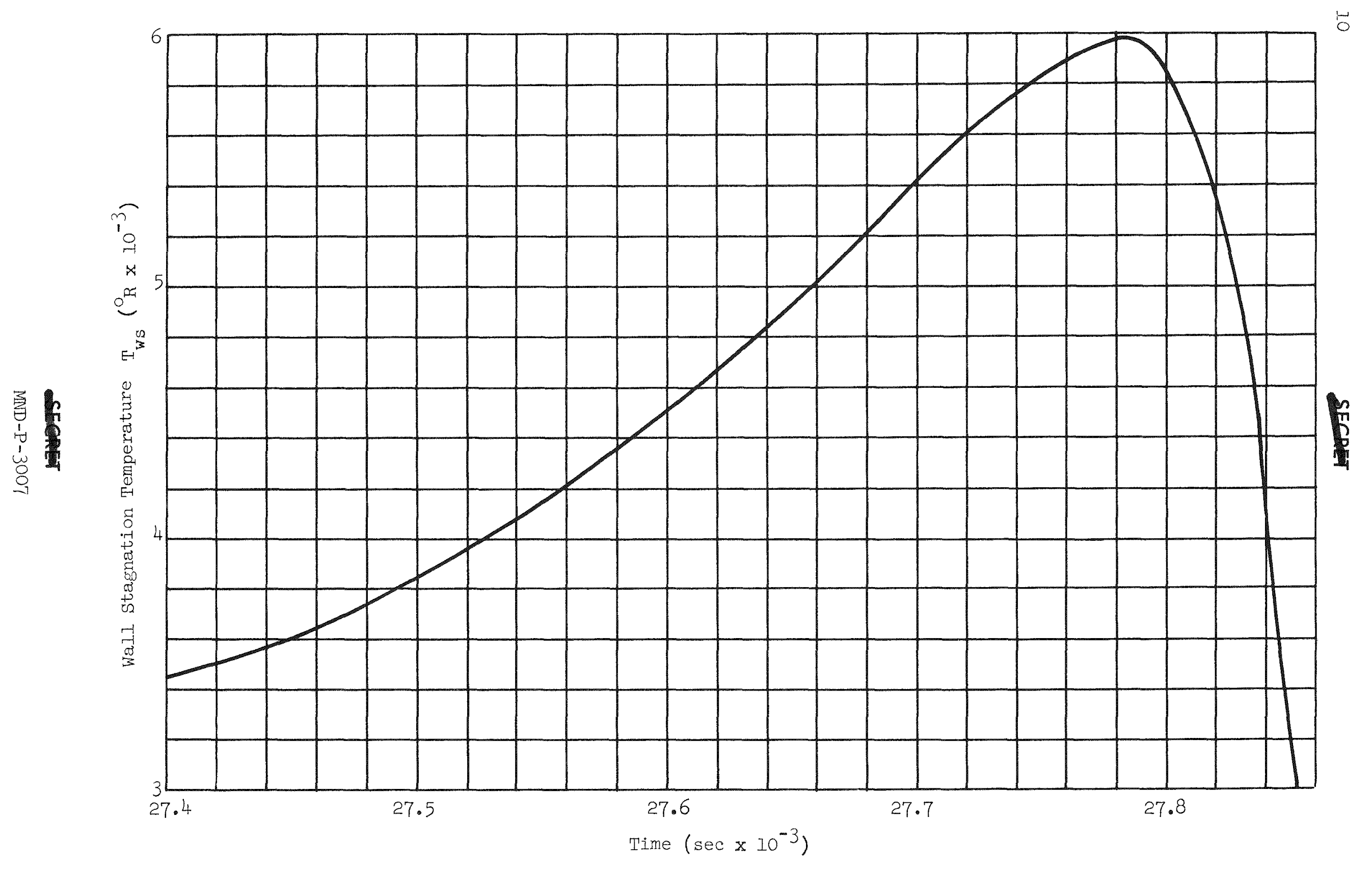

Fig. 5. Equilibrium Surface Stagnation Point Temperature of SNAP I-A APU Inner Container Only 
The total stagnation heat available is 57,500 Btu. The heat required to bring the inner container from 2000 to $6000^{\circ} \mathrm{R}$ was calculated to be $9000 \mathrm{Btu}$ which is much less than the total heat available. If, however, only $90 \%$ of the heat input were radiated from the body and $10 \%$ were absorbed, the stagnation skin temperature would be reduced from 6000 to $5870^{\circ} \mathrm{R}$. This, plus the comparatively short lag time, justifies the assumption of near equilibrium wall temperature conditions.

Conclusions.- Sublimation and oxidation of the molybdenum can occur above $2665^{\circ} \mathrm{R}$ if the graphite coating fails at any point.

At temperatures below $3000^{\circ} \mathrm{R}$, the possibility of graphite failure due to the differences in thermal expansion rates appears to be rather remote.

There is a high probability that some of the graphite may be torn off during the separation of the inner container from the outer container.

The possibility also exists that if the graphite is damaged, subIfmation of the molybdenum will be sufficlent to cause the graphite to flake from the remainder of the molybdenum surface.

At the peak heating rate the molybdenum is at melting temperatures and high deceleration loads may be sufficient to cause failure of the graphite.

It can be seen that the design of that SNAP I-A core that was analyzed has a very marginal chance of impacting intact on the earth's surface. It appears feasible to re-enter a SNAP I-A unit intact with certain design and material changes.

\section{Missile Abort on Various Points of the WS 117L Launch Trajectory}

Study has been conducted on the aerodynamic heating and motion of an orbital body returning ballistically from pre-orbital abort conditions. In each case the power package is assumed to be instantaneously free from the surrounding structure at the moment of abort. It is felt that this assumption will result in more critical re-entry conditions than those encountered by the entire payload or by the power package partially protected by surrounding structure. It would be desirable to study the failure modes of the booster structure at the time of abort to determine the effects of and perturbations resulting from the destruct or failure of the booster system.

The power package is composed of a core, surrounding environmental shields and thermoelectric elements. The ballistic parameter, $W / C_{D} A$, is assumed to be 31.2. The trajectory from abort to impact is defined 
by the booster conditions of velocity, altitude and attitude at time of abort. The time history to impact is determined by the solution of equations of motion of a point mass in a central inverse square gravity force field. The actual computations are accomplished on automatic digital computing machines.

The booster conditions at abort are based on a nominal booster trajectory supplied by the system contractor. Ihis trajectory assumes a 300-statute mile orbit launch on an azimuth of $107^{\circ}$ south of north. Aborts are considered on points along this trajectory that are selected on the basis of experience relating to failures during the boost of multistage vehicles. These points are:

(1) Time of inftial tilt

(2) Time of maximum dynamic pressure

(3) TIme of booster separation

(4) wime of sustainer burnout

(5) Time of vernier burnout

(6) Time of ring stage ignition.

Fallures during the flual stage are not considered due to the lack of time and the lack of adequate definition of the final stage performance. Future studies should investigete failures during this injection stage and should include investigations of possible off-nomina trajectories. These studies should be veighted as to the probablitty of achieving such failures and off-nominal trajectorles. Data also should be obtained on a more nearly polar launch and shovld include effects of wind profiles.

\section{RESULTS}

The results of this study are presented in Table 2 and Fig. 6 . It should be noted that some distortion of the scale in Fig. 6 is required to present the full scope of conditions. It can be seen that intact return is accomplished from launch through booster separation. The next conditions, sustainer and vernier burnout, are essentially the same and would result in some damage to the power package. Hovever, these conditions will not result in sufficient heating to produce an unsatis-' factory return. The conditions at sustainer burnout are comparable to those of an IRBM where a substantial peak temperature, $3900^{\circ}$ F, is achieved for a short time. The temperature is above $2200^{\circ}$ F for only 
TABLE 2

Mission Abort Data

\section{Trajectory Conditions}

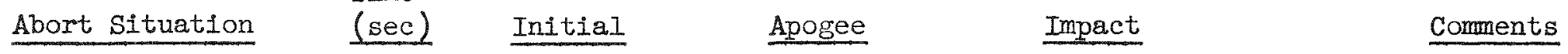

On launch pad

Free fall and impact--fire and explosion effects

\section{Pitchover \\ Altitude \\ Velocity \\ Attitude \\ Range}

Maximum Dynamic

Pressure

Altitude

Velocity

Attitude

Range

Booster Separation

Altitude

Velocity

Attitude

Range

Sustainer Burnout

Altitude

Velocity

Attitude

Range

Verniex Burnout

Altitude

Velocity

Attitude

Range

Final Stage Ignition

Altitude

Velocity

Attitude

Range
15

$\begin{array}{lll}9,000 \mathrm{ft} & -- & \\ 162 \mathrm{fps} & -- & 163 \mathrm{fps} \\ 90^{\circ} & -- & 90^{\circ} \\ 0 \text { naut mi } & -- & 0 \text { naut mi }\end{array}$

60

$$
\begin{aligned}
& 38,000 \mathrm{ft} \\
& 957 \mathrm{fps} \\
& 540
\end{aligned}
$$

0.1 naut $\mathrm{mi}$

$41,000 \mathrm{ft}$

$00^{--}$

0.5 naut mi

163 fps

$90^{\circ}$

147

250,000 ft
10,889 fps
$23^{\circ}$
60 naut mi

$586,000 \mathrm{ft}$

$0^{\circ}$

320 naut mi

$166 \mathrm{fps}$

60 naut mi

260

$720,000 \mathrm{ft}$

18,209 fps

$14.8^{\circ}$

340 naut mi

$1,417,506 \mathrm{ft}$

$0^{\circ}$ -

1,145 naut $\mathrm{mi}$

162 fps

$90^{\circ}$

2290 naut mi

289

$\begin{array}{lll}850,000 \mathrm{ft} & 1,584,000 \mathrm{ft} & -- \\ 18,230 \mathrm{fps} & 0^{0}-- & 162 \mathrm{fps} \\ 13.6^{\circ} & 90^{\circ} \\ 420 \text { naut mi } & 1,200 \text { naut mi } & 2400 \text { naut mi }\end{array}$

585
No aerodynamic heatinghazards essentially same a.s Item 1

Essentially no aerodynamic heating

Very low heat input, tends toward IRBM conditions $2000^{\circ} \mathrm{F}$ max stagnation temperature

(15 sec above $2200^{\circ} \mathrm{F}$ ) compares with IRBM $V$ 18,400 fps $35^{\circ}$

See Item 5

$\stackrel{\rightleftarrows}{\omega}$
Maximum temperature $3900^{\circ} \mathrm{F}$
$1,570,000 \mathrm{ft}$

$18,200 \mathrm{fps}$

2.50
162 fps

$90^{\circ}$

2400 naut mi 


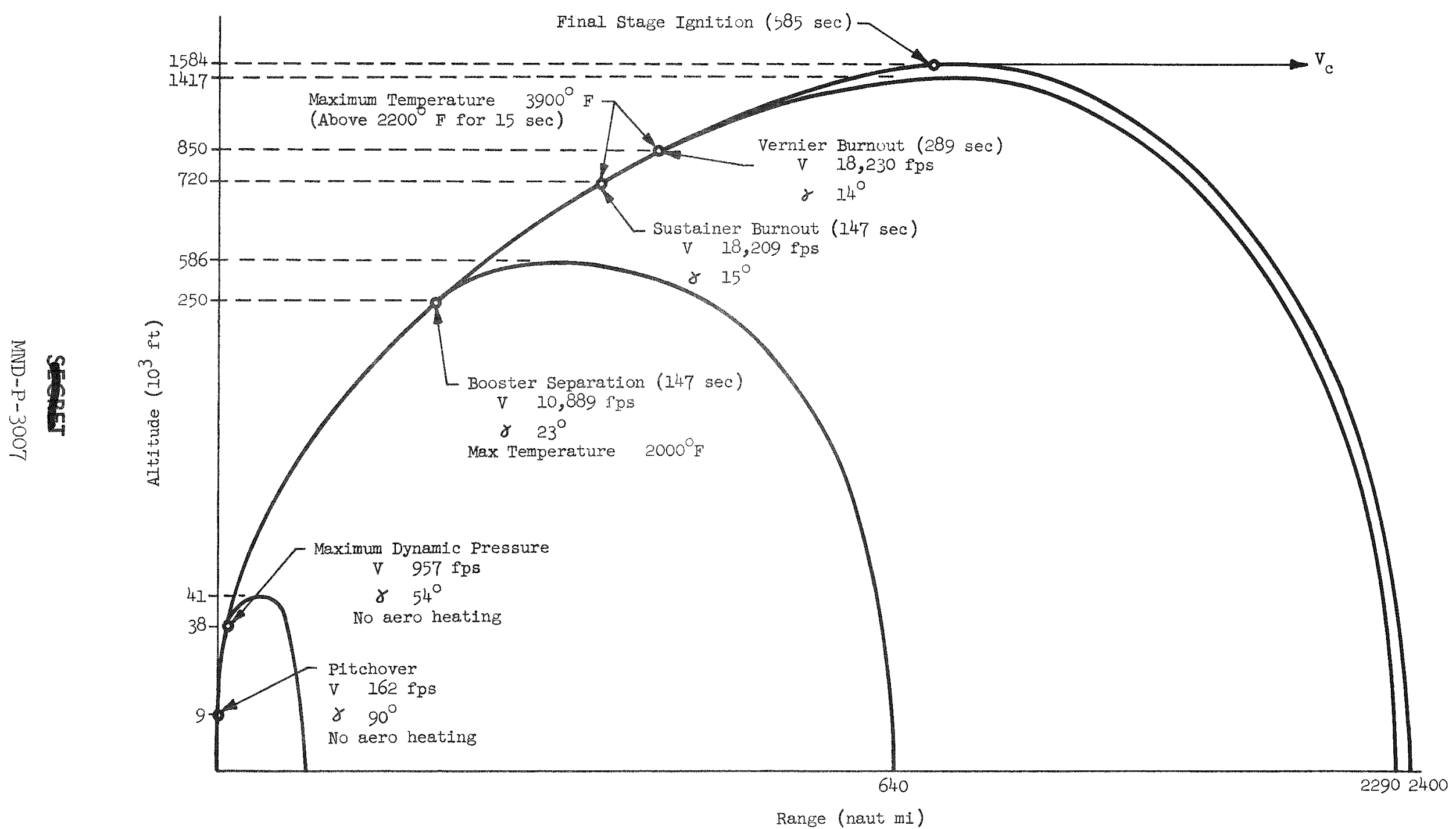


$15 \mathrm{sec}$. These temperatures are based on rqqdiation equilibrium stagnation point data and are sufficient to dissipate the external shielding and result in limited oxidation of the basic core. Again, essentially intact return of the core is expected.

Different criteria must be applied to the two concepts of re-entry. For intact re-entry the most severe heating conditions should be considered. Therefore, a preliminary analyses would consider a stabilized non-tumbling attitude in a turbulent flow field. Similarly an analyses of a burnup configuration would consider the least critical heat inputs such as a tumbling body in a laminar flow field. For a more sophisticated analysis, the theory of flow transition from laminar to turbulent flow should be carefully investigated in relation to the free-stream flow conditions of slip flow and high altitude, high speed continuous flow.

Finally, if the injection stage fails to ignite, the resultant trajectory will be essentially the same as that resulting from abort at vernier burnout. Return from this point also would result in intact landing of the core.

The range to impact should be noted also. After leaving the launch area the nearest down range land mass is the southern polar cap at a distance in excess of 5000 naut $\mathrm{mi}$. On this basis, it is apparent that impact from nominal trajectory aborts excluding those in the immediate launch area will be in a water area.

From the data presented, it is concluded that intact return from nominal abort conditions up to the time of final stage ignition can be assured and that the impact point will be in the launch area or over water. Hovever, a study of off-nominal conditions may yield other critical re-entry environments. In this case, the data must be evaluated on the basis of probability. Fallure during the final stage and before orbital injection will yield an area of uncertainty that cannot be defined until more complete data are available concerning the performance of the final stage.

A more detailed analysis of the pre-infection failures of the WS 117L will be reported in the next quarter.

\section{Analysis of Hazards Resulting from Missile Failures}

This analysis is presently being completed and will be reported in the next quarter.

2. A Statistical Analysis of Earth Impact Probabilities for a NorthSouth Polar Orbit

Polar cross-section of the earth.- To establish the impact proability for a satellite in a polar orbit, it was necessary to deter- 
mine the statistics for the earth's surface based upon a series of crosssections through the poles. The resultant statistics were derived by measuring the amount of land, water, and ice along each five-degree meridian and averaging the total of the 36 cross-sections measured.

Average Cross-Section Through the Poles

$(\%)$

$\begin{array}{ll}\text { Land } & 22.61 \\ \text { Water } & 59.37 \\ \text { Ice } & 18.02\end{array}$

Land Divisions

$(\%)$

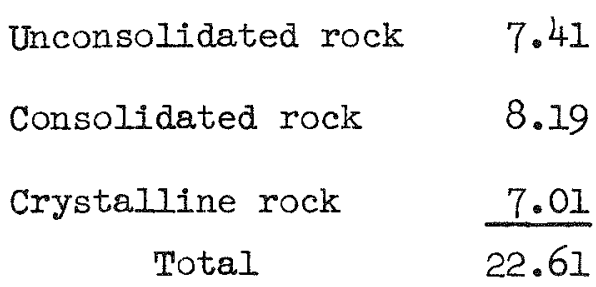

Water Divisions

$(\%)$

$\begin{array}{lr}\text { Oceans } & 58.54 \\ \begin{array}{ll}\text { Inland waters } \\ \text { Total } \\ \text { Ice Divisions }\end{array} & \frac{0.83}{59.37} \\ & (\%) \\ \text { Land ice } & 12.30 \\ \text { Water ice } & 5.72 \\ \text { Total } & 18.02 \\ \text { Earth total } & 100 \%\end{array}$


Post-re-entry impact probability.- Statistically, out of 100 APU cores re-entering from a polar orbit 66 will impact on water and 34 on land masses. A more detalled breakdown is as follows:

$\begin{array}{lr}\text { Thirty-four Impacted on Land Masse } & 12 \\ \text { Ice } & 7 \\ \text { Unconsolidated rock } & 8 \\ \text { Consolidated rock } & \frac{7}{34} \\ \text { Crystaline rock } & 6 \\ \text { Sixty-six Impacted on water } \\ \text { Ice } \\ \text { Inland waters } \\ \text { Oceans } & \frac{59}{66}\end{array}$

A further analysis of the 34 that will impact on land indicates that only a small percentage will impact in significantly populated regions. This is based on the fact that unconsolidated rock supports the majority of the earth's population while consolidated and crystalline rocks are less favorable for habitation. The 1ce-covered areas have a population density of essentialiy zero.

It is estimated that of 100 APU cores impacting on the earth's surface from decay of a polar orbit only 10 will impact in regions of significant population density. 
SECREJ

MND-P-3007 
II. TASK 2--BOILER DEVELOPMENT

\section{A. ELECTRIC MERCURY BOILERS}

Since the SNAP I program was being phased out in favor of a SNAP I-A thermoelectric generator program, it seemed advisable to discontinue the fabrication of electric boiler mockups that could not be properly utilized in elther program. As a result, the following declsions were made at the start of this quarter as to the future use and disposition of electric boiler mockups:

\begin{tabular}{|c|c|c|c|c|}
\hline Unit & $\begin{array}{l}\text { Thermal } \\
\text { Shutter }\end{array}$ & $\begin{array}{c}\text { Tungsten } \\
\text { Shield } \\
\end{array}$ & $\begin{array}{l}\text { Intended } \\
\text { Test Program } \\
\end{array}$ & Final Use \\
\hline PBP 4 & No & Yes & Dual boiler test & Dual boller test \\
\hline PBP 5 & No & Yes & Dual boiler test & Dual boiler test \\
\hline PBP 5A & No & Yes & $\begin{array}{l}\text { Back-up boiler for } \\
\text { dual boiler test }\end{array}$ & $\begin{array}{l}\text { Back-up boiler } \\
\text { for test }\end{array}$ \\
\hline PBP 6 & Yes & Yes & $\begin{array}{l}\text { Thermal shutter and } \\
\text { boiler performance }\end{array}$ & $\begin{array}{l}\text { Cancel and modify } \\
\text { for heat transfer } \\
\text { test }\end{array}$ \\
\hline PBP 6A & Yes & Yes & $\begin{array}{l}\text { Back-up boiler for } \\
\text { tests on No. } 6\end{array}$ & $\begin{array}{l}\text { Cancelled during } \\
\text { fabrication }\end{array}$ \\
\hline \multicolumn{5}{|c|}{$\begin{array}{l}\text { At the start of the quarter, PBP } 4 \text { and } 5 \text { were fabricated, loaded } \\
\text { and assembled into the dual boiler test loop for qualification testing. } \\
\text { Boilers PBP 5A, PBP } 6 \text {, and PBP } 6 \mathrm{~A} \text { were in various stages of fabrication } \\
\text { and assembly. It was decided to complete PBP } 5 \mathrm{~A} \text {, hold PBP } 6 \text { at its } \\
\text { present fabrication stage, and cancel PBP } 6 \mathrm{~A} \text { in its entirety. PBP } 5 \mathrm{~A} \\
\text { boiler would be checked out in the laboratory and then forwarded to } \\
\text { Thompson Ramo Wooldridge, Inc. as a spare part, while PBP } 6 \text { would be } \\
\text { stripped of its insulation and thermal shutter and be used as a high- } \\
\text { temperature heat source for a SNAP I-A heat transfer mockup experiment. }\end{array}$} \\
\hline
\end{tabular}

\section{B. ISOTOPE BOILER NO. I}

Manufacturing of the initial SNAP I isotope boiler was started in January 1959 and was over $50 \%$ completed by the start of the fourth quarter FY 59. Due to the SNAP I phase out program, the complete assembly was of no use in either the SNAP I-A thermoelectric generator program or the phase out program. Consequently, the SNAP I isotope Unit, BSP I, was cancelled during fabrication, and the manufacturing drawings were filed. 


\section{SNAP I-A THERMOELECTRIC GENERATOR}

During the first month of the quarter, conceptual design studies were carried out to establish the basic configuration of several thermoelectric generators. The 125-w generator designed for one-year operation was selected and preliminary engineering drawings prepared. Following initial review, detail manufacturing drawings were prepared and released to manufacturing for fabrication of three electrically heated thermoelectric generators. The initial unit is scheduled for final assembly in September 1959.

Following this release, drawings were prepared for a simplified generator mockup configuration that could be filled with mercury and used in developing ground handling techniques. Manufacturing was initiated for two units for Lockheed and two for Martin testing programs. Delivery of two mockup units to Lockheed is scheduled for 1 Hovember 1959.

During the design phase of the SNAP I-A generator, a parallel effort was undertaken to design and fabricate a heat transfer mockup test unit to check the qualities of Min K-130I insulation. A simplified cylindrical shape was selected that simulated the general area relationships of the SNAP I-A generator. Figure 7 illustrates the general size and temperature distribution while heat loss experiments were being conducted under a vacuum environment. Heat loss values for the heat transfer mockup were measured at $432 \mathrm{w}$. Figures 8 to 11 illustrate the assembly of the heat transfer mockup test unit. Continuation studies are to be conducted with the generator mockup next quarter to establish comparative area data for the thermal shutters.

\section{CONTROIS}

A schematic of the SNAP I-A control system is illustrated in Fig. 12. The hot junction of the thermoelectric generator is sensed by a resistance thermometer element. This element (R4) is one leg of a Wheatstone bridge. Resistor $\mathrm{R} 3$ is adjusted to balance the bridge and produce a null (zero) signal input to the servo amplifier when the hot junction ( $\mathrm{R} 4$ ) temperature is at design conditions.

As the hot function temperature deviates from the design temperature, the bridge is unbalanced and the servo-amplifier receives a signal of an amplitude proportional to the magnitude of the temperature deviation. There is also a $180^{\circ}$ phase shift of this signal between positive and negative magnitudes of temperature deviation from the design hot junction temperature. An output signal from the servo-amplifier drives a servo-motor which in turn positions the shutter via a reduction gear. If the hot junction temperature increases above the design 

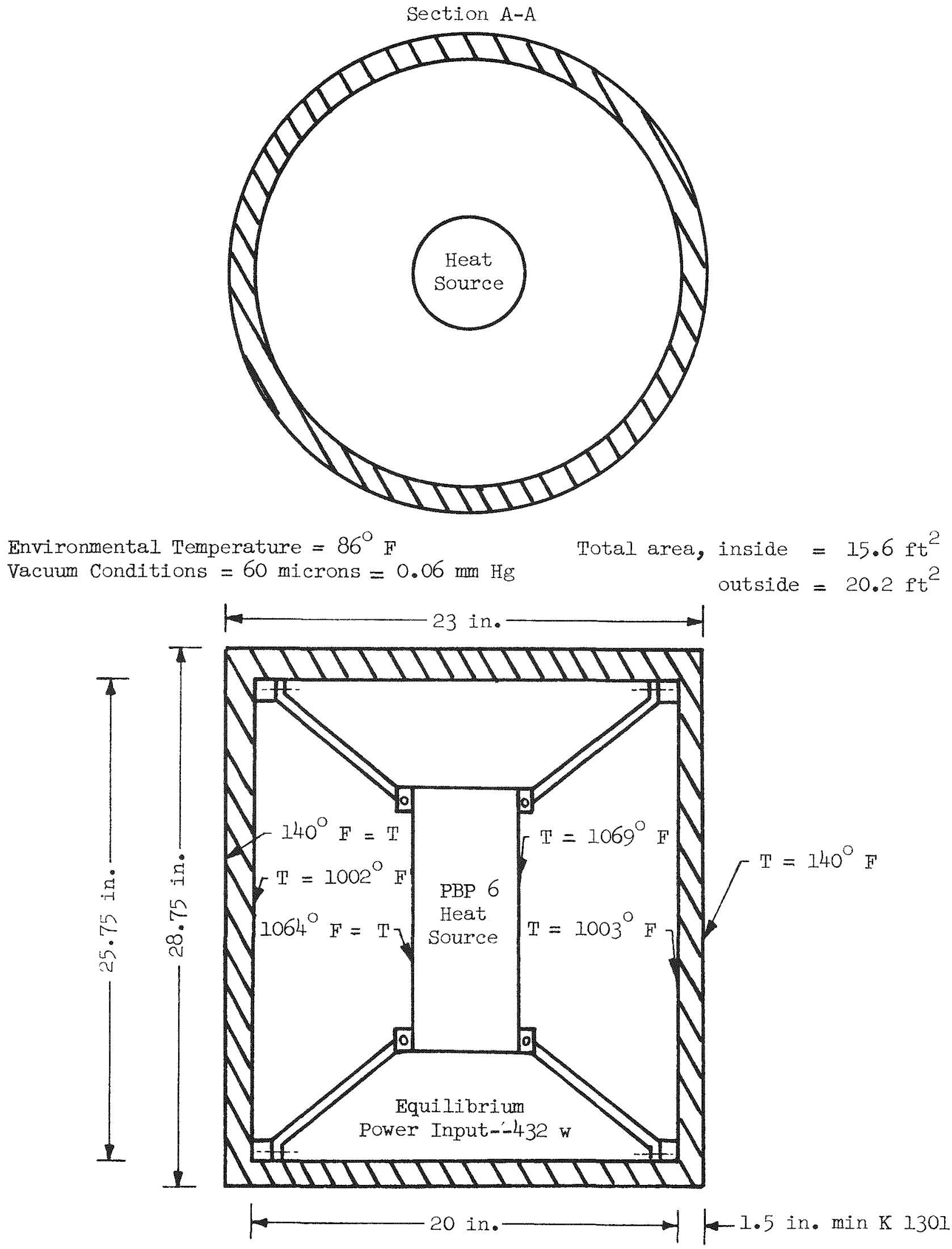

Fig. 7. Heat Transfer Mockup of SNAP I-A Generator 


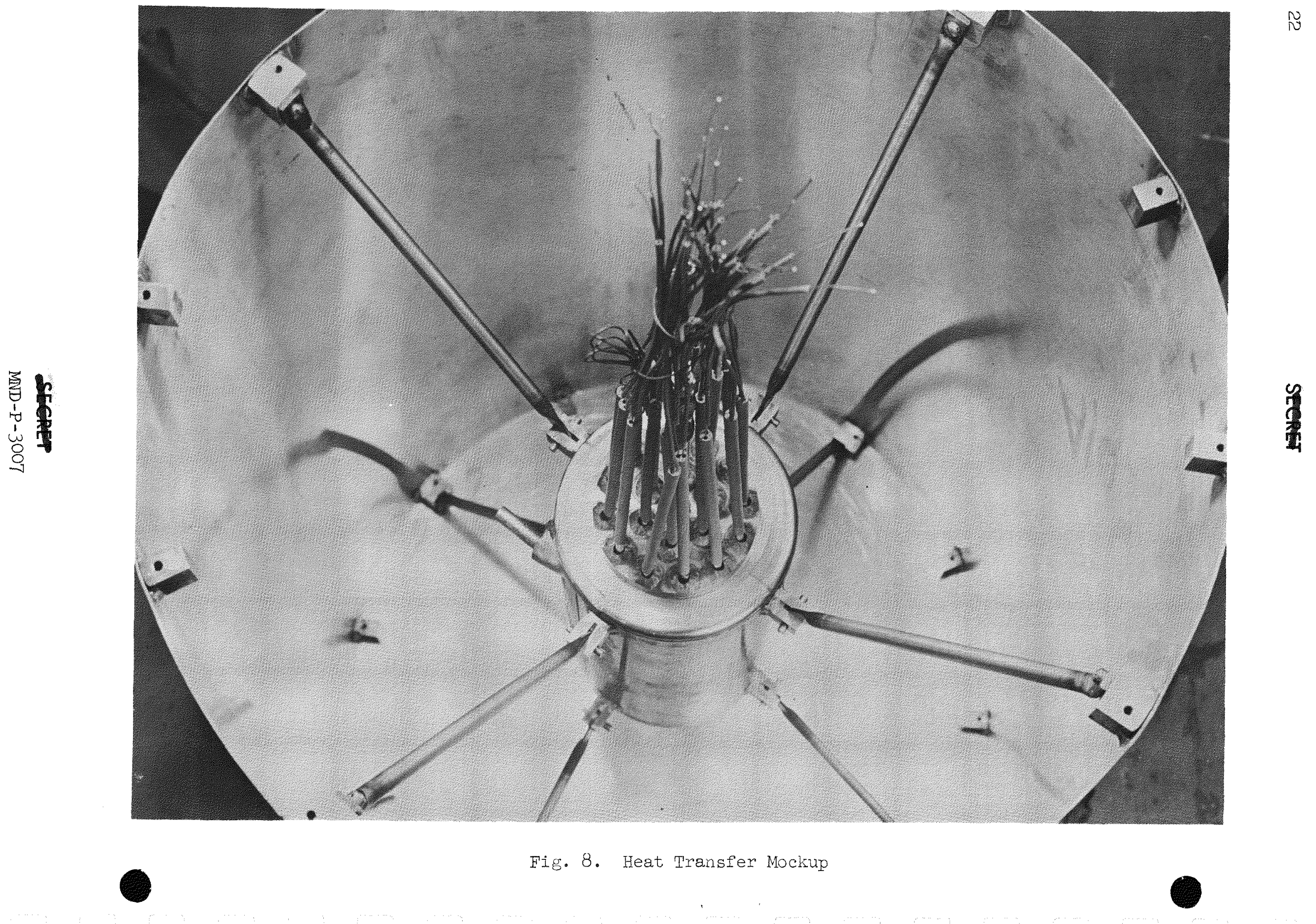




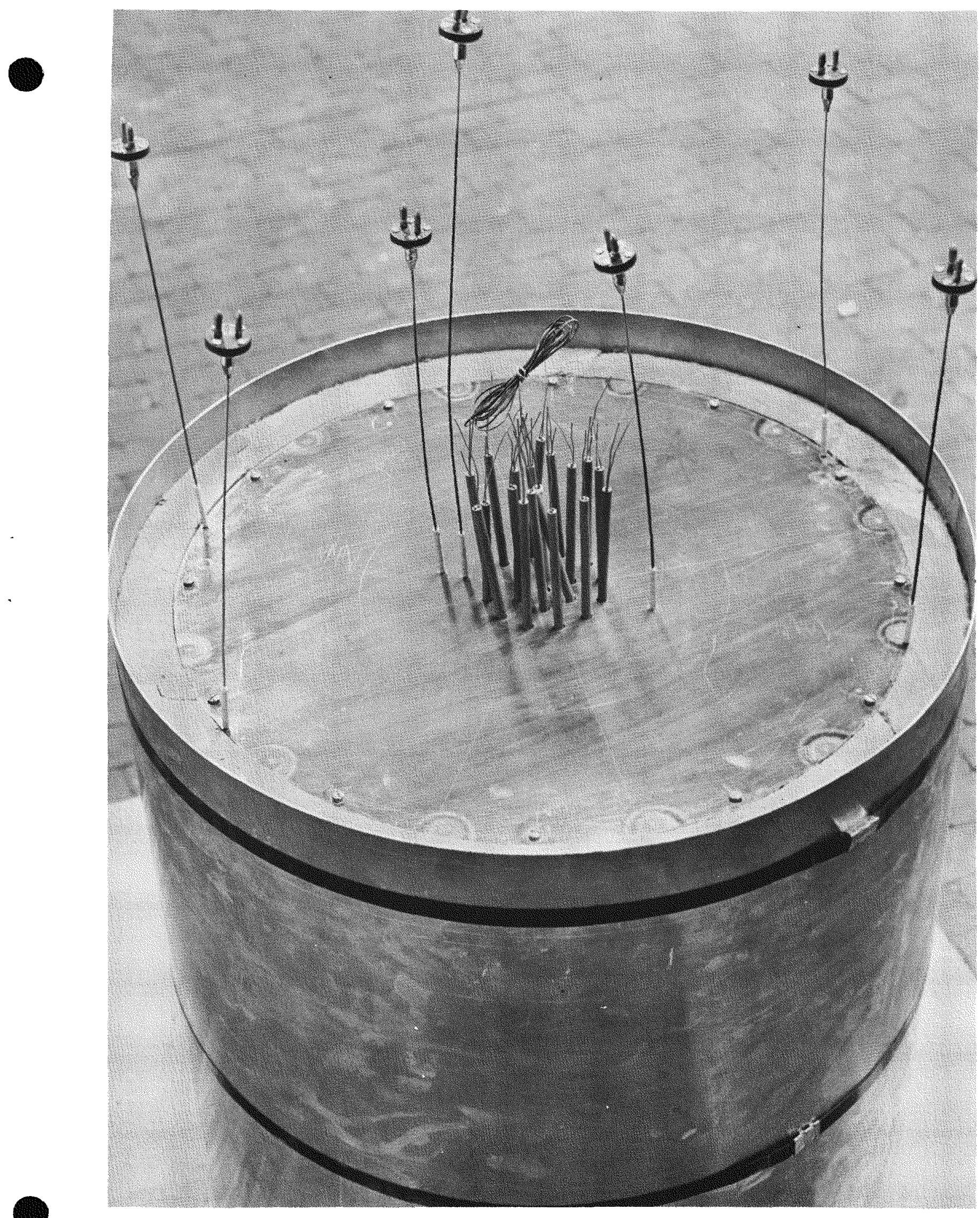

Fig. 9. Heat Transfer Mockup

\section{SECRET}

MND-P-3007 


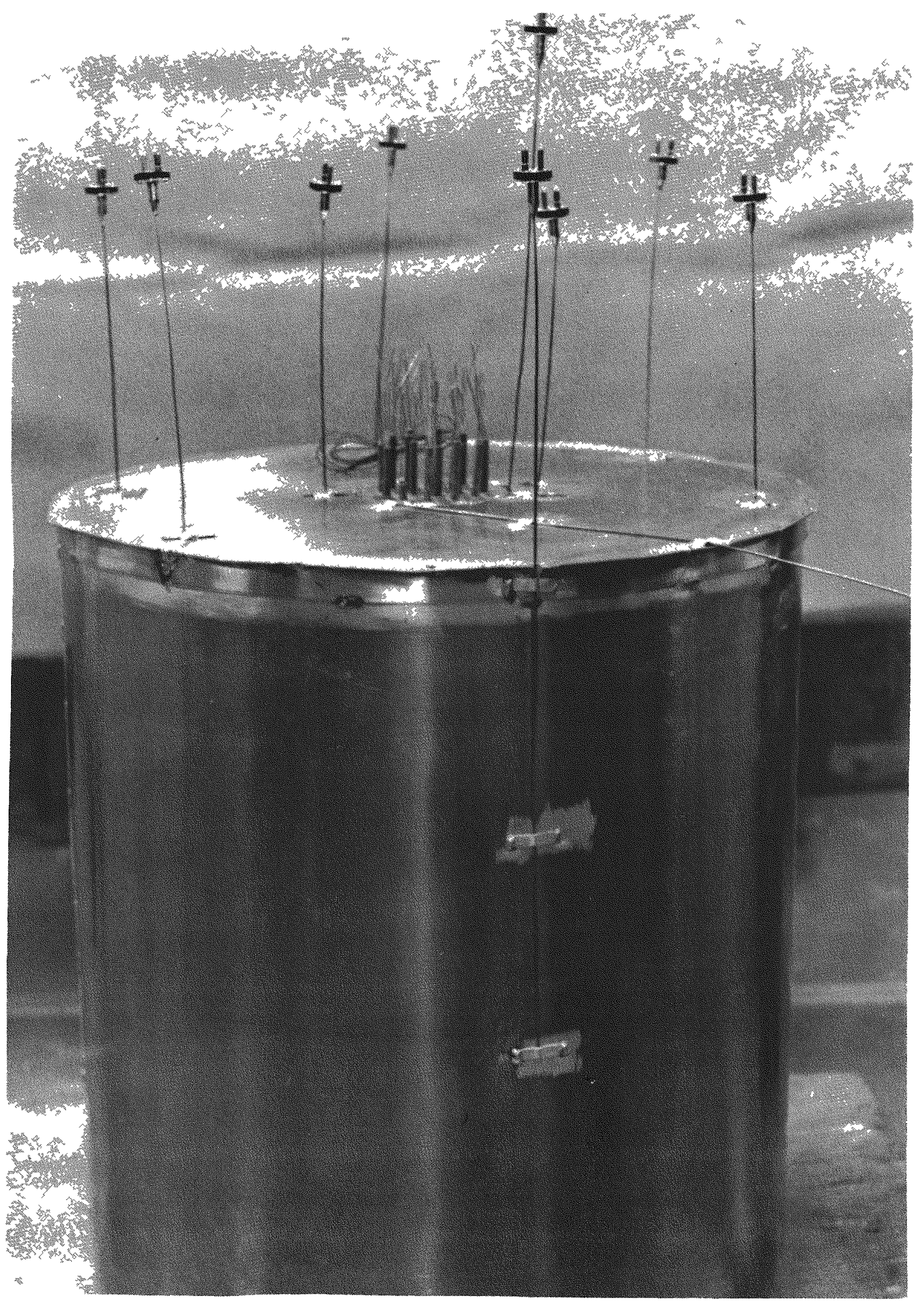

Fig. 10. Heat Transfer Mockup 

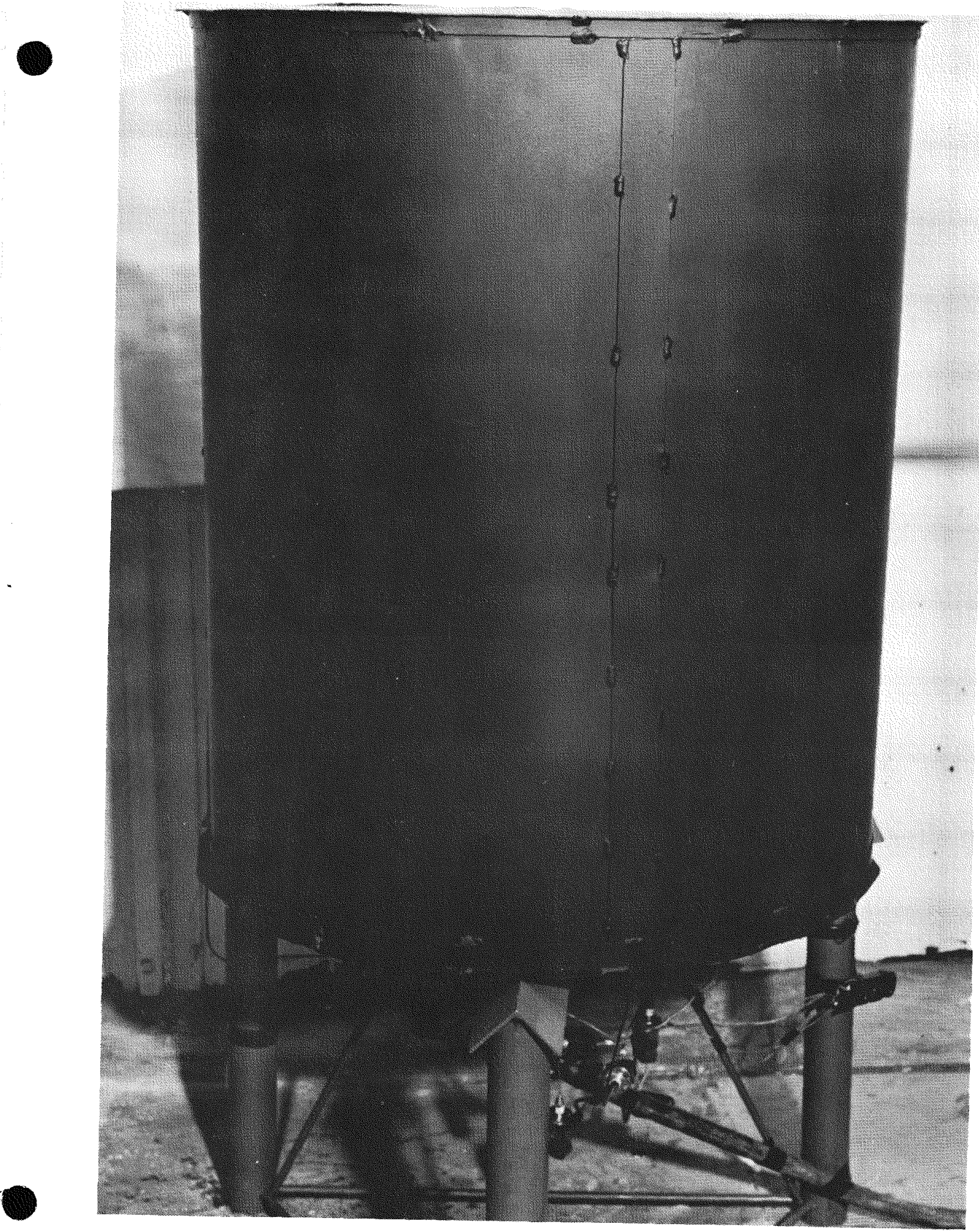

Fig. 11. Heat Transfer Mockup

\section{SECRET}

MND-P-3007 
point, the thermal shutter is driven into a more open position which allows a larger heat loss from the isotopic heat source thus lowering the hot junction temperature. Conversely, a decreasing hot junction temperature drives the shutter toward the closed position until the hot junction temperature recovers to its present design value. System sensitivity and response time will be a function of the amplifier gain, motor torque characteristics, gear ratio and system friction. Final system design parameters and component drawings are in process. Procurement of a better servo-motor to withstand the required total gamma dose rate is in process and delivery is expected in the next quarter. Radiation tests are to be performed on the new motor in the Martin Gamma Facility.

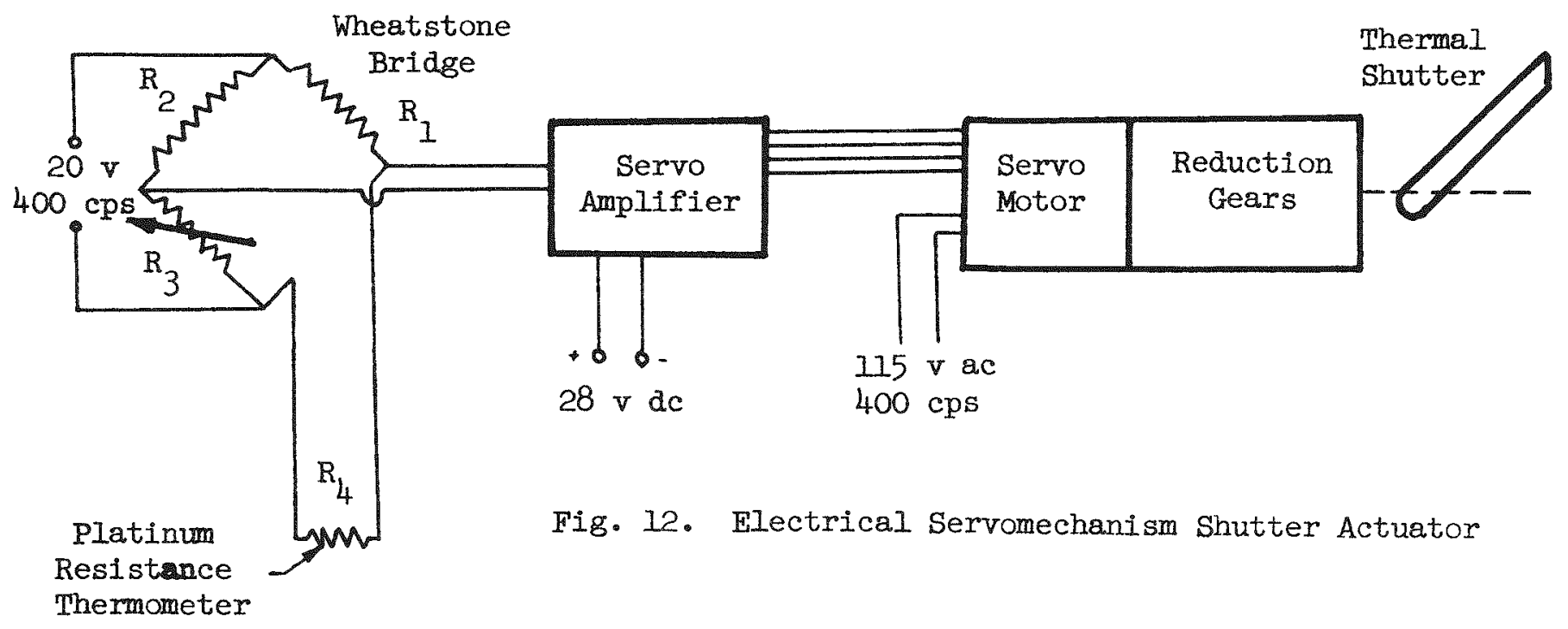

Figure 13 is a schematic of the thermal hydraulic shutter actuator design. Primarily it consists of a hot junction temperature sensing mercury bulb, bellows linear actuator, position and set point springs, a rack, and a pinion that positions the thermal shutter. Shutter position for this actuator system is proportional to the sensed hot junction temperature. During the useful life of the APU fuel, the hot junction temperature would vary over a range of possibly 1040 to $990^{\circ} \mathrm{F}$. At these temperatures, the vapor pressure of mercury changes from approximately 220 to 170 psi. For a 2 sq in. cross-sectional area bellows, the useable force change is $100 \mathrm{Ib}$. A reasonable travel of the rack to give the required shutter opening would be about $1-i n$. The required size of the constant force spring would be $340 \mathrm{Ib}$ and the linear spring size would be $50 \mathrm{lb} / \mathrm{in}$. for a bellows spring constant of $50 \mathrm{lb} / \mathrm{in}$. The chief advantages of this system are that it can be ruggedly built of materials that resist radiation damage, there are a minimum of moving parts and no source of electrical energy is required to drive the control device. All of the control actuating energy comes from the hot heat source Iuel block. Design of such a prototype is now in progress and procurement of a suitable bellows is being made. 


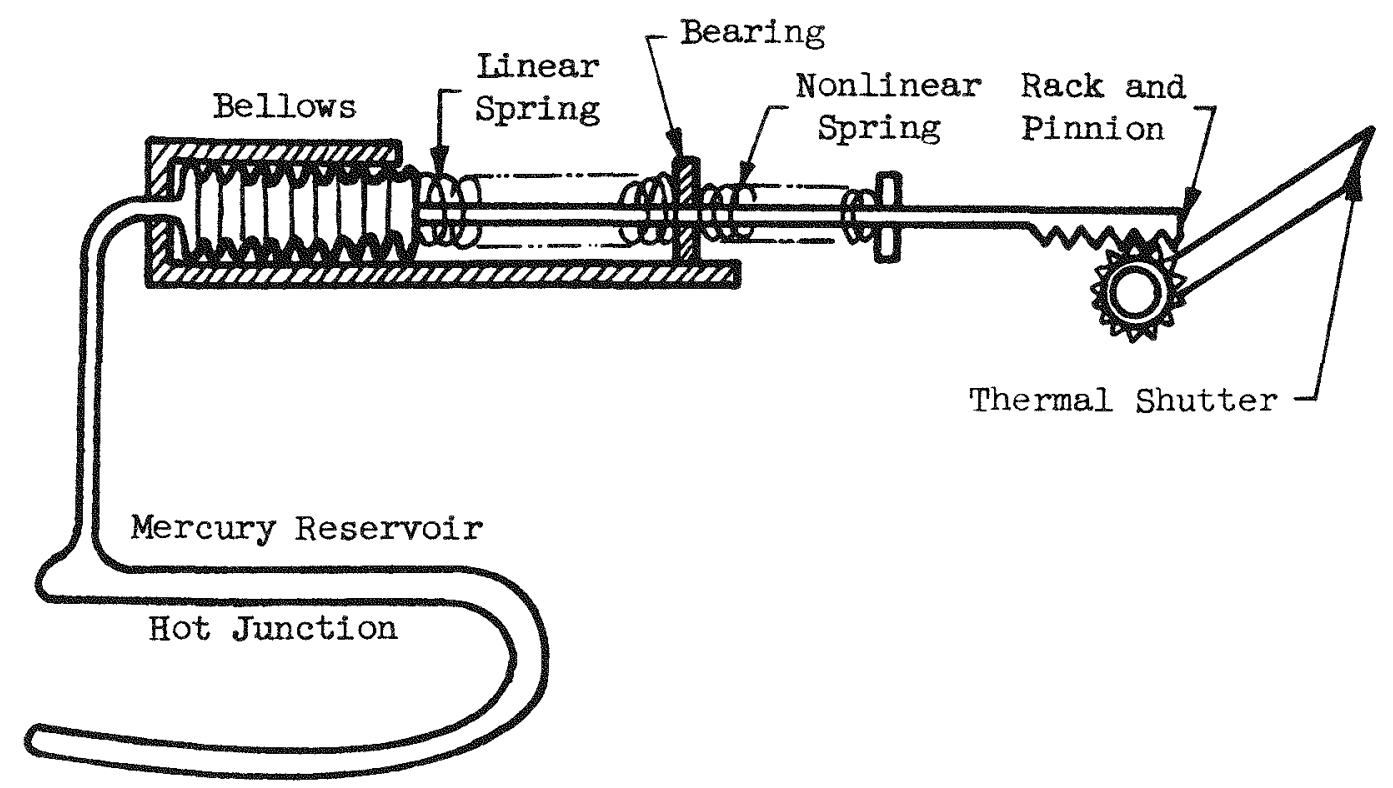

Fig. 13. Schematic of Mercury Vapor Pressuro Servomechanism Shutter Actuator

E. HEAT TRANSFER

1. Experimental

Dual boiler test 1oop. - SNAP I mercury boilers PBP 4 and 5 were installed and successfully operated in the dual boiler test facility. Throughout the operational test period, division of flow between the boilers was accomplished by means of air-operated, automatic flow control valves. After a short period of operation, both bollers developed mercury vapor leaks. Both of these leaks were due to a small crack running axially from the exit tube to the housing weld. Upon further investigation it was learned that an error was made in the welding procedure used to join the $347 \mathrm{SS}$ boiler coll to the $316 \mathrm{SS}$ test loop tubing. This error was corrected and the boilers operated without difficulty throughout the remainder of the test.

Initial difficulties in obtaining a reasonable system heat balance were corrected by reinstalling the boiler exit thermocouples down stream in the boiler exit line tee: a final heat balance within $10 \%$ was obtained. With the boilers operating at design conditions of 330 and $1350^{\circ} \mathrm{F}$ inlet and exit temperatures, 210 psi exit pressure and 0.935 lb/min mercury flow, the measured maximum dynamic pressure drop for each boiler was less than 20 psi. 
The dynamic system instrumentation to check flow and pressure could not be made to operate satisfactorily. "As the SNAP I program was to be discontinued the system analysis at step changes in flow was not performed. After checkout both boilers were cleaned and deIivered to Thompson Ramo Wooldridge on 25 April 1959 for further APU system testing. One spare mercury boiler, PBP 5A, was fabricated, installed in the experimental test loop, and operated for $28 \mathrm{hr}$. With a system heat balance maintained within $5 \%$, the average exit mercury temperature obtained was $1305^{\circ} \mathrm{F}$ with the molybdenum at $1602^{\circ} \mathrm{F}$, lead at $1515^{\circ} \mathrm{F}$, inlet at $330^{\circ} \mathrm{F}$ and flow of $0.935 \mathrm{lb} / \mathrm{min}$. The exit thermocouple and Instrument calibration were well within $5^{\circ} \mathrm{F}$. At the completion of shakedown tests, the unit was boiled dry, cleaned and shipped to Thompson Ramo Wooldridge for use as a spare boller.

Water cooling tests of mercury boiler.- Emergency water cooling tests were conducted with the electrically heated mercury boiler, PBP 3 , during the early part of this quarter.

The test boiler was stripped of its external can and thermal insulation, thus completely exposing the stainless steel boiler housing. The boiler was thermally shocked a total of $18 \mathrm{c}$ by instant immersion in room temperature water after heating to isothermal housing temperatures ranging from 500 to $1100^{\circ} \mathrm{F}$. No physical change effecting the boiler integrity resulted from these tests. Figure 14 shows the $1100^{\circ} \mathrm{F}$ housing thermal shock results of boiler component temperatures versus time. During the initial $15 \mathrm{sec}$ of immersion, the housing side (top) temperature decreased from 1100 to $220^{\circ} \mathrm{F}$, a rate of $59^{\circ} \mathrm{F} / \mathrm{sec}$ with $2.15 \mathrm{kw}$ power input. Equilibrium conditions were reached within 8 min with the boiler housing temperature approximately $150^{\circ} \mathrm{F}$, lead thermal bond at $160^{\circ} \mathrm{F}$ and molybdenum fuel block at $340^{\circ} \mathrm{F}$. At the conclusion of this test, VIsual and dye-penetrant inspection revealed no effect on the boiler integrity or structural strength. Electrical power to PBP 3 was limited to $2.15 \mathrm{kw}$ since some electrical heaters were burned out from previous high-temperature operations $\left(1650^{\circ} \mathrm{F}\right)$.

Electrically heated fuel container (SNAP I).- A comprehensive series of molybdenum fuel block equilibrium conditions and simulated brazing tests were performed. The results of these tests indicated that the self-brazing technique of fuel closure is feasible, controllable and attainable with the existing Martin cooling plate and a suitably fabricated insulation cap. Also, the equilibrium center temperatures of a half- and fully-loaded fuel block placed on an insulated base were determined to be 1165 and $1460^{\circ} \mathrm{F}$ respectively. The time for equilibrium heat up from room temperature with one-half of a full load ( $1918 \mathrm{w}$ ) was $3-1 / 2 \mathrm{hr}$ and $\mathrm{full}$ load (3836 w) heat up time from $1165^{\circ} \mathrm{F}$ was $2 \mathrm{hr}$. When the bare simulated fuel block was placed on the watercooled copper plate, the equilibrium temperature of the center of the 


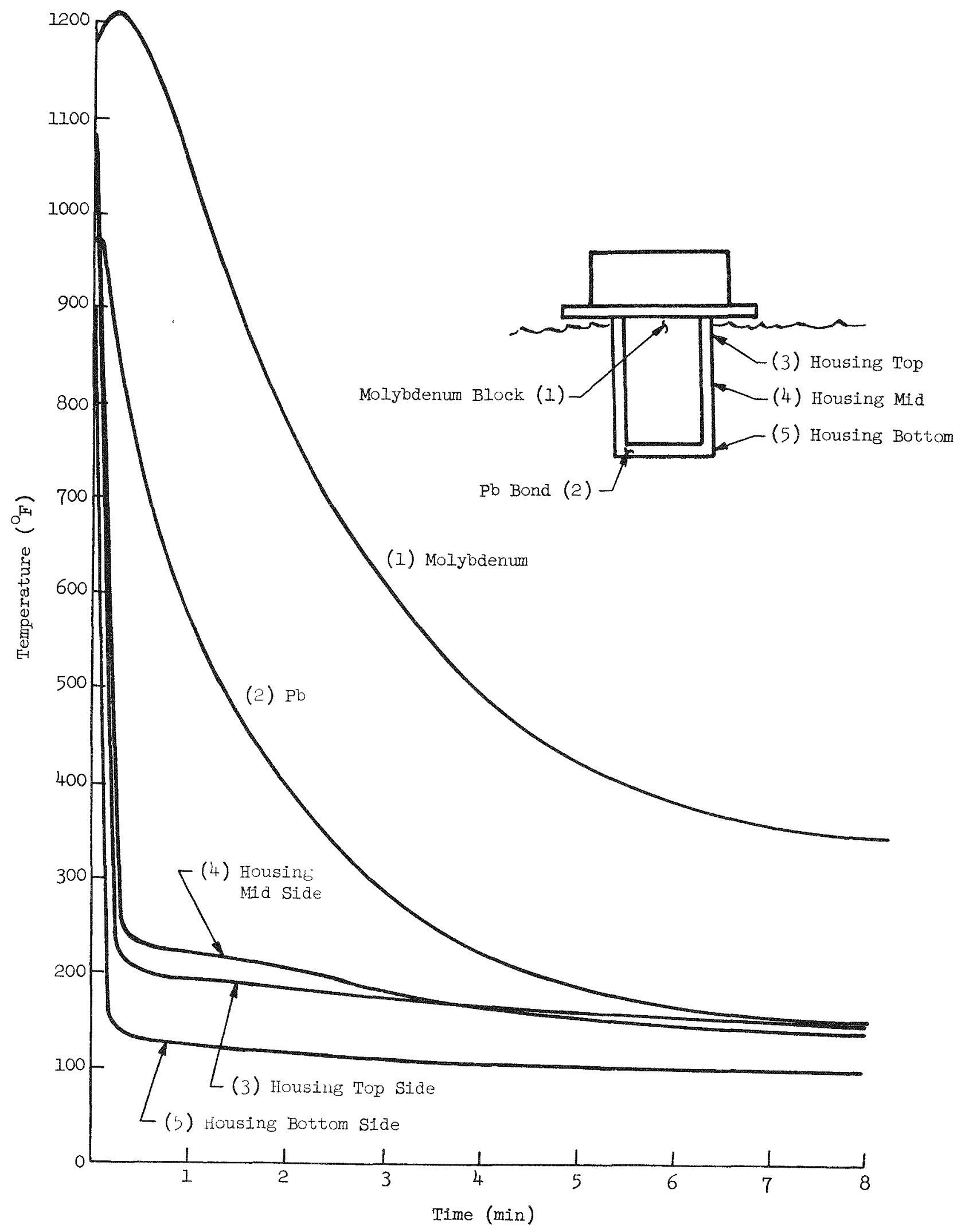

Fig. 14. Temperature Transient Curves--Boiler Mockup Immersion Tests 
block was $890^{\circ}$ F for the one-half fuel load and $1250^{\circ}$ F for a simulated fuel load. Varying the water flow rate through the cooling plate from 0.35 to $0.72 \mathrm{gpm}$ had no effect on these equilibrium temperatures. During this entire serles of tests, the electrically heated, simulated fuel block temperature was operated at temperatures less than $1650^{\circ} \mathrm{F}$ because of the maximum rated operating temperature of the heaters used. It is apparent from the data on a one-half loaded, base-insulated test that the top of a fuel block can be raised from $1165^{\circ}$ F to a brazing temperature of approximately $2000^{\circ} \mathrm{F}$ by placing a suitable insulation cap over the top end of the block.

Tests conducted with an insulation cap over the top portion of the simulated fuel block and with the bottom cooled by a cooling plate showed that the lower end of the block was approximately $400^{\circ} \mathrm{F}$ cooler and the top of the block was maintained at $1600^{\circ} \mathrm{F}$. When $a .002$ in. thick stainless shim and $0.020 \mathrm{in}$. thick stainless steel screen thermal barrier was placed between the block and cooling plate, the temperature difference between the top and bottom of the block was reduced to $100^{\circ} \mathrm{F}$. Therefore, by varying the amount of insulation at the bottom and top of the water-cooled fuel block, the required brazing temperature at the top of the block can be attained with the bottom end of the block maintained below the remelt temperature of the initial closure braze.

The second phase of this testing employed heating of the fuel block by means of an induction furnace. This test was performed at operational temperature and was successful in that the top of the fuel block was maintained at $1950^{\circ} \mathrm{F}$ while the bottom was held in the neighborhood of $1500^{\circ} \mathrm{F}$.

Analysis of SNAP I-A fuel container. - The initial fuel element planned for use in the SNAP I-A unit was a cylindrical molybdenum block, 3.75 in. in diameter by $11.0 \mathrm{in}$. in length, and containing 0.88 megacurie of Ce-144. The SNAP I fuel element was also a cylindrical molybdenum block, but 4-1/8 in. in diameter by 6 in. Iong and containing 0.5 megacurie of Ce-144. As the two fuel elements differ only in geometry and fuel loading, it is apparent that most of the effort expended on the SNAP I fuel element is applicable to the SNAP I-A concept.

Fuel loading and sealing of the SNAP I-A fuel element will be accomplished in a hot cell at the Oak Ridge National Laboratory.

The Ce-144 isotope which has previously been pelletized will be loaded into the molybdenum fuel container by remote handing techniques.

The molybdenum fuel block will be loaded from seven holes ( 929 thermal watts per hole). The equilibrium temperature of the block encountered during this loading technique will be as follows: 
Holes
Holes Loaded

1

2

3

4

5

6

7 (fully loaded)
Equilibrium Temperature

( $\left.{ }^{\circ}\right)$

760

1015

1190

1325

1435

1535

1615

As the brazing temperature of nicrobraze is $1950^{\circ} \mathrm{F}$, to apply a self-brazing technique, insulation must be applied to the block to obtain the proper temperature. The self-brazing procedure will consist of loading the fuel pellets into the molybdenum block, inserting a screw-in plug into each of the seven fuel cavities, laying solid nicrobraze over each plug, and then insulating the top of the block to obtain the $1950^{\circ} \mathrm{F}$ brazing temperature. When this procedure is complete the block should be held at the brazing temperature from 20 to 30 min to ensure complete sealing. The thermal insulation is then removed, and the block will return to its normal equilibrium temperature of $1615^{\circ} \mathrm{F}$.

IBM-704 fortran optimization code.- Initial coding of a thermoelectric optimization technique has begun. This work is still in the inftial stages but will be more extensively studies in the future. It is hoped that this code will be available for use in the redesigning of the SNAP I-A unit. 
MND-P-3007 
III. TASK 3--FUEL DEVEIOPMEINT

A. CERIUM FUEL STUDIES

Since the advent of the SNAP I-A thermoelectric generator, the cerium fuel investigation was divided into two distinct programs. One objective was the continuing development of a stable fuel form of ceric oxide that could withstand atmospheric re-entry, while the second objective was to develop a fuel that would burnup under re-entry conditions. Both objectives were pursued during this quarter but the major emphasis was placed on the study of burnup-type fuels, since the ceric oxide fuel technology was carried over from the SNAP I program.

\section{Ceric Oxide Re-Entry Type Fuel}

Previous ceric oxide fuel pelleting work with ORNL powder was unsuccessful in obtaining a high density pellet that would not fracture after a single compacting and ejection. Firm pellets of low density were obtained at 5 tsi on one pressing, but at higher pressures the pellet would be laminated after ejection and necessitate recrushing and repressing. The low density pellets were not suited for fuel element use. A solution to this problem was obtained, however, by using the following procedure. The pellet die ( $0.740 \mathrm{in}$. diameter) was reworked and a taper was provided for 1.5 in. to permit gradual expansion of the ceric oxide pellet during ejection from the die. Fuel pellets have now been pressed up to $30 \mathrm{tsi}$ without laminating. Calculated densities of these compacts are shown in Table 3 . The sintering cycle was $1400^{\circ} \mathrm{C}$ for $8 \mathrm{hr}$ in air.

TABLE 3

ORNL Cerium Oxide Sintered at $1400^{\circ} \mathrm{C}$

\begin{tabular}{|c|c|c|c|c|c|}
\hline \multirow{2}{*}{$\begin{array}{c}\text { Compacting } \\
\text { Pressure } \\
(\text { tsi) } \\
\end{array}$} & \multicolumn{2}{|c|}{ Density } & \multicolumn{2}{|c|}{ Shrinkage } & \multirow[b]{2}{*}{$\begin{array}{c}\text { Composition } \\
\left(\% \mathrm{CeO}_{2}\right)\end{array}$} \\
\hline & $\begin{array}{c}\text { Green } \\
(\%) \\
\end{array}$ & $\begin{array}{c}\text { Sintered } \\
(\%) \\
\end{array}$ & $\begin{array}{l}\text { Diameter } \\
(\%)\end{array}$ & $\begin{array}{l}\text { Height } \\
(\%) \\
\end{array}$ & \\
\hline 5 & 46 & 81 & 18.0 & 18.4 & 85 \\
\hline 15 & 54 & 91 & 16.6 & 16.3 & 85 \\
\hline 25 & 59 & 94 & 15.1 & 14.5 & 85 \\
\hline 5 & 43 & 91 & $22 \cdot 3$ & 23.5 & 97 \\
\hline 15 & 51 & 94 & 18.4 & 19.4 & 97 \\
\hline 25 & 56 & 94 & 16.6 & 16.9 & 97 \\
\hline 30 & 58 & 92 & 15.0 & 14.2 & 97 \\
\hline
\end{tabular}


2. Cerium Burnup Type Fuel

The basic requirement for the burnable cerium fuel is that the material should disintegrate to particles of 10 microns or smaller. It is hypothesized that if the fuel melted or vaporized during atmospheric re-entry this requirement could be met. The following is a list of cerium compounds and their properties which are being considered for the fuel form in the SNAP I-A burnup unit. The compounds are considered on the basis of melting temperature, cerium fuel density, preparation, fabrication, and oxidation-volatilization effects.

Cerium.- Melting point- $-793^{\circ} \mathrm{C}$, theoretical density, $-6.7 \mathrm{gm} / \mathrm{cc}$, cerium density $-6.7 \mathrm{gm} / \mathrm{cc}$. Cerium metal 1 s prepared by reduction of cerous chloride by calcium in graphite at $575^{\circ} \mathrm{C}$ or in a calcium oxide lined steel bomb, according to the following reaction:

$2 \mathrm{CeCl}_{3}+3 \mathrm{Ca} \rightarrow 3 \mathrm{CaCl}_{2}+2 \mathrm{Ce}$. Cerium metal ignites in air at 150 to $180^{\circ} \mathrm{C}$ and burns vigorously in halogen vapors above $200^{\circ} \mathrm{C}$.

Ceric oxide.- $\mathrm{CeO}_{2}$-melting point $2680^{\circ} \mathrm{C}$, theoretical density- 7.13 $\mathrm{gm} / \mathrm{cc}$, cerium density $-5.77 \mathrm{gm} / \mathrm{cc} . \mathrm{CeO}_{2}$ is prepared by thermal decomposition of ceric oxalate or nitrate at $650^{\circ} \mathrm{C}$ in air. It is oxidation resistant but is subject to reduction to $\mathrm{Ce}_{2} \mathrm{O}_{3}$ in contact with metals and in reducing atmospheres.

Cerous oxide.- $\mathrm{Ce}_{2} \mathrm{O}_{3}-$-melting point- $-1692^{\circ} \mathrm{C}$, theoretical density-$6.86 \mathrm{gm} / \mathrm{cc}$, cerium density $-5.85 \mathrm{gm} / \mathrm{cc} . \mathrm{Ce}_{2} \mathrm{O}_{3}$ prepared by thermal decomposition of cerous salts in hydrogen and by reduction of $\mathrm{CeO}_{2}$ in hydrogen. $\mathrm{Ce}_{2} \mathrm{O}_{3}$ when heated will react exothermically in air to produce $\mathrm{CeO}_{2}$.

Cerous fluoride.- $\mathrm{CeF}_{3}{ }^{--m e l t i n g}$ point-- $1460^{\circ} \mathrm{C}$, theoretical density-$5.8 \mathrm{gm} / \mathrm{cc}$, cerium density $-4.1 \mathrm{gm} / \mathrm{cc} \cdot \mathrm{CeF}_{3} 1 \mathrm{~s}$ prepared by wet chemical reaction of a cerous salt and hydrofluoric acid. CeF 3 is probably stable In air at high temperatures but will have a high vapor pressure at elevated temperatures.

Cerous phosphate.- $\mathrm{CePO}_{4}$-melting point > $1700^{\circ} \mathrm{C}$, theoretical density $-5.22 \mathrm{gm} / \mathrm{cc}$, cerium density $-3.12 \mathrm{gm} / \mathrm{cc} . \mathrm{CePO}_{4}$ is prepared by wet chemistry reaction of cerous ammonium sulfate and ammonium phosphate. $\mathrm{CePO}_{4}$ loses $\mathrm{P}_{2} \mathrm{O}_{5}$ when heated to $1700^{\circ} \mathrm{C}$. 
Cerous sulphide.- $\mathrm{Ce}_{2} \mathrm{~S}_{3}$--melting point--2100 $\mathrm{C}$, theoretical density $-5.10 \mathrm{gm} / \mathrm{cc}$, cerium density $--3.8 \mathrm{gm} / \mathrm{cc} . \mathrm{Ce}_{2} \mathrm{~S}_{3}$ is prepared by the following reactions:

$$
\mathrm{Ce}_{2}\left(\mathrm{SO}_{4}\right)_{3}+\mathrm{H}_{2} \mathrm{~S} \longrightarrow \mathrm{Ce}_{2} \mathrm{~S}_{3} \text { at } 800 \text { to } 1000^{\circ} \mathrm{C} \text { and } \mathrm{CeO}_{2}+\mathrm{H}_{2} \mathrm{~S} \longrightarrow
$$
$\mathrm{Ce}_{2} \mathrm{~S}_{3}$ at 1200 to $1400^{\circ} \mathrm{C} \cdot \mathrm{Ce}_{2} \mathrm{~S}_{3}$ will oxidize at elevated temperatures to $\mathrm{CeO}_{2} \mathrm{So}_{2}$

Cerium sulphide.- Ces--melting point--2450 $\mathrm{C}$, theoretical density $-5.9 \mathrm{gm} / \mathrm{cc}$, cerium density $-4.8 \mathrm{gm} / \mathrm{cc}$. Ces is prepared by the following reaction:

$$
\mathrm{Ce}_{2} \mathrm{~S}_{3}+\mathrm{CeH}_{3} \longrightarrow \mathrm{CeS} \text { at } 2200^{\circ} \mathrm{C} \text { in vacuum. CeS will oxidize at }
$$
elevated temperature to $\mathrm{CeO}_{2}+\mathrm{SO}_{2}$.

Cerium carbide. - $\mathrm{CeC}_{2}-$ melting point $>2000^{\circ} \mathrm{C}$, theoretical density- $-5.23 \mathrm{gm} / \mathrm{cc}$, cerium density $-4.47 \mathrm{gm} / \mathrm{cc} . \mathrm{Cec}_{2}$ is prepared by reaction of ceric oxide and carbon:

$$
\mathrm{CeO}_{2}+\mathrm{C} \longrightarrow \mathrm{CeC}_{2}+\mathrm{CO} \uparrow \text { at } 1200 \text { to } 1400^{\circ} \text { C. Cerium carbide }
$$
powder is reportediy pyrophoric at room temperature.

Cerium nitride. - CeN-melting point $>2200^{\circ} \mathrm{C}$, theoretical density not reported. CeN is prepared by reaction of ceric oxide, carbon and nitrogen:

$$
\mathrm{CeO}_{2}+\mathrm{C}+\mathrm{N} \longrightarrow \mathrm{CeN}+\mathrm{CO} \text { at } 1300^{\circ} \mathrm{C} \text {. Cerium nitride wiII }
$$
readily oxidize at elevated temperatures.

\section{Cerium intermetallics.- $\mathrm{Ce}_{2} \mathrm{~Pb}, \mathrm{Ce}_{2} \mathrm{Bl}$ and $\mathrm{Ce}_{2} \mathrm{Sn}$ have a melting} point of 1380 to $1400^{\circ} \mathrm{C}$. No density data are available. The intermetaliics may be prepared by reaction of cerium and the elemental powders or possibly by coreduction of $\mathrm{CeCl}_{3}+\left\{\begin{array}{l}\mathrm{PBCl}_{2}^{2} \\ \mathrm{BICl}_{3}^{2} \\ \mathrm{SnCl}_{2}\end{array}+\mathrm{Ca}\right.$. No information is available on the stablity of the intermetalics.

From these data, it was recommended that the following materials be studied in the laboratory for the materials preparation, fabrication of pellets, and the experimental testing of samples: 
Cerous oxide.- $\mathrm{Ce}_{2} \mathrm{O}_{3}$, which would be prepared by hydrogen reduction and sintering of $\mathrm{CeO}_{2}$ pellets. The cerous oxide powder is pyrophoric at temperatures above $100^{\circ} \mathrm{C}$ and therefore the Ce-144 could not be prepared as $\mathrm{Ce}_{2} \mathrm{O}_{3}$ powder and handled in air. It is also planned to prepare $\mathrm{Ce}_{2} \mathrm{O}_{3}$ pellets containing metal additions as molybdenum which will aid in the reduction of the $\mathrm{CeO}_{2}$ and as the molybdenum is readily oxidizable it will help to disintegrate an element on oxidation.

Cerous oxide-ceric carbide.- $\mathrm{Ce}_{2} \mathrm{O}_{3}-\mathrm{CeC}_{2}$ mixtures would be prepared by sintering mixtures of $\mathrm{CeO}_{2}$ and carbon in a hydrocarbon atmosphere such as methane. $\mathrm{A} \mathrm{Ce}_{2} \mathrm{O}_{3}$ matrix will aid in bonding the $\mathrm{CeC}_{2}$ particles and the cerium density will not be lowered as much as by the use of pure $\mathrm{CeC}_{2}$.

Cerous fluoride.- $\mathrm{CeF}_{3}$ could be prepared by wet chemical process and then dehydrated. The fluorides are readily sinterable and should give a high sintered density.

These materials and combinations are to be studied in the laboratory for fabricability, and sinterability. Burnup tests are to be performed by subjecting specimens to elevated temperatures in air atmosphere furnaces with static air and oxyacetylene torch tests and plasma arc heating tests.

The first preparation consisted of sintering straight ceric oxide and ceric oxide with metal powder blends. A sintering study of samples in hydrogen, argon and methane atmospheres was conducted to observe the effect of the atmospheric conditions on the compacts. Blends studied were:

(1) Straight ceric oxide

(2) Ceric oxide and molybdenum powder

(3) Ceric oxide and graphite

(4) Ceric oxide and iron powder

(5) Ceric oxide and niobium powder

(6) Ceric oxide and tantalum powder

(7) Ceric oxide and zirconfum hydride powder

(8) Ceric oxide and titanium hydride. 
These mixtures were compacted at 25 tsi and sintered at $1500^{\circ} \mathrm{C}$ in atmosphere for $8 \mathrm{hr}$. Sintering results of these blends indicated low densities of the material. Table 4 shows a comparison of sintering atmospheres and densities of some of the metal powder blends.

TABLE 4

Sintering Study for SNAP I-A Materials

\begin{tabular}{|c|c|c|c|}
\hline Composition & $\begin{array}{l}\text { Sintering } \\
\text { Atmosphere } \\
\end{array}$ & $\begin{array}{l}\text { Sintered } \\
\text { Density } \\
(\%) \\
\end{array}$ & $\begin{array}{l}\text { Ce Content } \\
(\mathrm{gm} / \mathrm{cc}) \\
\end{array}$ \\
\hline \multirow[t]{3}{*}{$\mathrm{CeO}_{2}$ (IIndsey) } & hydrogen & 90 & 5.24 \\
\hline & methane & 80 & 4.66 \\
\hline & argon & 88 & 5.05 \\
\hline \multirow{3}{*}{$\mathrm{CeO}_{2}+30$ wt $\% \mathrm{Mo}$} & hydrogen & 89 & 3.79 \\
\hline & methane & 65 & 2.90 \\
\hline & argon & 74 & $3 \cdot 30$ \\
\hline \multirow[t]{3}{*}{$\mathrm{CeO}_{2}+10$ wt $\% \mathrm{Mo}$} & hydrogen & 89 & 4.28 \\
\hline & methane & 67 & 3.22 \\
\hline & argon & 82 & 3.90 \\
\hline \multirow{3}{*}{$\begin{array}{l}\mathrm{CeO}_{2}+30 \% \mathrm{C} \\
\text { (graphite) }\end{array}$} & hydrogen & 46 & 1.81 \\
\hline & methane & 46 & 1.79 \\
\hline & argon & 45 & 1.76 \\
\hline \multirow{3}{*}{$\begin{array}{c}\mathrm{CeO}_{2}+10 \text { wt of } \mathrm{C} \\
\text { (graphite) }\end{array}$} & hydrogen & 75 & 3.19 \\
\hline & methane & 69 & 2.95 \\
\hline & argon & 78 & $3 \cdot 36$ \\
\hline \multirow{2}{*}{$\mathrm{CeO}_{2}+30$ wt $\% \mathrm{Nb}$} & hydrogen-- & reacted & sintering \\
\hline & argon & 56 & 3.16 \\
\hline \multirow[t]{2}{*}{$\mathrm{CeO}_{2}+10$ wt $\mathrm{Mb}$} & hydrogen & 66 & 3.78 \\
\hline & argon & 62 & 3.56 \\
\hline $\mathrm{CeO}_{2}+30$ wt of $\mathrm{Ta}$ & \multicolumn{3}{|c|}{ hydrogen--sample decomposed during sintering } \\
\hline \multirow[t]{2}{*}{$\mathrm{CeO}_{2}+20$ wt $\% \mathrm{Ta}$} & \multicolumn{3}{|c|}{$\begin{array}{c}\text { hydrogen-- } \\
\text { sample cracked and bloated during } \\
\text { sintering }\end{array}$} \\
\hline & $\operatorname{argon}--s$ & T & in \\
\hline
\end{tabular}


TABLE 4 (continued)

\begin{tabular}{|c|c|c|c|}
\hline Composition & $\begin{array}{l}\text { Sintering } \\
\text { Atmosphere }\end{array}$ & $\begin{array}{l}\text { Sintered } \\
\text { Density } \\
(\%)\end{array}$ & $\begin{array}{l}\text { Ce Content } \\
(\mathrm{gm} / \mathrm{cc})\end{array}$ \\
\hline \multirow{2}{*}{$\mathrm{CeO}_{2}+30$ wt $\% \mathrm{ZrH}_{2}$} & hydrogen & 64 & 2.45 \\
\hline & $\begin{array}{r}\text { argon-- sam } \\
\text { sin }\end{array}$ & me pyrop & n air after \\
\hline \multirow{2}{*}{$\mathrm{CeO}_{2}+10$ wt $\% \mathrm{ZrH}_{2}$} & hydrogen & 72 & 3.65 \\
\hline & argon & 68 & 3.45 \\
\hline \multirow{2}{*}{$\mathrm{CeO}_{2}+30$ wt $\% \mathrm{TiH}_{2}$} & hydrogen & 79 & 2.56 \\
\hline & argon & 88 & 2.86 \\
\hline \multirow{2}{*}{$\mathrm{CeO}_{2}+10$ wt of $\mathrm{TiH}_{2}$} & hydrogen & 77 & 3.72 \\
\hline & argon & 72 & 3.49 \\
\hline
\end{tabular}

Not shown in Table 4 are data of bodies containing 5 and 20 wt $\%$ blended powders. However, results of each of these percentages are similar to the data shown for 10 and 30 wt $\%$.

Testing procedures conducted on all of the samples prepared consisted of preheating the sample to $800^{\circ} \mathrm{C}$ in a static air atmosphere and then placing the pellet into a chamber heated to $1500^{\circ} \mathrm{C}$. The samples were tested in this manner for periods of 2 and 5 min. Figure 15 shows results of this test.

After the total seven-minute exposure the following effects were observed.

(I) The straight ceric oxide sintered in all atmospheres showed little change except for color and slight thermal shock cracks.

(2) Ceric oxide and molybdenum blends indicated various degrees of disintegration depending upon the percent composition of the molybdenum. With only 5 wt $\%$ Mo, the compacts cracked but a majority remained intact. The compacts with 30 wt $\%$ Mo showed definite melting and disintegration in the $7 \mathrm{~min}$ of exposure.

(3) Ceric oxide and graphite blends had to be specially treated after sintering. The sintered compacts when exposed to the room atmosphere hydrolized shortly after removal from the furnace and broke down to a fine powder. Figure 16 


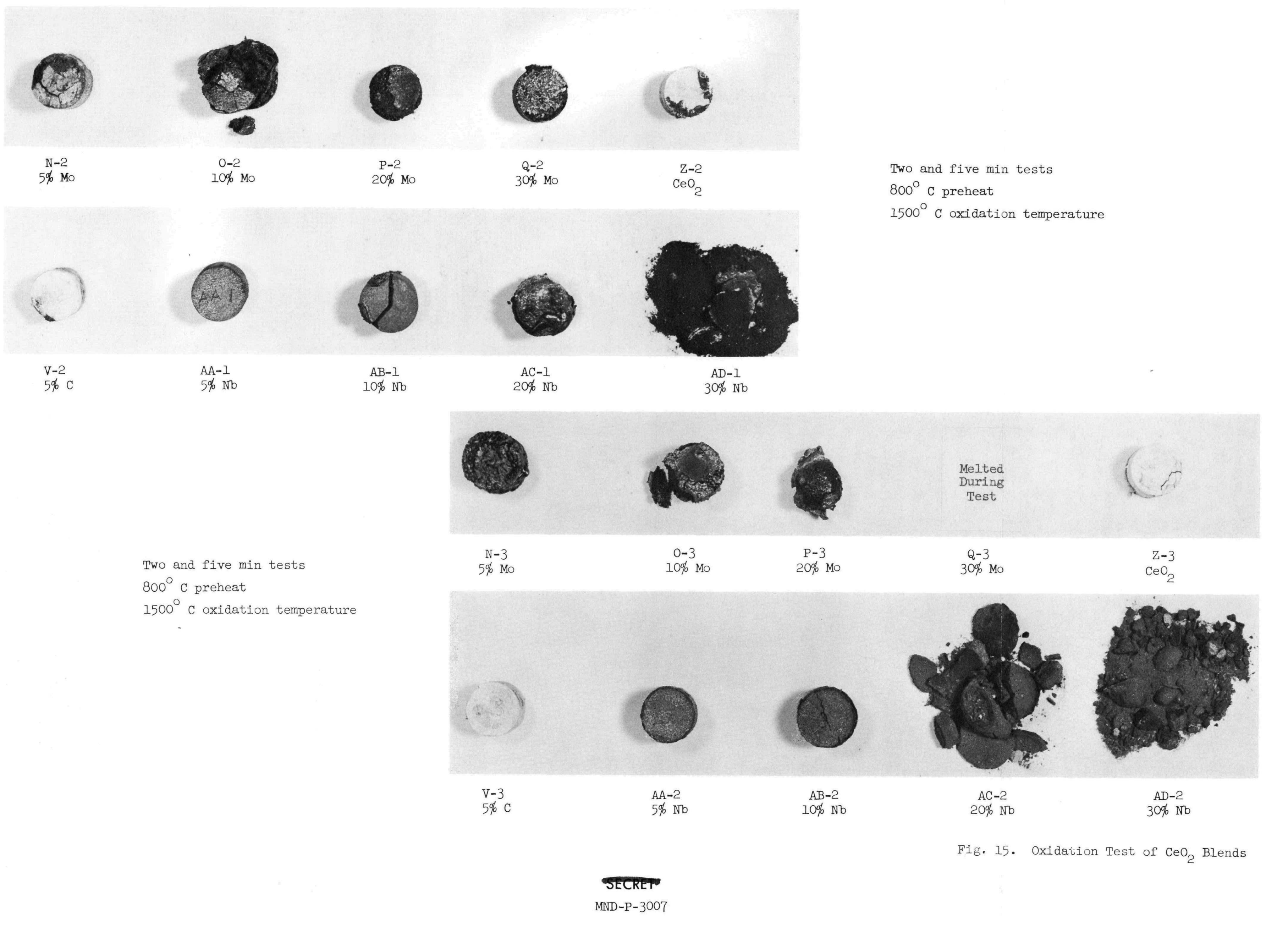




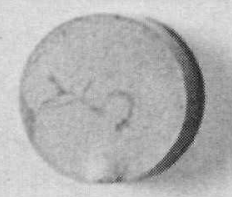

5\% C

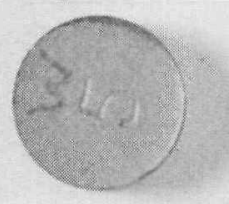

$10 \% \mathrm{C}$

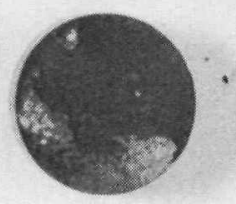

$20 \% \mathrm{C}$

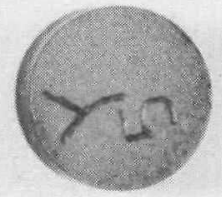

$30 \% \mathrm{C}$
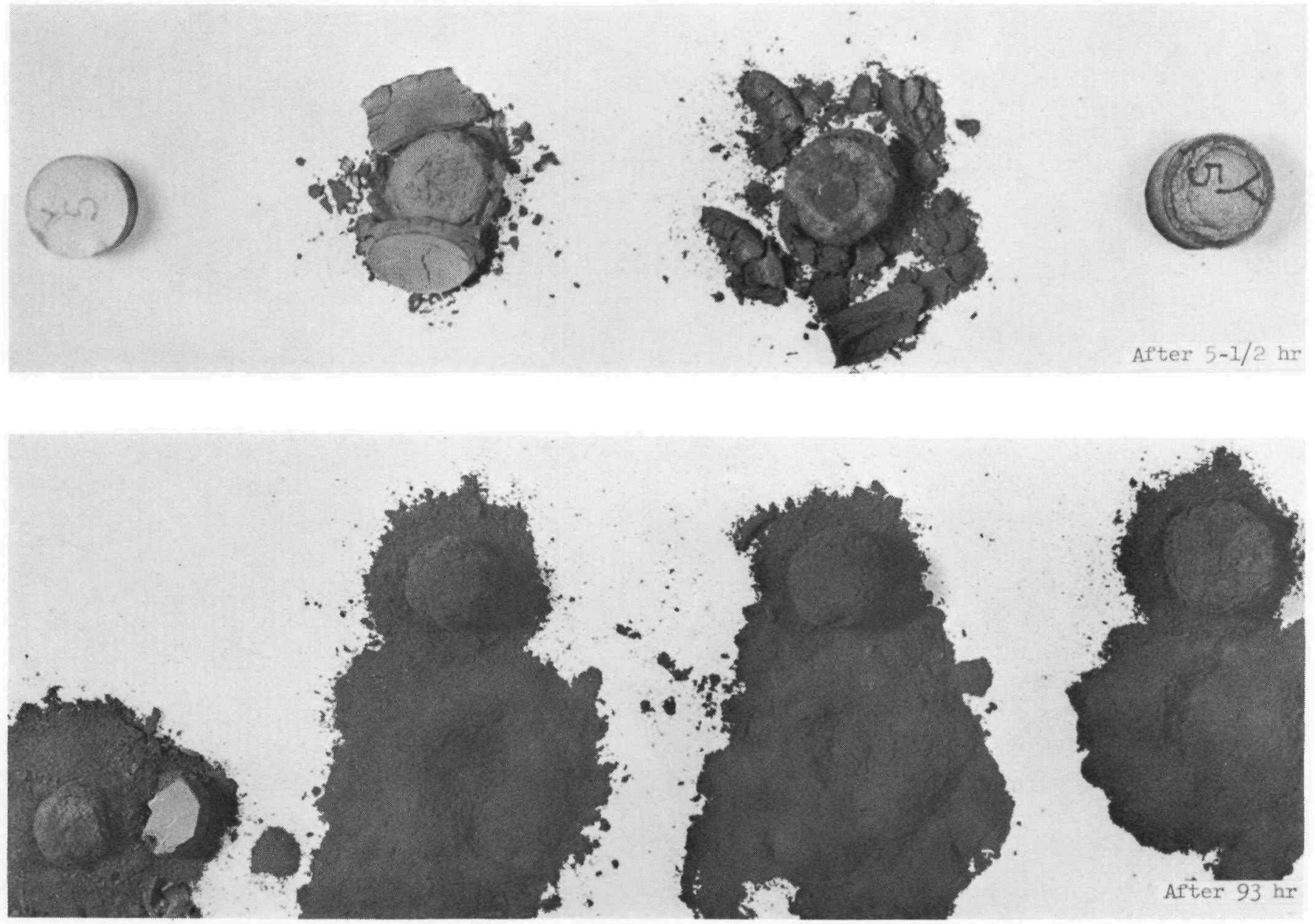

Fig. 16. Ceric Oxide and Graphite Blend after Hydrogen or Argon Sintering and Exposure to Normal Room Atmosphere 
shows the compacts after $1,5-1 / 2$ and $93 \mathrm{hr}$ at room temperature. This breakdown occurred after sintering in argon or hydrogen atmospheres.

(4) Ceric oxide and iron blends could not be investigated because of the high sintering temperature and was dropped from the study list.

(5) Ceric oxide and niobium blends, also, showed var:ous degrees of disintegration. The 5 wt of blend indicated very Iittle effect at $1500^{\circ} \mathrm{C}$ while most of the $30 \mathrm{wt} \%$ samples broke down. Blends of 10 and 20 wt $\%$ showed only slight reactions.

(6) Ceric oxide and tantalum blends did not sinter well. The compacts were laminated and distorted after sintering. However, after oxidation tests the 30 wt $\%$ blend fell apart but did not break down to a fine powder.

The study conducted with the ceric oxide and blends of metal powders showed a need for investigating other materials.

Cerous fluoride was purchased from the Iindsey Chemical Company and was calcined to eliminate the chemically comblned water from the material. A series of calclning temperatures were used ranging from 400 to $900^{\circ} \mathrm{C}$ at $100^{\circ} \mathrm{C}$ increments. Compacts were prepared for sintering in air, argon and hydrogen atmospheres. The material calcined at 400 and $500^{\circ} \mathrm{C}$ could not be pressed at 25 tsi. Pressure was lowered to 10 and 5 tsi to compact a pellet from this powder. Calcining above $500^{\circ} \mathrm{C}$ produced a material capable of compacting at $25 \mathrm{tsi}$. Powders calcined at 700 to $900^{\circ} \mathrm{C}$ caked and had to be crushed with 2 mortar and pestle prior to pressing. Table 5 lists the results obtained from various calcining temperatures. The sintering cycle was $1300^{\circ} \mathrm{C}$ for $8 \mathrm{hr}$ in air.

\section{TABLE 5}

Results of sintering at $1300^{\circ} \mathrm{C}$ in Air

\begin{tabular}{|c|c|c|c|c|c|}
\hline \multirow{2}{*}{$\begin{array}{l}\text { Calcining } \\
\text { Temperature } \\
\text { ( } \mathrm{C}) \\
\end{array}$} & \multirow{2}{*}{$\begin{array}{l}\text { Compact } \\
\text { Pressure } \\
\text { (tsi) } \\
\end{array}$} & \multicolumn{2}{|c|}{ Density } & \multirow{2}{*}{$\begin{array}{l}\text { Shrinkage } \\
\text { in Diameter } \\
(\%) \\
\end{array}$} & \multirow[b]{2}{*}{ Remarks } \\
\hline & & $\begin{array}{l}\text { Green } \\
(\%) \\
\end{array}$ & $\begin{array}{c}\text { Sintered } \\
(\%) \\
\end{array}$ & & \\
\hline 400 & 10 & 51 & 76 & & $\begin{array}{l}\text { Iaminated and } \\
\text { bloated slightly }\end{array}$ \\
\hline 500 & 5 & 48 & 62 & 17.85 & Bloated badly \\
\hline 600 & 25 & 82 & 73 & 6.83 & $\begin{array}{l}\text { Blosted and broke } \\
\text { in half }\end{array}$ \\
\hline
\end{tabular}


TABLE 5 (continued)

\begin{tabular}{|c|c|c|c|c|c|}
\hline \multirow{2}{*}{$\begin{array}{l}\text { Calcining } \\
\text { Temperature } \\
(\%) \\
\end{array}$} & Compact & \multicolumn{2}{|c|}{ Density } & \multirow{2}{*}{$\begin{array}{l}\text { Shrinkage } \\
\text { in Diameter } \\
(\%) \\
\end{array}$} & \multirow[b]{2}{*}{ Remarks } \\
\hline & $\begin{array}{c}\text { Pressure } \\
\text { (tsi) }\end{array}$ & $\begin{array}{c}\text { Green } \\
(\%)\end{array}$ & $\begin{array}{c}\text { Sintered } \\
(\%) \\
\end{array}$ & & \\
\hline 700 & 25 & 80 & 69 & 3.73 & Bloated and cracked \\
\hline 800 & 25 & 83 & 84 & 3.5 & Slight warpage \\
\hline 900 & 25 & 86 & 95 & 3.4 & Slight warpage \\
\hline
\end{tabular}

Results of the pellets sintered in air were not good. Except for the powder calcined at 800 and $900^{\circ} \mathrm{C}$, the pieces bloated and cracked during sintering. (See Fig. 17) A separate layer or outer shell formed around the pellet which peeled off easily. The inner body of the samples were very porous and brittle. Pieces pressed from powder calcined at 800 to $900^{\circ} \mathrm{C}$ were denser than the others but warped along the sldes and top.

Similar tests were run with the same powder except sintering was run in argon atmosphere.

Table 6 shows the results of samples sintered in argon atmosphere at 1200 and $1300^{\circ} \mathrm{C}$ for $8 \mathrm{hr}$. Specimen No. 900-A-1 was sintered in argon at $1200^{\circ} \mathrm{C}$ for $8 \mathrm{hr}$ but the initial material was calcined at $900^{\circ} \mathrm{C}$ in an argon atmosphere.

TABLE 6

Results of Sintering in Argon

\begin{tabular}{|c|c|c|c|c|c|}
\hline \multirow{2}{*}{$\begin{array}{c}\text { Calcining } \\
\text { Temperature } \\
\text { ( } \mathrm{C}) \\
\end{array}$} & \multirow{2}{*}{$\begin{array}{l}\text { Compacting } \\
\text { Pressure } \\
\text { (tsi) } \\
\end{array}$} & Sintering & \multicolumn{2}{|c|}{ Density } & \multirow{2}{*}{$\begin{array}{l}\text { Shrinkage } \\
\text { on Diameter } \\
(\%)\end{array}$} \\
\hline & & $\begin{array}{c}\text { Temperature } \\
(\mathrm{C})\end{array}$ & $\begin{array}{c}\text { Green } \\
(\%)\end{array}$ & $\begin{array}{c}\text { Sintered } \\
(\%) \\
\end{array}$ & \\
\hline 400 & 10 & 1300 & 52 & laminated & - \\
\hline 500 & 5 & 1300 & 49 & 73 & 23.26 \\
\hline 600 & 25 & 1300 & 78 & 86 & 7.02 \\
\hline 700 & 25 & 1300 & 81 & 87 & 5.26 \\
\hline 800 & 25 & 1300 & 83 & 92 & 5.00 \\
\hline 900 & 25 & 1300 & 86 & 96 & 4.73 \\
\hline 400 & 10 & 1200 & $\begin{array}{r}- \text { not } \\
\text { run }\end{array}$ & - & \\
\hline 500 & 5 & 1200 & $\begin{aligned} &- \text { not } \\
& \text { run }\end{aligned}$ & - & \\
\hline
\end{tabular}




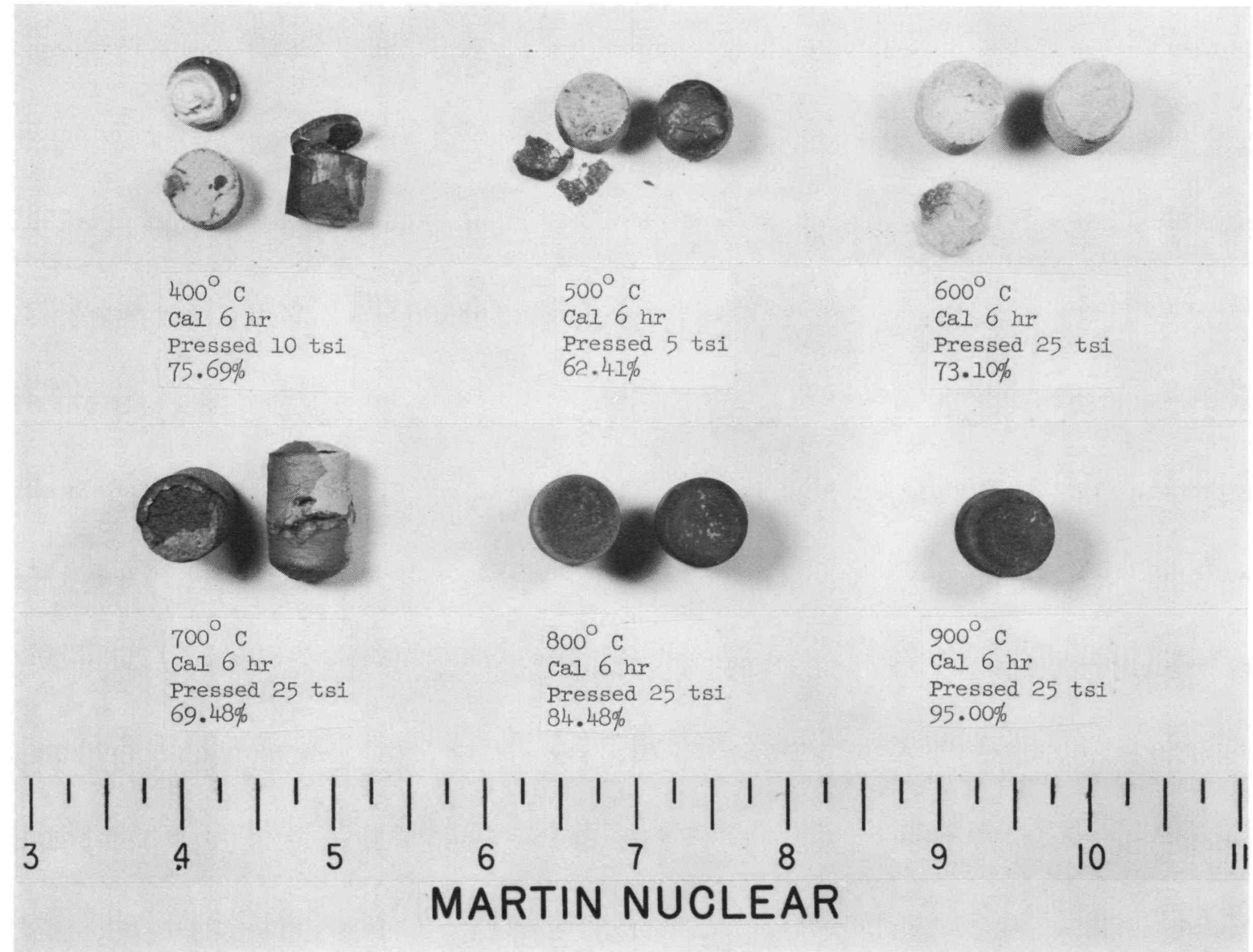

Fig. 17. Pellets Sintered in Air 
TABIE 6 (continued)

\begin{tabular}{|c|c|c|c|c|c|}
\hline \multirow{2}{*}{$\begin{array}{c}\text { Calcining } \\
\text { Temperature } \\
\left({ }^{\circ} \mathrm{C}\right) \\
\end{array}$} & \multirow{2}{*}{$\begin{array}{c}\text { Compacting } \\
\text { Pressure } \\
\text { (tsi) } \\
\end{array}$} & Sintering & \multicolumn{2}{|c|}{ Density } & \multirow{2}{*}{$\begin{array}{l}\text { Shrinkage } \\
\text { on Diameter } \\
(\%) \\
\end{array}$} \\
\hline & & $\begin{array}{l}\text { Temperature } \\
\left({ }^{\mathrm{C}}\right)\end{array}$ & $\begin{array}{l}\text { Green } \\
(\%)\end{array}$ & $\begin{array}{c}\text { Sintered } \\
(\%) \\
\end{array}$ & \\
\hline 600 & 25 & 1200 & 80 & 91 & 7.08 \\
\hline 700 & 25 & 1200 & 82 & 92 & 5.55 \\
\hline 800 & 25 & 1200 & 83 & 97 & 5.93 \\
\hline 900 & 25 & 1200 & 86 & 98 & 4.70 \\
\hline$* 900 \mathrm{~A}=1$ & 25 & 1200 & 85 & 89 & 2.40 \\
\hline
\end{tabular}

A single batch of material was also sintered at $1200^{\circ} \mathrm{C}$ for $15 \mathrm{hr}$. It was noticed that the calculated densities were about the same. Table 7 shows the results of this study.

\section{TABLE 7}

Results of sintering at $1200^{\circ} \mathrm{C}$ for $15 \mathrm{hr}$

\begin{tabular}{|c|c|c|c|c|c|}
\hline Calcining & Simtering & Compacting & \multicolumn{2}{|c|}{ Density } & Shrinkage \\
\hline $\begin{array}{l}\text { Temperature } \\
(\mathrm{C})\end{array}$ & $\begin{array}{l}\text { Temperature } \\
\text { ( } \mathrm{C})\end{array}$ & $\begin{array}{c}\text { Pressure } \\
(t s i) \\
\end{array}$ & $\begin{array}{c}\text { Green } \\
(\%) \\
\end{array}$ & $\begin{array}{c}\text { Sintered } \\
(\%)\end{array}$ & $\begin{array}{l}\text { on Diameter } \\
(\%) \\
\end{array}$ \\
\hline 600 & 1200 & 25 & 79 & 91 & 6.93 \\
\hline 700 & 1200 & 25 & 82 & 91 & 5.71 \\
\hline 800 & 1200 & 25 & 84 & 93 & 4.79 \\
\hline 900 & 1200 & 25 & 87 & 98 & 4.54 \\
\hline
\end{tabular}

$X$-ray diffraction study and chemical analysis of $\mathrm{CeF}_{3}$ calcined and sintered in air indicated the presence of cerium oxide. For example, material calcined at $900^{\circ} \mathrm{C}$ in air and sintered at $1300^{\circ} \mathrm{C}$ in air chemically analyzed to $21.7 \% \mathrm{CeO}_{2}$ and $22.7 \% \mathrm{Ce}_{2} \mathrm{O}_{3}$ with the balance thought to be $\mathrm{Ce}_{3}$. It should therefore be noted that the calculated densities in Tables 5, 6 and 7 are not accurate since the presence of cerium oxide had not been taken into account.

Pellets of $\mathrm{CeF}_{3}$ were sintered in hydrogen atmosphere for a long period of time. A needle like growth appeared on the compact. $\mathrm{X}$-ray and chemical analysis is now being conducted to determine the composition of the growth. FIgure 18 shows the $\mathrm{CeF}_{3}$ compacts after removal from hydrogen atmosphere. Partial results from $\mathrm{X}$-ray diffraction study show the following: 


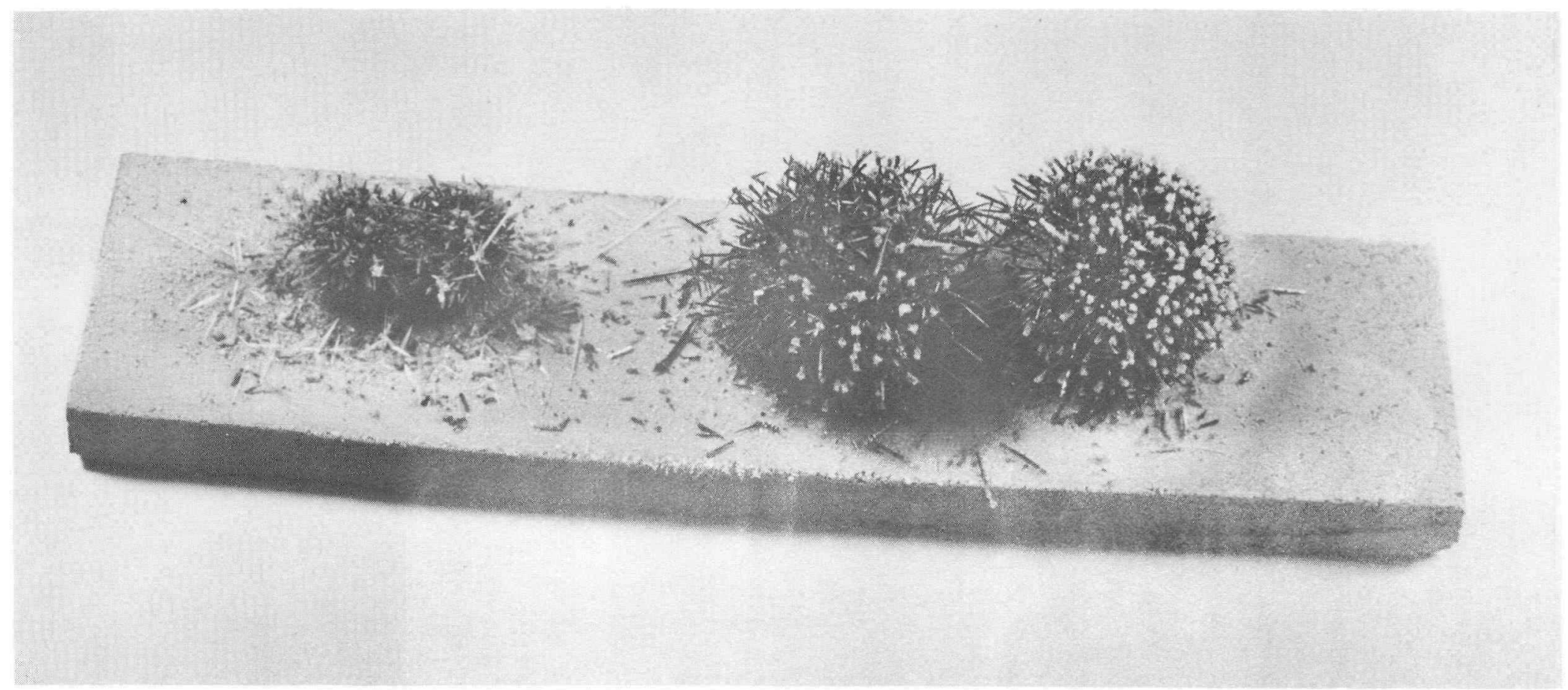

Fig. 18. $\mathrm{CeF}_{3}$ Pellet after Sintering in Hydrogen Atmosphere 
(1) Materials calcined in air and later sintered in air produce $\mathrm{CeO}_{2}$ with time.

(2) When $\mathrm{CeF}_{3}$ is sintered in argon, $\mathrm{CeF}_{3}$ remains, but another structure is present that, at this time, cannot be 1dentified.

(3) Sintering $\mathrm{CeF}_{3}$ samples in hydrogen produces a pattern that Is not $\mathrm{CeF}_{3}$ but is thought to be $\mathrm{CeF}_{4}$. However, there was no $\mathrm{CeO}_{2}$ present.

It has therefore been determined that for best results in preparing the $\mathrm{CeF}_{3}$ material calcining should be done in argon atmosphere and sintering should be done in an argon atmosphere.

Continuing the investigation for a burnup material a small batch of cerium phosphate was prepared in the laboratory with a wet chemistry process. Two batches were prepared and preliminary study was conducted. Table 8 shows the results observed:

\section{TABLE 8}

Cerium Phosphate Material sintered at $1300^{\circ} \mathrm{C}$

\begin{tabular}{|c|c|c|c|}
\hline Batch No. & Composition & OriginaI Material & $\begin{array}{l}\text { Sintered Density } \\
(\mathrm{gm} / \mathrm{cc})\end{array}$ \\
\hline 1 & $\mathrm{Ce} \mathrm{PO}_{4}$ & $\mathrm{Ce}\left(\mathrm{NO}_{3}\right)_{3} \cdot 6 \mathrm{H}_{2} \mathrm{O}$ & 4.4 \\
\hline 2 & $\mathrm{Ce} \mathrm{PO}_{4}$ & $\mathrm{Ce}\left(\mathrm{SO}_{4}\right)_{3} \quad \mathrm{H}_{3} \mathrm{PO}_{4}$ & 4.1 \\
\hline
\end{tabular}

The sinterability of the phosphate was not good. The samples cracked and distorted during sintering, so the calculated density is only an approximate value. Work is continuing with the phosphate compound with hopes for improving the sintering properties of the material.

\section{B. MOLYBDENUM TEST SPECIMENS}

The study of seals for closing the molybdenum fuel block has been narrowed down to one successful design. After all previous attempts at sealing the fuel holes and preventing the lead from escaping, only the 
hollowed soft iron cup with molybdenum pin seemed effective. The design consists of a molybdenum disc which keeps the hollow soft iron plug in place. A slightly tapered molybdenum pin was placed into the plug. This assembly was placed into a molybdenum container prepared with a series of grooves and threads and pressed into position. When the pin was placed into the plug the soft iron flowed into the grooves. A threaded molybdenum cap was placed in position on top of this assembly. A tight seal was made along the edges of the grooves by the expanding iron. A molybdenum screw was tightened down onto this seal and then brazed. The sample was reheated to $1700^{\circ} \mathrm{F}$ in an inverted position and allowed to soak at temperature for two hours. The specimen was checked for leaks by observing the appearance of the seal and by the change in weight. From the results of this test it was determined that the following precaution was required. When pressing the molybdenum pin into the plug care must be taken to be sure that the pin is completely sealed into the plug. This required a pressure of about $8000 \mathrm{Ib}$ total load.

\section{RE-ENTRY TYPE FUEL ASSEMBLY}

A study was conducted to evaluate the use of an ablative coating for the molybdenum block. The problem was to bond a graphite coating to a molybdenum fuel container. Two materials were considered after a serles of preliminary studies of brazes on graphite. Colmonoy No. 5, which is also the oxidation resistant coating on the molybdenum, and Nicrobraze 150 were used. A graphite container was machined to size to receive the completely coated block. Fither Colmonoy No. 5 or Nicrobraze 150 powders were placed in the bottom of the container and the block placed in the container on top of the powdered material. The assembly was heated to about $1100^{\circ} \mathrm{C}$ in argon atmosphere. The weight of the block displaced the molten brazing material and formed a bond between the graphite can and molybdemum block. Metallographic examination showed a diffusion of the braze into the graphite. However, cross-sectional examination of the assembly showed a number of small voids between the bottom end of the molybdenum block and the graphite. The brazing material, however, flowed up along the sides and bonded to the walls of the graphite container and sides of the block.

\section{OXIDATION RESISTANT COATTIMS}

Four molybdenum sandwiches were tested for $500 \mathrm{hr}$ at $500^{\circ} \mathrm{F}$ under mercury in open stainless steel containers. The molybdenum was joined into sandwiches with a mixture of $50 \%$ standard nicrobraze and $50 \%$ high melting nicrobraze. There was no welght change or any visual changes in the samples. 
Twelve samples of costed molybdenum was tested in mercury for 500 $\mathrm{hr}$ at $600^{\circ} \mathrm{F}$. The samples were placed in Pyrex test ampoules and then inserted in a Vycor Plask so that the samples were completely immersed. in mercury at all times. A uniform constant temperature of $600^{\circ} \mathrm{F}$ was maintained with Hoskins Pot Furnaces. There was no change in dimensions of the samples during the tests. A slight welght gain resulted in all cases from mercury adhering to the surface. The results of these tests are given in Table 9.

TABLE 9

Corrosion Test Results on Coatings

Sample

1

2

3

4

5

6

7

8

9

10

II

12
Coating

Colmonoy 5

Colmonoy 5

Colmonoy 5

Colmonoy 4

Colmonoy 4

Colmonoy 4

Colmonoy 6

colmonoy 6

Colmonoy 6

Coast Metal 50

Coast Metal 50

Coast Metal 50
Weight Gain

(gm)

0.0038

0.0077

0.0049

0.0026

0.0075

0.0037

0.0101

0.1887

0.0912

0.0093

0.0037

0.0041 
IV. TASK 4--MATTERIAIS CORROSION PROGRAM

A. IEFAD CORROSION TESTS

Ifquid lead corrosion tests were made on cerium fuel pellets. A total of 19 tests were run of which 11 were completed during this quarterly reporting period. All samples were placed in lead containing $I$ wt $\%$ nickel and 0.02 wt $\%$ carbon. The composition of the compacts was varied by the addition of carbon, molybdenum, niobium, titanium hydride and zirconium hydride. The corrosion tests were run for 500 hr at $1500^{\circ} \mathrm{F}$. Results of the tests are shown in Table 10.

TABLE 10

Iifquid Lead Corrosion Results

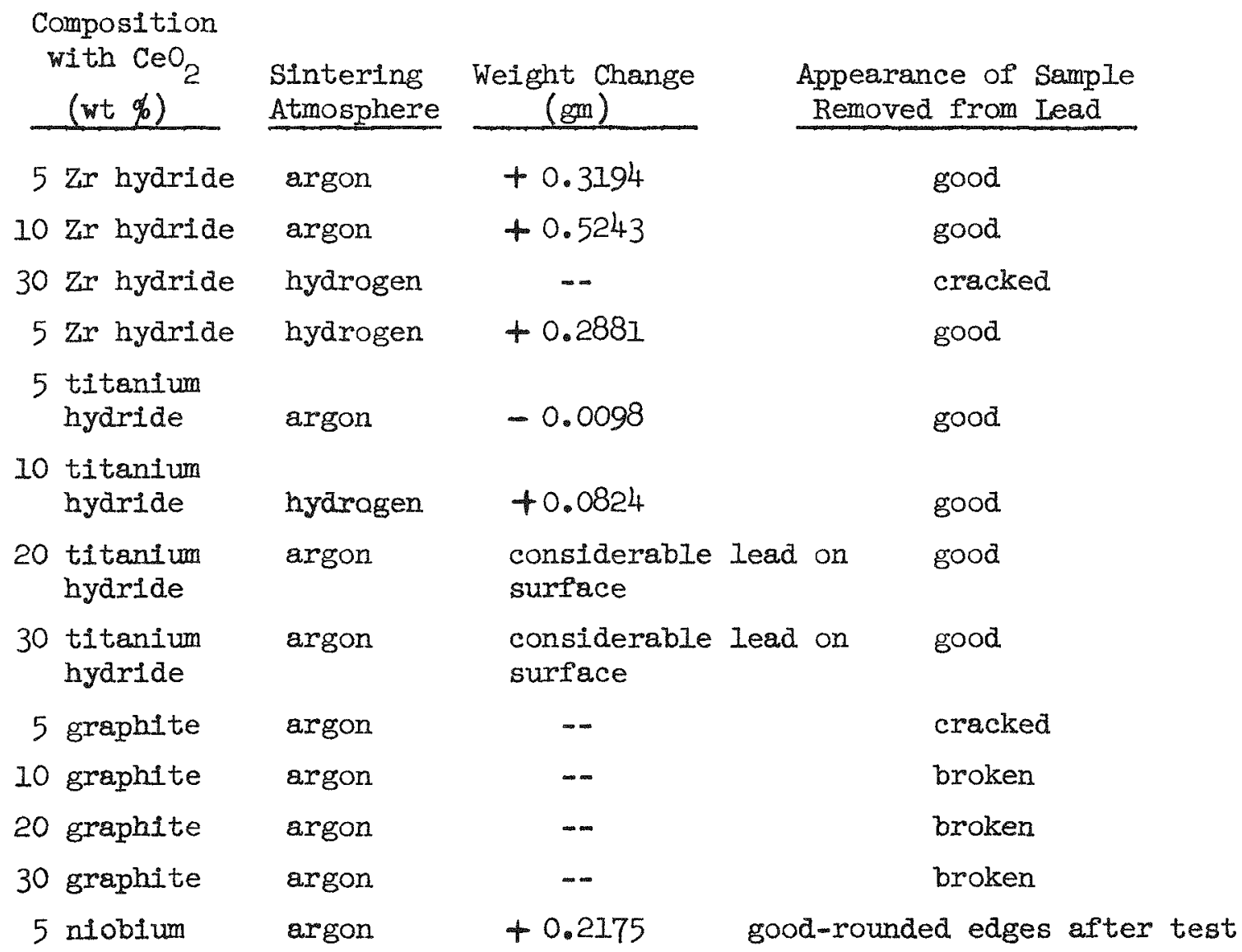


TABLE 10 (continued)

\begin{tabular}{|c|c|c|c|}
\hline $\begin{array}{l}\text { Composition } \\
\text { with } \mathrm{CeO}_{2} \\
\text { (wt o) } \\
\end{array}$ & $\begin{array}{l}\text { Sintering } \\
\text { Atmosphere }\end{array}$ & $\begin{array}{l}\text { Weight Change } \\
(\mathrm{gm}) \\
\end{array}$ & $\begin{array}{l}\text { Appearance of Sample } \\
\text { Removed from Lead } \\
\end{array}$ \\
\hline 10 niobium & argon & 0.0841 & good-rounded edges after test \\
\hline 20 niobium & argon & 0.2650 & good-rounded edges after test \\
\hline 30 niobium & argon & 0.3687 & good-rounded edges after test \\
\hline 5 molybdenum & argon & 0.1768 & good \\
\hline 10 molybdenum & argon & 0.0110 & good \\
\hline 20 molybdenum & argon & 0.0273 & good \\
\hline 30 molybdenum & argon & 0.0193 & good \\
\hline 10 molybdenum & hydrogen & 0.0842 & good \\
\hline 20 molybdenum & hydrogen & 0.1383 & good \\
\hline 30 molybdenum & hydrogen & 0.0831 & good \\
\hline $\mathrm{CeF}_{3}$ & $\begin{array}{l}\text { argon } \\
\left(1100^{\circ} \mathrm{C}-8\right. \\
\mathrm{hr}(\mathrm{r})\end{array}$ & -0.0035 & good \\
\hline $\mathrm{CeF}_{3}$ & $\begin{array}{l}\text { argon } \\
\left(1100^{\circ} \mathrm{C}-8\right. \\
\mathrm{hr})\end{array}$ & -0.0068 & good \\
\hline $\mathrm{CeF}_{3}$ & $\begin{array}{l}\text { argon } \\
\left(1100^{\circ} \quad \mathrm{C}-8\right. \\
\mathrm{hr})\end{array}$ & -0.0325 & good \\
\hline $\mathrm{CeF}_{3}$ & $\begin{array}{l}\text { argon } \\
\left(1200^{\circ} \mathrm{C}-15\right. \\
\mathrm{hr} \text { ) }\end{array}$ & 0.0344 & good \\
\hline $\mathrm{CeF}_{3}$ & $\begin{array}{l}\text { argon } \\
\left(1200^{\circ} \mathrm{C}-15\right. \\
\mathrm{hr} \text { ) }\end{array}$ & -0.0175 & good \\
\hline $\mathrm{CeF}_{3}$ & $\begin{array}{l}\text { argon } \\
\left(1200^{\circ} \mathrm{C}-15\right. \\
\mathrm{hr})\end{array}$ & -0.0776 & good \\
\hline $\mathrm{CeF}_{3}$ & $\begin{array}{l}\text { argon } \\
\left(1300^{\circ} \mathrm{C}-8\right. \\
\mathrm{hr}(\mathrm{s})\end{array}$ & -1.3400 & good \\
\hline $\mathrm{CeF}_{3}$ & $\begin{array}{l}\text { argon } \\
\left(1300^{\circ} \mathrm{C}-8\right. \\
\text { hr) }\end{array}$ & -- & $\begin{array}{l}\text { Excessive lead on surface. One } \\
\text { part of sample chipped. }\end{array}$ \\
\hline
\end{tabular}


TABLE 10 (continued)

\begin{tabular}{|c|c|c|c|}
\hline $\begin{array}{l}\text { Composition } \\
\text { with } \mathrm{CeO}_{2} \\
\text { (wt \%) } \\
\end{array}$ & $\begin{array}{l}\text { Sintering } \\
\text { Atmosphere }\end{array}$ & $\begin{array}{l}\text { Welght Change } \\
(\mathrm{gm})\end{array}$ & $\begin{array}{l}\text { Appearance of Sample } \\
\text { Removed from Iead }\end{array}$ \\
\hline $\mathrm{CeF}_{3}$ & $\begin{array}{l}\text { argon } \\
\left(1300^{\circ} \mathrm{C}-8\right. \\
\mathrm{hr} \text { ) }\end{array}$ & -0.6403 & good \\
\hline $\mathrm{CeF}_{3}$ & $\begin{array}{l}\text { argon } \\
\left(1300^{\circ} \mathrm{C}-8\right. \\
\mathrm{hr} \text { ( })\end{array}$ & -0.1899 & good \\
\hline $\mathrm{CeF}_{3}$ & $\begin{array}{l}\operatorname{air} \\
\left(1300^{\circ} \mathrm{C}-8\right. \\
\mathrm{hr}(\mathrm{r})\end{array}$ & - & badly broken \\
\hline
\end{tabular}

The corrosion tests were performed using inhibited lead (lead containing $I$ wt $\%$ nickel and 0.02 wt $\%$ carbon as a corrosion inhibitor). Other tests are being run in pure lead and a comparison will be made with these results. Weight gains are partially due to some lead adhering to the samples after removal from the testing containers.

Purified lead, totaling $8391 \mathrm{gm}$, was added to electrically heated mercury boilers, PBP 5A and also to PBP 6. Radiographs revealed that the boilers were completely filled with lead. Therefore, a short expansion tube was placed on each of the boilers to provide $0.5 \mathrm{cu}$ in. expansion at the operating temperature of $1500^{\circ} \mathrm{F}$.

\section{B. WOODS METAL TESTS}

One brazed molybdenum sample and one molybdenum sandwich were tested under Woods metal in open stainless steel containers for 500 hr at $500^{\circ} \mathrm{F}$. There was no change in either sample. However, Woods metal, four parts bismuth, two parts lead, one part tin and one part copper should not be used at temperatures much in excess of $650^{\circ} \mathrm{F}$ because of the rapid oxidation of the alloy.

\section{MERCURY CORROSION}

Four dynamic loop systems were fabricated to evaluate the corrosion of mercury over the temperature range of 325 to $1350^{\circ} \mathrm{F}$. The construction materials were Type 347 stainless steel, Type 446 stainless steel, niobium clad with Type 347 stainless steel and tantalum clad with Type 347 stainless steel. The Type 347 stainless steel clad provided both strength and oxidation resistance. 
To qualify the design of these loop systems and locate trouble areas, the unit made of Type 347 stainless was used as the guinea pig. This system was started and shut down several times. One shutdown was caused when the boiler tubes short circuited a heating element in the furnace resulting in a tube perforation. The coil was removed, cleaned, welded and reinstalled. The loop was then operated for $126 \mathrm{hr}$ until a power failure caused it to shutdown for approximately $5 \mathrm{hr}$. The 10op restarted automatically. However, it did not reach design conditions.

A week of effort to return the loop to design conditions was unsuccessful, so it was partially disassembled. Examination showed that some material had plated out on the valve stem causing improper seating with attendant improper flow control. The stem was cleaned and the valve reinstalled. After subsequent continuous operation for $176 \mathrm{hr}$ the exit leg of the boiler coil ruptured and the unit was dismantled for metallographic examination and evaluation.

The Type 446 stainless steel 10op was operated with simllar difficuities. During the first run a hole was burned in the coll section by a broken heating element. The coil section was removed, welded, cleaned and reinstalled. The unit ran for $100 \mathrm{hr}$ continuously until trouble was encountered with the power control units. The work on this loop was discontinued because of phase out of the program.

The Type 347 stainless steel clad niobium loop was installed and operated for about $50 \mathrm{hr}$ when the coil section ruptured.

After failure, the Type 347 stainless steel loop and the niobium loop with Type 347 stainless steel cladding was sectioned and examined micrographically for evidence of failure. It was concluded from the photomicrographs that the failures were due to defects in the tubing rather than from mercury corrosion. Each loop will be discussed separately.

\section{Type 347 Stainless steel}

This loop failed by a rupture in the outlet leg, (the straight section leading from the coil). A four-inch portion of this outlet leg near the coil was expanded probably by the combination of pressure and temperature. Samples were cut from the coil at the top, middle and bottom for examination.

Figure 19a shows the typical material. The material appears to be unaffected.

Figure $19 \mathrm{~b}$ shows the midale section of the coil where the temperature is hotter and is the area where the liquid mercury is being converted to vapor. This is the area where mass transfer would be most severe. The photographs show evidence of surface attack. 

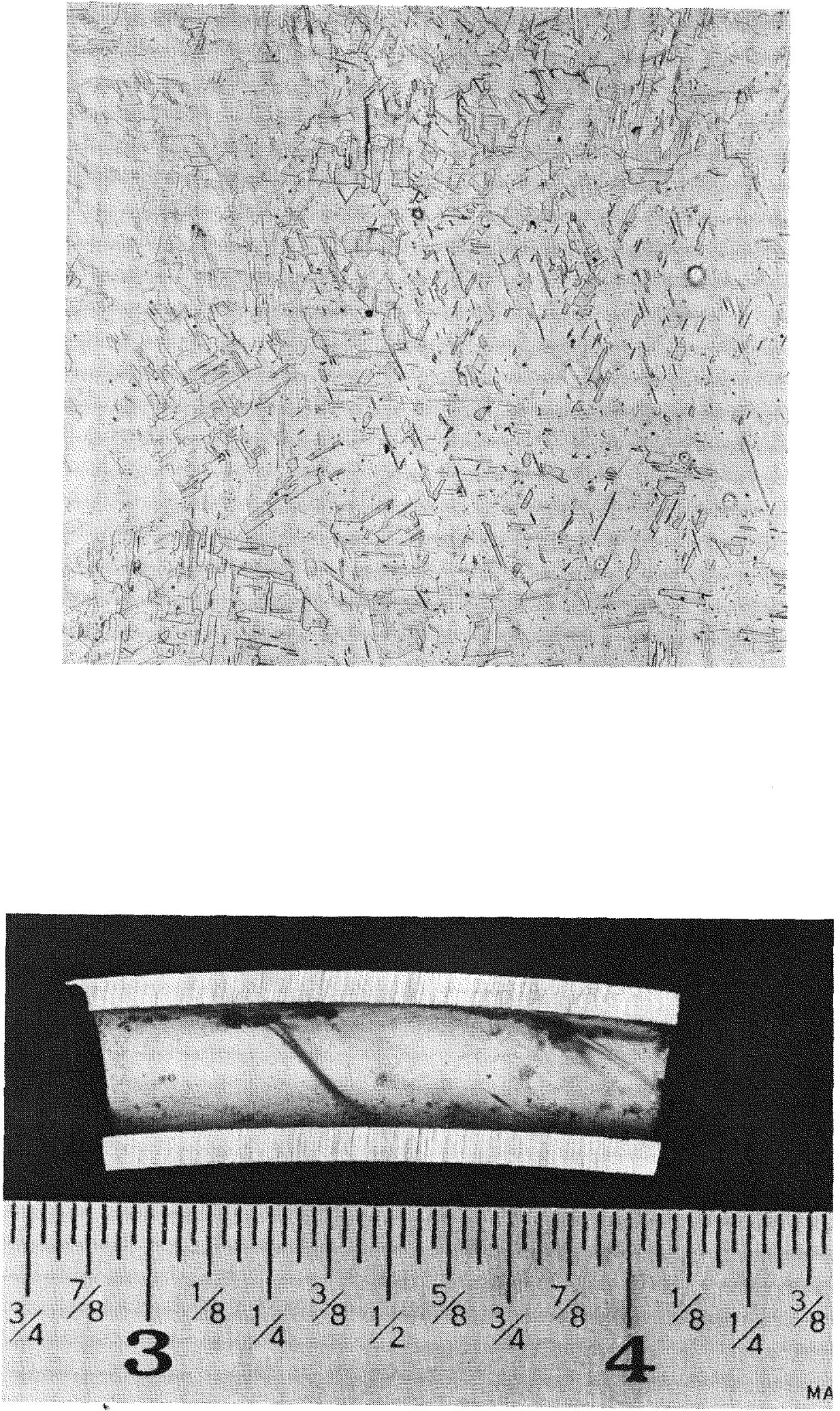

Fig. 19a.: Type 347 SS Sample Taken on Second Turn From Bottom of Coil and Reveals No Evidence of Corrosion 

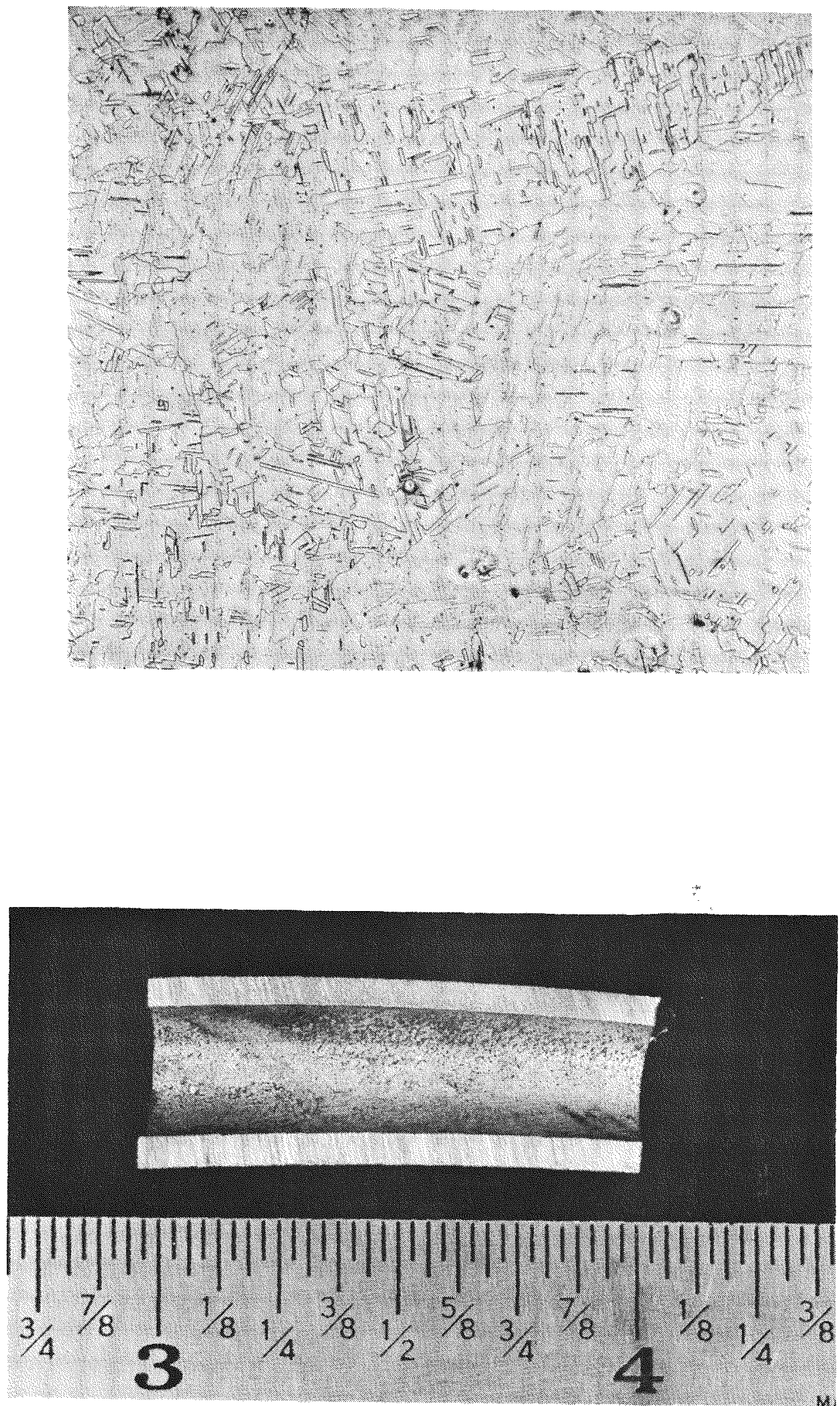

Area Magnified 75 Times

Fig. 19b. Sample Taken at Middle of Core Showing Some Evidence of Corrosion 
Figure 20 shows the top of the coil where the temperature is near $1350^{\circ} \mathrm{F}$ and dry mercury vapor was present. There is no sign of the attack as was evident in the middle section; however, a continuous crack running lengthwise to the tube is present. It is believed that this defect became more pronounced during service and was the cause for failure. The numerous small cracks shown in Fig. 21 are attributed to the enlargement of the tubing during the test.

2. Niobium Clad with Type 347 Stainless Steel

This loop failed in the coil at a point two turns from the top. Samples were taken from the top (point of failure), middle and bottom.

Figures 22 and 23 show the bottom and middle section which are typical of the material. The stainless steel is "dirty" and there is some grain growth evident in the middle specimen. This is to be expected since the temperature is higher in this area of the coil.

Figure 24 shows the point of failure. Re-examination of the asreceived material revealed that the stainless clad was weld-drawn tubing rather than seamless. The gross reaction of the stainless clad indicates that the failure started from the outside. It is believed that a faulty seam in the stainless clad exposed the niobium to the air thus permitting oxidation of niobium and resultant reaction with the stainless which formed the corrosion product evident on the cladding. 

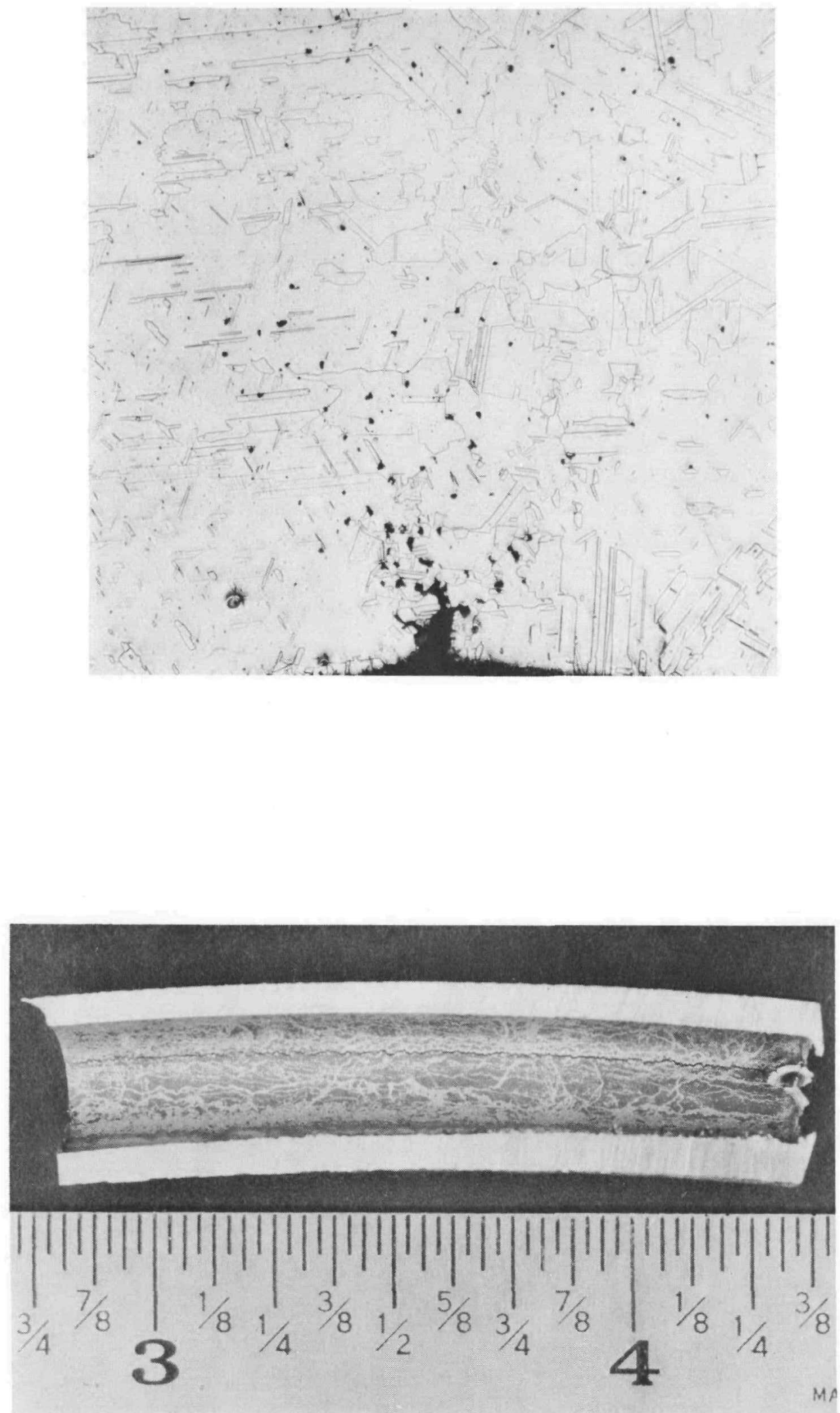

Fig. 20. Type 347 SS Sample Taken from Second Turn from Top of Coil Magn 75 

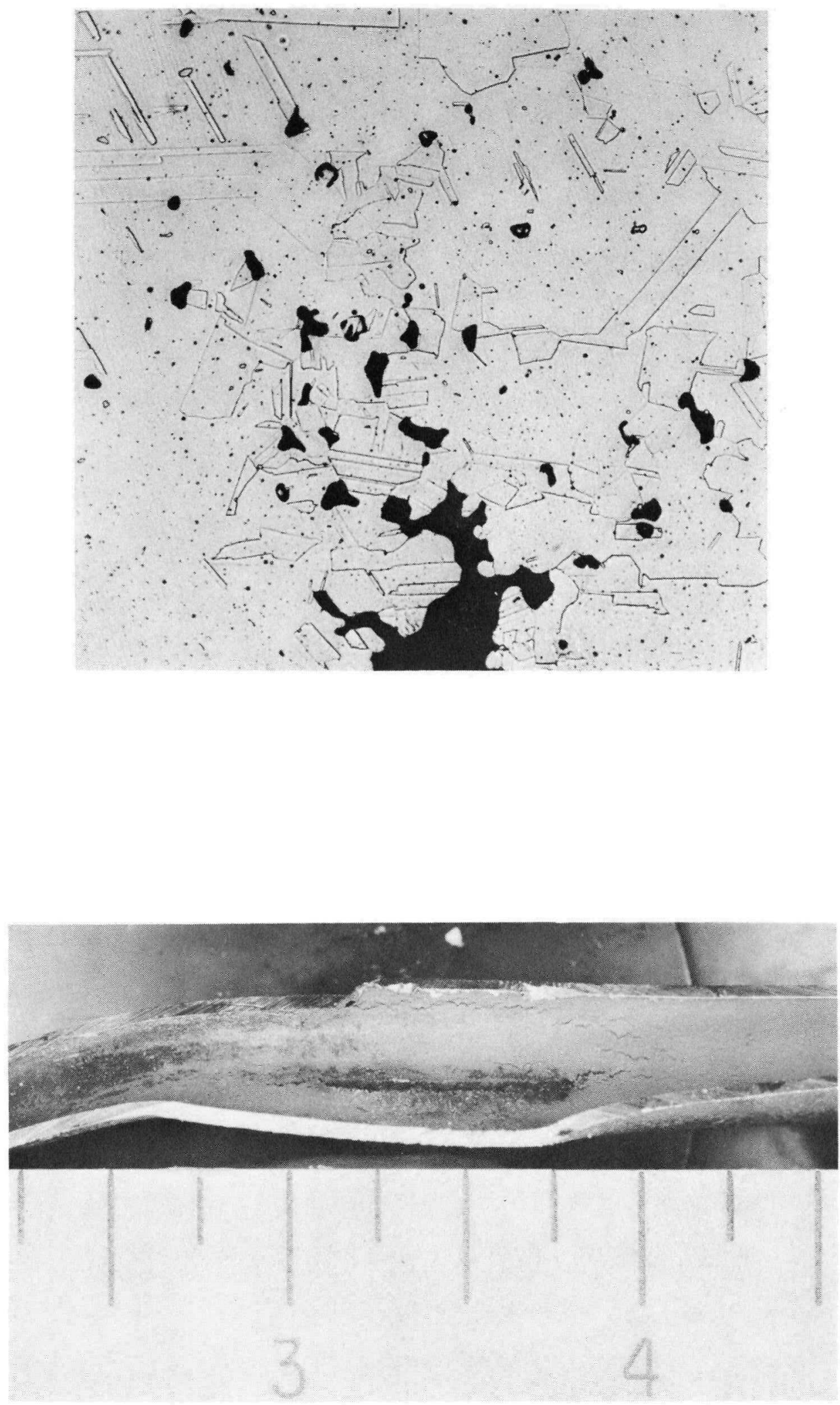

Fig. 21. Type 347 SS Showing Inside Surface of Tube at Point of Rupture on Exit Leg

\section{SECRET}

MND-P-3007 


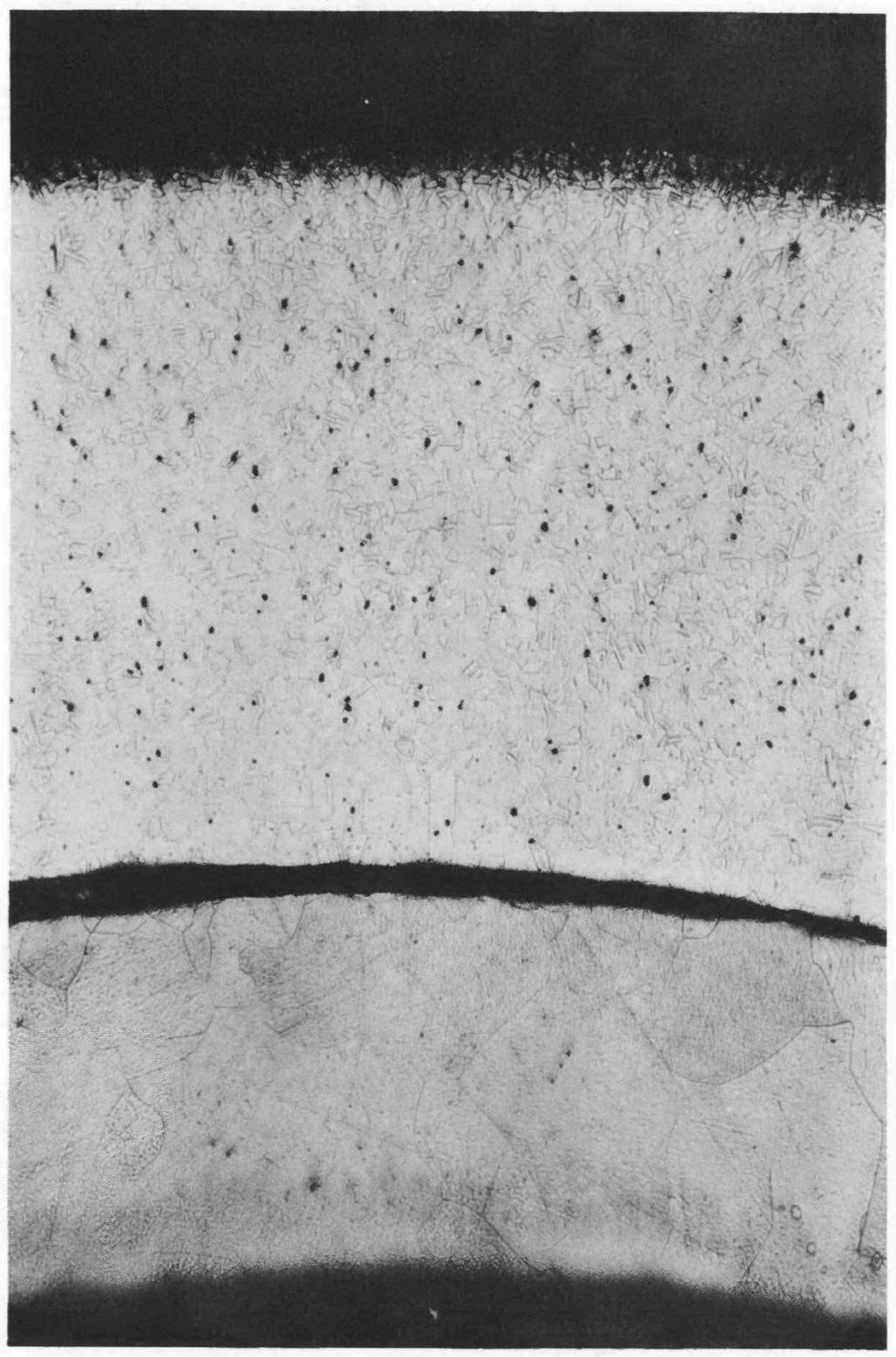

Fig. 22. Niobium Liner Clad with Type 347 SS Showing Sample Taken Two Turns from Bottom of Coil Magn 75

\section{SECRET}




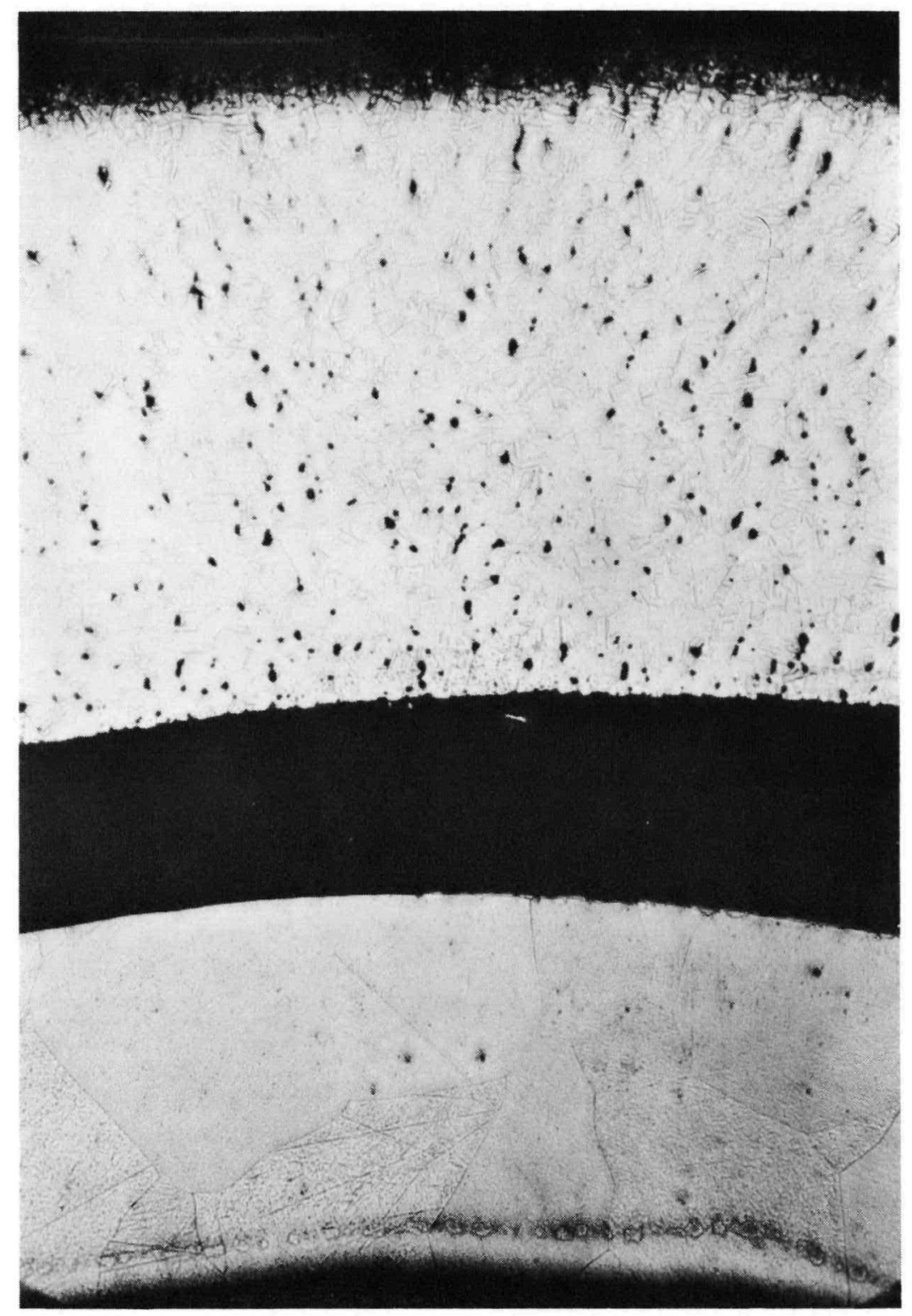

Fig. 23. Niobium Liner Clad with Type 347 SS Showing Sample from Middle of Coil Magn 75

\section{SECRET}



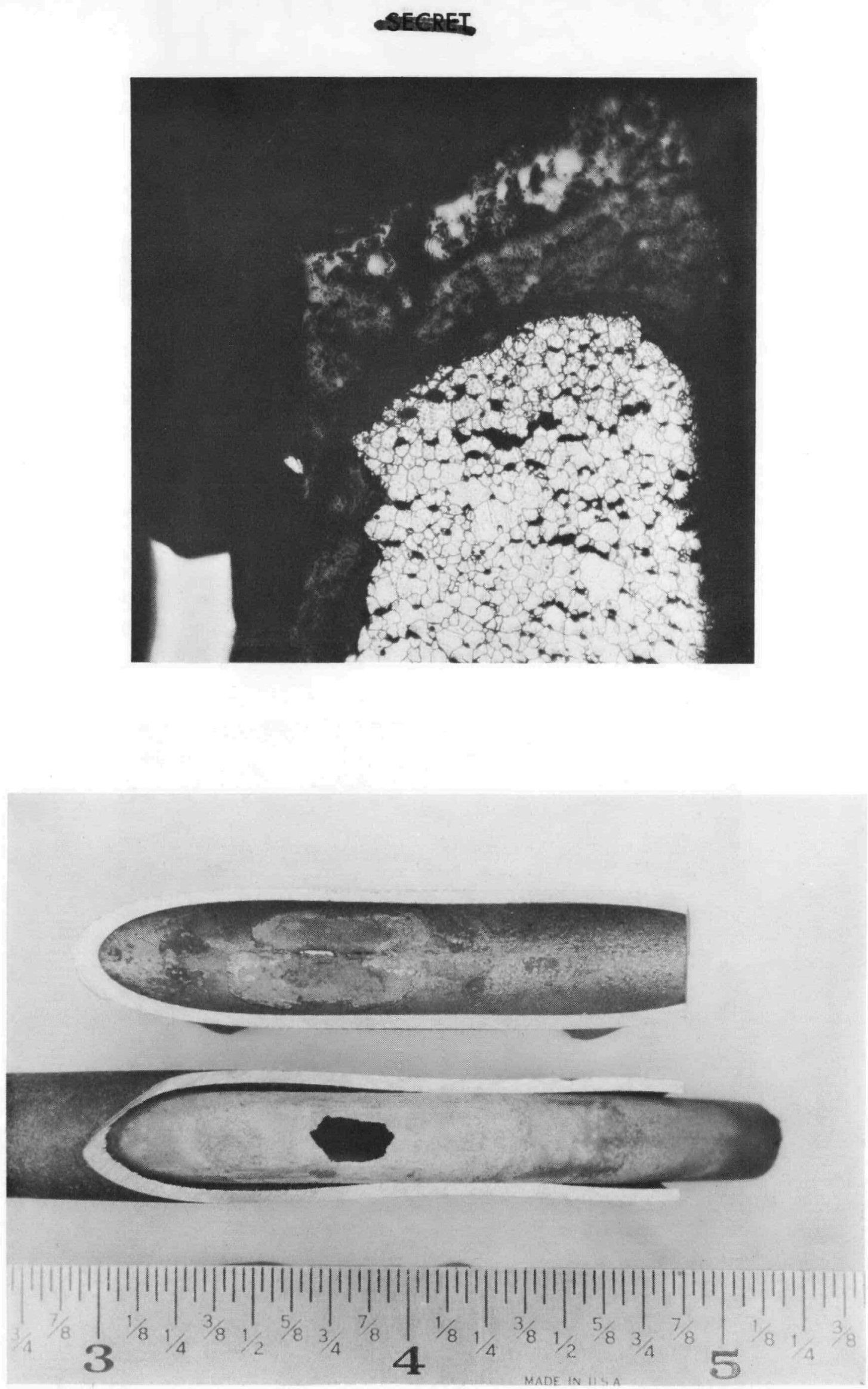

Fig. 24. Niobium Liner Clad with Type 347 SS Magn 75 


\section{TASK 5--POWER CONVERSION SYSTEM}

A major effort of the quarter was devoted to the fabrication, checkout and calibration of the ground test system (GTS) hardware and subsequent installation in the systems test enclosure, (STE). As a result, GTS-I was installed and a system test run of nearly $1 \mathrm{hr}$ with turbine speeds up to 40,000 rpm was completed in the STE. Other major efforts involved preparation of new program work statements for the fourth quarter of Fiscal 1959 to most effectively proportion the remaining fiscal year funds and the preparation of Fiscal 1960 SNAP I development programs.

The revised statement of work for the fourth quarter of Fiscal 1959 resulted in termination of the condenser study program and the turbine program was reduced to package test followup. Effort in all groups was concentrated on achieving satisfactory performance of the PTP in the breadboard test rig and adequate system performance in the STE.

In May, a coordination meeting was held to review planning for the Fiscal 1960 SNAP I development program. As a result of this meeting, TRW Document AE-224M, "TRW Recommendations for SNAP I Fiscal 1960 program, "dated 15 May, was prepared. The recommendations were that SNAP I development be continued in the following five basic areas:

(I) Ground test system development

(2) Flight test system development

(3) Environmental test program

(4) Improved SNAP I design and development

(5) One-kw modification of SNAP I.

Two other breakdowns of the ground test system development program were presented in TRW Document AE-229M. These breakdowns were:

(1) To provide an estimate for the portion of the GTS development program that is based upon continued performance improvement, but with less emphasis on endurance testing. It provides for no hot cell hardware design or fabrication.

(2) To describe a program which is essentially a six-month extension of the existing system testing. No component development would be performed and no new test hardware fabricated. 


\section{A. PROTOTYPE DESIGN}

The prototype SNAP I rotating machinery packages, PTP-I and PTP-2 were assembled and tested in the breadboard test rig. Cold gas $\left(\mathbb{N}_{2}\right)$ and mercury vapor runs, with turbine speeds up to 45,000 rpm were accomplished. Performance information, concerning the bearings, pump, turbine, and alternator was obtained.

A 48-hr endurance test, using PTP-1 was initiated on 13 May, and successfully completed on 15 May. The package was operated continuously with design inlet conditions maintained, and speeds varying from 30,000 to 45,000 rpm to obtain performance data over a range of speeds. The major portion of the run was made at the design shaft speed of 40,000 rpm. Following the endurance test, PTP-1 was removed from the breadboard test rig and prepared for installation in the ground test system.

Fabrication of ground test system hardware was completed in May. The GTS-1 assembly was initiated in May and completed in June utilizing PTP-I which underwent performance and endurance testing in May. The system was installed in the systems test enclosure and the first system test was conducted 29 June. A run of approximately 1 hr was made with package speeds up to $40,000 \mathrm{rpm}$.

\section{B. BREADBOARD TEST RIG}

Early in the reporting period, the additional equipment required to test the prototype test package was installed in the breadboard. These additions consisted primarily of a flow control and associated instrumentation for the pump, and a new Ine to accomodate the vert1cal discharge of the turbine exhaust. All new equipment was checked out during the nitrogen and mercury vapor runs of the PIP-1.

A total of $190 \mathrm{hr}$ of mercury vapor operation have been accumulated. General operation of the system has been quite satisfactory, and all equipment is in good operating condition. Only routine maintenance has been required, and no down time because of system malfunction bas been experienced.

\section{SYSTEMS TEST ENCLOSURE}

Installation of the ground test system bollers was completed in May. During checkout of the bollers, the wire guard heaters on the discharge Iines malntained a maximum ine temperature of only $1100^{\circ} \mathrm{F}$. As a result, tubular type heaters and insulation were ingtalled on the 
Iine and a satisfactory discharge temperature of $1300^{\circ}$ F was obtained. Tests were then conducted to determine heat losses from the boilers and heated lines. At the design temperature, slightly more than $1 \mathrm{kw} /$ boiler was lost to the surrounding environment.

Wet boiler tests were initiated in June. During these tests, boiler operation exhibited an oscillating pressure level. Boiler pressure varied approximately 20 psi with a period of $10 \mathrm{sec}$. The boilers were fitted with automatic flow rate controllers. During the final boiler test, these controllers were put into operation. With the flow controllers in operation, it was determined that boiler performance was adequate to proceed with system tests. The ground test system was installed in the STE without incldent. During initial systems test, cavitation occurred in the auxillary pump. This problem was traced to a high pressure setting of the relief valve in the bypass line, thus preventing sufficient bypass flow for cooling. After correction, system testing continued and the STE performed satisfactorily.

\section{CONTROLS}

Two liquid mercury pressure regulators were fabricated during this reporting period. Testing and calibration was completed on the controls test rig. One pressure regulator was installed in the STE as part of GTS-1.

A high temperature radiation-resistant torque motor was received and tests showed that force and deflection produced was within specification values and the unit was accepted. Additional work to provide a motorized startup was completed. The original motoring equipment, in conjunction with a vibration machine power supply and phase shifting equipment, supplied ample starting torque for an alternator with turbine attached.

\section{E. ALTERNATOR}

Alternator development during the quarter resulted in satisfactory stator bore sealing and attainment of the $85 \%$ efficiency design objective.

The investigation of large iron losses which reduced the efficiency of the first prototype alternator has been completed and results indicated that the majority of losses occurred in the rotor shrink ring. These losses could be reduced appreciably by decreasing the ratio of slot opening to air gap. 
The previous stator bore sealing difficulties were evaluated and as a result, a ceramic sleeve was incorporated into a test unit for evaluation. Subsequent tests showed the new sealing technique to be satisfactory.

The test unit was fitted with laminations of smaller slot opening and stacked and canned without welding to further minimize iron losses. The improved alternator after sealing and testing showed a design point efficiency greater than $85 \%$. This unit was submitted to the Prototype Group for incorporation into PIP-2.

\section{F. CONDENSER}

The condenser program was terminated 15 April.

\section{G. MATERIAIS EVALUATION}

\section{Loop Testing}

During this quarterly report period, 1000 hr dynamic mercury corrosion tests ( $785^{\circ} \mathrm{F}$ and $40 \mathrm{psig}$ ) on AM-350, $\mathrm{PH}-15-7-\mathrm{MO}$, 446 stainless steel and titanium loops were initiated and completed. Metallurgical examination of sections from previously tested AISI 446 and 410 stainless steel loops were also completed.

The AM-350 and PH-15-7-Mo 10ops exhibited no Ioss in wall thickness as a result of the 1000-hr tests. A slight amount of scum was evident on the mercury which was drained from these loops. No sludge or deposit was found in the subcoolers.

The 446 stainless steel loop exhibited a slight surface attack as evidenced from wall thickness measurements and a black powder found on the surface of the liquid mercury.

The titanium loop test was completed in the first week of June. Preliminary observations show considerable surface attack and a large quantity of sludge within the loop.

Metallurgical examination of sections from the AISI 446 and 410 stainless steel loops indicated no evidence of mercury corrosion, and only a small amount of removed material was found which consisted primarily of chromium. 
2. Non-Metallic

Autoclave tests on coils coated with finglehard CA9R resin, Dow Corning R752I with zirconlum orthosilicate fillers, Eccoseal IR72339 with beta spodumene, and Mycalex test discs all showed evidence of mercury penetration by spectrographic analysis.

Specimens of Mycalex No. 555 and No. 560 were submerged in liquid mercury at $600^{\circ} \mathrm{F}$ for $104 \mathrm{hr}$ and in mercury at room temperature for $220 \mathrm{hr}$. Examination of the interior of the specimens showed minute quantities of mercury to be present in both. Spectrographic analysis of the liquid mercury and the scum found on top of the mercury revealed small amounts of silicon, boron, sodium, and several other elements, which had evidently been dissolved from the mycalex samples.

Stainless steel panels coated with VG-260 glass frit were exposed to a $600^{\circ} \mathrm{F}$ mercury environment for over $150 \mathrm{hr}$. No mercury penetration of the glass could be detected.

\section{H. TURBINE}

During PIP-I tests, It was evident that the first stage nozzle exit pressure was less than designed. To correct this condition, it was recommended that the PTP-2 second stage nozzle area be decreased. Fabrication of PIP-2 parts was completed in the latter part of May. Revisions to the second and third stage nozzles were accomplished as dictated by PTP-I test results and Turbine Group recommendations. The unit was assembled and installed in the breadboard in June. At the close of the reporting period, testing was under way with the package running satisfactorily at design speed on mercury vapor.

While PIP-1 tests showed second and third stage turbine inlet pressures to be below design values, turbine performance came very close to expectations. Using the parasitic losses and alternator efficiency supplied by the various component groups, turbine efficiency and turbine power were determined to be $40.5 \%$ and $677 \mathrm{w}$ respectively at design speed and inlet conditions.

A TATP turbine data analysis was conducted early in the reporting quarter. This analysis indicated $46.3 \%$ overall peak efficiency. Using the measured pressures at the interstages, the flow through each nozzle was determined and compared with the measured flows through the turbine. Correlation between the measured and calculated flows was within the accuracy of the data. A report has bean initiated to describe the results of TATP IBM off-design data simulation. 


\section{PUNP}

A complete analysis of data obtained from previous tests has confirmed the performance presented in the last progress report (Quarterly Report No. 9, 7 Apri1 1959).

An engineering report describing the test results of a pump-bearing combination operated in the free running bearing test rig was completed. This report includes an estimated performance map for the prediction of system Plow characteristics. The pump as presently designed, produces an excessive pressure at design flow. To reduce the pressure, pump diameter should be reduced slightly. A study to determine the effect of decreasing pump diameter indicates that a significant saving in power can be achteved.

Preliminary evaluation of data taken during the PIP-1 48-hr endurance run indicated that pump performence 1s satisfactory for the GTS tests. 
VI. TASK 6--GROUND TESTF

\author{
A. GROUND TEST FIXTURE
}

Efforts directed toward equipment and piping layouts in support of the ground test were brought to a logical conclusion. This made it possible to plan a new test program and integrate SNAP I-A requirements.

\title{
B. ENVIRONMENTAL TESTING
}

The SNAP I-A device uses thermocouple assemblles to convert the heat available from radiolsotope decay to electrical energy. The primary radiation emitted by the encapsulated Ce-144 is a 2.18 mev gamma ray. Recoil electrons generated in the semiconductor material are of sufficiently high energy to cause doubt as to the stability of current carrier concentration as a function of cumulative dose, and to affect the transient characteristics of these elements. In an effort to determine the effects of this radiation, a limited radiation effects study was initiated. A statement of work was generated and submitted to vartous outside vendors, and proposals were requested. The scope of work covered the effect of an accelerated accumulated dose as well as the effect of imulated radiation levels of 2 mev gama rays on the operating efficiency of lead telluride thermocouple elements. Initial physical and electrical characterist1cs will be checked against postirradiation characteristics to obtain qualitative or semi-quantitative indications of radiation damage.

A detalled analysis of the proposals recelved from seven different cormpanies yielded the following information. The theoretical effects of electromagnetic radiation on solid state thermoelectric materials can be classifled in two categories:

(I) Cumulative effects

(2) Transient effects.

These are treated separately in the following discussion.

1. Cumulative Effects

High energy electromagnetic radiation absorbed in semi-conductor crystals results in the physical displacement of atoms from their normal lattice positions thereby causing a change in the number of metastable 
electron sites. In the case of gamma radiation, displacement of these atams is effected by the secondary recoll Compton electrons created by the interaction of the gammas with the free electrons in the material. It is evident that these recoli electrons must be extremely energetic If they are to cause such displacement. If the binding energy for atoms in a lattice position is assumed to be approximately $25 \mathrm{ev}^{*}$, the calculated energy of recoll Compton electrons must be of the order of magnitude of 1 to 2 mev to transfer this amount of energy. This may be calculated from the following equation (Ref. I, p 329).

$$
E_{d}=2 \frac{M e}{M_{2}} \frac{E_{t}}{M_{e} C^{2}} \quad\left(E_{t}+M_{e} C^{2}\right)
$$

where

$$
\begin{aligned}
& E_{t} \text { - threshold energy of incldent particle for displacement } \\
& \mathrm{E}_{\mathrm{d}} \text { - displacement or binding energy }
\end{aligned}
$$

The 2-mev gamma rays which result from the decay of Ce-144 can concelvably cause a significant number of recoil electrons in this energy region. Since gamma rays are extremely penetrating, such electrons would be found throughout the thermoelectric target material. One woula therefore expect that lattice displacements would also be homogeneously distributed in the thermoelectric material.

In this study, It was desirable to simulate a Ce-144 soucce by using an electron accelerator. Two approaches may be taken: first, one could actually use hard X-rays produced by impinging an extremely energetic electron beam on a primary target material; second, one could use the accelerated electrons themselves. The distribution of $\mathrm{X}$-rays produced by the first method is given in Fig. 25. The plot in this figure is based on using 6-mev electrons from the accelerator Impinging on a thick tungsten target. It should be noted that the distribution does not accurately simulate radiation from the radioisotope source which consists of 2.18 and $1.48 \mathrm{mev}$ gammas. (Other gammas of lower energy are present but these are not significant from a standpoint of radiation damage.) The number of photons above $2 \mathrm{mev}$ is significant and would cause lattice displacements more energetic than would be experienced in actual operation. Such displacements would be more difficult to anneal out than would be the case for ce-144.

The second possible method of simulating 2 mev ganma rays would be to use $2 \mathrm{mev}$ electrons as they are produced directly in the accelerator beam. This method would duplicate the predominant recoil

* Solla State Physics Vol. 2, Academic Press, New York, 1956, p 311. 


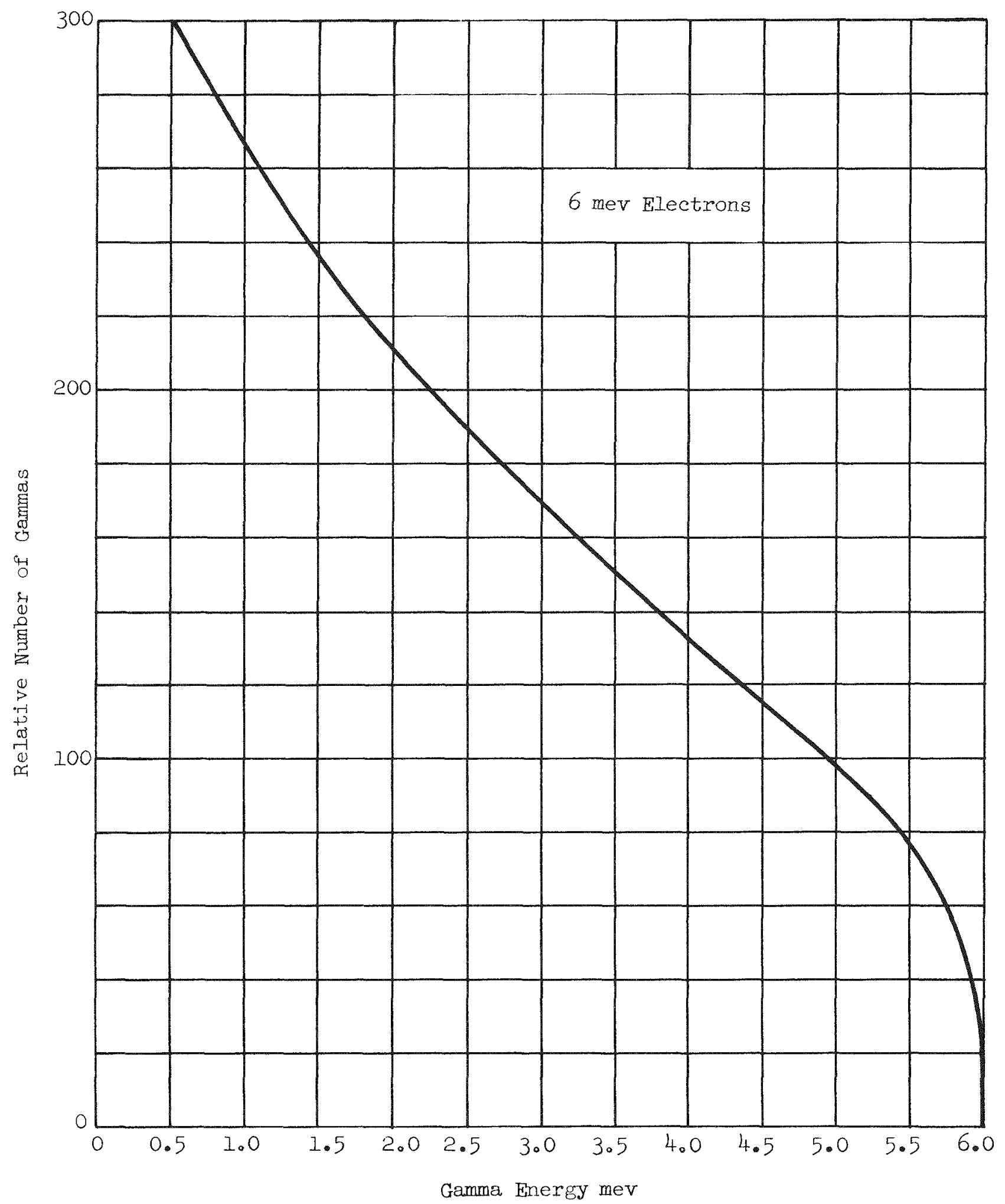

Fig. 25. Distribution of Gamma Rays Produced by Electron Bombardment of Primary Target Material 
electron energies that would be experienced in the 1sotope. If one were to irradiate a sample in the configuration actually used in the generator (approximately 1 in. long by 0.3 in. daimeter), the penetration of these electrons would be confined to a surface layer of the elements. Thus one would not be producing lattice displacements homogeneously throughout the thermoelectric material. On this basis, the original statement of work stated that the use of electromagnetic radiation ( $1 . e$. gama rays) was preferable.

Since the effective penetration depth of electrons is . Iimited to a surface layer of the element, a sufficiently thin sample exposed uniformly to an electron beam on all sides should yleld results which would fairly accurately reproduce those obtainable with Ce-144. Moreover, it can be shown that $2 \mathrm{mev}$ electrons lose their damaging effects in approximately 0.85 of lead telluride.*

It is conceivable, therefore, that if the thermoelectric materials can be sliced into thin samples approximately $1.75 \mathrm{~mm}$ in cross section and exposed on both sides to an electron beam of $2 \mathrm{mev}$, one could expect a fairly homogeneous penetration into the sample. of the proposals received, only one organization suggested this approach. However, considerable doubt existed as to whether these elements could be successfully sliced without breakage or physical damage and the company was requested to actually slice one of the segmented elements received from the supplier. The sliced elements were received in good condition; the slicing operation was carried out successfully without any apparent impairment of the segmentation interface. Thermoelectric efficiency was measured before and after slicing. Again, no measurable significant changes were experlenced.

\section{Transient pefects}

In a radiation field one would expect the electrons of a thermoelectric material to be exclted out of their metastable positions into the conduction band. This effect would presumably take place only while the semiconductor was actually in the radiation field. From a theoretical standpolnt, the effect should actually enhance the thermoelectric efficiencles of the semiconductor. It is felt that this effect should be experimentally ascertained in the program.

Negotiations with the subcontractor are presently under way. It is expected that the work will be completed in the next quarter.

* Halliday, D., Introductory Nuclear Physics, John Wlley and Sons, New York, 1950, p 162. 
VII. TASK 7--THERMOELECTRIC POWER SYSTEM

A. SNAP III-A

The latest Westinghouse report stated that many thermocouples broke during the assembly of the thermoelectric panels into the generator structure.

Since the Research Laboratory is not geared to mount a substantial effort to complete this unit, the partially complete generator will be transferred to the New Products Department which constructed the 100-w TAP-100 generator for RADC.

The variable heat dump is finished and performance data on this component will be taken while the thermoelectric panels are being reassembled.

A new delivery date of I December 1959 has been assigned for the delivery of the completed SNAP III-A to the Martin Company. Parametric tests will then be conducted.

\section{B. SNAP III-B}

A detailed weight breakdown of SNAP III-B is given in Table 11. The generator weight may be changed by reducing the weights of individual components as well as by overall geometrical and detail redesign. A straight-forward redesign should double the w/lb rating of the present unit.

\section{TABIE 11}

Component Welghts of SNAP III

$\begin{array}{lc} & (\mathrm{gm}) \\ & 120 \\ \text { Insulation } & 490 \\ \text { Case } & 338 \\ \text { Cold junction housing } & 192 \\ \text { Heat source } & 286 \\ \text { Thermocouple elements } & 43 \\ \text { Hot shoes } & 177 \\ \text { Cold junction socket } & 73 \\ \text { Springs, screws and washers } & 111 \\ \text { Element cap (pair and wire) } & 1770 \\ \text { Assembled welght } & 1850 \mathrm{gm}(4.08 \text { Ib) } \\ & \\ & \\ \text { MND-P-3007 }\end{array}$


Instrumental errors and errors due to non-equilibrium temperatures probably average $3 \%$. Data from a given generator reproduce fairly well, but units may vary in thermoelectric properties and electricel and thermal contact resistances such that overall efficiencies differ as much as 10\%. Also, the data cover several different generators which were constructed with different insulators. Thus, all the electrical performance data should be regarded as typical rather than precise.

SNAP III-B performance will be discussed in terms of heat balance. Assuming Thompson effects are negligible,

$$
P_{\text {Isotope }}=K_{T E}\left(T_{H}-T_{c}\right)+K_{I n s}(G, P)\left(T_{h}-T_{c}\right) \pi I-\frac{I}{2} r I^{2}
$$

where

$$
\begin{aligned}
& G \quad \text { - generator fill gas (i.e., hydrogen or argon-methane) } \\
& T \text { - Peltier coefficient } \\
& I \quad \text { - current } \\
& T_{h}-\text { hot junction temperature } \\
& T_{c}-\text { cold junction temperature } \\
& P \quad-\text { internal gas pressure } \\
& r \quad-\text { internal resistance }
\end{aligned}
$$

The interaction of these terms accounts for the performance of the device. The effect of the generator fill pressure is shown in Fig. 26. A typical volt-ampere curve is shown in Fig. 27. The effect of Peltier cooling on the hot junction as a function of load resistance is ilIustrated. The upper and lower crosses correspond to hot junction temperatures of 1000 and $900^{\circ} \mathrm{F}$, respectively. The slight non-linearity is the combined result of Peltier cooling and shifting of the figure of merit with a change in hot junction temperature.

A study of electrical power output in a bell jar versus load resistance parametric in thermal power for vacuum and one atmosphere fill pressure is shown in Figs. 28 through 31 for two SNAP III configurations. These generators are identical except that in the one design the diameter of the thermoelectric element is reduced to increase the efficiency at lower power inputs by increasing the hot junction temperatures. For space conditions, the higher power generator may be rated at around $2.5 \mathrm{w}$ and the lower power unt at $1.5 \mathrm{~W}$. Note that a hot junction temperature constraint of $1100^{\circ} \mathrm{F}$ is used 



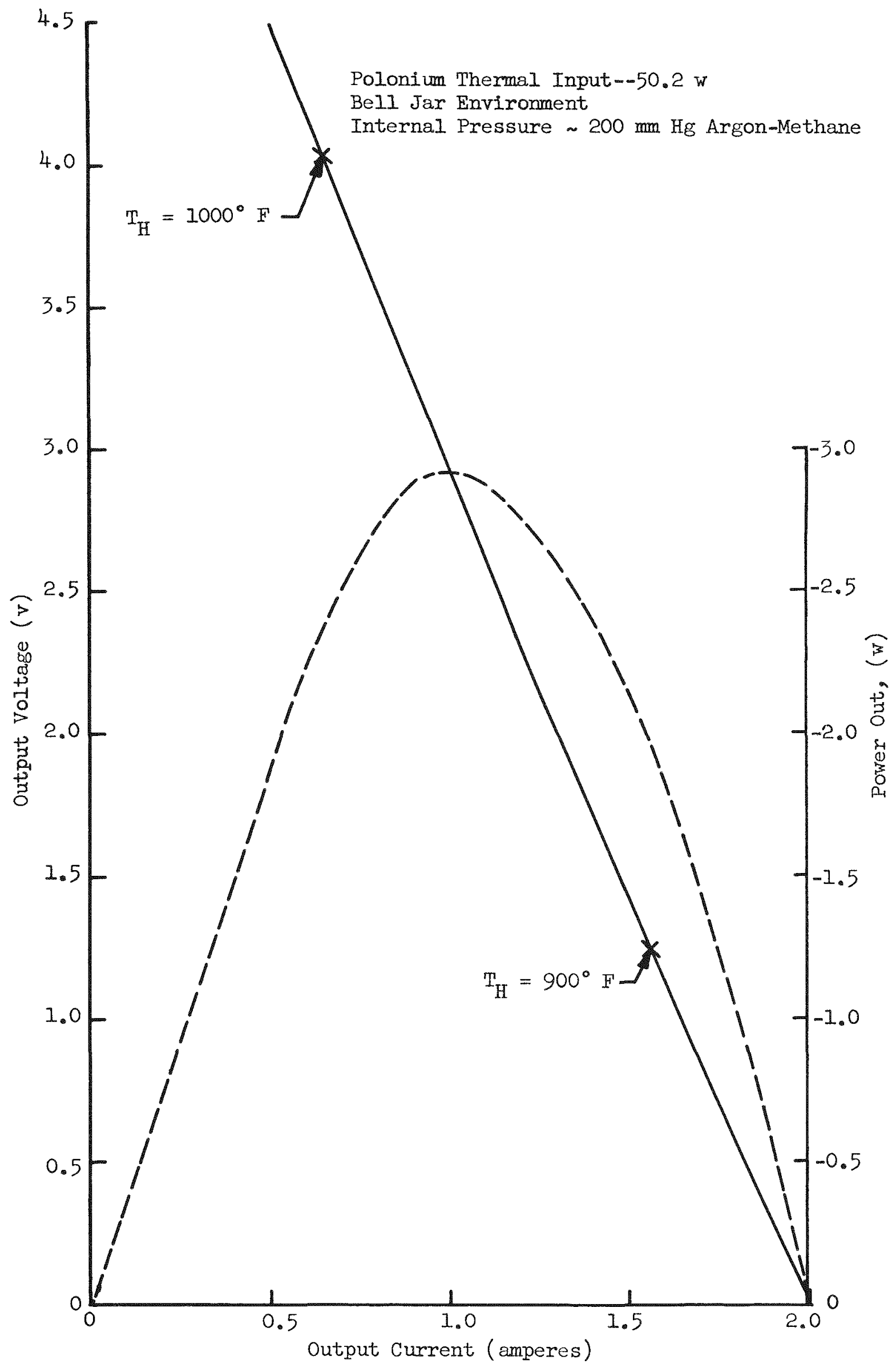

Fig. 27. Volt-Ampere and Power Output Curves for Second Po-2IO Fueled SNAP III 


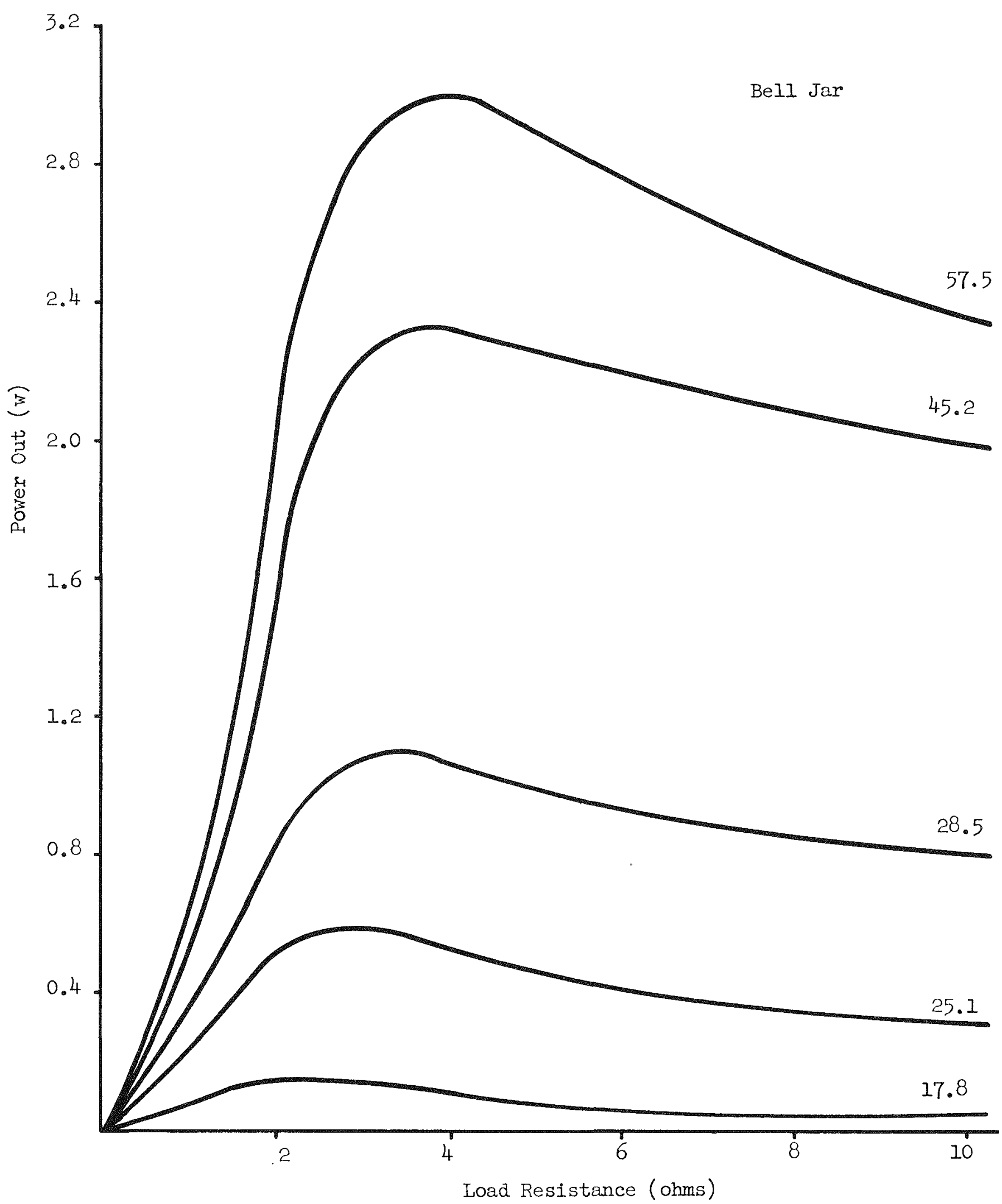

Fig. 28. Power Out vs Load Resistance Parametric in Power In (SNAP III Filled with Atmosphere 85\% He--15\% H)

\section{SECRET}

MND-P-3007 


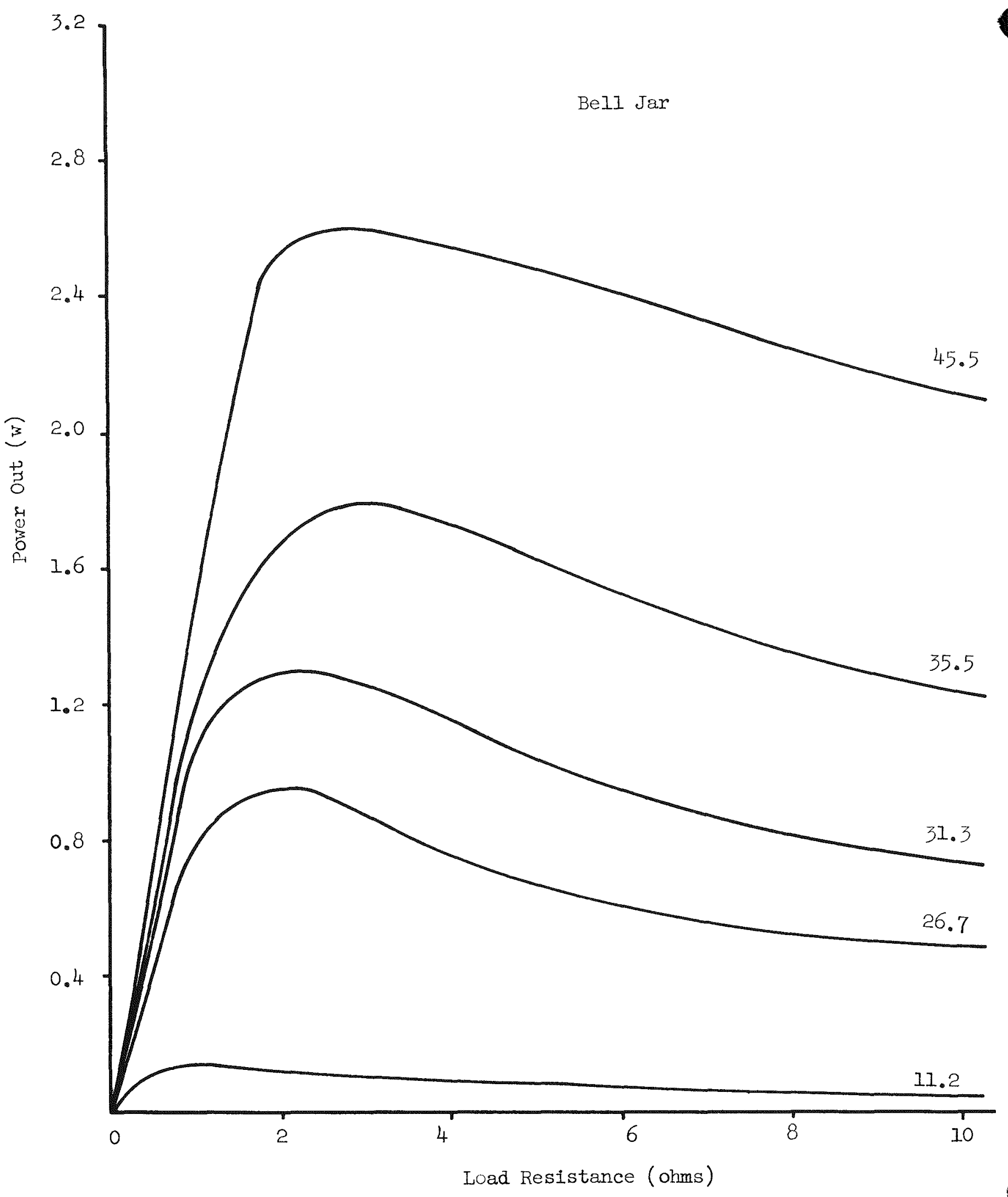

Fig. 29. Power Out vs Load Resistance Parametric in Power In (SNAP III Evacuated)

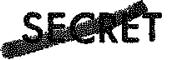

MND-P-3007 


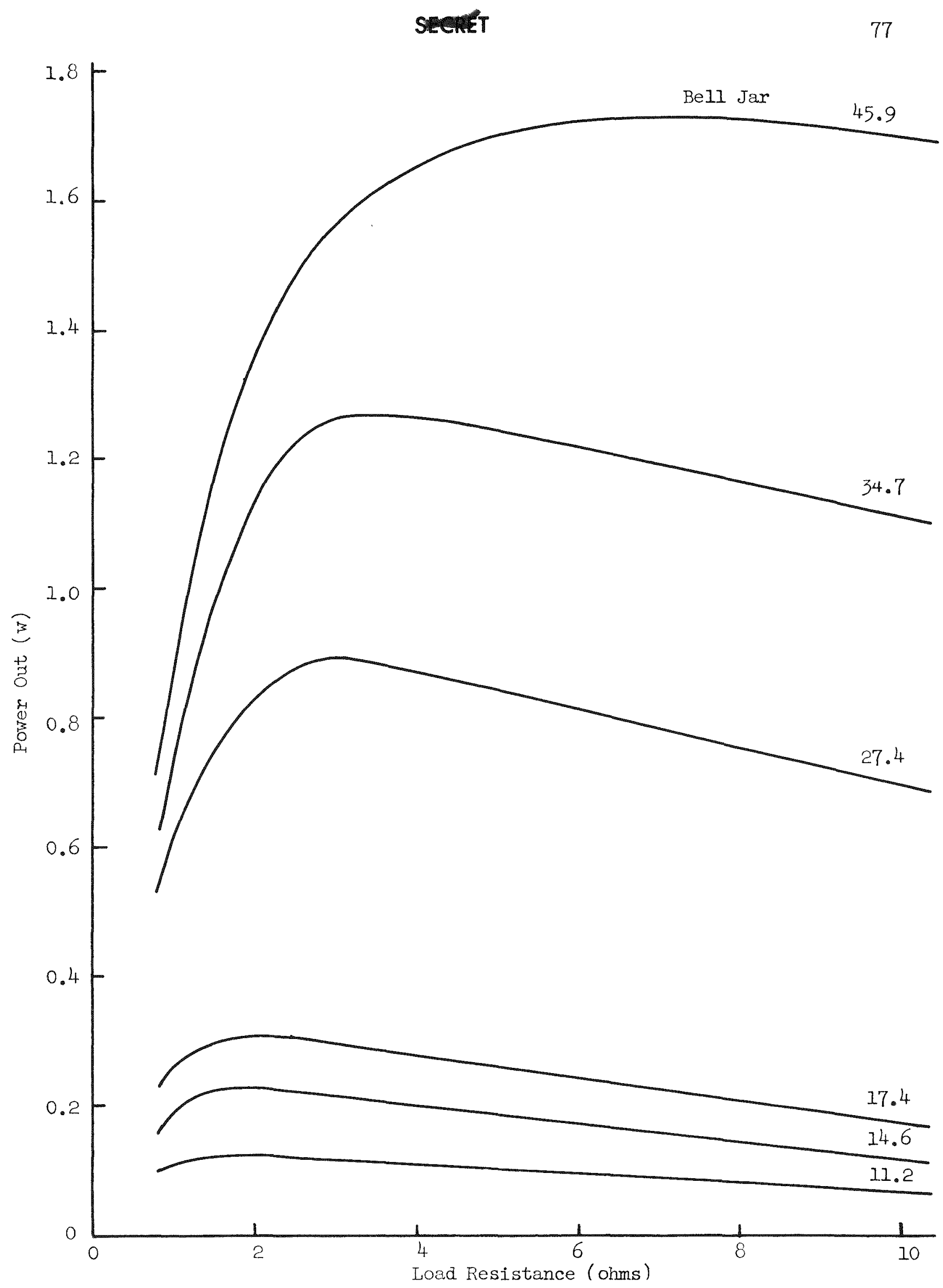

Fig. 30. Power Out vs Ioad Resistance Parametric In Power In (Low Power SNAP III with Atmosphere of 95\% A--5\% H) 


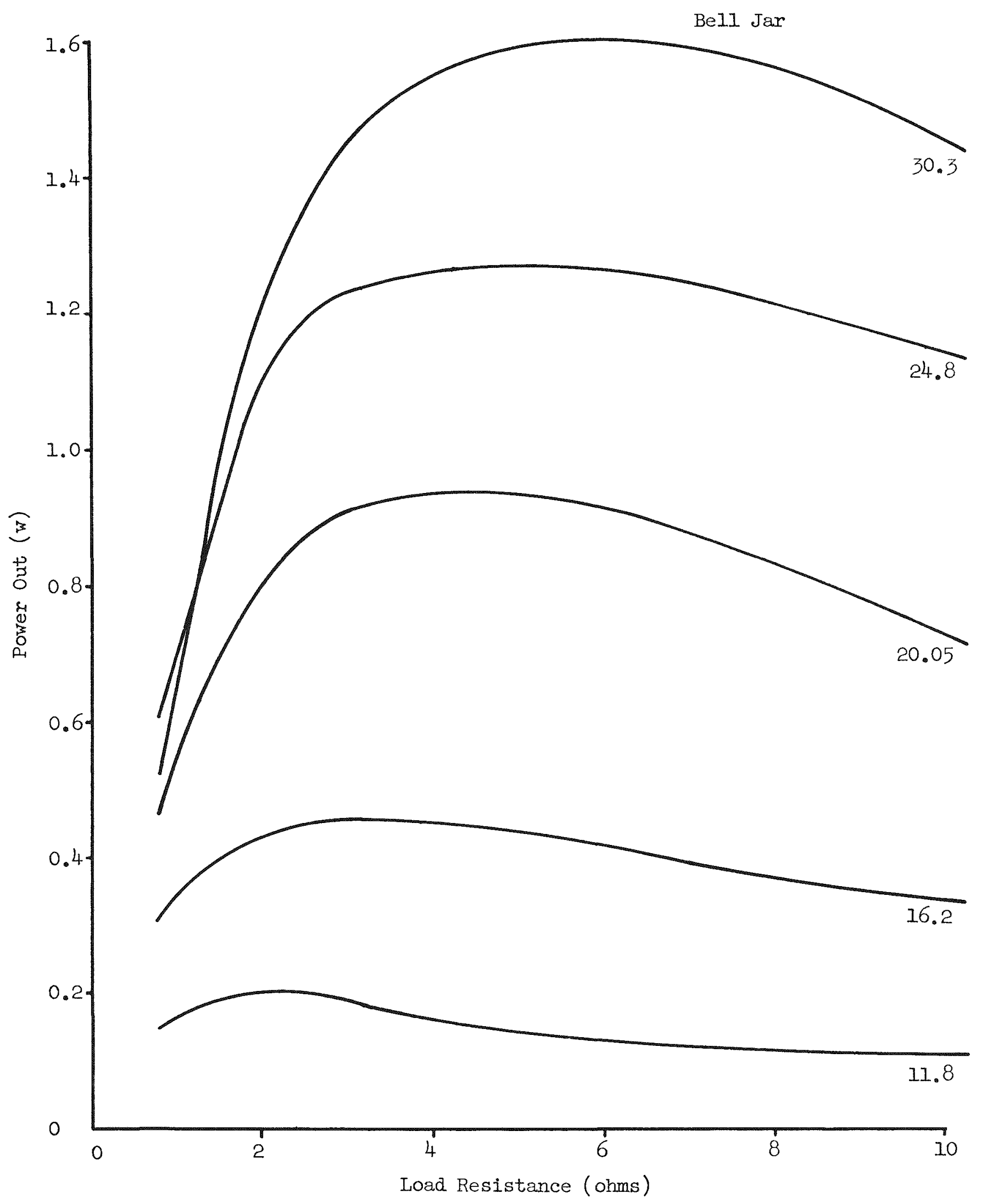

Fig. 31. Power Out vs Load Resistance Parametric in Power In (Low Power SNAP III Evacuated)

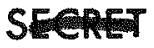

MIVD-P-3007 
for an atmosphere of reducing gas fill pressure and a constraint of $900^{\circ} \mathrm{F}$ for the evacuated condition. These values are selected to give generator lifetimes of over a year. For shorter missions both constraints could be relaxed somewhat. The reducing atmosphere not only protects the thermoelectric elements from oxidation but also decreases the sublimation rate of lead telluride.

All of these data were taken in a bell jar with the generator resting on an insulated tripod. A circuit was provided for automatically switching load resistances, and readings of load voltage, open circuit voltage, and short circuit current were taken at each equilibrium point.

For a given generator internal fill pressure condition and load resistance, a cross plot of power output versus power input with isotope power input versus time will give a good indication of the performance of SNAP III in a space environment. These data may be summarized for a given load resistance as shown in Figs. 32 and 33. These bell jar results may be compared with the room ambient data plotted in Fig. 34. Obviously, operation in a space environment seriously decreases the generator's performance. For high efficiency, the desirability of having the generator evacuated is apparent.

Radiation damage of the thermolectric material by gamma rays is being investigated. A couple similar to those in SNAP III has been irradiated for over $400 \mathrm{hr}$ in Co-60 fields of $1.6 \times 10^{5} \mathrm{r} / \mathrm{hr}$. A temperature gradient is being maintained in the test and no change in output has been observed. 


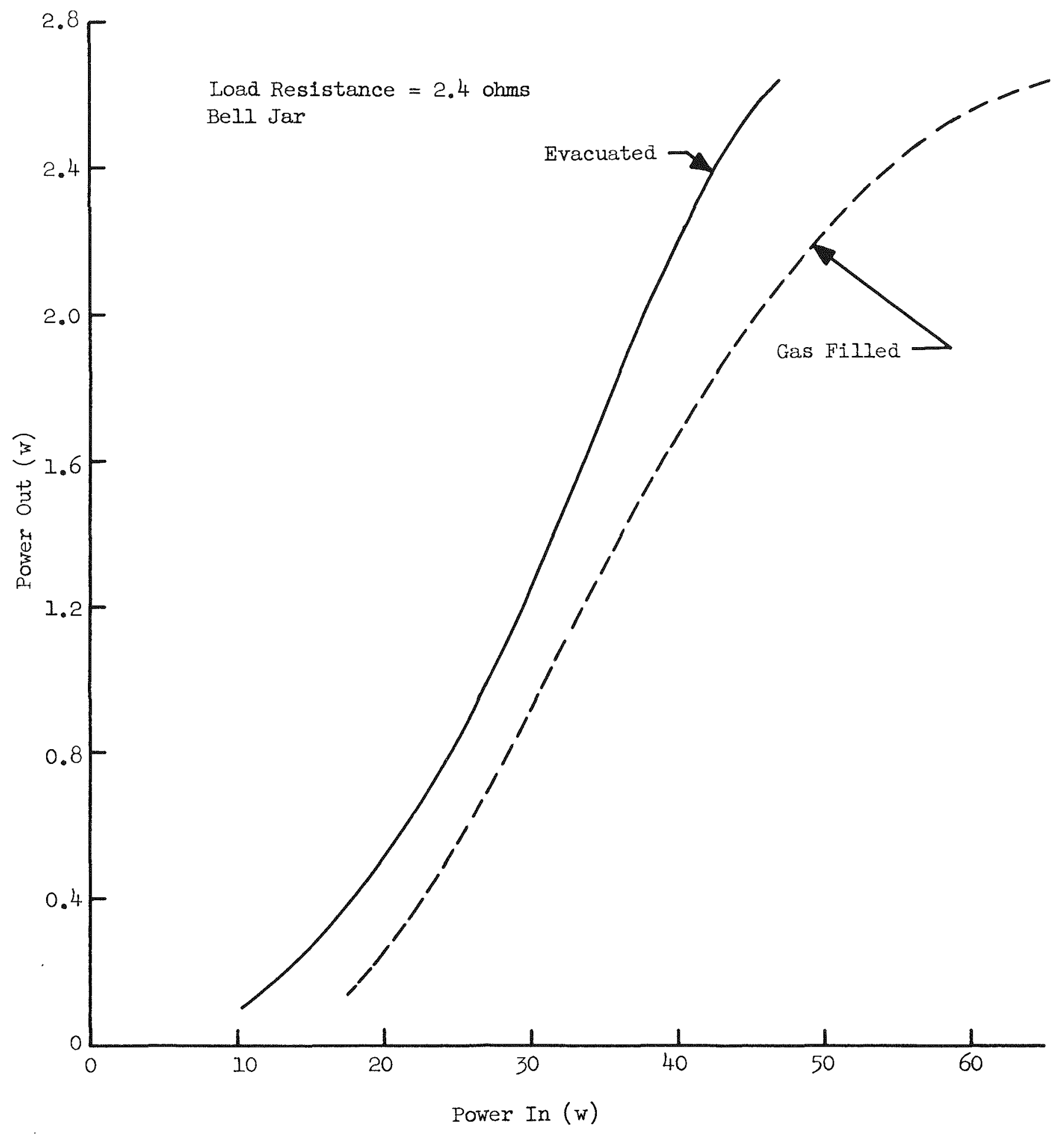

Fig. 32. Power Out vs Power In for SNAP III Evacuated and Gas Filled Conditions

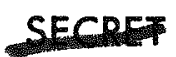

MND-P-3007 


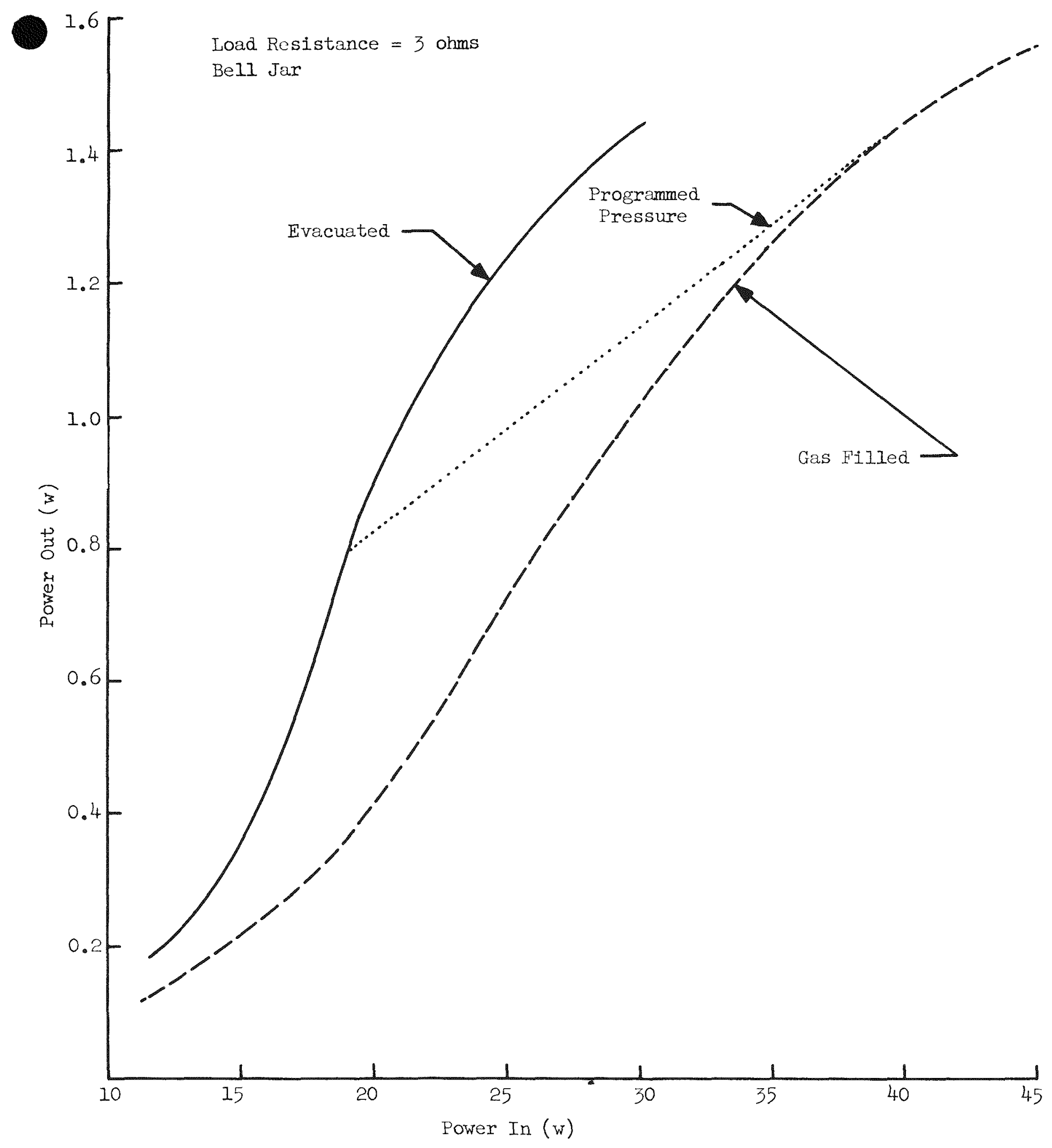

Fig. 33. Power out vs Power In for Low Power SNAP III Evacuated and Gas Filled Conditions 


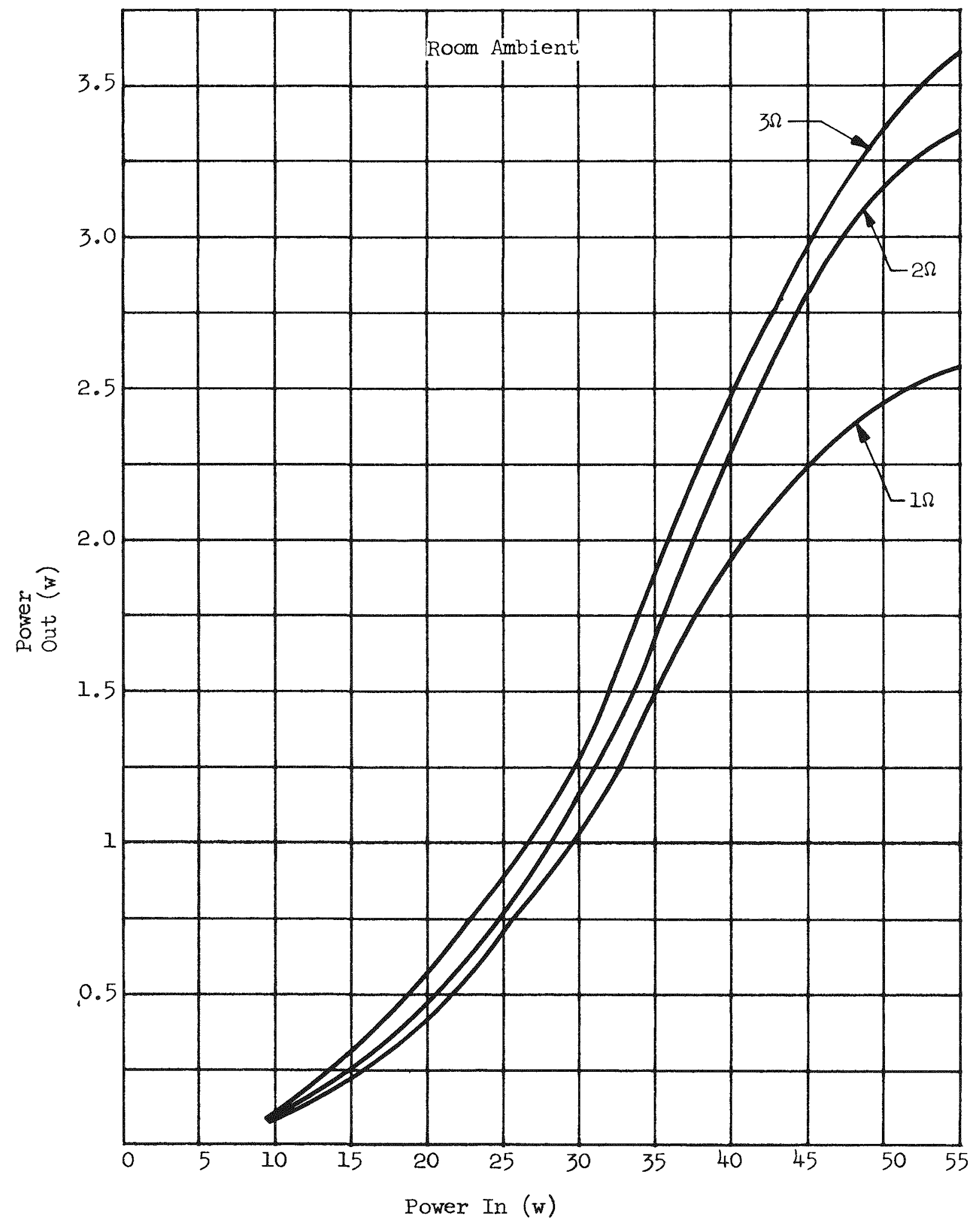

Fig. 34. Power Out vs Power In for Evacuated SNAP III 
VIII. TASK 8--GROUND HANDLIIVG AND TRANSPORTATION

A new conceptual design report, MND-P-1878, was completed. This report covers the various phases of transporting, installing and servicing the SNAP I-A fuel container. As detalled in the report, the fuel block will be loaded into a transport cask and shipped to Martin. There it will be transferred to the power conversion unit for the ground tests.

A special purpose shipping cask designed to facilitate transfer of the isotope from the cask to the power conversion unit without the use of a shielded cell and remote manipulators is shown in Fig. 35. The cask as shown is in the upright position which is the position used during shipment and handling. Trunnions are provided on each side to turn the cask over for the transfer process.

A sliding plug is provided at one end of the cask. This will permit close coupling of the cask to the power unit before opening the plug. The isotope block is supported in a cylindrical cavity by a ram rod which extends through the bottom of the cask. A coupling, similar to the quick disconnect couplings used for fluid lines, connects the block by a knob to the ram. An extension is added to the rod before the loading operation. Ioading the block into the power unit is accomplished by jacking or manually depressing the rod, forcing the block out. The coupling is released by a plunger extending through the center of the rod. A tubular coil is wrapped around the inner container. Water is circulated through the coil to cool the isotope block during the transfer operations.

The cask is designed to meet the radiation attenuation and heat transfer requirements for shipping the heat source by air. During transportation, natural convection is used to remove the heat via cooling fins placed around the outside of the container. Woods metal or other low melting point metal is used around the isotope to transfer the heat to the cask. Lead is used as a shield to minimize weight and size. The lead is completely contained in a steel shell such that if an accident or fire should occur during transportation, melting lead will not escape and the shield will be malntained.

Calculations indicate that 13 in. of lead will reduce the dose rate to approximately $10 \mathrm{mr} / \mathrm{hr}$ at $3 \mathrm{ft}$ from the center of the fuel block.

During the transfer process the power conversion unit will be positioned on a special fixture dolly as shown in Fig. 36. The dolly is used for installing the isotope block into the power conversion unit in the field for short term storage of the loaded units, and for installation of the power units in the missile. Included on the dolly are support fixtures which hold the power units containing 4000 Ib of mercury used as the biological shield. Each support fixture also supports an auxiliary mercury 


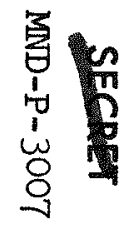

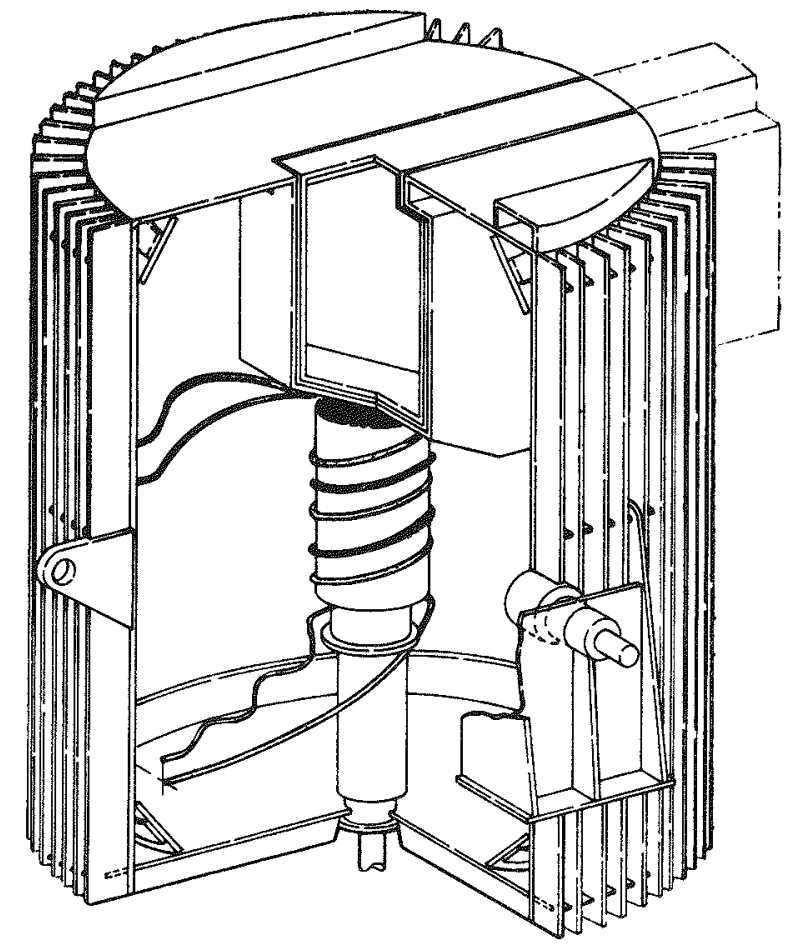

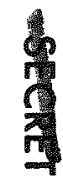



retaining shield which, in the event of a leak in the power unit shield, will maintain the mercury level above the isotope block. Adjustments are provided on the base of the fixture to permit fine alignment of the power unit with the loading fixture and with the missile structure. Motor driven jacks elevate and level the dolly. A collector pan is located under each power unit to catch spilled mercury which is drained to a sump on the servicing cart. A mercury level controller is positioned between the power units. This controls the starting and stopping of the service cart mercury pump and thereby maintains the proper level of shield mercury even if a leak develops. Since the cart is designed for short term service, quick disconnects are provided on the dolly to plug into a permanent cooling and servicing system. Four sets of double wheels are provided for transporting the power units around the base site. Each wheel set has full castering capability to facilitate alignment with the missile mating fixture.

The arrangement to be used in the field loading of the APU is shown in Fig. 37. The field loading fixtures are provided to permit transfer of the isotope block from the transport cask to the power unit without the use of a hot cell and remote handling equipment. The reverse operation can also be accomplished with this equipment. A structural steel stand supports the quick change cask in an inverted position and the power unit dolly is positioned under a cask. A split tank or collar shield is bolted on between the cask and power unit and filled with mercury. During the loading operation this shield provides full shield thickness for the isotope as it passes from the cask to the power unit. Prior to transferring the isotope, an extension rod is added to the ram which extends through one end of the cask, the heat transfer medium is drained, and the sliding plug opened. The isotope is lowered into the mercury filled power unit and locked in place.

Mating of the loaded APU and the nose cone will be accomplished as shown in Fig. 38. A nose cone is shown in a vertical position on a support fixture with the rocket engine and nozzle extending below the platform. Clearance below the platform is provided for moving the power unit dolly under the vehicle structure. There, the power units are jacked into mating position, final adjustments are made with hand cranks provided on the support dolly, and the power conversion units are bolted onto the vehicle. When servicing and electrical Iines are attached, the complete missile assembly is ready to be hoisted by crane and fitted to the top of the missile.

Production drawings are nearing completion on the quick change field loading cask, the isotope transfer mechanism and a gimbal fixture to support and rotate the power conversion unit during the radiation spectrum measurements. These items should be completed early in the next quarter. 


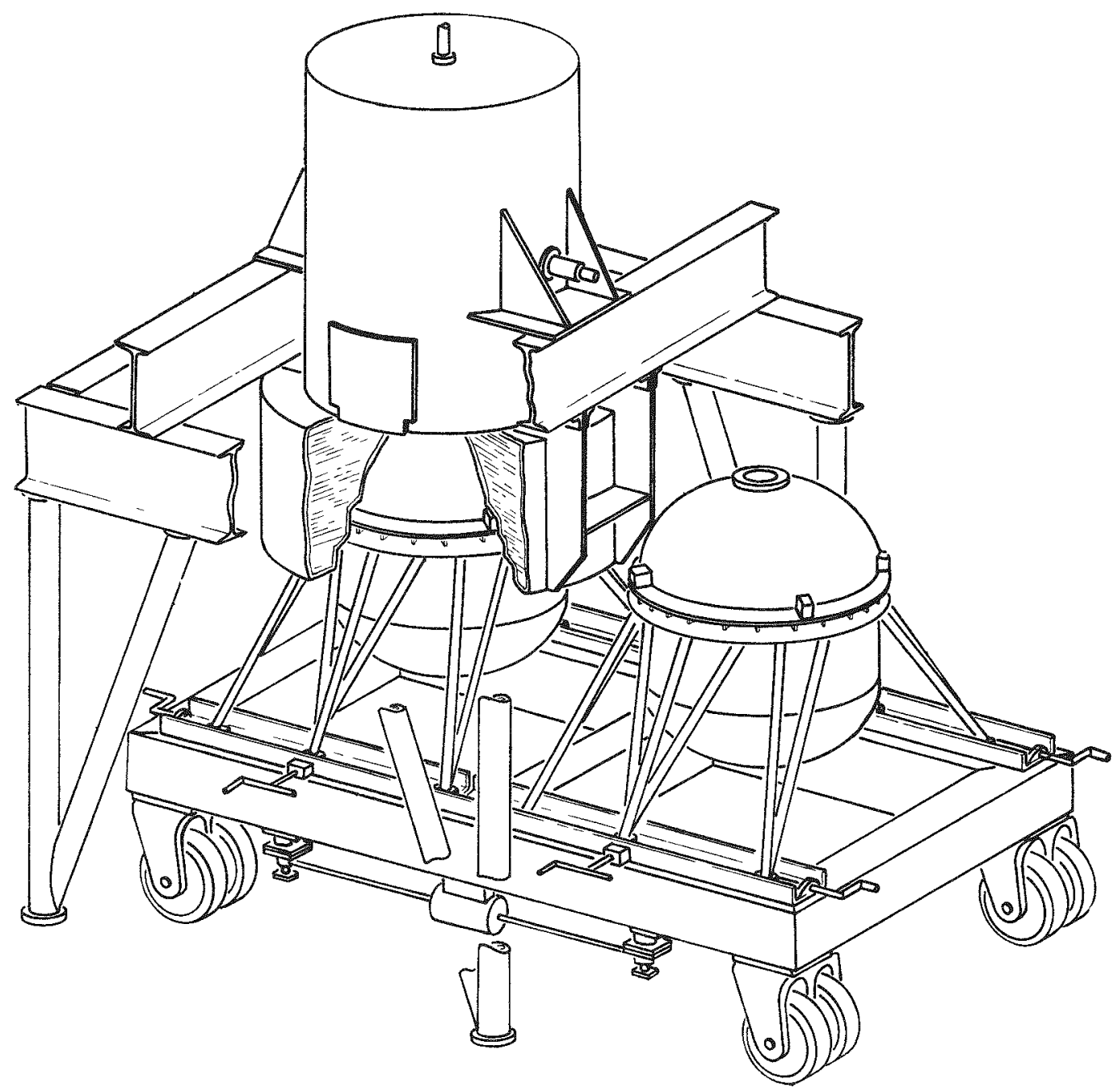

Fig. 37. Field Loading of APU 


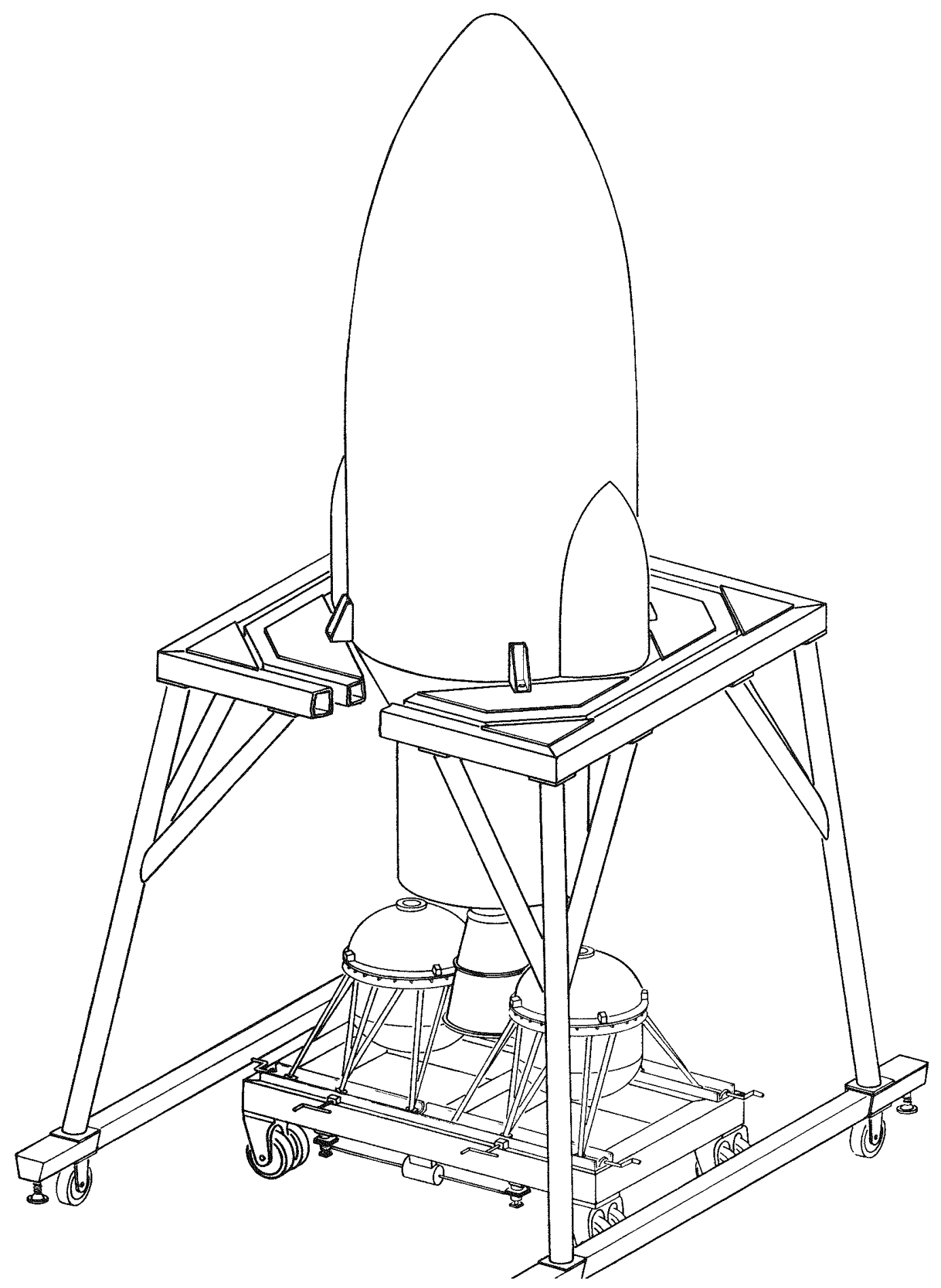

Fig. 38. Mating of Loaded APU and Nose Cone

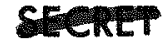

MND-P-3007 
Work resumed on the construction of equipment mockups for space requirements and handling procedures testing. Mockup drawings are being revised to agree with the latest conceptual changes.

The dose rates for emergency situations occurring while the handling and loading operations are in process were calculated. For the calculations, it was assumed that the primary mercury shield had ruptured and the mercury had drained into the outer auxiliary retaining shield such that the molybdenum fuel block was covered with only $1 / 2$ in. of mercury.

At one meter directly above the center of the block with the tungsten shield removed, the calculated dose rate was $4700 \mathrm{r} / \mathrm{hr}$. Dose rates due to air scattering at one meter from the center of the block along the horizontal center line under these conditions were calculated by three different approximate methods. Values of $3.7,2.4$ and 0.67 $\mathrm{r} / \mathrm{hr}$ were obtained. The first and last values listed may be considered as upper and lower limits, respectively.

It is apparent that upon rupture of the primary mercury shield, operating personnel can approach the unit only if they maintain positions below the mercury level of the unit. 


\section{SEERET}

MND-P-3007 
IX. TASK 9--THERMIONIC CONVERSTON SYSTEM

\section{A. SNAP III $=\mathrm{C}$}

All machined parts for six single-stage prototypes (three for $50 \mathrm{w}$ / cu in. isotope and three for $50 \mathrm{w} / \mathrm{cc}$ isotope) have been completed. One unit has been assembled and tested in a bell jar. The electrical output was a factor of three under that for which the converter was designed. A poor thermal hond from the collector to the casing resulted in a high collector temperature and excessive back emission. The unit is being reworked to correct this condition.

Problems of evacuation tube seal-off and casing and base plate design for a vacuum seal are being investigated.

High temperature electrical lead-throughs have been designed. Ieadthroughs from other compantes have been tested.

The ablifty of the collector to remain activated will be measured by measuring emission current versus time for a number of collector materials. No emitter is present so that the collector characteristics will be measured with no effect due to deposition of barium or barium oxide from the emitter. The work function has been related to emission current by RIchardson's equation. The tubes used are sealed diodes made by the cathode manufacturers.

Tests of Type $B$ cathodes at close spacing indicate considerable drift of the collector work function with time. It appears that barium or barium oxide from the emitter accumulates on the collector. The collector work function increased from 1.8 or 1.9 to about $2.2 \mathrm{v}$. At $2.2 \mathrm{v}$, the anode work function remained constant. The work function of pure barium is $2.2 \mathrm{v}$.

Two remedies are being tested. Emission of barium decreases exponentially with time. Aging the emitter for several hours before assembly may eliminate the problem. Also, running the collector at higher temperatures may reduce the concentration of condensed barium.

Activation at close spacing was accomplished earlier in the contract period. Tests will be made with regard to the effect of a dry, inert atmosphere on the cathodes after activation. These tests are of interest because it is planned to ship and load the isotope into the converter in a dry, inert gas, probably argon.

Cursory tests using cesium in the diode have shown marked improvement in converter performance. A cesium tube for the use of many types of emitters and collectors has been designed. Tests of this tube will be begun soon. 
The technical aspects of loading the two-stage prototype with $\mathrm{Ce}-144$ has been discussed with Oak Ridge National Laboratory.

The cerium pellet will be welded into a molybdenum capsule. The Martin Company is responsible for developing the adequate remote weldIng technique to be used.

It is planed to complete the cerlum loading by mid-November.

\section{B. SNAP III-D}

Work on reducing the emftter-collector spacing was continued. Short circuit currents of 0.25 amp have been achieved. Experimental tubes using both mesh and solid collectors have been bullt. Activation of emitter and collector are far superior with the mesh collector. Addition of cesium vapor did not substantially improve the tube performance. The emitter temperature was probably too low to give appreciable lonfzation. 
X. TASK 11--LOWER POWERED OPERATIONAI SNAP III-F

A. VEHICLE INTEGRATION

\section{Generator Requirements}

Integration discussions have been initiated with personnel at Lockheed Missile Systems Division and Jet Propulsion Laboratory. AIthough neither requirement is firm, preliminary generator specifications were established.

Lockheed Missile Systems Division

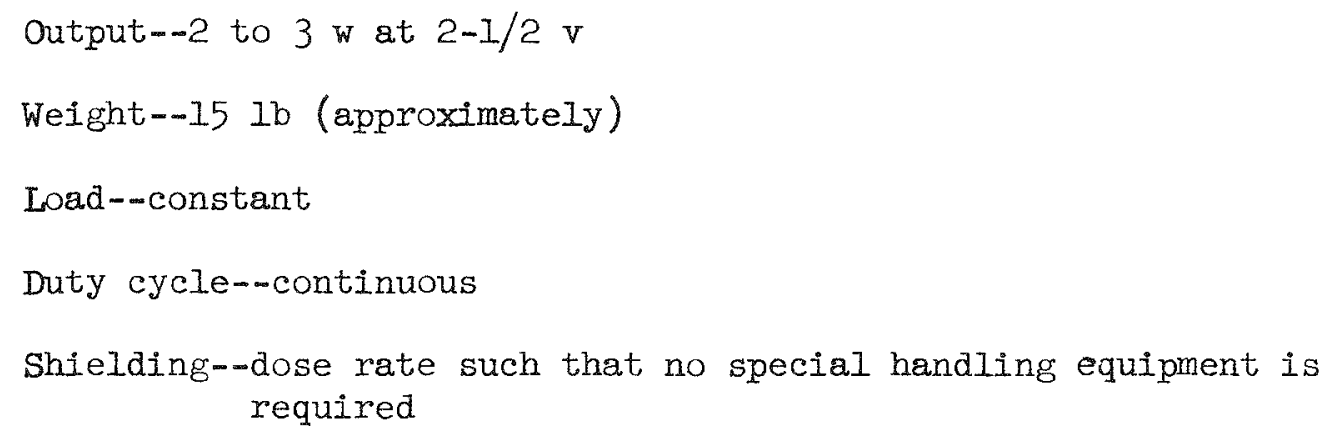
by LMSD.

The shielding requirement that no special handling equipment be required is very optimistic and would severely limit the choice of radioisotope heat source that could be used.

Although LMSD indicated that the mounting and heat sink would be provided, a possible alternate installation was devised using direct radiation to space. In this installation it was assumed that the radiation characteristics of the isotope fuel were such that the shielding required could be incorporated within the generator structure. The generator is located in the aft portion of the booster adapter area of the vehicle at Frame Station 446.7. Figure 39 shows the configuration of the Lockheed nose cone and adapter mated to an Atlas booster as in the Sentry Program. No re-design is necessary if a Thor booster is substituted for the Atlas booster as in the Discoverer Program. In this 


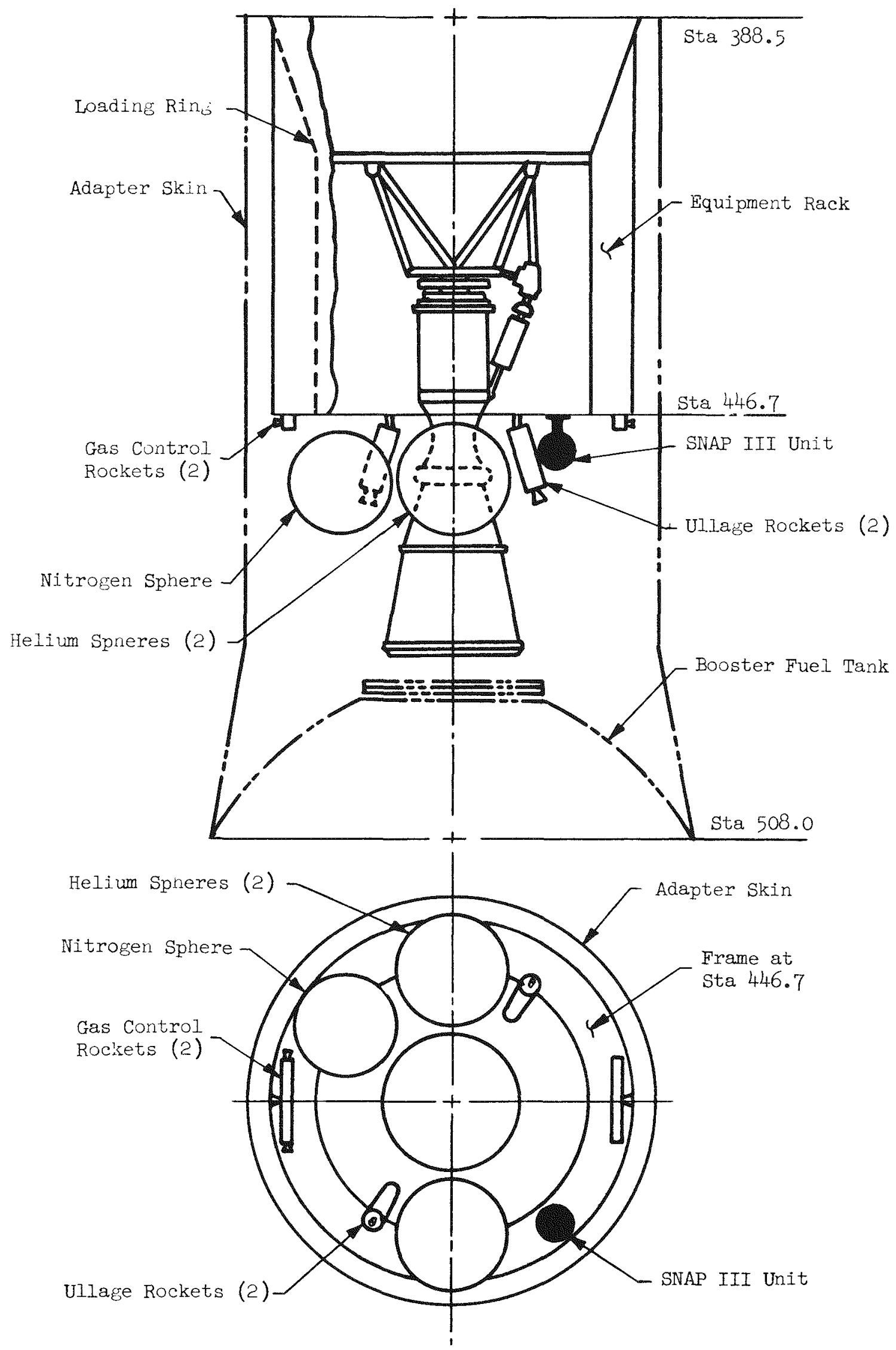

Fig. 39. Booster Adapter Configuration

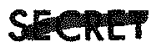


position the thermoelectric unit can be mated to the adapter prior to hoisting the assembly into position atop the booster, causing little if any interference with ground handling or static test firing of the vehicle.

The unit is remotely located from any component of the vehicle that could have a temperature effect on the outer skin of the generator. As shown in Fig. 39, the unit is located above the exhaust nozzle of the rocket engine and ullage rockets but below the nozzles of the gas control rockets. During orbital flight, the temperature of the mounting structure was assumed to be the same as or lower than that of the unit.

To be readily accessible for attachment, the unit is connected directly below the structural members in the adapter. An access door built into the adapter skin provides a quick means of removing the unit from the vehicle after the adapter is mated to the booster on the launch pad. A hand disconnect for electrical leads can be provided for quick installation and removal of the generator.

The generator can be attached to the adapter structure by means of a tube welded to the unit with a flange at one end for bolt attachment to the frame. Design criteria for the tubular structure is eight g fore and aft load with two $g$ side loading. With the unit supported as shown, the eight $g$ compression load is critical when combined with the cantilever effect produced by the two g side loading. A tubular structure is the most efficient as it presents an adequate cross-sectional area for the compression load and a large section modulus for the cantilever side load.

Jet Propulsion Laboratory

Output -13 w at $3 \mathrm{v} \min$

Weight--15 Ib (approximately)

Load--constant

Duty cycle--continuous

Shielding--not firmly established

Environment--per previous specification (Vega Vehicle)

Converter--not firmly established

Countdown--plug-in type unit

Installation--payload configuration. Not firmly established. Heat sink would be direct radiation to space.

Operational life--150 hr (approximately). 
Although the shielding requirements were not firmly established at this time, the radiation tolerances will be very low due to cosmic radiation counting experiments included in the payload. The source of the converter was indefinite but it was suggested that it be included in the program as a distinct cost item for evaluation. Health physics monitoring on the pad by Martin personnel will be required.

2. Ground Handling

Ground handling studies were started on a limited basis. Due to the variety of isotope fuels considered, the handling requireinents vary over a wide range. Therefore, the studies have been limited to preliminary concepts only and no definitive results will be possible until the fuel is selected.

\section{Hazards and Shielding}

For space applications of radioisotope fueled auxiliary power units, the principal environmental hazard is that imposed by the toxicity of the radionuclide fuel when released to the biosphere. Aside from the direct radiation hazard which is attenuated by shielding, the radioisotope employed must be contained under any concelvable condition, operational or accidental, so long as its environment is the biosphere.

Absolute containment is achieved by establishing a framework of conditions to which the particular device will be subject. Once these conditions are established, the most stringent in terms of internal and external mechanical, thermal, and chemical forces, define the design criteria. These extreme conditions include handling accidents, missile vehicle failures, and re-entry through the atmosphere and subsequent earth impact. If the device is designed for the most stringent frame of conditions conceivable, it is certain that containment will be achieved under all conditions imposed.

Handling accidents include the mishanding of the APU, free fall impact from an aircraft crash in transit, fall from the missile vehicle to the launch pad, fires, and natural phenomena.

Rocket vehicle failures can be divided into two groups: launch pad failures and in-flight failures. The launch pad failure would result in the complete destruction of the missile where the APU would experience

(1) mechanical impact, shock waves, and impact of accelerated fragments, (2) thermal stress, shock, and energy input, and (3) chemical attrition by the fuel and oxtdizer of the booster vehicle. For vehicle failure above $100,000 \mathrm{ft}$ moderate aerodynamic heating and high velocity impact forces would be imposed upon the APU. 
The re-entry or post-orbit conditions imposed upon the APU include intense aerodynamic heating, and high velocity impact. In this respect several alternatives may be presented for the post-orbit fate of the APU including (1) burn-up by aerodynamic heating and oxidation, (2) intact contained re-entry, (3) destruct in orbit, and (4) prolongation of orbital Iffetime. Of the above alternatives only (I) and (2) apply with certainty according to the present state of the art.

Burn up is achieved by aerodynamic heating and oxldation of the incoming APU which enters the earth's atmosphere at a high velocity. The radioisotope must be capable of being dispersed in fine particles (several microns) so that the residence time of the radionuclide beyond the biosphere will resolve the hazard by natural decay.

Intact re-entry and earth impact is accomplished by using ablative or heat absorbing materials to combat aerodynamic heating and by utilizing high strength high temperature containment materials for impact. For small source strengths, a contained source presents a relatively minor radiation hazard even when impacting on a land mass.

Detailed data will be available when the following reports are released:

$$
\begin{aligned}
& \text { MND-1963--Preliminary Hazards Evaluation of a Curium-242 Auxiliary } \\
& \text { Power Supply }
\end{aligned}
$$

MND-P-2047--Hazards Summary Report for a Three-Watt Polonium-210 Fueled Thermoelectric Generator

MND-P-2048--Hazards Summary Report for a Two-Watt Strontium-90 Fueled Thermoelectric Generator

MND-P-2049--Hazards Summary Report for a Two-Watt Promethium-147 Fueled Thermoelectric Generator.

A summary of the radiation levels, shielding requirements, and a discussion of the post orbit hazards derived from these reports are included here for purposes of isotopic fuel comparisons. The generator configurations are described and illustrated in section $C$ of this task.

Radiation levels.- The radiation levels around the various heat sources differ greatly in the intensity, type and energy of the radiation. These levels are dependent not only on the characteristics of the radiation emitted but also on the intermediate reactions that occur. Pure alpha-emitter sources, such as $\mathrm{cm}-242$, produce limited quantities of neutron radiation as a result of $(\alpha, n)$ reactions within the source and spontaneous fission. Pure beta-emitters, when contained in materials of high atomic number ( $\mathrm{Z}$ ), produce X-rays (bremsstrahlung) as the electrons are slowed down in the source and container materials. Isotopes with direct gamma emission provide the greatest external radiological hazard. All dose rates given in thls section are based on the radiation level at time of launch. 
The strontium-90 APU produces bremsstrahlung photons due to the steel and tungsten container surrounding the fuel. As reported in MND-SR-1672 and 1673 , measurements of the bremsstrablung radiation were made with a 100 channel pulse height analyzer with a millicurie source of Sr-90. Beta attenuation in a srB6 pellet produced radiation in the low kev range, while attentuation in the molybdenum cladding produced radiation in the $1.5 \mathrm{mev}$ range. The bremsstrahlung spectra was sufficient to obscure a $1.73 \mathrm{mev}$ gamma ray peak emitted in approximately $0.02 \%$ of the decays of Yttrium-90. Based on extrapolation of the best available data, an 8300-curie source encapsulated in steel and tungsten would have a dose rate of $1.6 \mathrm{r} / \mathrm{hr}$ at a distance of $3 \mathrm{ft}$ with no additional shielding.

The Promethium-147 source emits low energy beta particles, which produce bremsstrahlung of low energy and intensity. The dose rate due to the $1.66 \times 10^{5}$ curies of Promethium-147 is less than $1 \mathrm{mr} / \mathrm{hr}$ at $3 \mathrm{ft}$ from an unshielded source encapsulated in Hastelloy C. Available promethium, however, may contain Promethium-148 as an impurity, which emits several gammas with an average energy of $0.7 \mathrm{mev}$. Oak Ridge National Laboratory measurements give the impurity level of Promethium-148; as $3.6 \mathrm{mc}$ per curie of Promethium-147 in material separated from 14-mo-old fission products. The dose rate at $3 \mathrm{ft}$ from the unshielded 14-mo-old APU source is $6.15 \mathrm{r} / \mathrm{hr}$. At the time of launch, the 43 -day old $\mathrm{Pm}-148$ has decayed so that the dose rate is then $3.75 \mathrm{r} / \mathrm{hr}$.

Radiation levels around the Polonium-210 APU are estimated on the basis of measurements made on the SNAP III demonstration unit. Gammas of energy $0.803 \mathrm{mev}$ are emitted in $1.2 \times 10^{-3} \%$, of the decays of Polonium-210; the gamma dose rate is $16 \mathrm{mr} / \mathrm{hr}$ at $3 \mathrm{ft}$ from the center of the 1570-curie APU source. Fast neutrons are produced by $(\alpha, n)$ reactions with impurities in the fuel or the container. The neutron flux at $3 \mathrm{ft}$ from the center of the source is $7 \mathrm{n} / \mathrm{cm}^{2}-\mathrm{sec}$; if it is assumed that the effective neutron energy is $4.5 \mathrm{mev}$, the dose rate is $1.0 \mathrm{~m} \mathrm{rem} / \mathrm{hr}$. The total dose rate is $17 \mathrm{~m} \mathrm{rem} / \mathrm{hr}$.

The Curium-242 source decays by alpha emission to Plutonium-238. A few of the transitions are to higher excited states of Plutonium-238, which decay to the ground state by gamma emission. If allowance is made for absorption of these gammas in the source material, the gammas contribute $2.86 \mathrm{mr} / \mathrm{hr}$ to the dose rate at $3 \mathrm{ft}$ from the center of the 2734-curie source. Curium-242 also undergoes spontaneous fission, emitting gammas and neutrons. The spontaneous fission gamma ray dose rate is $2.54 \mathrm{mr} / \mathrm{hr}$ at $3 \mathrm{ft}$ from the APU; the spontaneous fission neutron dose rate is 31.5 m rem/hr. The alphas emitted by Curium-242 produce neutrons by means of the reaction $0^{16}(\alpha, n) \mathrm{Ne}^{19}$ in the oxygen in $\mathrm{Cm}_{2} \mathrm{O}_{3}$; these neutrons contribute $21.5 \mathrm{~m} \mathrm{rem} / \mathrm{hr}$ to the dose rate at $3 \mathrm{ft}$. The total dose rate at $3 \mathrm{ft}$ from the center of the unshielded source, is $58.3 \mathrm{~m} \mathrm{rem} / \mathrm{hr}$. 
Shielding requirements.- If no biological shielding is provided, other than that afforded by the fuel itself, the cladding, graphite, and outer container, the strontium and promethium APU will have radiation environments sufficiently high to present problems in handling. While weight limitations prevent the inclusion in the APU of sufficient shielding to reduce the dose rates at $3 \mathrm{ft}$ to tolerance levels, it is possible to reduce the dose rates considerably, thus simplifying the handling procedures.

Tungsten was chosen as the shielding material for the strontium-90 source. It is desirable to use a dense material with a high atomic number as a gamma shield. An alloy such as Mallory 1000 (90\% tungsten) has very good tensile strength and impact resistance, compared to other gamma shielding materials such as lead. Its very high density permits a slight weight saving compared to an equivalent lead shield. The maximum thickness of tungsten permitted by limitations of the APU weight is $0.64 \mathrm{~cm}$ (0.25 in.); the tungsten shield is located immediately outside the Hastelloy $C$ cladding. This shield, together with the Hastelloy $\mathrm{C}$ and other materials surrounding the source, reduces the dose rate at $3 \mathrm{ft}$ from the center of the source to $0.9 \mathrm{r} / \mathrm{hr}$.

In the interest of weight conservation, no biological shield as such has been provided in the promethium APU. In this case, special handling procedures have been accepted rather than a weight increment. If a tungsten shield $1 \mathrm{~cm}$ ( 0.40 in.) was introduced in place of the molybdenum container, the dose rate at time of launch would be $1.3 \mathrm{r} / \mathrm{hr}$ at $3 \mathrm{ft}$ from the center of the source (14-mo promethium at time of preparation). The weight penalty is $4.91 \mathrm{~b}$.

To comply with Government regulations, any of the sources must be shipped in a container such that the dose rate at one meter from the center of the source is $10 \mathrm{~m} \mathrm{rem} / \mathrm{hr}$ or less. To meet this requirement, shielded shipping containers must be provided. For economy, lead is chosen as the gamma shield material in the containers. The lead thicknesses required are: Strontium-90, 4 in.; Promethium-147, 14-mo, freshly prepared, no tungsten, 3.6 in.; Polonium-210, 0.4 in.; Curium-242, none. The neutron dose rate due to the Polonium-210 source is too low to require shielding if the ganmas are sufficiently attenuated.* The Curium242 APU neutron dose rate is reduced to $6 \mathrm{mr} / \mathrm{hr}$ at $1 \mathrm{~m}$ by $5 \mathrm{in}$. of borated water; the gamma flux then need not be attenuated.*

The results presented in this section are summarized in Table 12. A comparison of activity versus time is shown by Fig. 40.

The Krypton-85 generator described in Section $\mathrm{C}$ of this task was examined but no radiation or hazards study was made. However, $\mathrm{Kr}-85$ is the best suited for re-entry burn-up of the isotopes considered.

* We have neglected gamma attenuation in neutron shields and vice versa. 


\section{TABLE 12}

Radiation Levels and Shielding Requirements

\begin{tabular}{|c|c|c|c|c|c|c|}
\hline Isotope & Curies (a) & Radiation (b) & $\begin{array}{l}\text { Unshielded Dose } \\
\text { Rate (c) } \\
\end{array}$ & Shield & $\begin{array}{l}\text { Shielded } \\
\text { Dose Rate (c) }\end{array}$ & $\begin{array}{l}\text { Shield for } \\
\text { Shipment (d) }\end{array}$ \\
\hline $5 r-90-Y-90$ & 8300 & Bremsstrahlung & $1.6 \mathrm{r} / \mathrm{hr}$ & $0.25 \mathrm{in.}$ & $0.9 \mathrm{r} / \mathrm{hr}$ & 4 in. lead \\
\hline$P m-147-P m-148$ & $1.66 \times 10^{5}$ & Gammas & $3.75 \mathrm{r} / \mathrm{hr}(\mathrm{e})$ & $0.4 \mathrm{in}$. & $1.3 \mathrm{r} / \mathrm{hr}$ & 3.6 in. Iead \\
\hline Po-210 & 1570 & Gammas & $17 \mathrm{~m} \mathrm{rem} / \mathrm{hr}$ & None & $17 \mathrm{~m} \mathrm{rem} / \mathrm{hr}$ & $0.4 \mathrm{in.}$ lead \\
\hline$c m-242$ & 2734 & Neutrons & $58 \mathrm{~m} \mathrm{rem} / \mathrm{hr}$ & None & $58 \mathrm{~m} \mathrm{rem} / \mathrm{hr}$ & $\begin{array}{l}5 \text { in. borated } \\
\text { water }\end{array}$ \\
\hline
\end{tabular}

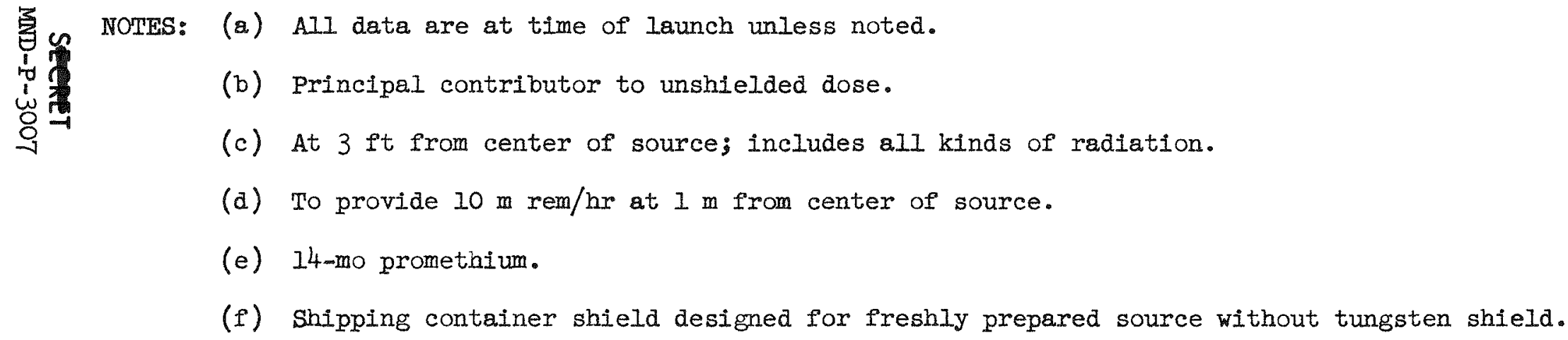




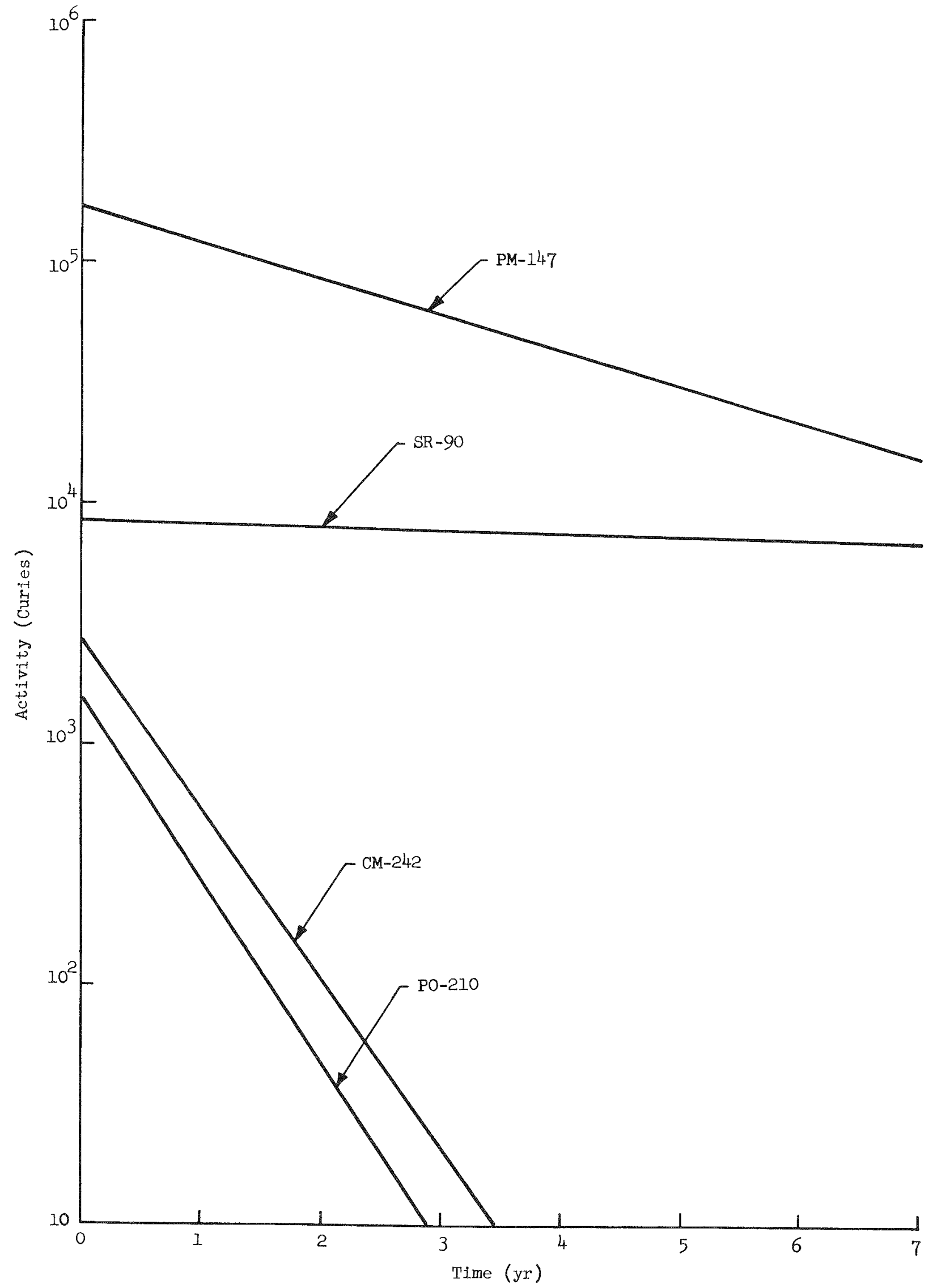

Fig. 40. Decay of Radioisotope Fuels

\section{SEGRET}

MND-P-3007 
Post-orbit hazards.- Several alternatives may be considered for the post-orbit fate of the APU. The most logical considerations are burnup by aerodynamic heating and intact impact on the earth's surface.

The radiological hazard of the APU during this post-orbit phase of operation can be analyzed by considering the consequences of dispersing the isotope at a high altitude and by establishing the probability of the unit hitting a populated area on the earth's surface. Dispersion of the isotope would result from the burn up or in-orbit destruction of the unit. Impact probabilities are necessary to evaluate the hazard of a situation resulting from the release of the isotope near or on the surface of the earth upon re-entry.

The following is a discussion on the parameters that determine the radioactive fallout and impact probabilities. The radioactive fallout is based on the dispersion of the isotope at burnup and orbital altitudes. The impact probability is based on the unit re-entering the atmosphere from an orbital path over the earth's north and south poles.

The average altitude for burnup of an APU re-entering from an orbit is estimated to be $150,000 \mathrm{ft}$. The proposed satellite orbit is $300 \mathrm{mi}$ or $1.58 \times 10^{6} \mathrm{ft}$. Contamination below $70,000 \mathrm{ft}$ is not desired; therefore, when considering isotope dispersion, it would be desirable for the fallout rate and the isotope decay to be such that the radiological dose rate is tolerable at $70,000 \mathrm{ft}$.

The flilout time with respect to altitude is a function of the particle diameter, density and drag coefficient, as well as the fluid density and fluid viscocity. Figure 41 shows the fallout time of various particle sizes from one micron diameter to 32 micron diameter. The plot is based on the empirical equation

$$
t=\frac{a}{k_{s} d^{2} \frac{\left(\rho-\rho_{0}\right)}{\mu}}
$$

where

$$
\begin{aligned}
& t \text { - time, sec } \\
& \text { a - altitude, cm } \\
& \text { d - particle diameter, } \mathrm{cm} \\
& \rho \text { - particle density, } \mathrm{gm} / \mathrm{cc} \\
& \rho_{0} \text { - fluid density, } \mathrm{gm} / \mathrm{cc} \\
& \mu \text { - absolute viscosity of fluid, poises }
\end{aligned}
$$




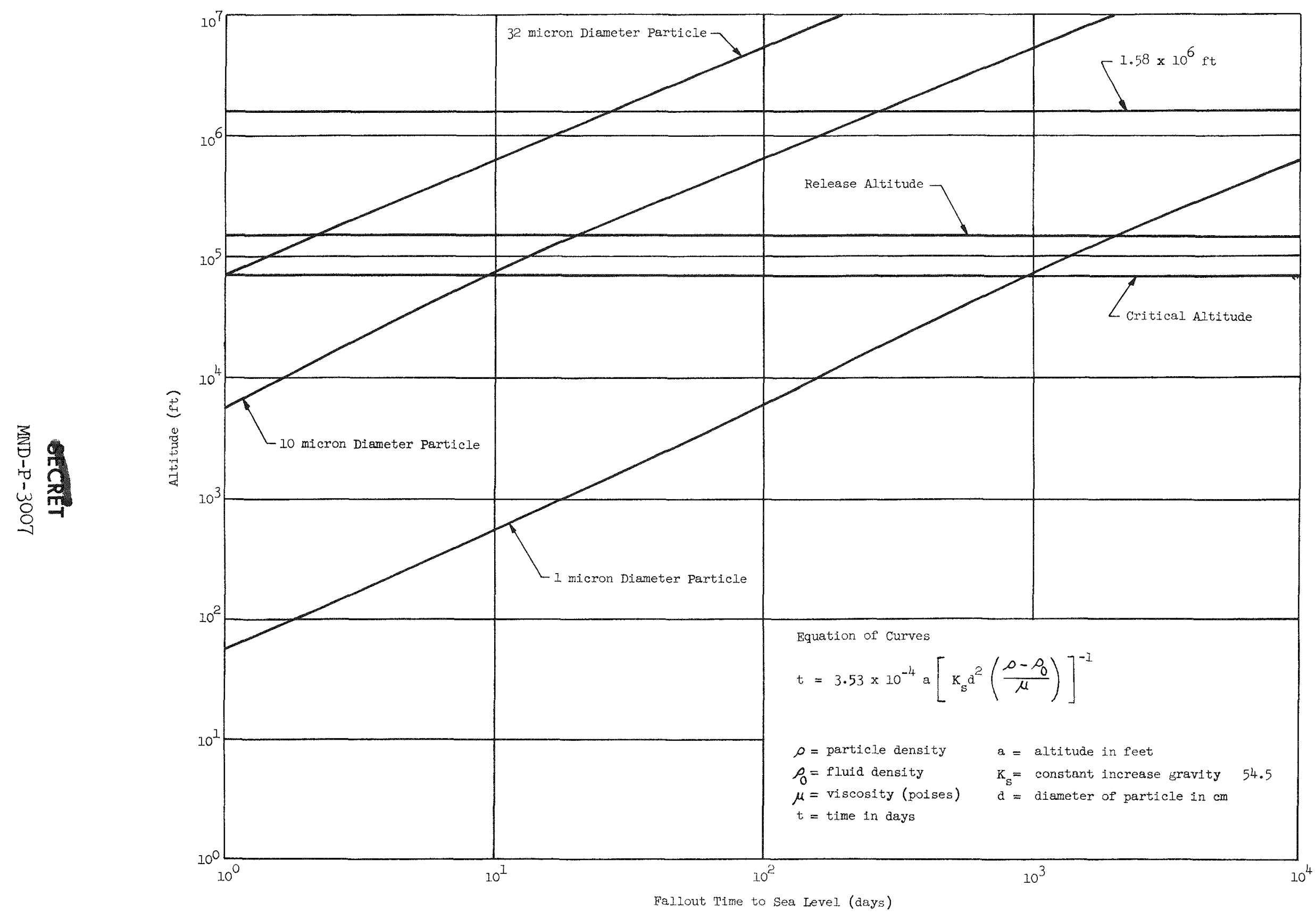

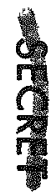

Fis. 41. Fallout Time vs Altitude for Various Particle Sizes 


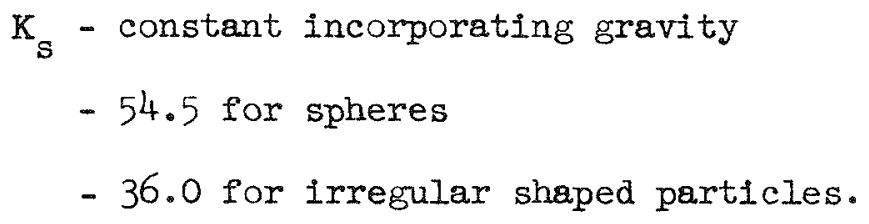

The fluid density and viscosity variations with altitude were considered in the plot. Also, the fallout time shown on this figure is based on a spherical particle with a density of $7 \mathrm{gm} / \mathrm{cc}$. The particle was considered falling with a streamline motion, where the Reynolds number is greater than $10^{-4}$ but less than 2 .

It appears from this plot that unless the isotope has a very short half-life or the quantity of the isotope is small, dispersion can only be considered for an isotope that is dispersed into particles less than 3 microns in diameter. This would be the case even if the isotope containment capsule was destroyed in orbit (at $1.58 \times 10^{6} \mathrm{ft}$ ). The time required for the various sized particles to fall from orbital altitude and burnup altitude to $70,000 \mathrm{ft}$ is shown in Table 13.

\section{TABLE 13}

\section{Fallout Time}

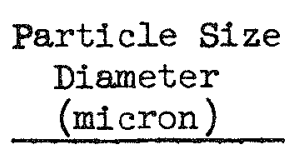

1

10

32
Fallout Time from $1.58 \times 10^{6}$ ft to $70,000 \mathrm{ft}$ (days)
Fallout Time from $150,000 \mathrm{ft}$ to $70,000 \mathrm{ft}$ (days) 1050 11 1
Fallout Time from $150,000 \mathrm{ft}$ to Sea Level

21 (days)

2100

$\frac{\text { (days) }}{2100}$

As an example of fallout rate and isotope decay, consider the $1570-$ curie Polonium-210 generator. According to the investigations of $\mathrm{C}$. Chamie, as reported by Gmelin, the diameter of polonium atom groups is smaller than one micron, based upon measurements of alpha stars. The time required for the polonium particles to fall from 150,000 to 70,000 ft according to Table 13 would be 1050 days or 7.6 half-lives. If a one half-Iife orbital Iffetime is assumed, the original 1570 curies of polonium would decay to approximately 4.6 curies when the dispersed isotope reached the $70,000 \mathrm{ft}$ altitude level. These curies would be diffused in a large volume of air at this point, and would result in little or no radiological hazard.

In order to establish the impact probability of an isotopic power generator re-entering from a north-south orbit, it is necessary to determine a statistical analysis for the earth based on a cross-section 
through the poles. After this has been accomplished, the impact probabilities of the isotope containment capsule hitting this cross-section can be determined.

Statistically, out of 100 APU re-entering from a north-south orbit 66 will impact in water and 34 on land masses. A more detailed breakdown is as follows:

Of the 34 Impacted on Iand Masses:

(1) 12 will impact on ice

(2) 7 on unconsolidated rock

(3) 8 on consolidated rock

(4) 7 on crystalline rock

34 total

of the 66 Impacted on Water Areas

(1) 6 will impact on ice

(2) 1 on inland waters

(3) 59 on oceans

66 total

A further analysis of the 34 that will impact on land indicated that only a small percentage will affect populated regions. This analysis was based on the fact that unconsolidated rock supports the majority of the earth's population while consolidated rock regions are generally unfavorable to human habitation and consequently sparsely populated. The remaining land area is covered by ice or crystalline rock and virtually uninhabited. Of the 15 APU which will land in unconsolidated and consolidated rock regions approximately one-third will land in regions that are uninhabited or very sparsely populated because of unfavorable climate or terrain.

From this analysis then it can be predicted that of 100 APU landing on the earth's surface from a north-south orbit, approximately 10 will affect populated regions. However, in regions of unconsolidated rock which supports most of the population, a source capsule will generally be buried from 6 to 10 ft upon impact, thereby providing adequate shielding from external radiation. 


\section{B. FUEL ELEMENT DESIGN, FABRICATION AND TEST}

A literature search was initiated to evaluate the high temperature properties and fabricability of various container materials. Several visits were made to discuss material properties and welding techniques.

The materials to be considered for evaluation must have reasonable mechanical and physical properties under the assumed conditions listed in Table 14.

The refractory metals provide the most probable container material for intact re-entry situations. Some of their physical properties are listed in Table 15. Tungsten is superior to all others from the standpoint of highest melting point. However, in the range from 400 to $1800^{\circ}$ $\mathrm{F}$ both Molybdenum $-0.5 \mathrm{Ti}$ alloy and rhenium exhibit superior strength properties. Between 1800 and $3600^{\circ} \mathrm{F}$, the tensile strength of tungsten surpasses that of the nearest competitor, rhenium, by a factor of two. The change in tensile strength with temperature is illustrated by Figs. 42 and 43. The trend of the curves indicates that tungsten will increase its strength advantage over other materials at temperatures exceeding $3600^{\circ} \mathrm{F}$. The only known data source on refractory metals above $2000^{\circ} \mathrm{F}$ is provided by these curves. Insufficient data on long term tensile strength, stress rupture properties and shock resistance requires that a test program be completed before an intelligent material selection can be made.

TABLE 14

Container Environmental Conditions

\begin{tabular}{|c|c|c|c|c|c|}
\hline Situation & $\begin{array}{l}\text { Temperature } \\
\left(\mathrm{O}_{\mathrm{F}}\right) \\
\end{array}$ & $\begin{array}{l}\text { Internal } \\
\text { Pressure } \\
\text { (psi) } \\
\end{array}$ & $\begin{array}{l}\text { Impact } \\
\text { Shock }\end{array}$ & $\begin{array}{c}\text { Thermal } \\
\text { Shock }\end{array}$ & $\begin{array}{l}\text { Corrosive } \\
\text { or Oxidiz- } \\
\text { ing Media } \\
\end{array}$ \\
\hline Normal operating & 1100 & 0 to 9400 & - & -- & Minimum \\
\hline Pad abort & 3000 & - & Medium & High & High \\
\hline In-flight abort & Moderate & -- & High & High & High \\
\hline Re-entry & $\begin{array}{l}2000 \text { to } 3000 \\
\text { for } 30 \mathrm{~min} \\
4000 \text { to } 10,000 \\
\text { for } 30 \mathrm{sec}\end{array}$ & o to 9400 & High & High & High \\
\hline
\end{tabular}

All the refractory metals have poor oxidation resistance at elevated temperatures. A number of oxidation resistant coatings, Colmonoy 5 and Silicide, provide protection for molybdenum up to $3000^{\circ} \mathrm{F}$ for $1400 \mathrm{hr}$. 
TABLE 15

Some Physical Properties of the Refractory Metals

\begin{tabular}{|c|c|c|c|c|c|c|}
\hline & Property & Tungsten & Molybdenum & Niobium & Tantalum & Rhenium \\
\hline & Melting point $\left({ }_{F}\right)$ & 6152 & 4752 & 4379 & 5425 & $5756 \pm 36$ \\
\hline & Density $\left(\mathrm{gm} / \mathrm{cm}^{3}\right)$ & $19 \cdot 3$ & 10.2 & 8.57 & 16.6 & 21.0 \\
\hline & Density $\left(1 \mathrm{~b} / \mathrm{in} .{ }^{3}\right)$ & 0.697 & 0.369 & 0.310 & 0.600 & 0.72 \\
\hline & $\begin{array}{l}\text { Specific heat at } 70^{\circ} \mathrm{F} \\
\left(\mathrm{cal} / \mathrm{gm} /{ }^{\circ} \mathrm{C}\right)\end{array}$ & 0.034 & 0.061 & 0.064 & 0.0356 & 0.033 \\
\hline & $\begin{array}{l}\text { Thermal conductivity } \\
\text { (cal/cm- }-{ }^{\circ}-\text { sec) }\end{array}$ & 0.31 at $20^{\circ} \mathrm{C}$ & $\begin{array}{l}0.346 \text { at } 17^{\circ} \mathrm{C} \\
0.260 \text { at } 1800^{\circ} \mathrm{C}\end{array}$ & $\begin{array}{l}0.125 \text { at } 0^{\circ} \mathrm{C} \\
0.130 \text { at } 100^{\circ} \mathrm{C}\end{array}$ & 0.130 at $20^{\circ} \mathrm{C}$ & - \\
\hline & & 0.27 at $1000^{\circ} \mathrm{C}$ & $\begin{array}{l}0.235 \text { at } 1200^{\circ} \mathrm{C} \\
0.225 \text { at } 1600^{\circ} \mathrm{C}\end{array}$ & $\begin{array}{l}0.145 \text { at } 400^{\circ} \mathrm{C} \\
0.151 \text { at } 500^{\circ} \mathrm{C}\end{array}$ & $\begin{array}{l}0.129 \text { at } 100^{\circ} \mathrm{C} \\
0.174 \text { at } 1475^{\circ} \mathrm{C}\end{array}$ & -- \\
\hline 霓 & & 0.25 at $1600^{\circ} \mathrm{C}$ & 0.225 at $2000^{\circ} \mathrm{C}$ & 0.156 at $600^{\circ} \mathrm{C}$ & 0.198 at $1820^{\circ} \mathrm{C}$ & -- \\
\hline & Linear coefficient & 4.43 at $20^{\circ} \mathrm{C}$ & $5.35 \times 10^{-6}$ at $20^{\circ} \mathrm{C}$ & $7.20 \times 10^{-6}$ at $100^{\circ} \mathrm{C}$ & $5.9 \times 10^{-6}$ at $0^{0} \mathrm{C}$ & 6.7 at 20 to $500^{\circ} 0$ \\
\hline & $\begin{array}{l}\text { OI expansion } \\
\left(\mathrm{cm} / \mathrm{cm} /{ }^{\circ} \mathrm{C}\right)\end{array}$ & 5.17 at $1000^{\circ} \mathrm{C}$ & $5.70 \times 10^{-6}$ at $500^{\circ} \mathrm{C}$ & $7.88 \times 10^{-6}$ at $400^{\circ} \mathrm{C}$ & $6.5 \times 10^{-6}$ at $100^{\circ} \mathrm{C}$ & -- \\
\hline & & & & $8.04 \times 10^{-6}$ at $500^{\circ} \mathrm{C}$ & & \\
\hline & & 7.24 at $2000^{\circ} \mathrm{C}$ & - & $\begin{array}{l}8.25 \times 10^{-6} \text { at } 600^{\circ} \mathrm{C} \\
8.52 \times 10^{-6} \text { at } 1000^{\circ} \mathrm{C}\end{array}$ & -. & -- \\
\hline
\end{tabular}




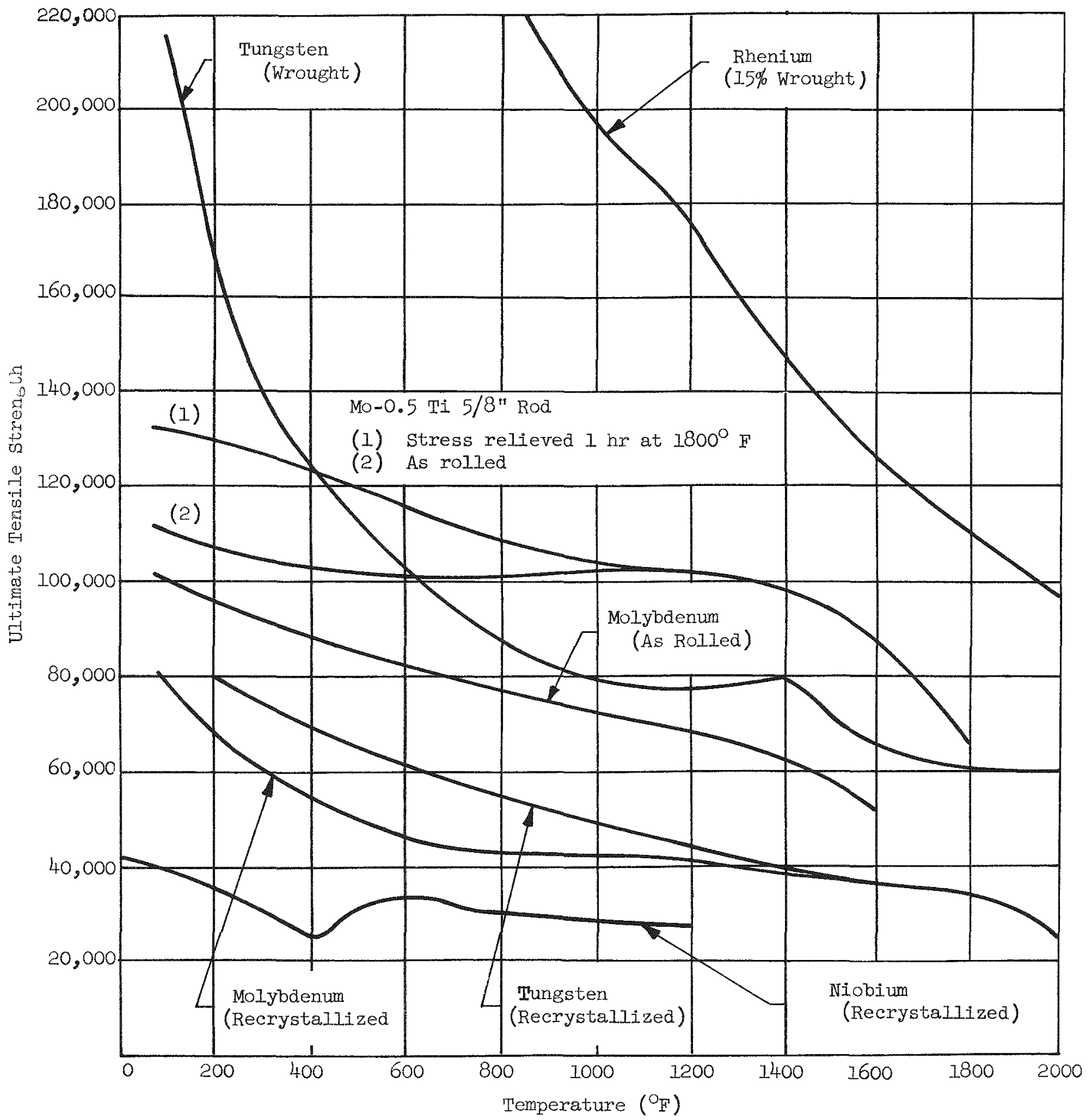

Fig. 42. Short Time Tensile Strength Versus Test Temperature for Some Refractory Metals in Different Conditions as Indicated on Curves from 0 to $2000^{\circ} \mathrm{F}$ 


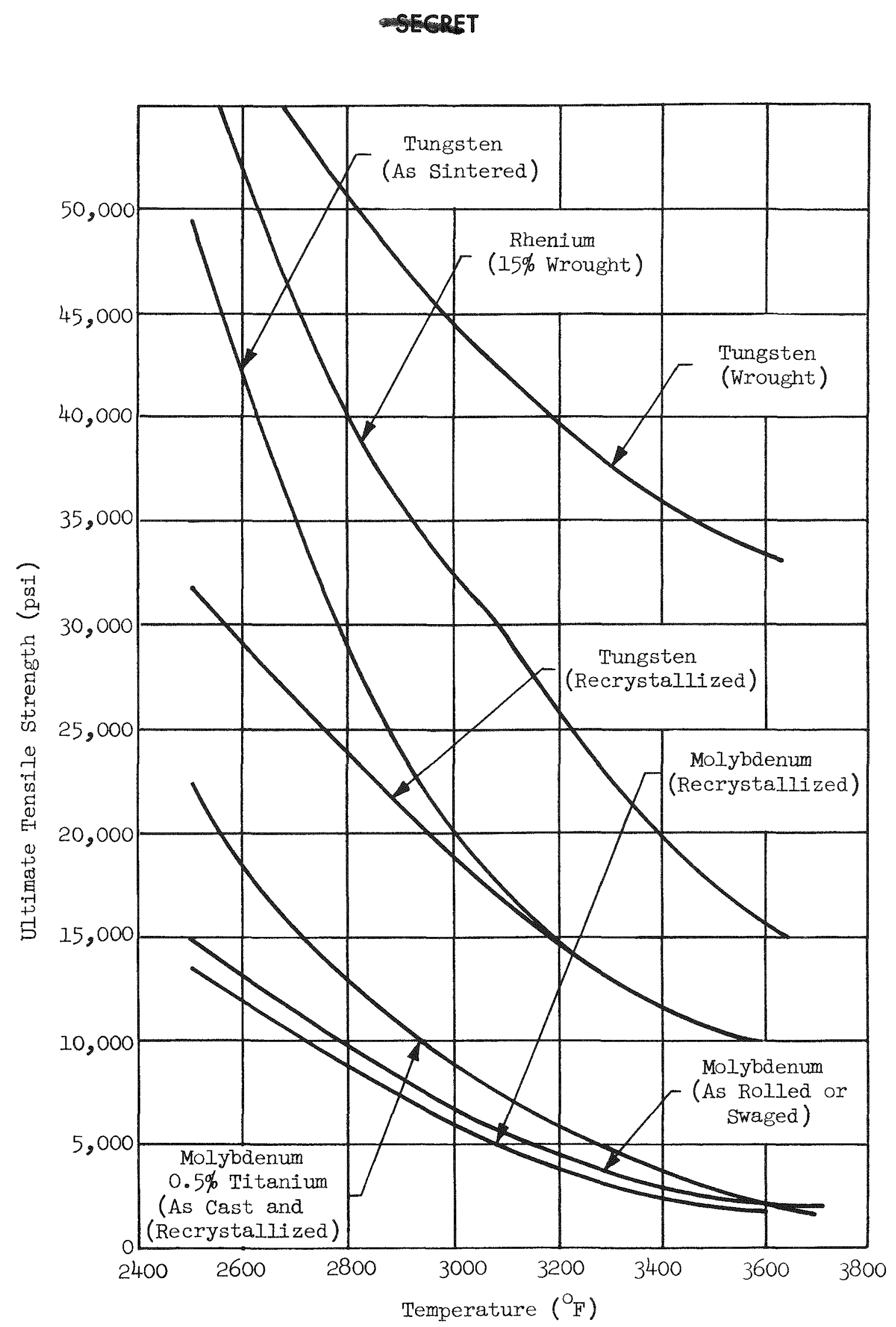

Fig. 43. Short Time Tensile Strength Versus Test Temperature for Some Refractory Metals in Different Conditions as Indicated on Curves above $2400^{\circ} \mathrm{F}$

\section{SECRET}


The silicide coatings offer no potential for tungsten or rhenium since their effectiveness is a function of the amount of diffusion with the molybdenum. Coating tests to date indicate that protection can be provided to only $2000^{\circ}$ F for tungsten or rhenium using Colmonoy 5. Further test work will be required in this area to provide long term data on existing materials or to develop new protection methods.

Tungsten, molybdenum and rhenium have very poor machinability and weldablity. These materials can be machined only with great difficulty and with special tool bits. Brazing can be readily accomplished but would not be reliable during subsequent high temperature operation. Fusion welding of high purity are cast molybdenum has been accomplished using the tungsten inert arc process with good weld design and close control of welding speed and power supply. Reproduction is difficult and is dependent on technique development and experience. This process is possible but more difficult when using tungsten or rhenium. Electron beam welding offers the best potential source of a reproducible closure method. Sample containers of molybdenum were fabricated and welding tests were conducted on the electron beam welder at Sciaky Brothers, Inc., Chicago, Illinois. The maximum capacity of the machine was used without effecting a satisfactory weld. This indicated that the power supply and focus control were not adequate to overcome the heat loss through the container walls. Improvements in the machine capacity currently under way may allow welding of a $1 / 4$ in. diameter plug in a container having $1 / 4$ in. thick walls. A machine developed by the Lawrence Radiation Laboratory, Iivermore, Calffornia, has displayed a greater capacity but is presently down for modification. The schedule for completion of these modifications is indefinite at the present time and future machine committments will limit external utilization to experimental testing.

The survey of electron beam welding capabilities will continue and a visit to Temescal Metallurgy Corporation, Richmond, California, is planned in the near future.

The super alloy group of materials cannot compete with refractory metals in the high temperature regions but are attractive in other areas. The chemical compositions and some physical properties of these alloys are shown in Tables 16 and 17, respectively. The melting points listed indicate that these materials could not survive re-entry intact without extensive ablative material or nose cone shielding. However, for a burnup situation, these temperature limitations improve fuel dispersion possibilities since the container would disintegrate at a higher altitude.

The pad abort temperatures and shock would impose the most severe conditions if intact re-entry is not required. Although the temperatures anticipated exceed the melting point, the time span of exposure is short enough that significant deterioration will not occur. 
Chemical Compositions of Super Alloys for Use Above $1000^{\circ} \mathrm{F}$

\begin{tabular}{|c|c|c|c|c|c|c|c|c|c|c|c|c|c|c|c|c|c|c|}
\hline \multirow[b]{2}{*}{ Alloy } & \multicolumn{17}{|c|}{ Composition of Indicated Constituents ( $\%)$} & \multirow[b]{2}{*}{ Producer } \\
\hline & $\mathrm{Cr}$ & $\mathrm{Ni}$ & Co & Mo & W & $\underline{\mathrm{C}}$ & $\mathrm{Fe}$ & $\underline{S I}$ & $\underline{M n}$ & $\underline{B}$ & Al & $\mathrm{TI}$ & $\underline{\mathbf{s}}$ & $P$ & $\mathrm{Nb}$ & $\underline{\mathrm{Cu}}$ & $\underline{v}$ & \\
\hline Rene 41 & $\begin{array}{l}18.0 \\
20.0\end{array}$ & $\mathrm{BaI}$ & $\begin{array}{l}10.0 \\
12.0\end{array}$ & $\begin{array}{r}9.0 \\
10.5\end{array}$ & -- & $\begin{array}{l}0.6 \\
1.2\end{array}$ & - & -- & -- & 0.005 & $\begin{array}{l}1.4 \\
1.6\end{array}$ & $\begin{array}{l}3.00 \\
3.30\end{array}$ & -- & -- & - & -- & -- & $\begin{array}{l}\text { Cannon Muskegon } \\
\text { Corporation }\end{array}$ \\
\hline Heynes 25 & $\begin{array}{l}19.0 \\
21.0\end{array}$ & $\begin{array}{r}9.0 \\
11.0\end{array}$ & $\mathrm{Bal}$ & - & $\begin{array}{l}14.0 \\
16.0\end{array}$ & $\begin{array}{l}0.05 \\
0.15\end{array}$ & $\begin{array}{l}3.00 \\
\operatorname{Max}\end{array}$ & $\begin{array}{l}1.00 \\
\operatorname{Max}\end{array}$ & $\begin{array}{l}1.00 \\
\operatorname{Max}\end{array}$ & $\begin{array}{l}1.00 \\
2.00\end{array}$ & -- & -. & - & -. & -- & -- & -- & $\begin{array}{l}\text { Haynes Stellite } \\
\text { Company }\end{array}$ \\
\hline$J-1570$ & 20.0 & 30.0 & 39.0 & -- & 6.5 & 0.2 & -- & -- & -- & -- & - & 4.0 & $-\infty$ & $-\infty$ & -- & $-\infty$ & -- & $\begin{array}{l}\text { Carboloy Dept } \\
G E\end{array}$ \\
\hline $\mathrm{HE} 1049$ & $\begin{array}{l}26.0 \\
18.0\end{array}$ & $\begin{array}{c}10.0 \\
0.37\end{array}$ & 45.0 & 0.03 & $\begin{array}{l}15.0 \\
11.0\end{array}$ & $\begin{array}{l}0.40 \\
0.13\end{array}$ & $\begin{array}{l}3.00 \\
0.18\end{array}$ & $\begin{array}{l}0.8 \\
0.01\end{array}$ & $\begin{array}{l}0.8 \\
0.03\end{array}$ & $\begin{array}{l}0.4 \\
0.005\end{array}$ & - & $\operatorname{Tr}$ & 0.005 & $\mathrm{Tr}$ & -- & -- & -- & $\begin{array}{l}\text { Haynes Stellite } \\
\text { Company }\end{array}$ \\
\hline HDA 8151 & 22.0 & 2.20 & $\mathrm{BaI}$ & 4.5 & 13.0 & 0.24 & 2.13 & 0.48 & 0.72 & 0.043 & -- & 0.30 & 0.004 & 0.30 & -- & -- & $=$ & $\begin{array}{l}\text { Haynes Stellite } \\
\text { Company }\end{array}$ \\
\hline $\begin{array}{l}\text { Hastelloy } \\
\text { R }\end{array}$ & 15.5 & 62.0 & 2.5 & 5.5 & -- & 0.015 & 10.0 & 0.6 & -- & -- & 2.0 & 2.5 & $-\infty$ & -- & -. & - & -- & $\begin{array}{l}\text { Haynes Stellite } \\
\text { Company }\end{array}$ \\
\hline Inconel $\mathrm{X}$ & $\begin{array}{l}14.0 \\
16.0\end{array}$ & $\begin{array}{l}70.0 \\
\mathrm{Min}\end{array}$ & -. & -- & - & $\begin{array}{l}0.08 \\
\operatorname{Max}\end{array}$ & $\begin{array}{l}5.00 \\
9.00\end{array}$ & $\begin{array}{l}0.50 \\
\operatorname{Max}\end{array}$ & $\begin{array}{l}0.3 \\
1.00\end{array}$ & -- & $\begin{array}{l}0.40 \\
1.00\end{array}$ & $\begin{array}{l}2.25 \\
2.75\end{array}$ & $\begin{array}{l}0.01 \\
\operatorname{Max}\end{array}$ & -- & $\begin{array}{l}0.70 \\
1.20\end{array}$ & $\begin{array}{l}0.20 \\
\text { Max }\end{array}$ & -- & $\begin{array}{l}\text { International } \\
\text { Nickel Company }\end{array}$ \\
\hline$x 40$ & 25.0 & 10.3 & 55.0 & -- & 7.4 & 0.48 & 1.0 & -- & -- & -- & -- & -- & -- & -- & $-\infty$ & -- & -- & $\begin{array}{l}\text { Haynes Stellite } \\
\text { Company }\end{array}$ \\
\hline Inco 700 & 15.0 & 50.0 & 27.0 & 3.00 & -- & 0.10 & -- & -- & -- & -- & 3.00 & 2.25 & -- & -- & -- & -- & - & $\begin{array}{l}\text { International } \\
\text { Nickel Company }\end{array}$ \\
\hline $5-816$ & 20.0 & 20.0 & 44.0 & 4.00 & 4.00 & 0.4 & 2.8 & -- & -- & -- & -- & - & - & -- & 3.75 & -. & -- & $\begin{array}{l}\text { Allegheny Ludlum } \\
\text { Steel Corporation }\end{array}$ \\
\hline Haynes 21 & 26.5 & 3.0 & 62.0 & 5.25 & $\cdots$ & 0.30 & 1.5 & -- & -- & -- & -- & -- & -- & -- & -- & -- & - & $\begin{array}{l}\text { Haymes Stellite } \\
\text { Company }\end{array}$ \\
\hline M252 & 19.0 & 53.5 & 10.0 & 10.0 & -- & 0.1 & 2.0 & -- & $\ldots$ & -- & 0.75 & 2.5 & -- & -- & - & - & - & Unknown \\
\hline $\begin{array}{l}\text { Hastelloy } \\
\text { B }\end{array}$ & - & 65.0 & -- & 28.0 & -- & 0.1 & 5.0 & -. & -. & -- & $\ldots$ & -- & - & -- & -- & -- & 0.4 & $\begin{array}{l}\text { Haynes Stellite } \\
\text { Company }\end{array}$ \\
\hline Incoloy $\mathrm{T}$ & 20.0 & 32.0 & -- & $-\infty$ & -- & 0.1 & 47.0 & -. & - & -- & - & 1.0 & -- & -- & -- & -- & -- & $\begin{array}{l}\text { International } \\
\text { Nickel Company }\end{array}$ \\
\hline $\begin{array}{l}310 \text { stain- } \\
\text { less }\end{array}$ & 25.0 & 20.0 & - & - & - & 0.1 & 53.0 & -- & -- & - & $-\infty$ & -- & $=-$ & -- & -- & -- & -- & -- \\
\hline $\begin{array}{l}321 \text { stain- } \\
\text { less }\end{array}$ & 27.5 & 10.0 & -- & -- & - & 0.06 & 70.0 & -- & $-\infty$ & -- & -- & 0.5 & -- & $-\infty$ & $=$ & -- & -- & $-\infty$ \\
\hline A286 & 15.0 & 26.0 & -- & 1.15 & -- & 0.05 & 54.0 & -- & -- & -- & 0.17 & 2.0 & - & $-\infty$ & -- & -- & 0.2 & Unknown \\
\hline Timken & 16.0 & 25.0 & -- & 6.25 & -- & 0.09 & 51.0 & -. & -- & -- & -- & -- & -- & -- & -- & -- & -- & $\begin{array}{l}\text { Timken Roller } \\
\text { Bearing Company }\end{array}$ \\
\hline Ispelloy & 11.0 & - & -- & 3.00 & -- & 0.25 & 84.5 & -- & 1.00 & -- & -- & -- & -- & -- & -- & -- & 0.25 & Unknown \\
\hline $17-22 \mathrm{AV}$ & 1.25 & $-\infty$ & -- & 0.50 & - & 0.3 & 95.5 & 0.70 & 0.75 & -- & - & -- & -- & -- & -- & -- & 0.85 & Unknown \\
\hline
\end{tabular}


TABLE 17

Some Physical Properties of the Super Alloys

\begin{tabular}{|c|c|c|c|c|c|c|c|c|c|c|c|c|}
\hline \multirow[b]{2}{*}{ Alloy } & \multirow{2}{*}{$\begin{array}{c}\text { Melting } \\
\text { Point } \\
(\mathrm{F}) \\
\end{array}$} & \multirow{2}{*}{$\begin{array}{c}\text { Density } \\
\text { (1b/ } \\
\left.\text { in. }{ }^{3}\right) \\
\end{array}$} & \multicolumn{10}{|c|}{ Thermal Conductivity, $\mathrm{K}\left(\mathrm{Btu} / \mathrm{ft}^{2} / \mathrm{in} \cdot / \mathrm{hr} /{ }^{\circ} \mathrm{F}\right)$} \\
\hline & & & $50 *$ & $100 *$ & $200 *$ & $300 *$ & $400 *$ & $500 *$ & $600 *$ & $700 *$ & $800 *$ & $900 *$ \\
\hline Rene 41 & $\begin{array}{l}\text { Not } \\
\text { available }\end{array}$ & 0.298 & -- & -- & 86 & 100 & 113 & 127 & 139 & 152 & 165 & -- \\
\hline Haynes 25 & $\begin{array}{l}2425 \\
2570\end{array}$ & 0.330 & $-\infty$ & 67 & 82 & 97 & 112 & 127 & 142 & 157 & 172 & 190 \\
\hline $\mathrm{HE} 1049$ & -- & 0.321 & -- & -- & -- & -- & -- & -- & -- & - & -- & -- \\
\hline$J-1570$ & - & 0.313 & -- & -- & $-\infty$ & - & - & -- & -- & - & - & -- \\
\hline$--m-1-n-n$ & 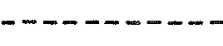 & - & -- & $-\infty$ & -- & $-\cdots$ & $\cdots$ & $\cdots$ & $\cdots-$ & $-\cdots$ & $-\infty-\infty$ & $\ldots$ \\
\hline HDA 8151 & -- & -- & -- & -- & -- & - & - & - & $-\infty$ & - & -- & -- \\
\hline Hastelloy $\mathrm{R}$ & 2400 & 0.296 & -- & 72 & 86 & 101 & 115 & 130 & 144 & 159 & 173 & -- \\
\hline Inconel $\mathrm{X}$ & $\begin{array}{l}2540 \\
2600\end{array}$ & 0.300 & 102 & 110 & 124 & 140 & 156 & 174 & 188 & 212 & 236 & 258 \\
\hline$\times 40$ & -- & 0.31 & -- & -- & $-\infty$ & - & - & - & - & -- & -- & - \\
\hline$s-816$ & $\begin{array}{l}2350 \\
2450\end{array}$ & 0.313 & -- & -- & 107 & 119 & 130 & 141 & 155 & 155 & -- & -- \\
\hline Haynes 21 & 2465 & 0.300 & -- & - & 101 & 111 & 121 & 132 & 142 & - & -- & -- \\
\hline Hastelloy B & $\begin{array}{l}2408 \\
2462\end{array}$ & 0.334 & -- & -- & 85 & 91 & 98 & 106 & 114 & -- & -- & -- \\
\hline Inconel $\mathrm{T}$ & - & 0.288 & - & 100 & 112 & 120 & 128 & 135 & 141 & 148 & -- & -- \\
\hline $\begin{array}{l}310 \text { Stain- } \\
\text { Less }\end{array}$ & $\begin{array}{l}2550 \\
2650\end{array}$ & 0.29 & -- & 8.0 & 98 & 106 & 114 & 10.8 & -- & -- & - & -- \\
\hline $\begin{array}{l}321 \text { stain- } \\
\text { less }\end{array}$ & $\begin{array}{l}2550 \\
2600\end{array}$ & 0.29 & -- & 9.3 & -- & -- & -- & 12.8 & -- & -- & $-\infty$ & -- \\
\hline A286 & $\begin{array}{l}2500 \\
2600\end{array}$ & 0.286 & $=-$ & $=-$ & 111 & 124 & 139 & 151 & 165 & -- & -- & -- \\
\hline
\end{tabular}

* These temperatures are in $\left({ }^{\circ} \mathrm{C}\right)$ 
The resistance of the material to impact and thermal shock is difficult to determine from available data. The best laboratory testing method, Charpy V-Notch, is difficult to reproduce and only compares one material to another. The best data available indicates that Haynes 25 provides the most impact resistance. However, its impact strength is greatly reduced by only $4 \mathrm{hr}$ aging at $1800^{\circ} \mathrm{F}$. Hastelloy $\mathrm{R}$ provides a lower initial impact strength but aging for $16 \mathrm{hr}$ at $1800^{\circ} \mathrm{F}$ does not decrease its impact strength significantly. The lack of data and the transient nature of the environment precludes a rigorous analysis and conclusive results can only be obtained through tests.

The super alloys have higher initial strengths than the refractory metals but they deteriorate significantly when aged at elevated temperatures. Figures 44 and 45 illustrate that the rate of change is quite rapid. Using Cannon Muskegon Rene 41 as an example at the assumed normal operating temperature of $1100^{\circ} \mathrm{F}$, the stress rupture strength after $1000 \mathrm{hr}$ of aging has decreased by a factor of two from the initial ultimate tensile strength. This represents the situation that would exist at launch if the generators were loaded 30 days prior to launch date. If the radioisotope fuel used is such that no internal pressure is generated within the capsule, launch or pad abort conditions are the most critical during operational life until disintegration occurs on re-entry. In the case of alpha emitting fuels, the internal helium pressure will continue to increase throughout operational life. This situation would make complete containment improbable with decreasing material allowables unless a method to bleed off the helium can be devised.

The oxidation resistance of the super alloys is generally good. Data available on Hastelloy $X$ and Haynes 25 indicates that no problems would exist at $1100^{\circ} \mathrm{F}$ in normal ambient conditions. It may be assumed that Rene 41 will have comparable resistance since the chemical compositions are similar.

The weldability of super alloys is generally good. The Haynes alloys and Rene 41 are readily welded by standard resistance or inert arc welding techniques.

Much of the data presented here was obtained or confirmed by discussions with personnel at Battelle Memorial Institute, Columbus, Ohio.

Conceptual designs of isotope containers were completed and are illustrated in the generator configurations presented in the following Section of this Chapter. 

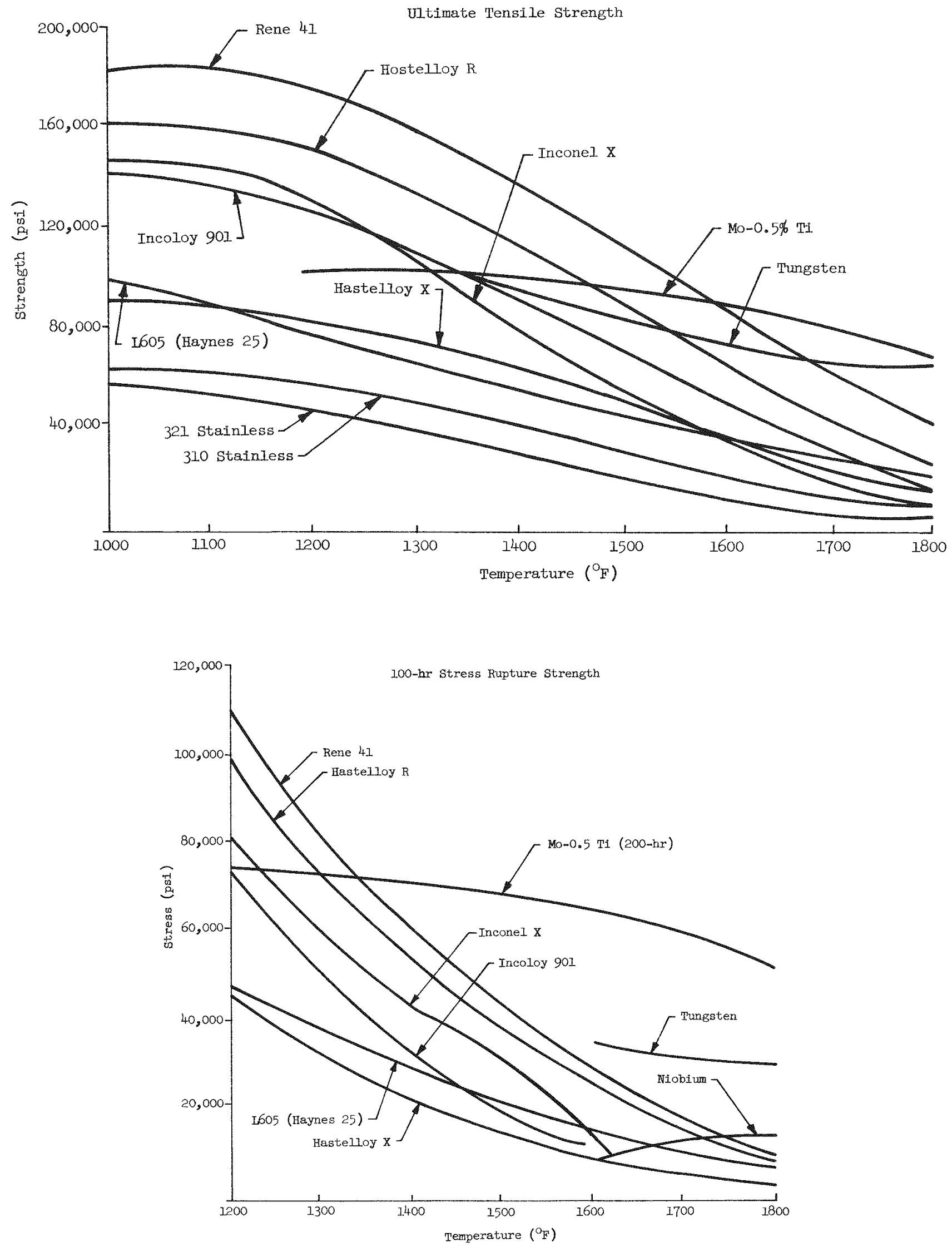

Fig. 44. Tensile Strengths vs Temperature for Some Super Alloys 


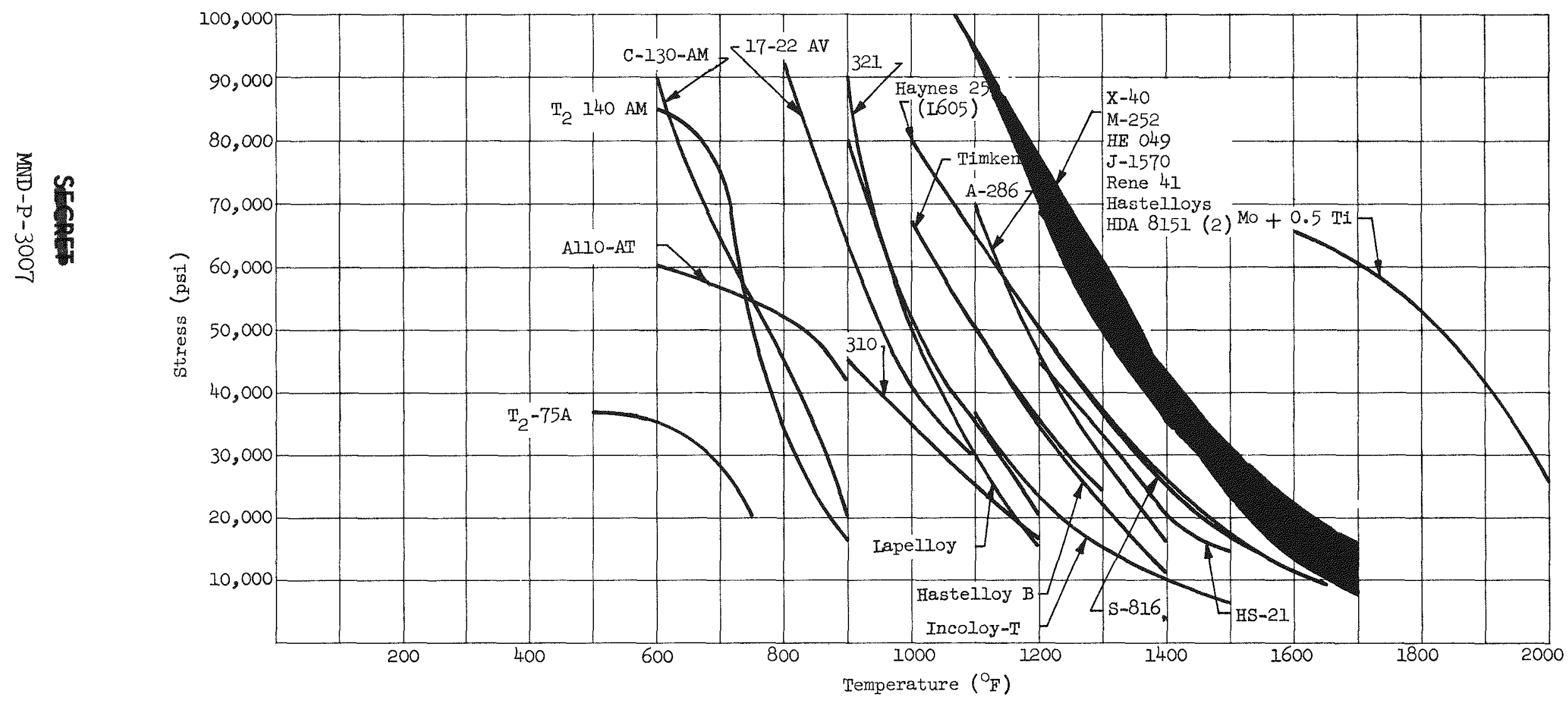

竞

Fig. 45. One Thousand-Hour Stress Rupture vs Temperature of Various Super Alloys 


\section{GENERATOR DESIGN, FABRICATION, AND TEST}

\section{Generator Design}

Five auxiliary power unit conceptual designs were completed for hazards evaluation. Each converts the radioactive decay heat of an isotope to electrical power with a thermoelectric conversion system. The isotopes employed in these generators are Polonium-210, Strontium90, Promethium-147, Curium-242 and Krypton-85. Table 18 compares the units with respect to shape, size, weight and operating characteristics. It is apparent that curium and polonium fueled units are the most efficient for space missions.

Because the particle sizes of the strontium, promethium and curium fuel forms as oxides are excessive when the fuel is dispersed on re-entry, it was decided to design the containment capsules for intact impact on the earth's surface. This was accomplished by surrounding the containment capsules with graphite spheres. The graphite serves as a heat absorption material to resist aerodynamic heating during re-entry. Polonium fuel, however, can safely be dispersed in the upper atmosphere by burnup on re-entry, so no ablative or heat sink materials were incorporated into this design. Figures 46 through 50 show the conceptual designs of these generators. A brief description of each unit follows.

Polonium-210 generator.- This unit produces $2.92 \mathrm{w}$ of electrical energy from $50.2 \mathrm{w}$ of thermal energy, with a total efficiency of $5.82 \%$. Twenty-seven pairs of lead telluride elements are utilized to produce $2.95 \mathrm{v}$. The 1570 curies of source material is encapsulated in three successive containers: two stainless steel capsules with welded tops; a single steel canister with a welded top; and a stainless steel block capped by a welded steel plug.

Strontium-90 generator.- This design produces $2.33 \mathrm{w}$ of electrical energy from $54 \mathrm{w}$ of thermal energy with a total efficiency of $4.3 \%$. The generator utilizes 24 pairs of elements to produce $2.86 \mathrm{v}$. It employs a cylinder of strontium titanate as the heat source. The primary cladding of the radioisotope fuel is Hastelloy $c$, a nickel-alloy. The clad fuel is encased in a tungsten container which serves as a radiation shield to attenuate bremsstrahlung and gamma radiation and as a high temperature impact resistance shell. A graphite sphere surrounds the tungsten container. This is placed with the thermoelectrics in a spherical aluminum outer shell.

Promethium-147 generator.- This design converts 43.5 thermal watts to $2 . \overline{2}$ electrical watts at an overall conversion efficiency of $5.1 \%$. Twenty-four pairs of elements produce $2.8 \mathrm{v}$. The fuel form is $\mathrm{Pm}_{2} \mathrm{O}_{3}$, which has a density of $6.6 \mathrm{gm} / \mathrm{cc}$ and a power density of $1.5 \mathrm{w} / \mathrm{cc}$. The source cladding is molybdenum placed within a graphite sphere with an aluminum outer shell. 


\section{TABLE 18}

Generator Specifications

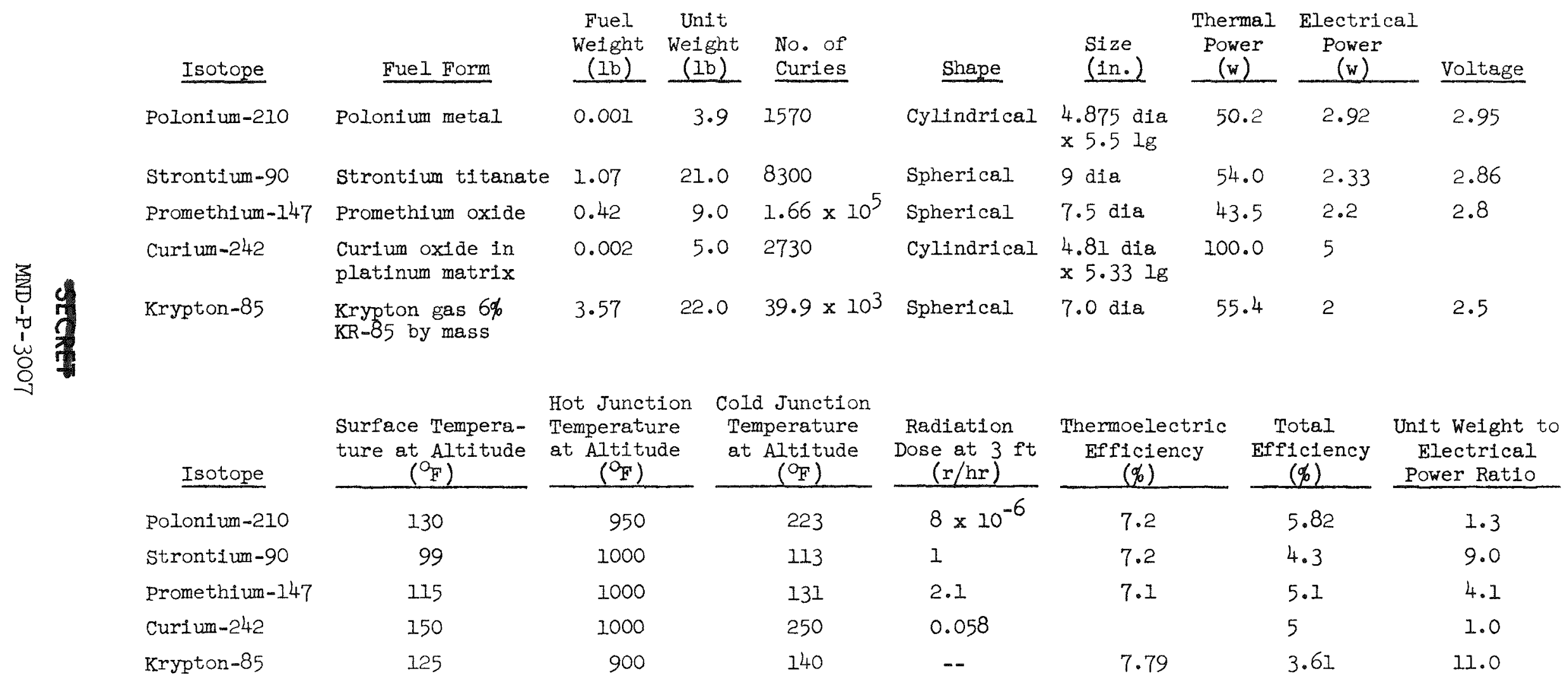




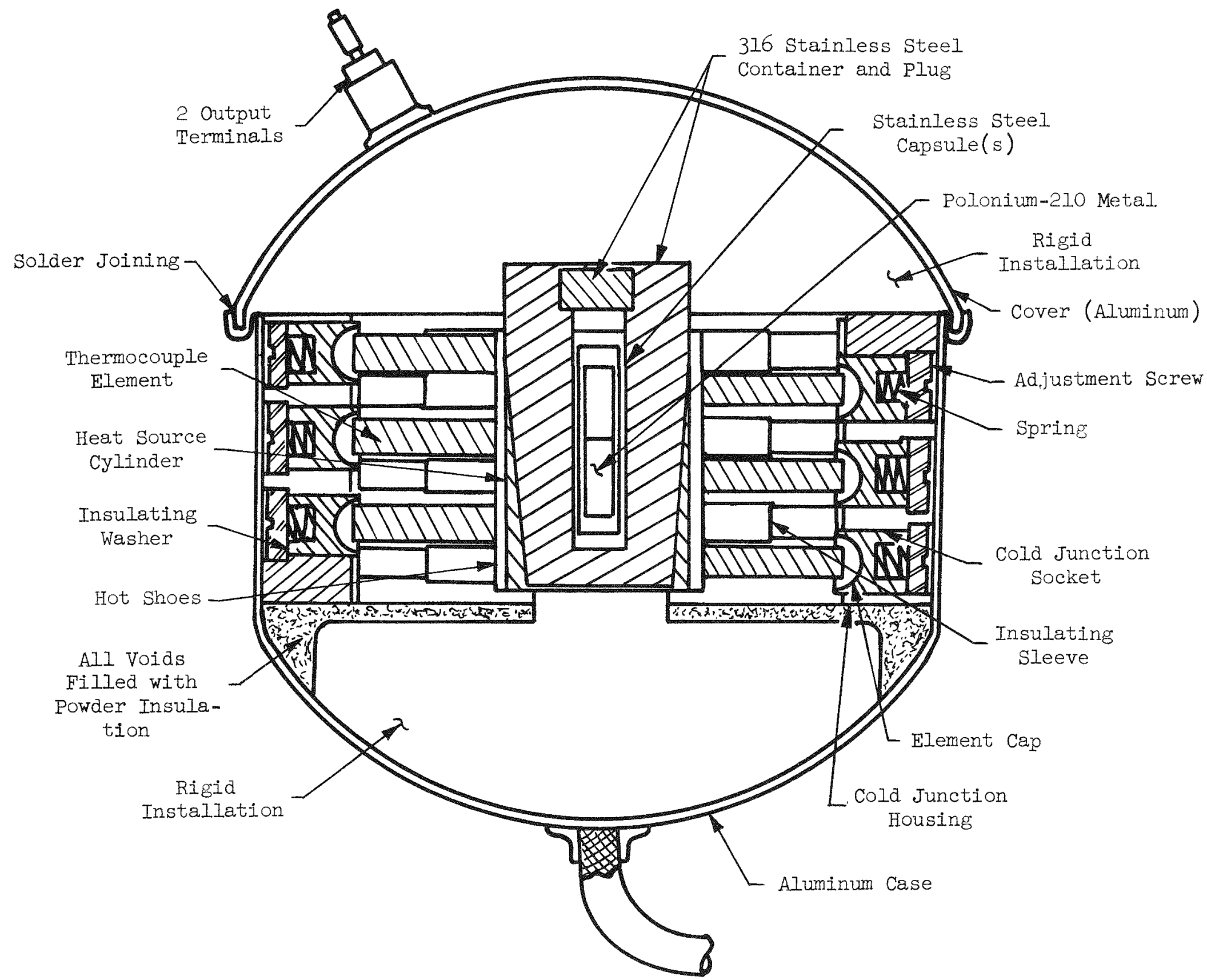




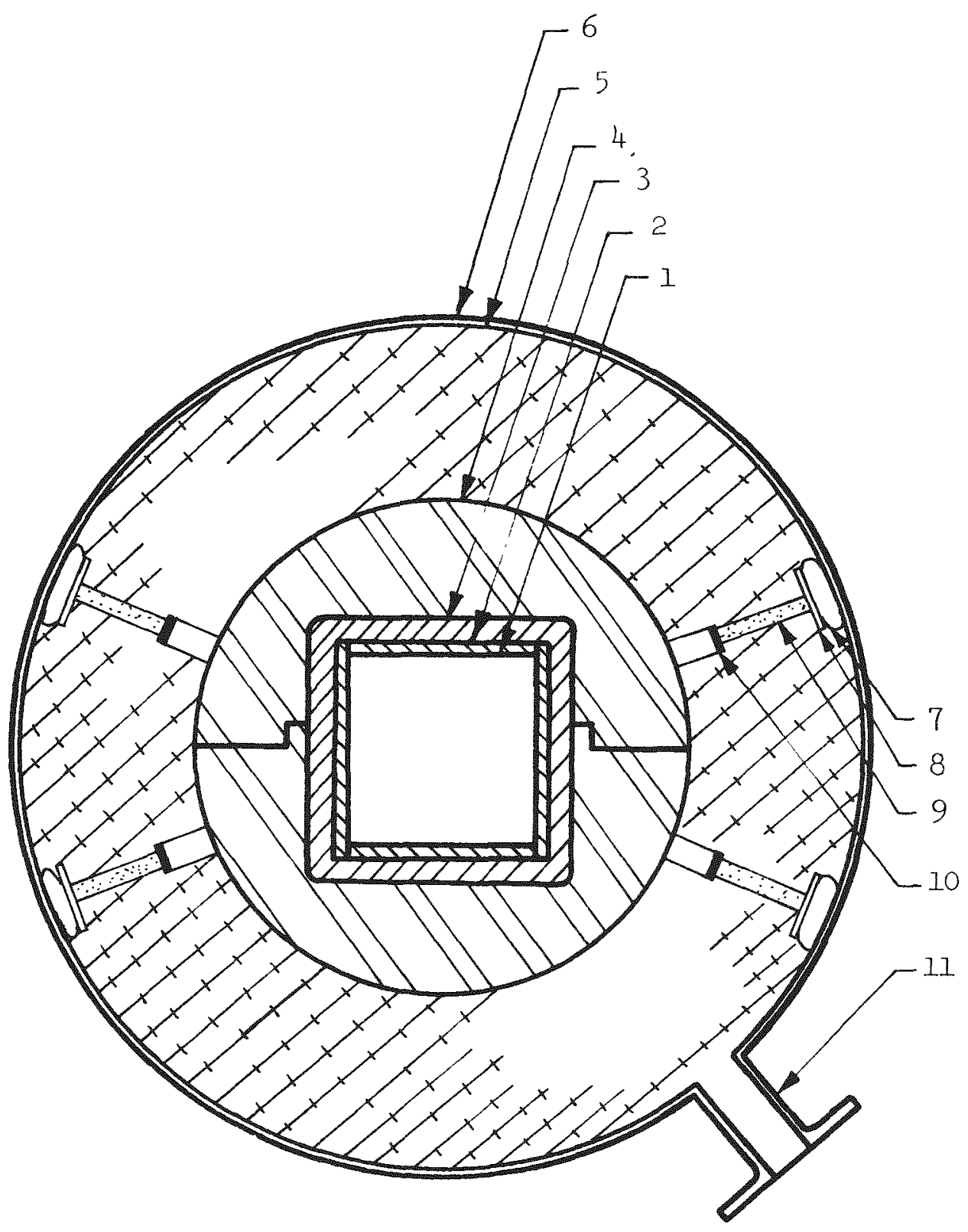

$\begin{array}{llrl}1 & \text { SrTiO }_{3} & 7 & \text { Spring } \\ 2 & \text { Cladding (Hastelloy) } & 8 & \text { Contact, Oxide } \\ 3 & \text { Shield (Tungsten) } & 9 & \text { Thermoelectric Element } \\ 4 & \text { Graphite } & 10 & \text { Contact, Oxide, Spacer } \\ 5 & \text { Thermolectric Insulation } & 11 & \text { Mounting Flange } \\ 6 & \text { Shell } & & \end{array}$

Fig. 47. Strontium Fueled Generator 


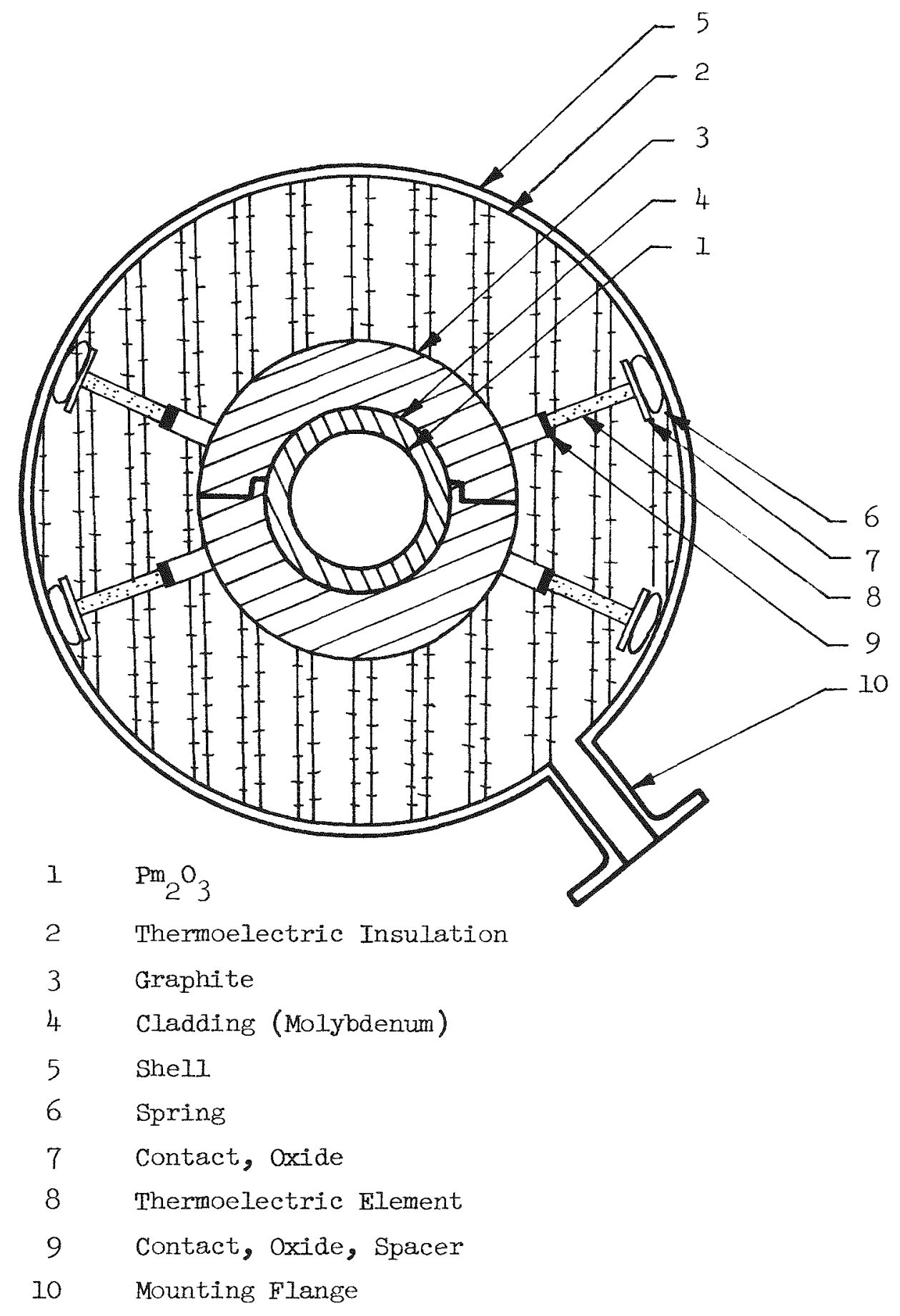

Fig. 48. Promethium Fueled Generator 


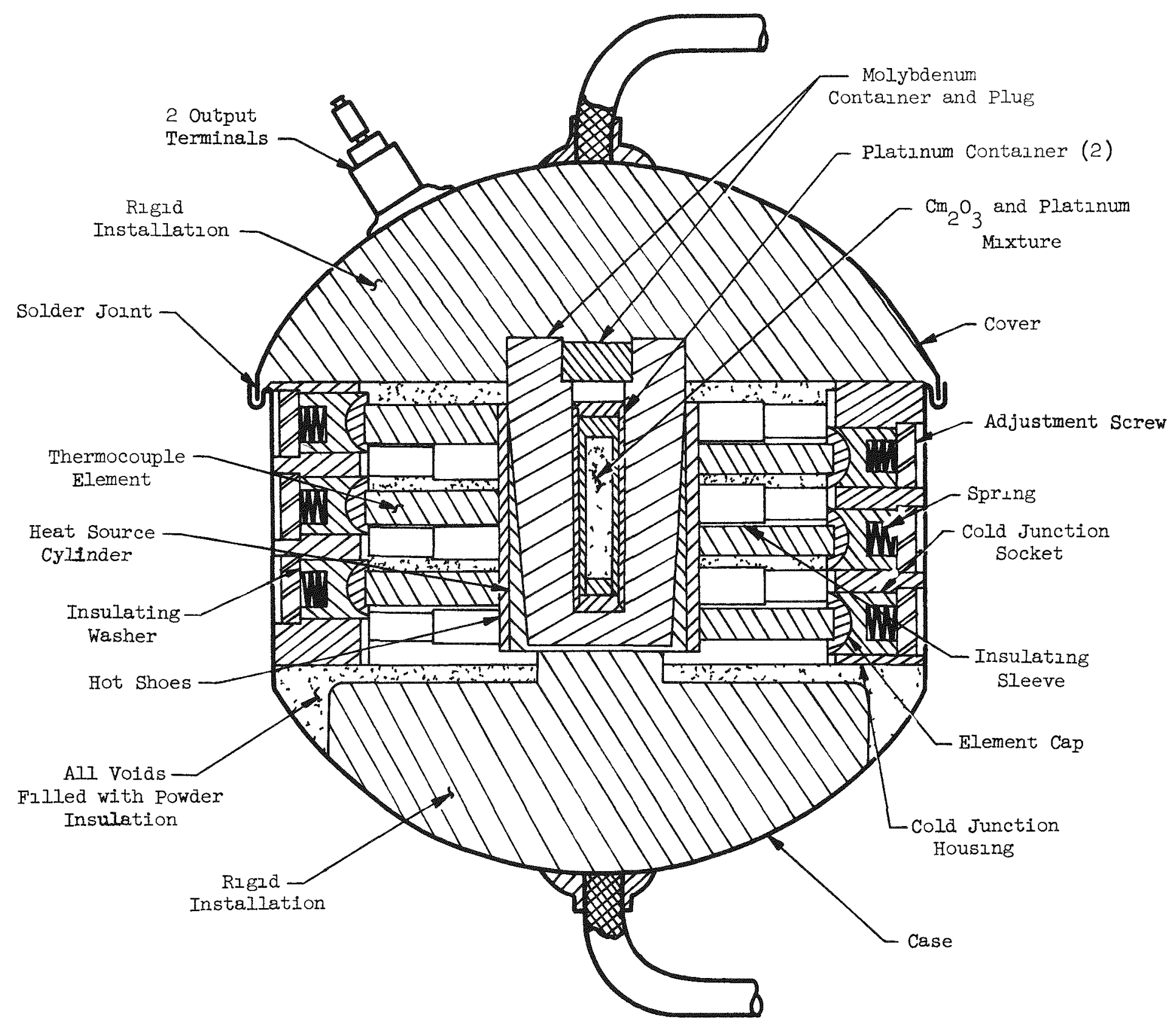




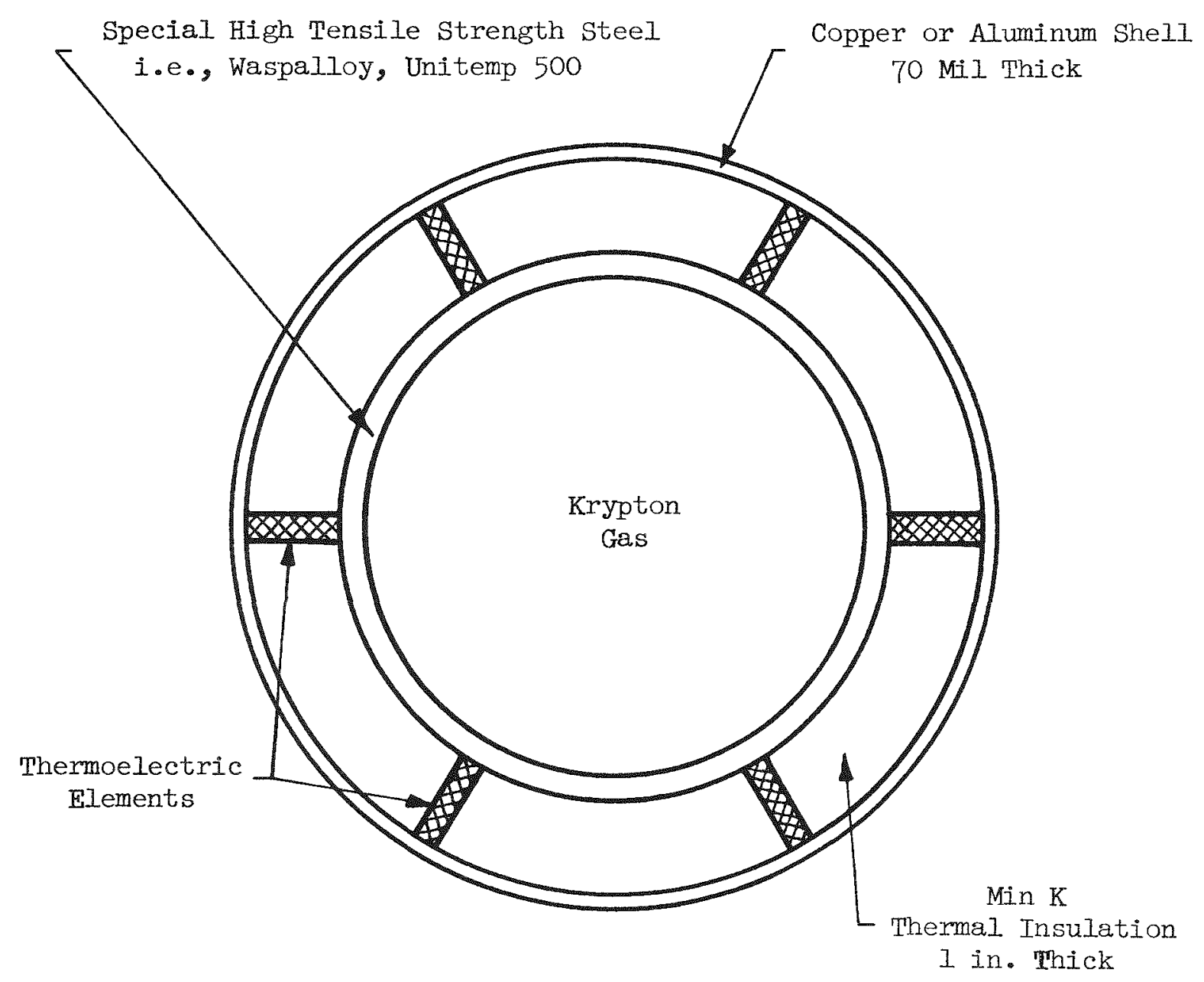

Fig. 50. Krypton Fueled Generator 
Curium-242 generator.- This unit converts $100^{\circ}$ thermal watts to 5 electrical watts at an overall conversion efficiency of $5 \%$. The fuel can be in the form of curium oxide $\left(\mathrm{Cm}_{2} \mathrm{O}_{3}\right)$ compacted in a platinum matrix. The ratio of platinum to curium atoms is at least 8 to $I$ so that the overall corrosion rate of the cermet thus formed will approach the corrosion rate of the platinum. The use of platinum assures heat elements of high specific power, and a minimum of corrosion in naturally occurring aqueous media. A second fuel form can be curium metal dispersed in a noble metal matrix. This fuel will have a higher specific power and will reduce the number of neutrons. Either fuel form will be encased within two concentric welded containers of a high melting point noble metal such as platinum or iridium placed in a cast cylindrical block of molybdenum sealed with a welded plug.

Krypton-85 generator.- This unit produces $2 \mathrm{w}$ of electrical energy from $55.4 \mathrm{w}$ of thermal energy, with a total efficiency of $3.61 \%$. The primary effort of this configuration study was expended on isotope containment. The krypton gas available contained only $6 \%$ Krypton-85 by mass. This condition required that a large amount of gas be contained as compared to the activity present. A spherical container 4 in. in diameter capable of containing the gas at high temperatures and pressures was designed but the feasibility of sealing this container could only be established by test. The best container materials would be Waspalloy or Unitemp 500 but the stress rupture versus time and temperature characteristics of these metals are not definitely known. A relatively heavy outer container of copper or aluminum was used as a secondary means of containment should a leak develop in the inner vessel.

A configuration study to satisfy the JPL requirements cited in Section A of this task was initiated in June. Three concepts are currentIy being considered. They are (I) multiple units of SNAP III-B configuration, (2) a single unit utilizing SNAP III-B type configuration, and (3) a unit utilizing radiative heat transfer similar to the current SNAP I-A configuration. No conclusive results of this study are available to date.

\section{Environmental Testing}

The SNAP III generator is reliable under normal handling. For space vehicle application, however, discriminative environments must be considered, such as vibration, acceleration and shock. The current SNAP III-B configurations, consisting of two $3.5 \mathrm{w}$ units and two $1.5 \mathrm{w}$ units are being tested in simulated space vehicle and booster environments. This will determine integrity, efficiency and reliability.

Specifications have been developed for the WS II7L and Vega Vehicles in conjunction with Lockheed Missile Systems Division and Jet Propulsion Laboratories, respectively. The Vega Vehicle requirements are as follows:

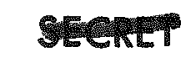

MND-P-3007 
Vibration.- White Gaussian Noise, hand-limited between 15 to 1500 cps to a maximum force of $12.5 \mathrm{~g}$.

Sinusoidal motion swept from 15 to $1500 \mathrm{cps}$, increasing directly with frequency to a maximum amplitude of $8.0 \mathrm{~g}$.

White noise superimposed or sinusoid swept from 500 to $1500 \mathrm{cps}$ with a maximum force of $9.5 \mathrm{~g}$.

This was programmed on a $10 \mathrm{~min}$ recording tape furnished by the Jet Propulsion Laboratories. The requirement was for two runs for a total of 20 min in each orthogonal plane.

Acceleration.- A static acceleration of $15 \mathrm{~g}$ to be maintained for a period of $5 \mathrm{~min}$ in each orthogonal plane.

Shock.- Four $50 \mathrm{~g}$ shocks in each orthorgonal plane. The wave form of each shock is an acceleration of $50 \mathrm{~g}$ magnitude with a rise time of less than I ms.

The WS II7L vehicle requirements are as follows:

Vibration.- Sinusoidal vibrations of

5 to $24.5 \mathrm{cps}$ at $1 / 8 \mathrm{in}$. amplitude for $5 \mathrm{~min}$

25 to $2000 \mathrm{cps}$ at $7.5 \mathrm{~g}$ amplitude for $5 \mathrm{~min}$

2000 to $2500 \mathrm{cps}$ at $10 \mathrm{~g}$ amplitude for $5 \mathrm{~min}$

Random Motion in a frequency range 15 to $2000 \mathrm{cps}$

$0.01 \mathrm{~g}^{2} / \mathrm{cps}$ maximum $(4.5 \mathrm{~g} \mathrm{Rms})$ for $5 \mathrm{~min}$

$0.002 \mathrm{~g}^{2} / \mathrm{cps}$ effective ( $2 \mathrm{~g} \mathrm{Rms}$ ) for $10 \mathrm{~min}$

vibrations are applied in each orthogonal plane.

Acceleration.- Longitudinal (y) axis, $10 \mathrm{~g}$ for $10 \mathrm{~min}$, lateral axes $(\mathrm{X}$ and $\mathrm{z}) 2 \mathrm{~g}$ for $10 \mathrm{~min}$.

Shock.- In each orthogonal plane the shock pulse shall have an acceleration of $40 \mathrm{~g}$ with a rise time of $2 \mathrm{~ms}$, a dwell time of $3 \mathrm{~ms}$ and a decay time of $0.4 \mathrm{~ms}$.

These tests were started on 15 May 1959. Figure 51 shows a typical test set-up with generator installed in fixture and mounted on the vibration shaker table (Calidyne Model No. 177A). The vibration, shock and acceleration tests for the Vega Vehicle environment were completed on 26 June 1959. Detailed results are available in Report No. MND-P-2101, 


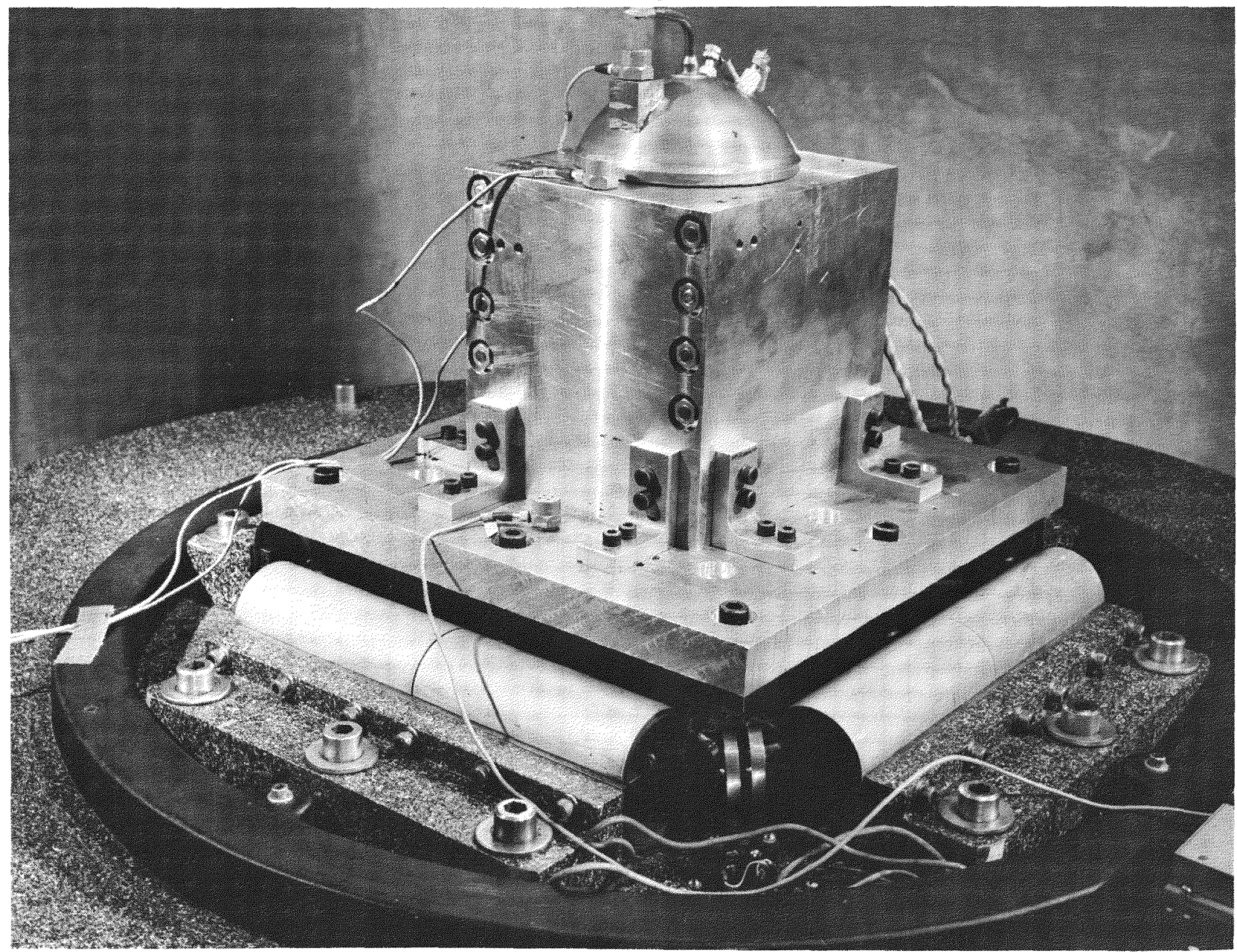

Fig. 51. Photograph of SNAP III in Test Fixture 
SNAP III Generator Environmental Test. Figure 52 shows a typical result from the vibration test, where the efficiency varies slightly. Figure 53 shows a representative acceleration test, where negligible change in efficiency was observed.

In the shock test, the heater simulating the radioisotope failed, but the generator continued operation on residual heat (Fig. 54). The shock test was completed after a new heater was installed with no effect on efficiency of operation.

The generator was in operation for approximately $300 \mathrm{hr}$ during the environmental test. Maximum variations in efficiency were approximately $5 \%$ of generator performance with a maximum recovery time of less than 10 min. Oscillating direct current on the direct current output was observed during the vibration and shock test, but disappeared when the environmental forces were discontinued. In all cases efficiency recovery was complete, and generator operation was maintained throughout the test.

To prove reliability all four SNAP III generators will be qualified under the WS $117 \mathrm{~L}$ and Vega Vehicle specifications.

\section{Power Flattening}

The activity of isotope fuel sources decays with time and when used as a power source for thermoelectric generators, the electrical power will also decay with time. To obtain a constant electrical output, the excess thermal output of the source at start of life must be dissipated. If the generator mission requires a constant electrical power output through a source half-life, the power dumped at the beginning of this half-Iife is equal to the gross power needed for the net electrical output throughout the mission life.

The majority of the practical schemes that would flatten power by varying the heat loss of the generator with time can be divided into two general classes: first, the opening and closing of a highly conductive path to the generator skin, actuated by a system variable; and, secondly, the varying of the insulation conductivity by pressure change, again actuated by a system variable, or a preset orifice. The schemes that have been investigated in the first case include bimetallic strip movement, expansion of a bar, spring compression and expansion, all actuated by a hot junction temperature change sensed by a bellows or diaphragm. The insulation conductivity change included a preset leak and a leak controlled by a hot junction temperature change with various actuators. All the systems except the preset leak involve actuators and moving parts, and for this reason were not considered as reliable. The conductance of the actuators and the supporting structure in the case of the spring systems causes an undesirable heat loss at the end of life. The tests required to produce a workable mechanfcal system would be extensive. For these reasons, a preset leak was chosen as the most feasible system to investigate further. 


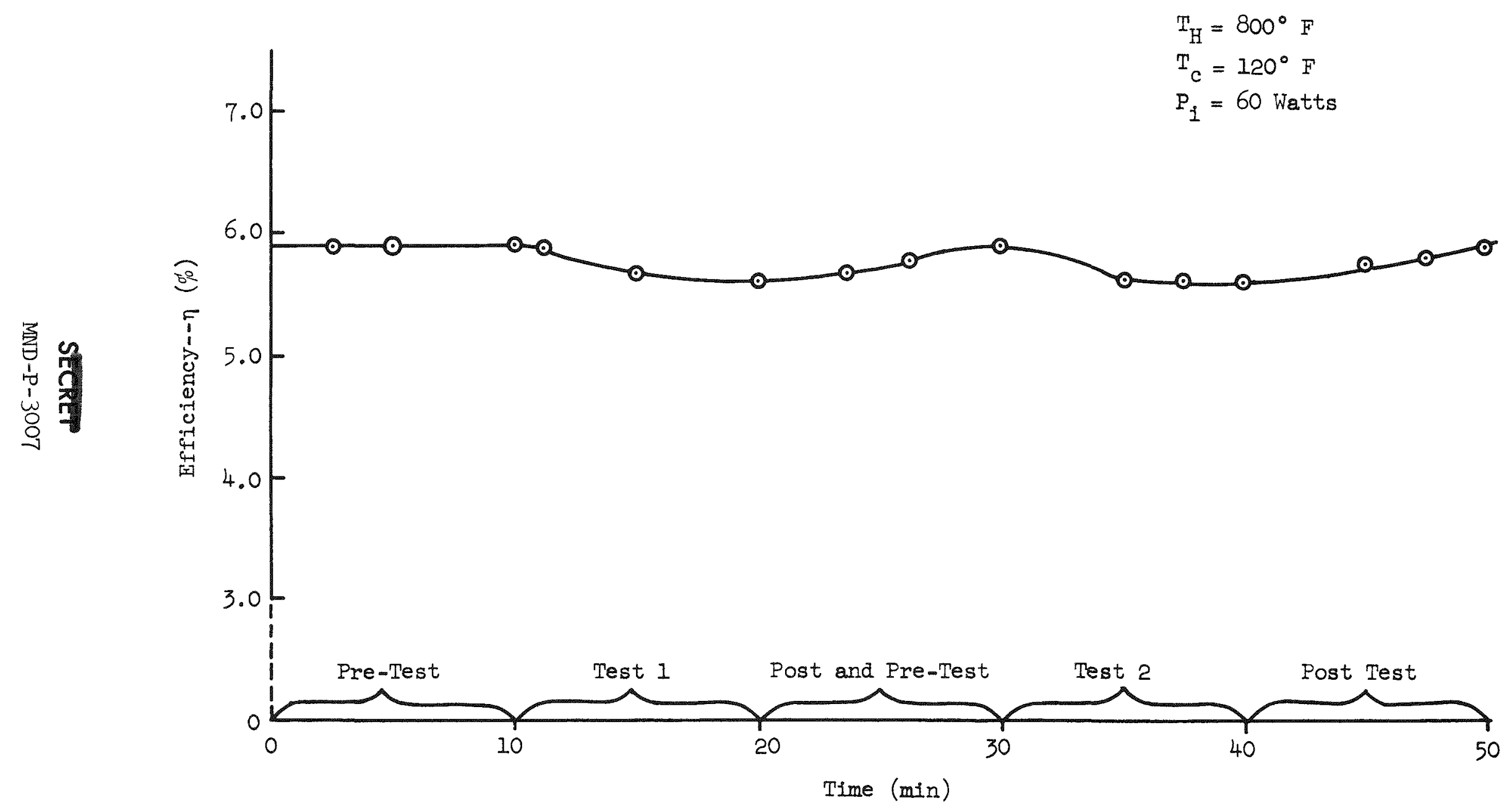




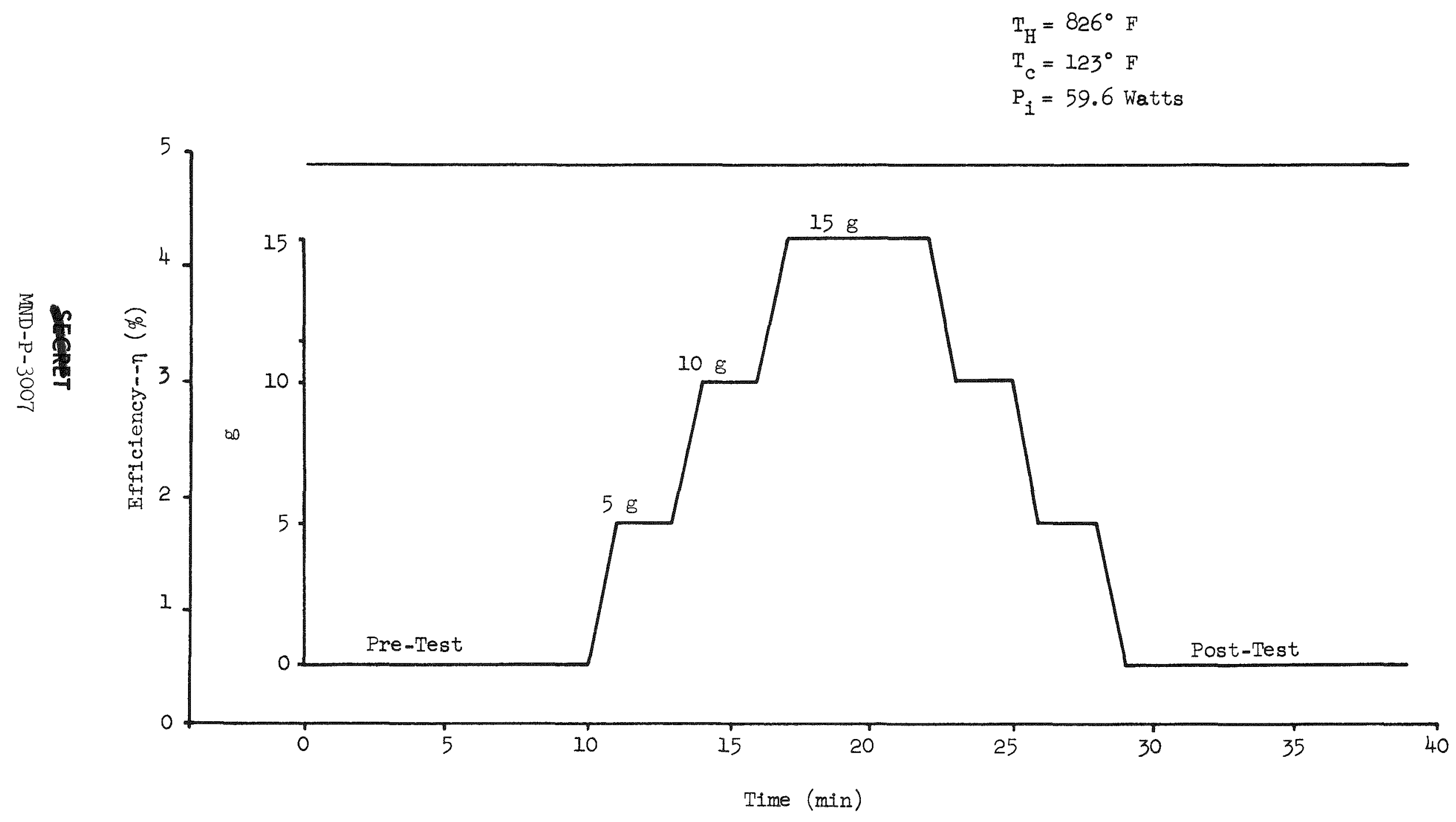

Fig. 53. Acceleration Test SNAP III, Y Plane 

The preset leak system works on the principle that the conductivity of a porous insulation is reduced when a conducting gas is removed from its void spaces. Assuming a space environment, this gas removal process may be accomplished by allowing an initial gas charge in the insulation container to leak through an orifice to the space void. If the relationship of insulation conductivity versus gas content is known, the heat flow through the insulation at any time becomes a function of orifice size and initial gas charge. Since the conductivity of the thermoelectric materials is essentially constant, the heat flow path depends on the ratio of conductivity, thermoelectric versus insulation. If this ratio is varied inversely proportional to total heat available, the heat flow through the thermoelectric couples may be held constant, which will ensure a constant power output.

The optimum inftial and final gas charge was established by the following considerations. To minimize initial isotope investment, the insulation heat loss should be a minimum at the end of operational life. This is accomplished by discharging gas at a rate such that the final insulation cavity pressure is at or near a vacuum. Data obtained from Westinghouse Research Laboratory investigations indicates that the greatest conductivity change of porous insulation takes plase during a gas pressure variation from one atmosphere to zero. The initial pressure was assumed to be optimum at one atmosphere. The actual insulation void volume of the SNAP III-B generator was not known. A rough theoretical volume was calculated based on generator dimensions and theoretical versus actual insulation density. This calculated volume was used to determine if the orifice size required to pass the initial gas charge was within practical limits. Helium was chosen as the gas since its conductivity would help to assure a sufficient variation in insulation characteristics.

A theoretical calculation indicates that it is feasible to control the power output by the gas leak method for an operational life of approximately $70 \%$ of the isotope half life. This calculation was based on the existing SNAP III-B generator configuration and performance under the conditions and assumptions cited previously. The calculation results are plotted in Fig. 55 .

A test program using an electrically heated SNAP III-B generator was started in June. This program will validate the basic assumptions by determining the following:

(1) The relationship between source thermal power and gas pressure for a constant electrical output.

(2) The insulation vold volume.

(3) The orifice required to provide the desired pressure decay rate.

Figure 56 is a schematic diagram of the test set-up. 


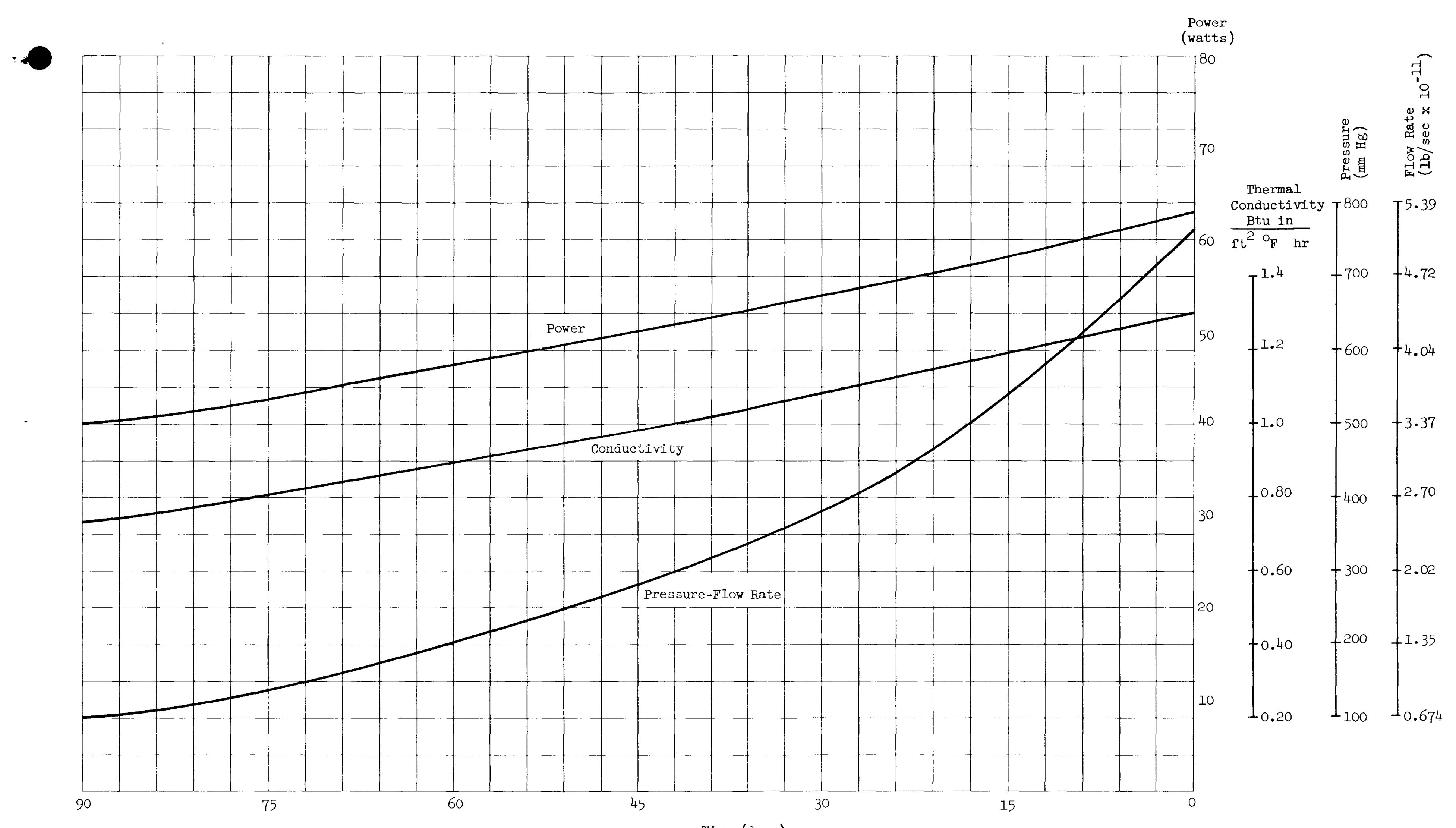

Time (days) 


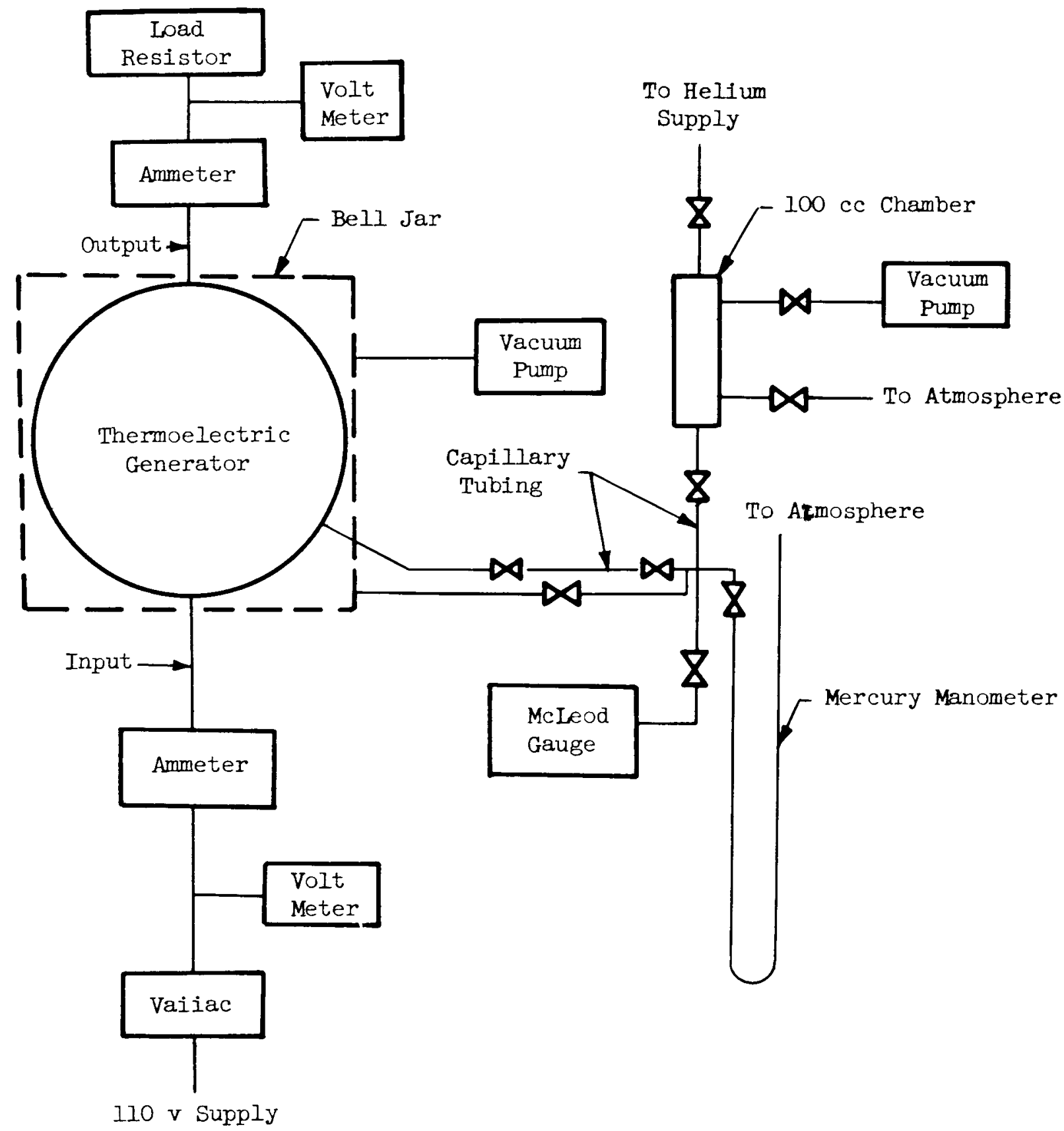

Fig. 56. Test Schematic 


\section{Material Tests}

Tests were conducted to determine the effect of adherent, dense oxide films on lead telluride thermoelectric elements. The films reduce sublimation of material from the hot leg of the element when operated in vacuum. Adherent coatings of $\mathrm{Al}_{2} \mathrm{O}_{3}$ and $\mathrm{ZrO}_{2}$ may be applied to the thermoelectric elements by proper element surface preparation and positioning of the flow spray gun.

Approximately 0.010 in. thick coatings of $\mathrm{Al}_{2} \mathrm{O}_{3}$ and $\mathrm{ZrO}_{2}$ were applied to all surfaces of $3 / 8 \mathrm{in}$. diameter and 1 in. long $\mathrm{Pb}-\mathrm{Te}$ elements. The specimens were then heated at $1000^{\circ} \mathrm{F}$ and 0.5 microns pressure for varying periods of time and evaluated on basis of weight loss which is assumed to be due to sublimation. The coated pieces are compared to an uncoated specimen which was similarly tested.

Weight changes were recorded over an accumulated period of $175 \mathrm{hr}$ at intervals of $\mathrm{I} \mathrm{hr}, 8 \mathrm{hr}$ and $24 \mathrm{hr}$ thereafter until end of test. The difference in weight loss between the coated and uncoated pieces is shown in Table 19.

TABLE 19

Effect of Oxide Coating $\mathrm{Pb}-\mathrm{Te}$ Elements

Total Weight Loss ( $\%$ of Initial Weight)

\begin{tabular}{|c|c|c|c|c|c|c|c|c|}
\hline \multirow[b]{2}{*}{$\begin{array}{l}\text { Specimen } \\
\text { Number }\end{array}$} & & \multicolumn{7}{|c|}{ Total Time (hr) } \\
\hline & Specimen Type & 1 & 9 & 33 & 57 & 81 & 105 & 175 \\
\hline$I A$ & Uncoated $\mathrm{Pb}-\mathrm{Te}$ & $-\infty$ & 12.0 & 20.0 & 28.0 & -- & -- & - \\
\hline \multirow[t]{2}{*}{$2 \mathrm{~A}$} & $\mathrm{Al}_{2} \mathrm{O}_{3}$ coat on & & & & & & & \\
\hline & $\mathrm{Pb}-\mathrm{Te}$ & 0.012 & 0.064 & 0.4 & 0.5 & 0.6 & 0.7 & 0.9 \\
\hline \multirow[t]{2}{*}{$3 \mathrm{~A}$} & $\mathrm{ZrO}_{2}$ coat on & & & & & & & \\
\hline & $\mathrm{Pb}-\mathrm{Te}$ & 0.015 & 0.029 & 0.096 & 0.099 & 0.11 & 0.13 & 0.27 \\
\hline \multirow[t]{2}{*}{$1 B$} & $\mathrm{AI}_{2} \mathrm{O}_{3}$ coat on & & & & & & & \\
\hline & $\mathrm{Pb}-\mathrm{Te}$ & 0.009 & 0.028 & -- & -- & -- & -- & 0.27 \\
\hline \multirow[t]{2}{*}{$2 \mathrm{~B}$} & $\mathrm{ZrO}_{2}$ coat on & & & & & & & \\
\hline & $\mathrm{ZrO}_{2}$ & 0.01 & 0.04 & - & -- & -- & -- & 0.17 \\
\hline
\end{tabular}


Specimens $I B$ and $2 B$ were a second set of samples continuously heated for $166 \mathrm{hr}$ after the first $9 \mathrm{hr}$ check.

The test results indicate that significant protection is afforded by the oxide coatings on the basis of weight loss. However, in order to determine more conclusively the usefulness of the coating, it is necessary to determine the thermoelectric properties of the coated elements. Tests are planned with a simulated electric generator using coated elements operating in a vacuum.

It is planned to study methods of improving the coating effectiveness by reducing the porosity through glassy additions to the flame spray materials or application of glasses over the oxide coating. 


\section{TASK 12--THERMOIETECTRIC CONVERSION}

\section{A. THEERMOELECIRIC DESIGN}

Several conceptual design studies were undertaken during this quarter to evaluate the operational parameters of the thermoelectric power conversion system and to make several designs avallable for consideration as power requirements and operating life times were more firmly established. The designs studies were as follows:

(1) Conceptual design of a 125-w, 6-mo life APU, (Report MND-P-1973).

(2) Conceptual design of a 175-w, 4-mo Iife APU, (Report MND-P-2074).

(3) Conceptual design of a 125 w, 12-mo life APU, (Report $\mathrm{MND}-\mathrm{P}-2074$ ).

Ce-144 was taken as the isotopic power source and molybdenum as the fuel container. The results of these studies have shown that all three designs are feasible and practical. All design parameters were maintained within present state of the art limitations to minimize the number of development problems. Since thermoelectric materials technology is in a period of very rapid development, the materials performance considered in the reports mentioned are already obsolete. The basic performance improvement involves changes in materials doping thus elfminating the need for two segment elements to obtain the same level of efficiency.

Due to the nature of the thermoelectric materials under consideration, a constant generator power output is preferable. This is accomplished by means of synthetic power flattening of the device. AII units investigated are of the radiative boundary type. Heat is generated within the fuel and radiated to what may be described as the inner skin of the unit. The heat is then conducted through the thermoelectric elements and is subsequently dumped to the surroundings by radiation from the surface of this device. All parameters are adjusted such that the inner skin of the unit which serves to supply heat to the hot junction of the thermoelectric elements is at 10000 F. Partial exposure of this inner skin, which is commonly identified as the thermal shutter, is the power flattener.

The thermoelectric element detall design of a 125-w output, 12-mo If as follows: 


\begin{tabular}{|c|c|c|}
\hline & $\mathrm{N}$-Element & P-Element \\
\hline Diameter, in. & 0.375 & 0.375 \\
\hline Length, in. & 0.78 & 0.66 \\
\hline Resistivity at $75^{\circ} \mathrm{F}, \mu \Omega$ in. & 150 & 200 \\
\hline $\begin{array}{l}\text { Seebeck effect }\left(1000 \text { to } 335^{\circ} \mathrm{F}\right) \text {, } \\
\mu \mathrm{v} /{ }^{\circ} \mathrm{F}\end{array}$ & 135.5 & 136.7 \\
\hline $\begin{array}{l}\text { Thermal conductivity (1000 to } \\
335^{\circ} \mathrm{F} \text { ) }\end{array}$ & $1.12 \mathrm{Btu} / \mathrm{hr}$ ft ${ }^{\circ} \mathrm{F}$ & $0.936 \mathrm{Btu} / \mathrm{hr}$ ft ${ }^{{ }^{O} \mathrm{~F}}$ \\
\hline $\begin{array}{l}\left.\text { Resistivity (1000 to } 335^{\circ} \mathrm{F}\right), \\
\text { in. }\end{array}$ & 1251 & 1504 \\
\hline Doping & Sodium & Lead lodlde \\
\hline Figure of merit & $0.5412 \times 10^{-3} \mathrm{O}^{-1}$ & \\
\hline Efficiency (bare couple), \% & $6.75 \%$ & \\
\hline Couples, No. & 277 & \\
\hline Material & Lead telluride & \\
\hline Power output, w & 125 & \\
\hline Voltage, $v, d-c$ & 28 & \\
\hline
\end{tabular}

The installation configuration of the thermoelectric couple assembly is shown in Fig. 57. A total of 277 couples of this configuration w11l be nested between the inner stainless steel skin and the outer aluminum skin and will be completely shrouded in highly compacted Min-K insulation. The electrical interconnection between couples is obtained by the use of stranded copper wires which are attached to adjacent electrical solder lugs. Details of the thermoelectric element assembly are shown in Fig. 58.

\section{B. THERMOELECTRIC TEST EQUIPMENT}

1. Guarded Hot Plate

To closely evaluate the physical properties of insulation and thermoelectric assembly performance, a guarded hot plate has been designed and fabrication initiated. This test device is designed to 


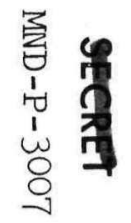

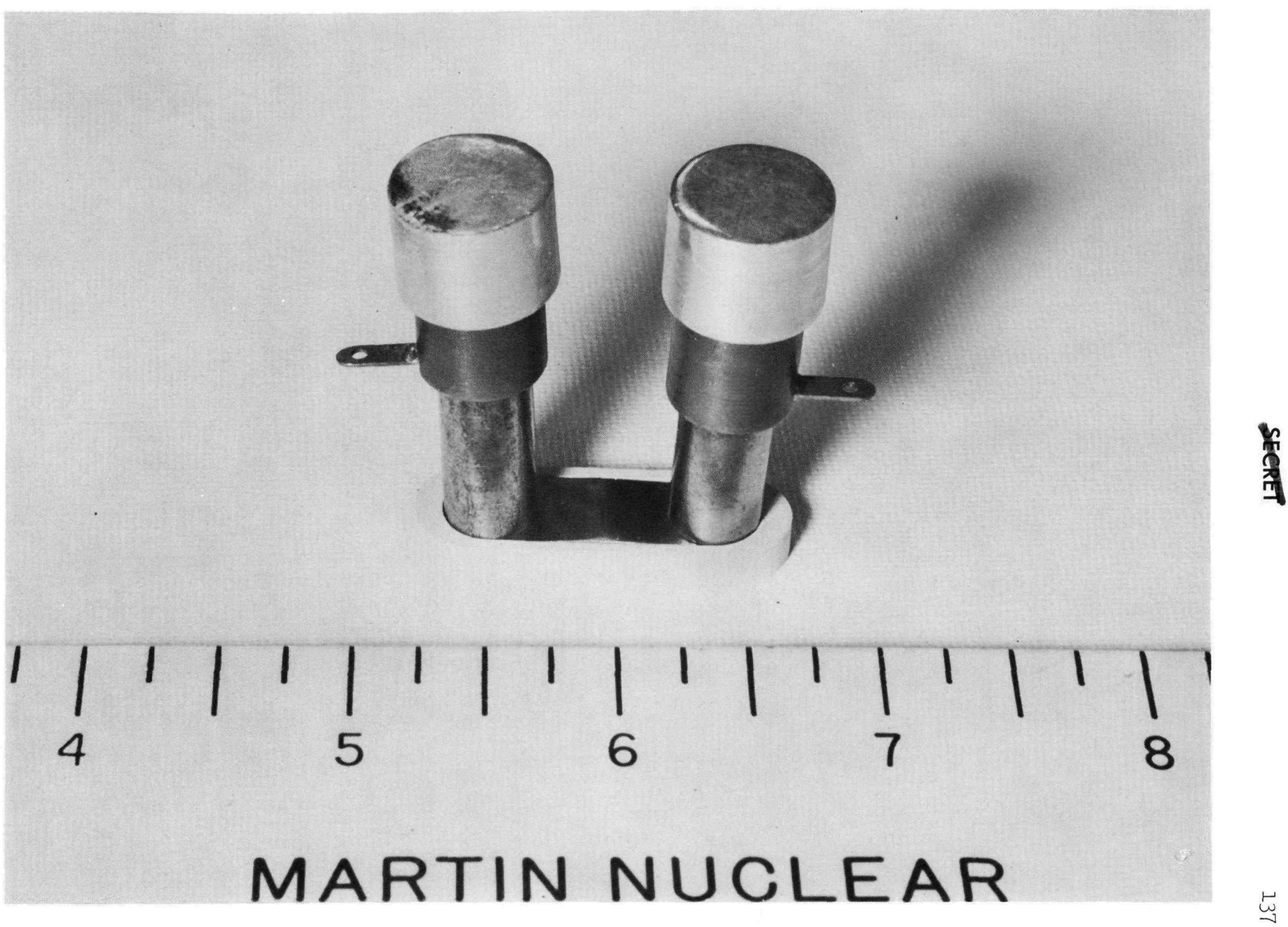

Fig. 57. SNAP I-A Thermoelectric Couple Assembly 


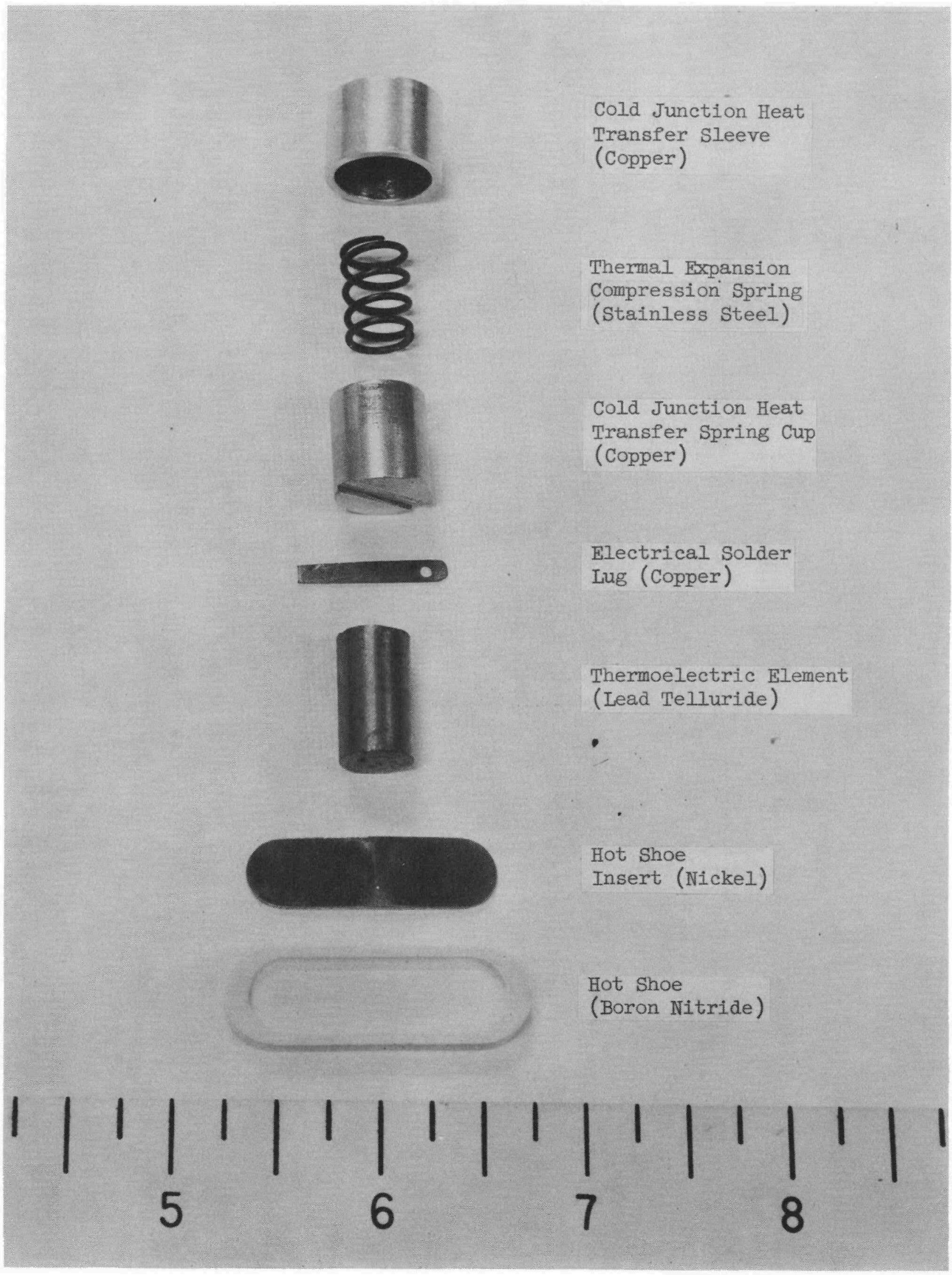

Fig. 58. SNAP I-A Thermoelectric Element Assembly Details 
ASTM requirements for the measurement of thermal conductivity. The device will be unique only in that measurements in terms of both temperature and pressure may be obtained. This information is extremely valuable in the design of an APU for space application.

Thermoelectric couple assemblies may be tested for system efficiency in this hot plate as an added feature. The apparatus is designed such that a representative segment of the SNAP I-A unit may be tested at design and environmental conditions, thus providing a representative performance check of the complete unit.

\section{Materials Test Devices}

Quality Control test equipment is presently being designed to facilltate recelving inspection of thermoelectric materials and assemblies. This equipment will be used to measure three temperature levels of Seebeck voltage and room temperature resistivity in a reasonably rapid fashion.

A Ilterature search and llaison with thermoelectric material vendors are continuing to optimize the design of laboratory test equipment for measurement of resistivity, seebeck coefficlent and thermal conductivity. This equipment will be used to evaluate, on a laboratory basis, new thermoelectric materials, as an ald in the development of the SNAP I-A program.

\section{NEW THERMOELECTRIC MATERIAIS}

In the interest of improving performance, structural integrity, cost, material, weight and reliability, various thermoelectric materials, materials fabrication and assembly configurations will be tested. Present plans include the evaluation of thermoelectrlc materials from three sources of supply and several varlations of heat transfer materials and configurations. Tests will cover:

(I) Cast thermoelectric materials.

(2) Compacted and sintered thermoelectric materials.

(3) Thermoelectric materials that are compacted and sintered simultaneously.

(4) Copper and aluminum heat transfer materials.

(5) Various techniques to provide for thermal expansion.

(6) Coatings to control material sublimation. 
SEentT

MND-P-3007 


\title{
XII. TASK 13--SYSTEM DESIGN AND INTEGRATION--SNAP VII
}

\section{A. PROGRAM MANAGEMENT AND INTEGRATION}

\begin{abstract}
A large portion of the effort originally planned under this task was directed toward the production of curium under Task 14 as submitted in MND-P-1564 (Revision 2), Program Plan for Contract AT(30-3)-217. Consequently, a visit was made to Lawrance Radiation Laboratory, Livermore, California, to discuss the americium and curium preparation and purification processes used at that facility. Since they were preparing to process some irradiated material during the month of June, arrangements were made for two Martin Nuclear Division personnel directly concerned with process design to observe their operation.

During this same trip, a specification for the americium chemical process apparatus was agreed upon through discussians at Dublin Industries, Dublin, California.
\end{abstract}

Later in the reporting period the objective of the program was reduced to a conceptual design effort only. This greatly reduced the integration effort required and no further contacts were made. The fuel form and container design were continued at a limited level as required to support generator design.

The ground handling study was not initiated as planned since selection of a generator configuration was not made due to a reduced effort in this area.

\section{B. GENERATOR DESIGN}

The approach to the problem of a generator design to efficiently utilize the high specific power of curium was to investigate a number of configurations. The configuration selected would then be analyzed in detail using the results of concurrent design studies as a basis for actual construction.

The first design considered utilized the radiative method of heat transfer from a central heat source to the thermoelectric hot junction. Using this concept, a further break down is possible in that the ground handling shield may be wholly contained within the unit, partially contained, or completely external to the unit. A second configuration using a convective method of heat transfer with similar shielding arrangements would be more complex but also worthy of consideration. The most simple, therefore, most desirable appeared to be the radiative type with internal shielding, and this design was the first investigated. 
The critical dimension governing the geametry of this unit is the thickness of the internal shield. This thickness of shlelding required for the fast neutrons resulting from spontaneous fission and $(\alpha, n)$ reactions was computed by several methods. The most conservative method was used to prepare the plot shown in Fig. 59. From Health Physics data, it was decided to design the unit for a dose of 1 rem per hour at the unit surface.

A temperature gradient study was then performed to obtain the surface temperature of the central heat source. With the assumed curium power density of $855 \mathrm{w} / \mathrm{cm}^{3}$ or $122 \mathrm{w} / \mathrm{gm}$, it is necessary to include a filler material of good thermal conductivity to reduce the thermal gradient in the fuel itself. A plot of heat source surface temperatures vs surface area was then constructed. This is shown in Fig. 60 . A limiting surface temperature of between 1500 and $1600^{\circ}$ F was assumed in order to realize reasonable structural material allowables.

The thermoelectric elements were then investigated to determine the optimum segmentation temperature and the resulting overall figure of merit. This figure of merit value vs segmentation temperature is shown in Fig. 6I.

The surface area needed to radiate a given quantity of heat to space can be calculated as shown in Fig. 62. This calculation assumes an emissivity of 0.90 and takes into account the direct and replected radiation from the sun.

A thermoelectic length of $I$ in. and an insulation thickness of $1-1 / 2$ in. was then assumed to complete the factors required to design the unit. An iteration process was then used to solve for the unit geometry from the plots previously presented. This iteration process is in the final phases but conclusive results are not available at this time.

\section{HAZARDS ANALYSIS}

Hazards studies of generator configurations were limited to those considered in Report No. MND-1963, "Preliminary Hazards of a cm ${ }^{242}$ Auxiliary Power Supply."

The initial emphasis in the original program was directed toward the fuel processing effort. Data on the properties of americium and curium was needed for the design of fuel processes and equipment. After the objective of the program was reduced to a conceptual design only, it was decided to continue the effort to assemble a completed report. 


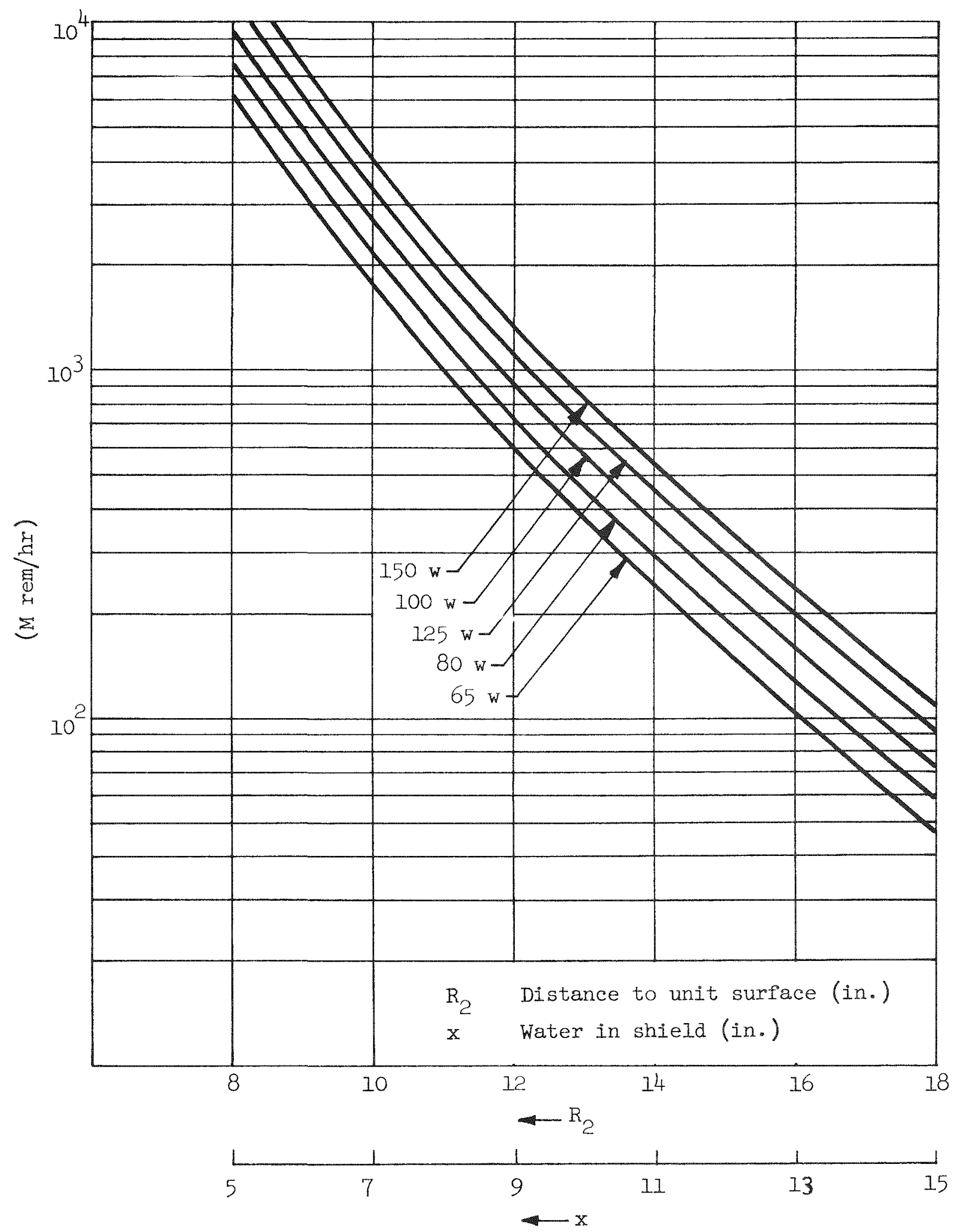

Fig. 59. Dose at Surface of Unit with Indicated Thickness of Water 


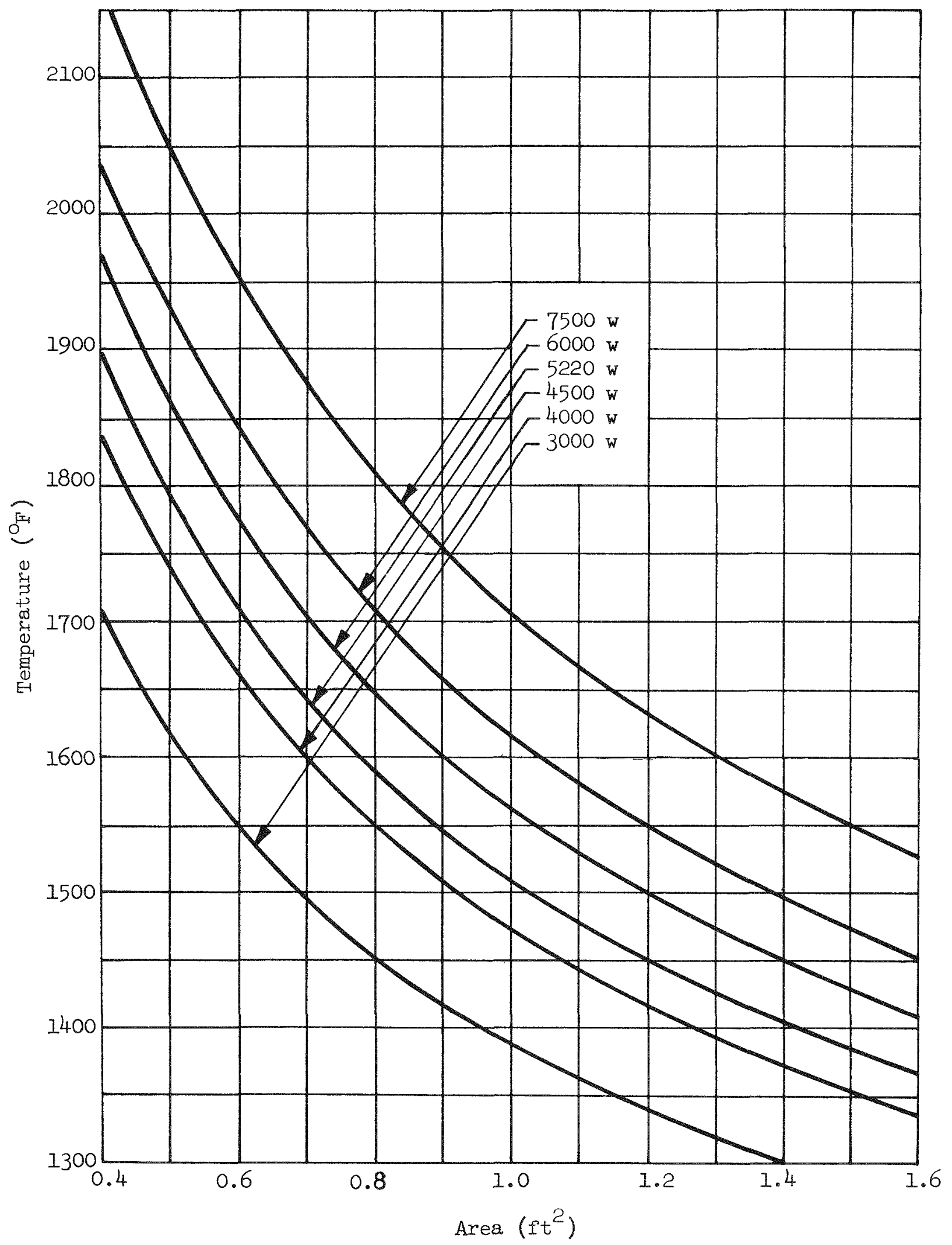

Fig. 60. Surface Temperature vs Fuel Container Surface Area 


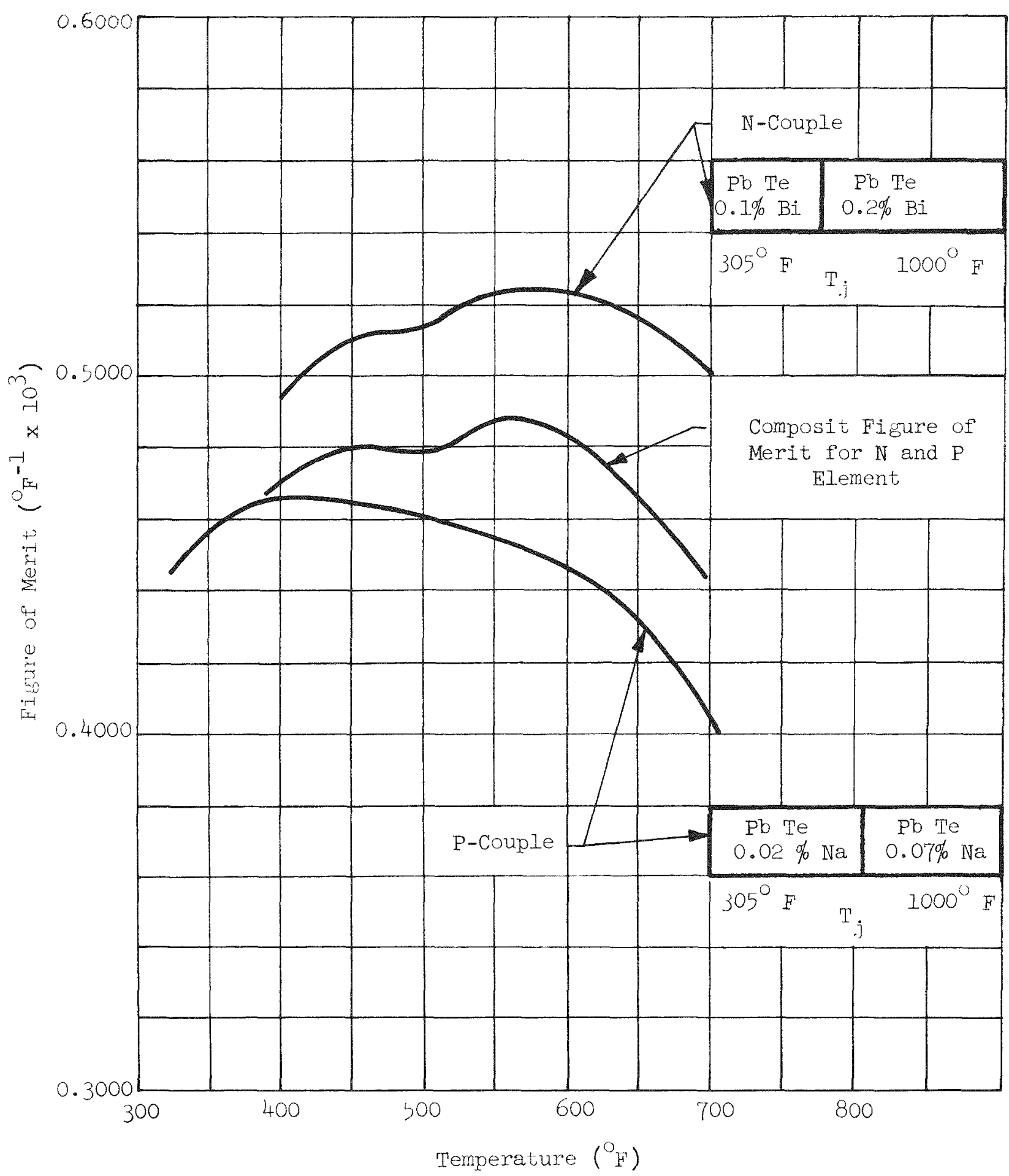

Fic. 61. Figure of Merit vs Segmentation Temperature (100-watt Unit) 


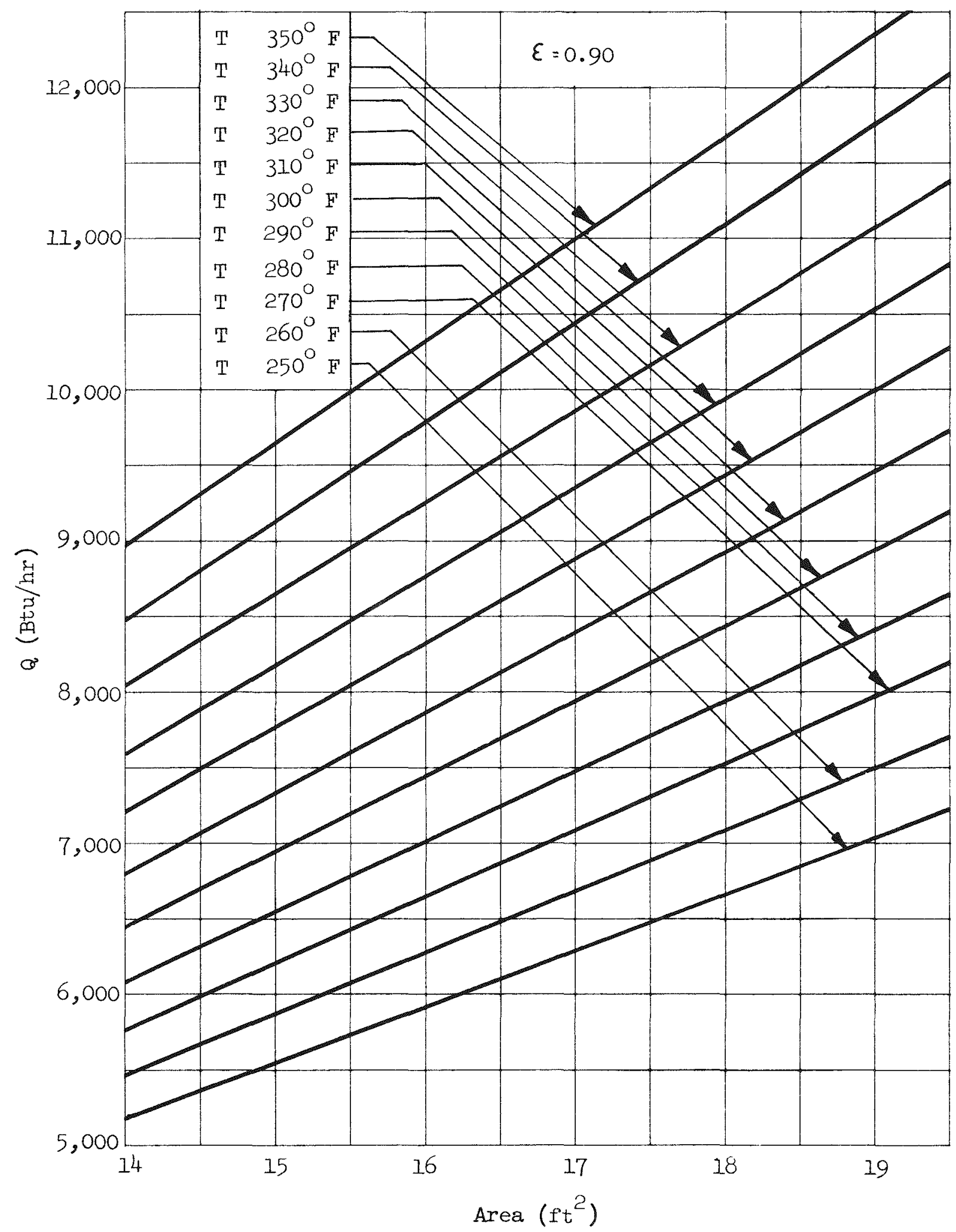

Fig. 62. SNAP VII Radiator Characteristics 
This report will be of great value to future programs and the general industry since very little published data is currently available. The result will be published as No. MND-P-1972, "Americium-241 and Curium242 Fuel Processing Hazards."

The following excerpts are included as a sample of its contents:

Table 20--Radioblological Properties

Table 2l--Nuclear Properties

Chemical Properties of Curium

TABIE 20

Radioblological Properties of $\mathrm{Cm}-242$ and Am-24I

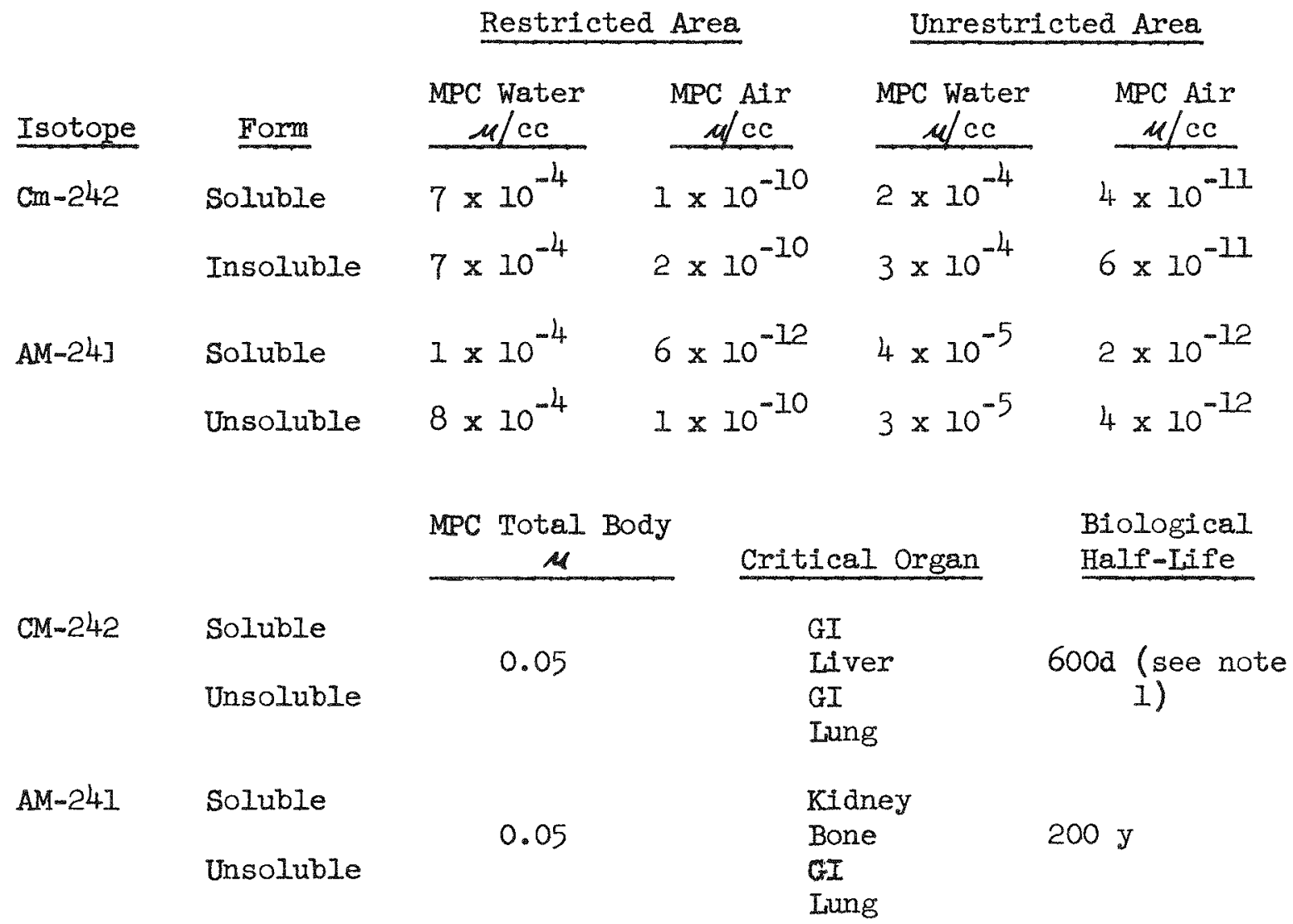

NOTES:

1. Reference --National Bureau Standards Handbook 52. All other values taken Ref. 4.

2. MPC-Maximum Permissible Concentration

3. $\mu / \mathrm{CC}-\mathrm{Mi}$ crocuries per cubic centimeter. 


\section{TABLE 21}

Nuclear Properties

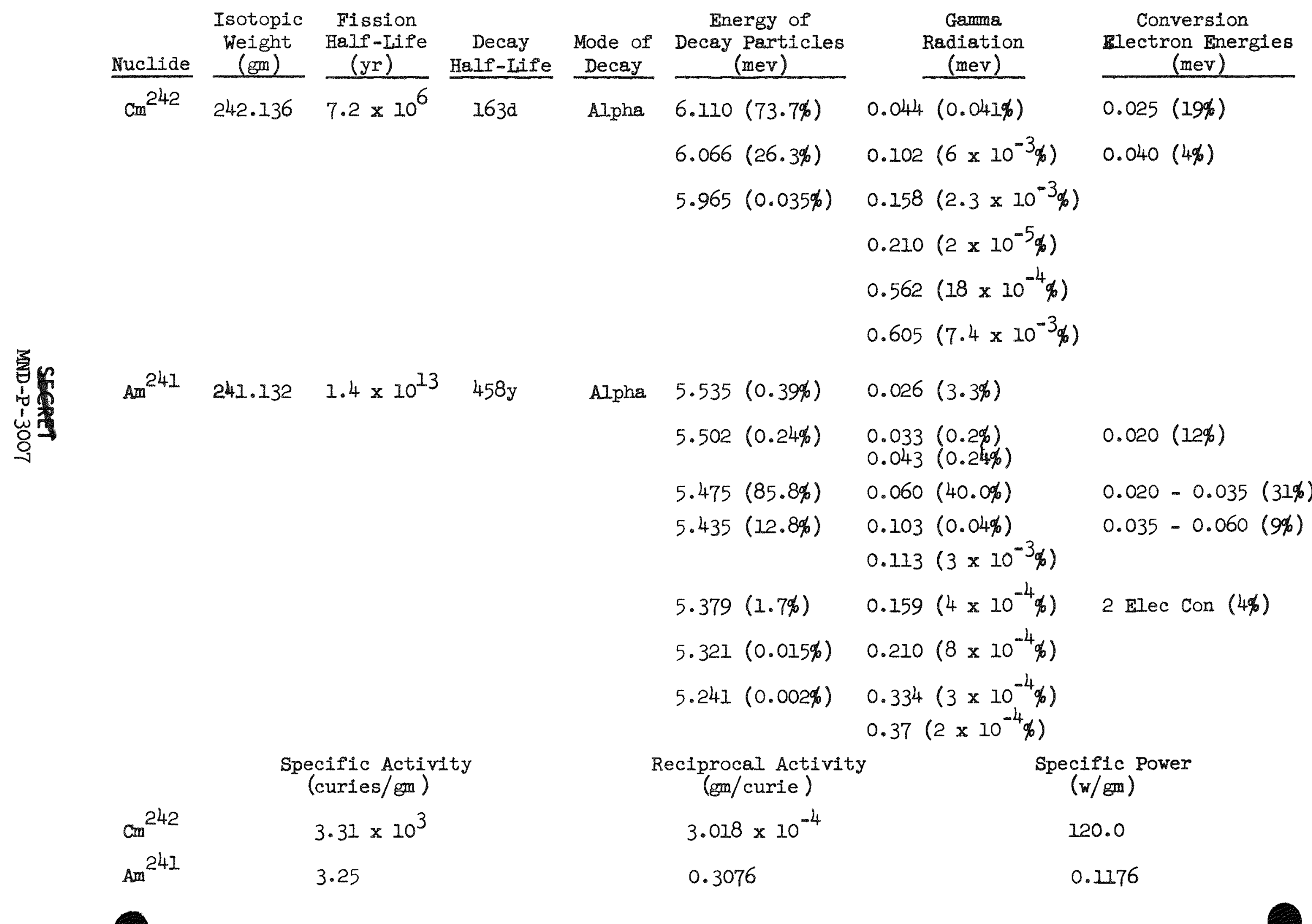


1. Chemical Properties of Curium

Curium (element 96) is the seventh member of the second rare earth series, the actinide series. In this transition series, the inner electron orbits of the $5 \mathrm{f}$ shell are being filled. Curium, being the seventh member of this series, represents the element analogous to gadolinium in the lanthanum series that has these inner orbital shells half filled.

To date all attempts to oxidize or reduce curium from its tripositive state in aqueous medium have failed. From the attempts to oxidize Curium242 and Curium-244 both in macro amounts and tracer scale it may be concluded that the potential is more negative than $-2 \mathrm{v}$, or that the rates are too slow for concentrations of curium that will allow an oxidation medium to exist.

Attempts to reduce curium to the dispositive state have been attempted. Barium metal in hydrochloric acid was used as the reducing agent. No positive evidence for any reduction has been observed.

Curium metal has been prepared on the microgram scale by the reduction of curium trifluoride with barium metal vapor at $1275^{\circ} \mathrm{C}$, using a vacuum furnace and a double crucible system similar to that described by Fried and Davidson.

The conditions for reduction to a usable metal were rather critical. Reduction at $1380^{\circ} \mathrm{C}$ left the metal as a thin film adhering to the wall of the crucible. Reduction at about $1250^{\circ} \mathrm{C}$ resulted in the formation of a cokey residue, indicating poor agglomeration of the metal. Reduction with barium vapor at $1275^{\circ}$ left a good spheroidal piece of metal is between 1250 to $1275^{\circ} \mathrm{C}$.

From the mass and volume measurements the density of the metal was computed to be approximately $7 \mathrm{gm} / \mathrm{cc}$. This is very low and perhaps it is explained by the presence of a void in the piece of metal examined.

Curium tetrafluoride and curium dioxide have been prepared in an anhydrous form from Curium-244 (an alpha emitter with a half life of $17.9 \mathrm{yr}$ ) but these higher oxidation states have not been possible to date from Curium-242.

Curium tetrafluoride was formed by fluorinating curfum trifluoride at $400^{\circ} \mathrm{C}$ for $1 \mathrm{hr}$. The curium tetrafluoride formed appeared as IIght greenish-tan aggregates with a monoclinic crystal structure.

Curium dioxide can be produced from curium sesquioxide by heating $\mathrm{Cm}_{2} \mathrm{O}_{3}$ in 1 atmosphere of oxygen at $650^{\circ} \mathrm{C}$, then cooling the compound slowly. Curium dioxide is a black powder while curium sesquioxide is a white or faint tan color. 
A chemical separation of americium and curium has been developed based upon the carbonate completing of Americium VI. A slurry of americium and curium hydroxide in approximately 0.03 molar $\mathrm{NaHCO}_{3}$ is treated with ozone and the americium under these conditions is oxidized to the Am(VI) state as a soluble complex. The curium hydroxide is unchanged and may be separated by filtration.

It has also been found that rare earth americium oxalates may be dissolved in excess carbonate then the americium may be oxidized to the insoluble Americium(V) compound with ozone.

A list of solubilities of curium salts is as follows. It can be seen that these solubilities are typical of other rare earths.

Compound

(1) Curium Carbonate

(2) Curium Hydroxide

(3) Curium Trifluoride

(4) Curium Nitrates

(5) Curium Oxalate

(6) Curium Oxide

\section{Formula}

$\mathrm{Cm}_{2}\left(\mathrm{CO}_{3}\right)_{3}$

$\mathrm{Cm}(\mathrm{OH})_{3}$

$\mathrm{CmF}_{3}$

$\mathrm{Cm}\left(\mathrm{NO}_{3}\right)_{3}$

$\mathrm{Cm}_{2}\left(\mathrm{C}_{2} \mathrm{O}_{4}\right)_{3}$

$\mathrm{Cm}_{2} \mathrm{O}_{3}$
Solubility

Insoluble in water

Soluble in excess $\left(\mathrm{NH}_{4}\right)_{2} \mathrm{CO}_{3}$

One miligram per liter $\mathrm{H}_{2} \mathrm{O}$

One miligram per liter $\mathrm{H}_{2} \mathrm{O}$

Soluble in $\mathrm{H}_{2} \mathrm{O}$

Very insoluble in $\mathrm{H}_{2} \mathrm{O}$

Fairly soluble in $\mathrm{H}_{2} \mathrm{O}$

\section{FUEL DEVELOPMENT}

The schedule for americium preparation and curium purification as originally submitted in MND-P-1564 (Revision 2) called for immediate work in these areas. Design effort was initiated in both areas and significant results were achieved prior to the reduction in program scope. A diagram of the planned process is shown in Fig. 63 .

The americium process equipment was based on that developed by Lawrance Radiation Laboratory. The americium pellet and encapsulating dies with their individual dry boxes were completely designed. 


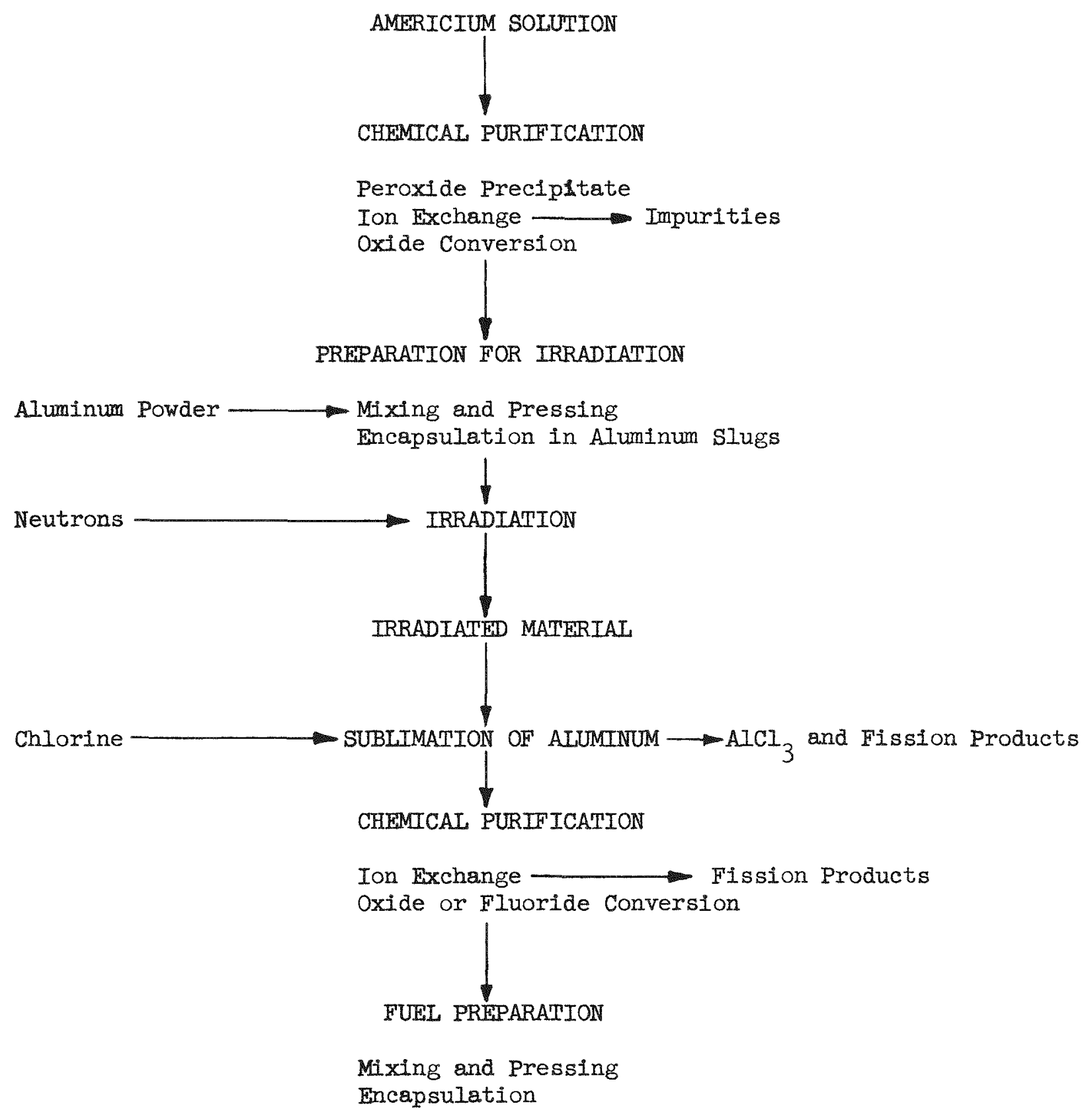

Fig. 63. Am-Cm Process Diagram 
Specifications were prepared for the americium chemical purification equipment and firm bids were received for its fabrication. The press used at the Iawrance Radiation Iaboratory was manufactured by The Dennison Engineering Company, Columbus, Ohio. Since the box and die design were based on the use of this type press, a specification was prepared based on their press performance. Firm bids were also received for this equipment.

The first step in the curium purification process is the removal of the aluminum cladding from the irradiated material. The process used by Lawrance Radiation Laboratory was satisfactory for small amounts but was very slow and tedious. To provide for processing on the scale proposed, chlorine sublimation process was devised as shown in Fig. 64.

Design of experimental apparatus for investigating a process for removing aluminum by chlorination and distillation of the chloride has been completed. The aluminum chloride that is formed is sublimed at the reaction temperature of 550 to $600^{\circ} \mathrm{C}$ and is carried to the $\mathrm{AlCl}_{3}$ condenser as a gas. The gas leaving the $\mathrm{AlCl}_{3}$ condenser is Argon with unreacted chlorine, gaseous fission products and entrapped particles. This is passed through a tower where NaOH solution removes the unreacted chlorine and fission product gasses. The gas is dehumidified and passed through an absolute filter.

The reaction vessel is flanged at the inlet end for access for insertion of the aluminum slug and removal of the boat containing the residue. The reaction vessel is a $1-1 / 2$ in. OD pipe and the inlet and outlet tubes are $3 / 8 \mathrm{in}$. ID. These tubes are heated to $250^{\circ} \mathrm{C}$ to prevent unwanted condensation of the sublimed $\mathrm{AlCl}_{3} \cdot$ Hastelloy $\mathrm{C}$ is contemplated for the tubing and reaction vessel.

The $\mathrm{AlCl}_{3}$ condenser is now designed as a cylindrical vessel six inches in diameter and seven inches high with a series of concentric baffles inside. Gas will enter along the outer shell, flow through a baffle system, pass through a fiberglass filter and exit at the top center of the vessel. After condensation of the $\mathrm{AlCl}_{3}$ from one slug, the vessel should be approximately three-quarters full of fluffy $\mathrm{AlCl}_{3}$ crystals. During initial tests it is proposed to clear the vessel for re-use on a batch basis. The condenser may then be dried by a gas flow through the line with no cooling of the condenser.

The tower for removing chlorine and other gaseous products is a packed tower with a closed liquid cycle using a $\mathrm{NaOH}$ solution. 


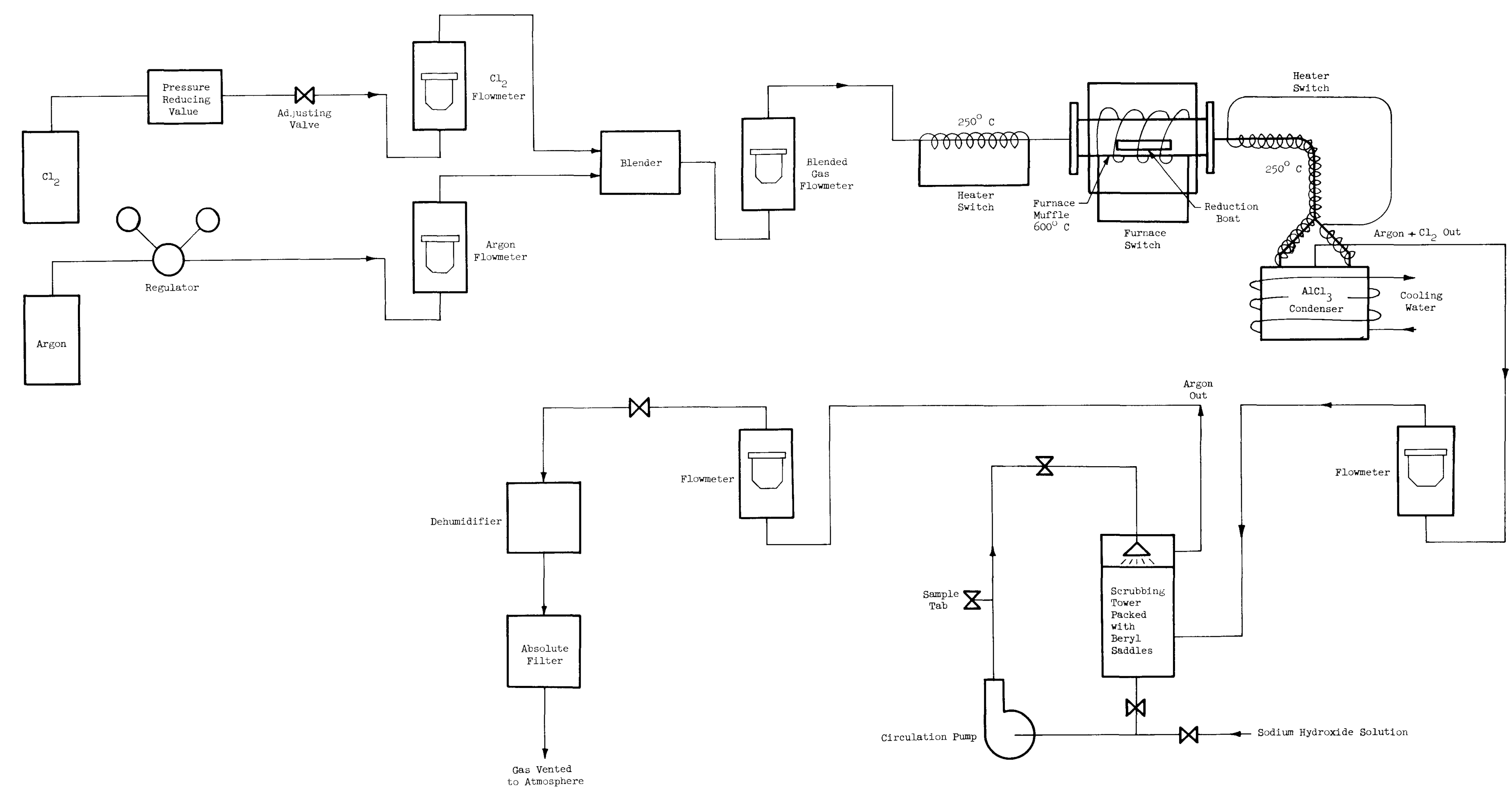

Fig. 64. Chlorine Sublimation Process 